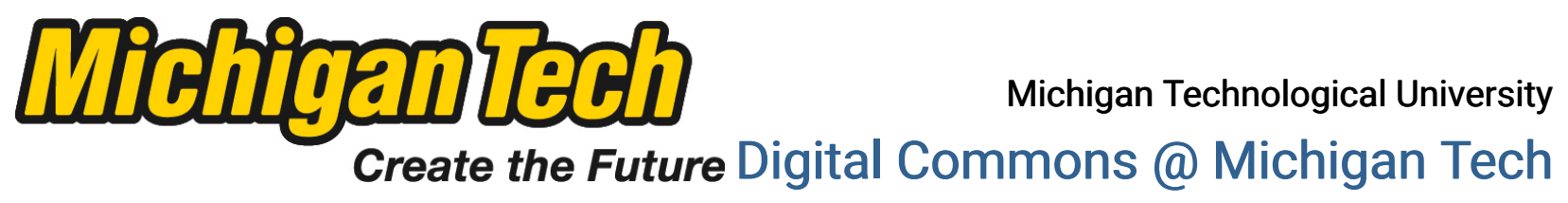

Dissertations, Master's Theses and Master's Reports - Open

2013

\title{
AN EXPERIMENTAL INVESTIGATION INTO THE EFFECTS OF BIODIESEL BLENDS ON PARTICULATE MATTER OXIDATION IN A CATALYZED PARTICULATE FILTER DURING ACTIVE REGENERATION
}

James Pidgeon

Michigan Technological University

Follow this and additional works at: https://digitalcommons.mtu.edu/etds

Part of the Mechanical Engineering Commons

Copyright 2013 James Pidgeon

\section{Recommended Citation}

Pidgeon, James, "AN EXPERIMENTAL INVESTIGATION INTO THE EFFECTS OF BIODIESEL BLENDS ON PARTICULATE MATTER OXIDATION IN A CATALYZED PARTICULATE FILTER DURING ACTIVE REGENERATION", Master's Thesis, Michigan Technological University, 2013.

https://doi.org/10.37099/mtu.dc.etds/483

Follow this and additional works at: https://digitalcommons.mtu.edu/etds

Part of the Mechanical Engineering Commons 
AN EXPERIMENTAL INVESTIGATION INTO THE EFFECTS OF BIODIESEL BLENDS ON PARTICULATE MATTER OXIDATION IN A CATALYZED PARTICULATE FILTER DURING ACTIVE REGENERATION

By

James M. Pidgeon

\begin{abstract}
A THESIS
Submitted in partial fulfillment of the requirements for the degree of MASTER OF SCIENCE

In Mechanical Engineering
\end{abstract}

MICHIGAN TECHNOLOGICAL UNIVERSITY

2013

(C) 2013 James M. Pidgeon 
This thesis has been approved in partial fulfillment of the requirements for the Degree of MASTER OF SCIENCE in Mechanical Engineering.

Department of Mechanical Engineering - Engineering Mechanics

Thesis Co-Advisor: Dr. Jeff Naber

Thesis Co-Advisor: Dr. John Johnson

Committee Member: Dr. Jason Keith

Department Chair: William W. Predebon 


\section{Table of Contents}

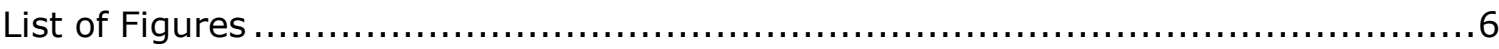

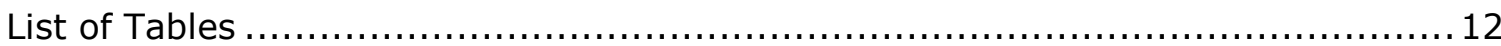

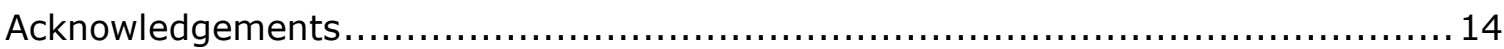

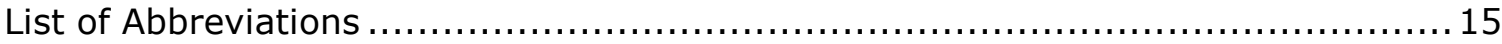

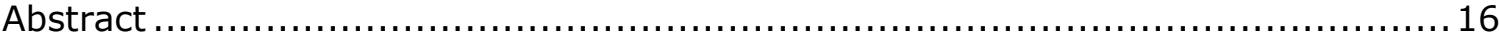

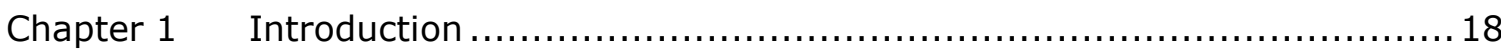

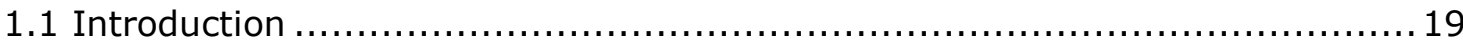

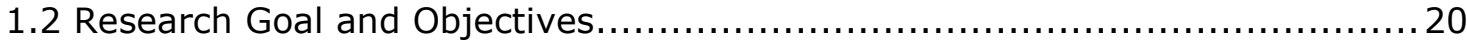

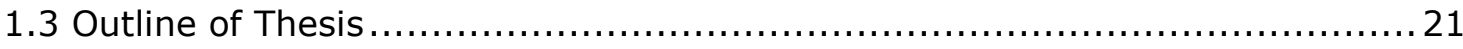

Chapter 2 Background and Literature Review ................................... 23

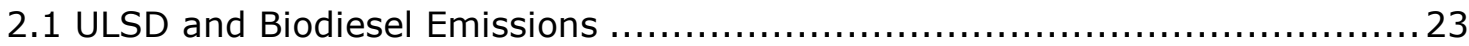

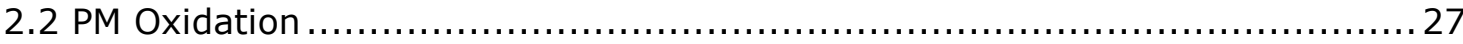

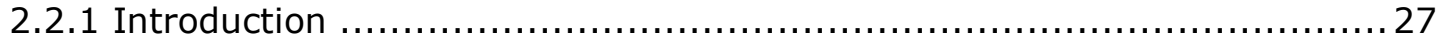

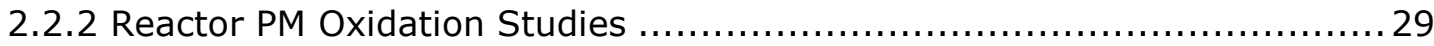

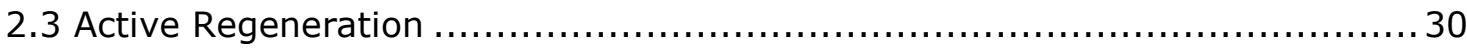

2.4 Downstream PM Concentration Sensor........................................... 32

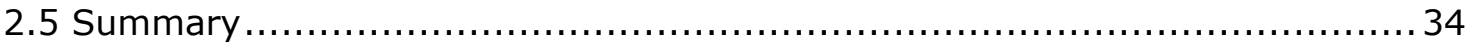

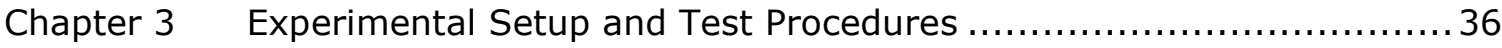

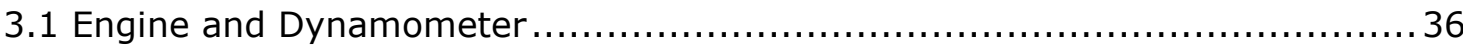

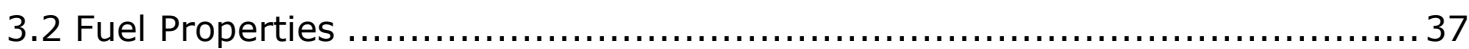

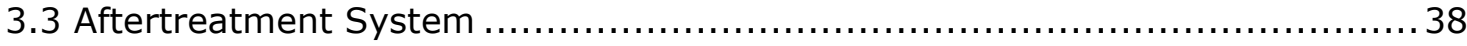

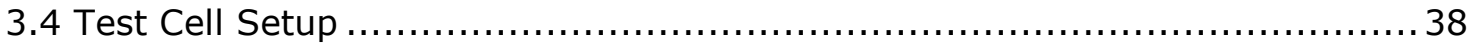

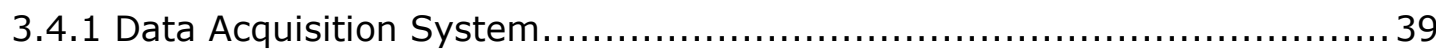

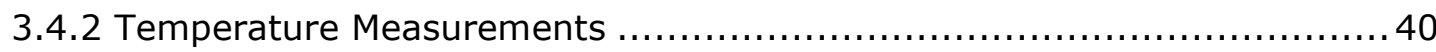

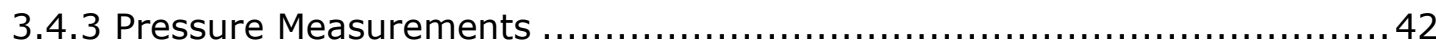

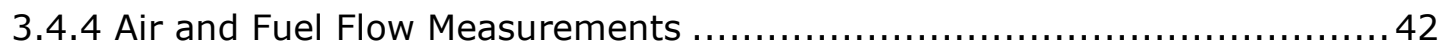

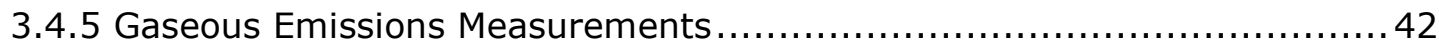

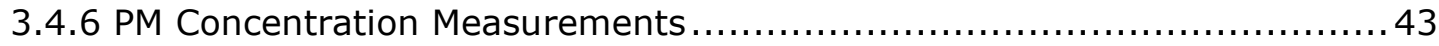

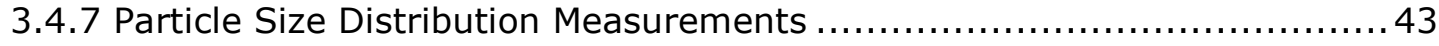

3.4.8 CPF PM Mass Retained Measurements ..................................... 44

3.5 Experimental DCPF PM Concentration Sensor ................................ 48

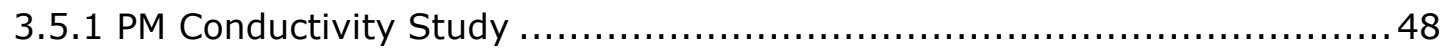

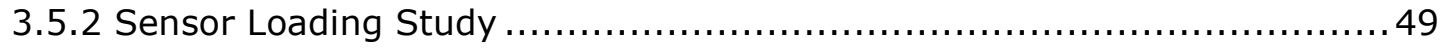




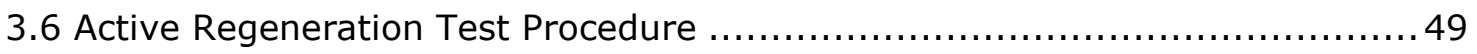

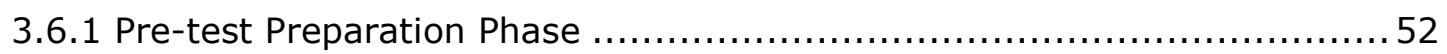

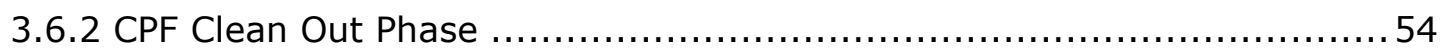

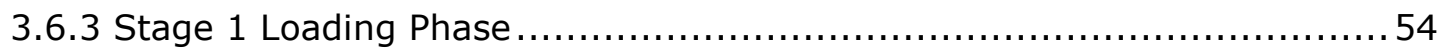

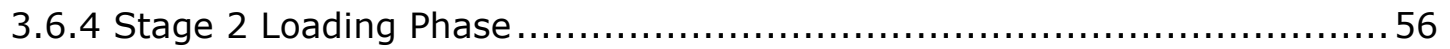

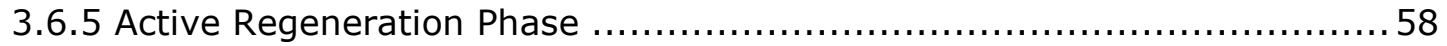

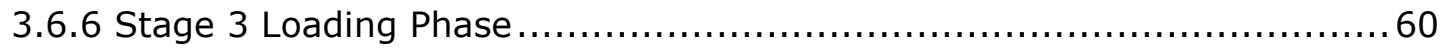

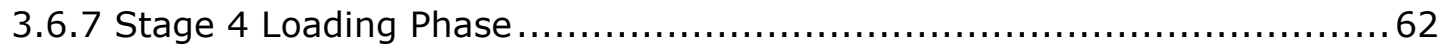

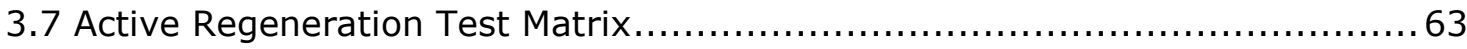

3.8 PM Reaction Rate Calculation Method .....................................66

3.9 Activation Energy Determination Method................................... 67

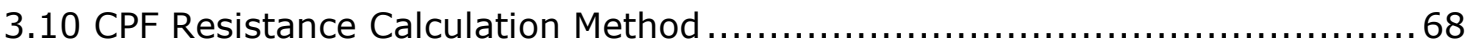

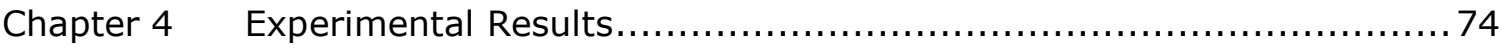

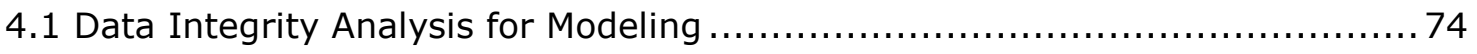

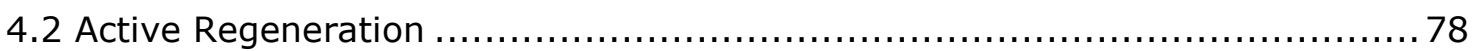

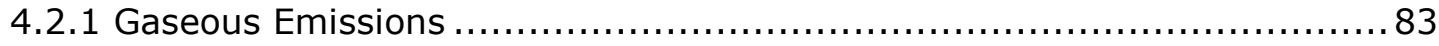

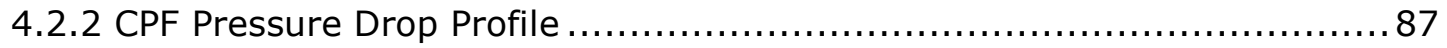

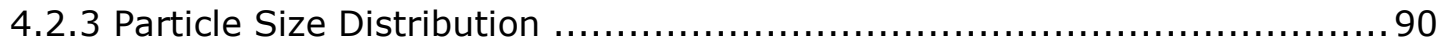

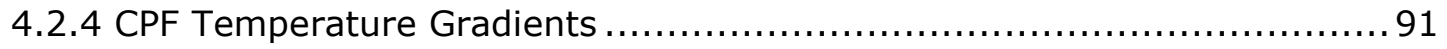

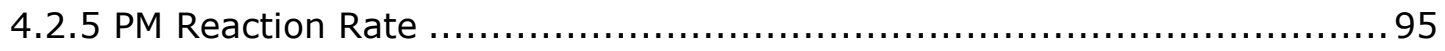

4.2.6 Activation Energy Determination ..................................... 97

4.2.7 Regeneration Efficiency of Fuel Dosing ................................. 99

4.2.8 In-cylinder and Post-turbo Dosing Methods............................ 103

Chapter 5 Conclusions and Recommendations .............................. 104

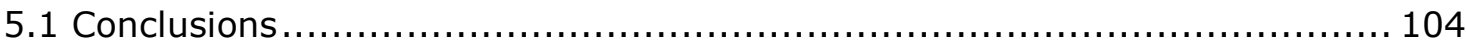

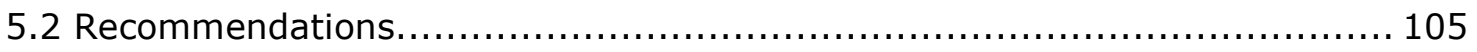

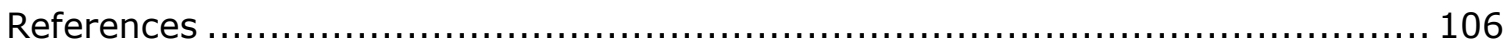

Appendix A Biodiesel Blend Molecular Formula Calculations ....................... 109

Appendix B Dilution Ratio Calculation Method ...................................... 112

Appendix C PSD Data Correction Method ........................................... 114

Appendix D CPF Mass Measurement Procedure.................................... 116

Appendix E Stage 1 Loading PM Mass Balance Calculations (by Kiran Premchand

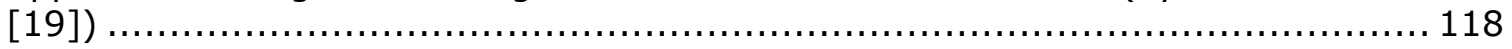

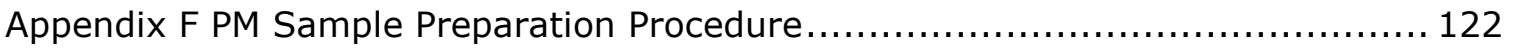

Appendix G Auxiliary Fuel Dosing Injector Calibration Procedure .................... 123 


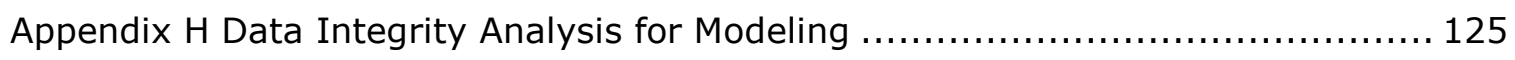

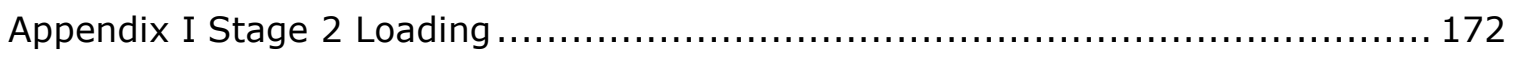

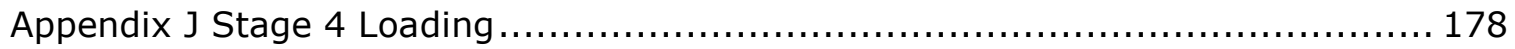

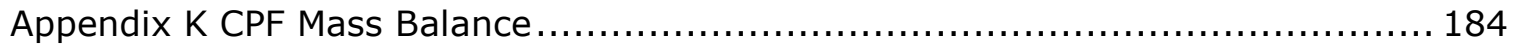

Appendix L Doser Flow Rate Comparison ........................................ 189

Appendix M Gaseous Emissions Summary ........................................ 191

Appendix N Engine Air Flow Rate and CPF Pressure Drop Profile .................... 194

Appendix O Regeneration Efficiency of Fuel Dosing Calculation Method .............. 204

Appendix P CPF Pressure Drop Comparison between National Instruments (NI)

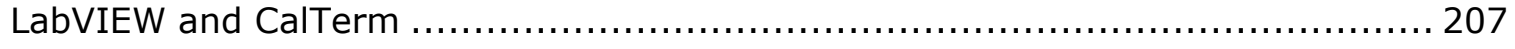

Appendix Q Permission to Use Copyrighted Material............................... 223 


\section{List of Figures}

Figure 2.1: DOC Conversion Efficiencies for Various Gaseous Species [6] ............. 25

Figure 2.2: Example of CPF Wall Flow Substrate Structure............................. 25

Figure 2.3: Relative Change of $\mathrm{NO}_{x}$ Emissions with SME Biodiesel Blends Compared

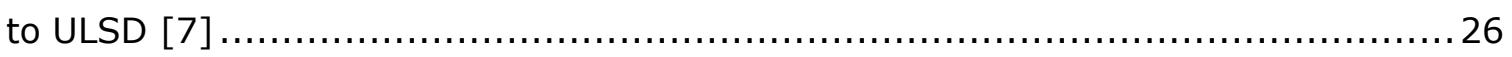

Figure 2.4: Relative Change of TPM Emissions with SME Biodiesel Blends Compared

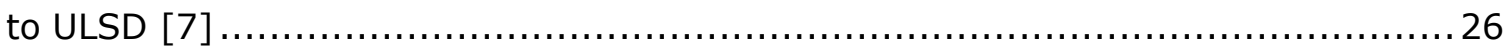

Figure 2.5: Passive Oxidation CPF PM Reaction Rate vs. 1000/Average CPF

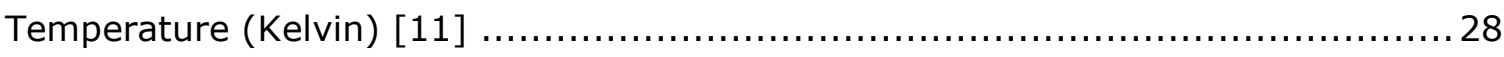

Figure 2.6: Soot Reactivity Measured During Temperature Ramps [13] ............... 30 Figure 2.7: Efficiency of PM Oxidation as a Function of Average CPF Temperature $\left(T_{R}\right)$

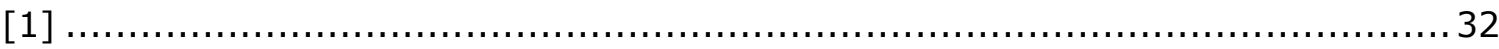

Figure 2.8: Signal Characteristics of the Resistive Particulate Matter Sensor and Images Showing PM Deposition on Electrodes [5], Copyright (c) SAE International,

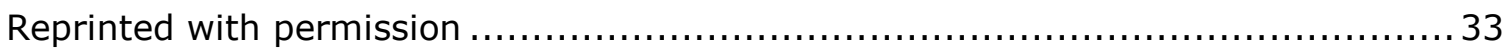

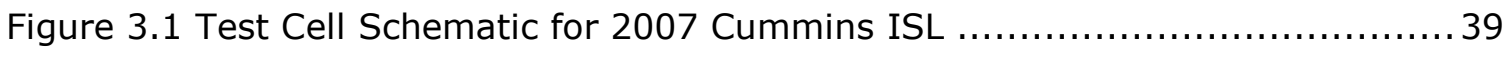

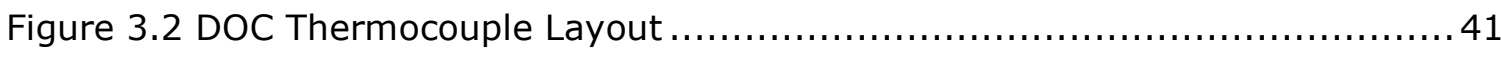

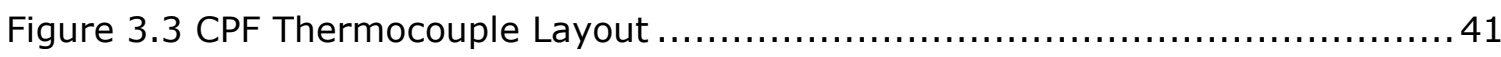

Figure 3.4: Overview of the ISL Active Regeneration Test Procedure $\ldots \ldots \ldots \ldots \ldots \ldots \ldots . . . .45$

Figure 3.5: Pre-test Preparation Phase Gaseous Emissions Sampling Strategy ....... 53

Figure 3.6: Gaseous Emissions Sampling Strategy for Stage 2 Loading Phase ........ 57

Figure 3.7: Gaseous Emissions and PSD Sampling Strategy for Active Regeneration Phase 60

Figure 3.8: B20-1 Experimental CPF Flow Resistance (subplot 1), Exhaust Viscosity and CPF Average Temperature (subplot 2), Exhaust Mass Flow Rate (subplot 3), and

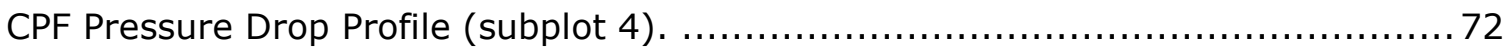

Figure 4.1: Pre-test Phase for Active Regeneration Average Engine-Out PM Concentrations in Chronological Order ............................................... 82

Figure 4.2: ULSD-3 DCPF HC Measurement during Active Regeneration (In-cylinder

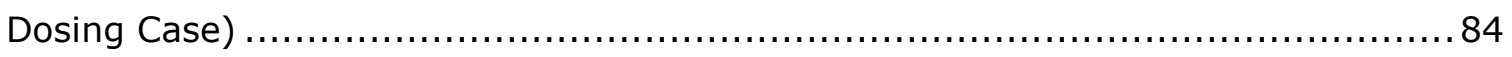

Figure 4.3: Comparison of CPF Pressure Drop for ULSD-4, B10-1, and B20-5, all at Nominal $525^{\circ} \mathrm{C} \mathrm{CPF}$ Inlet Temperature using In-Cylinder Dosing .................... 88 Figure 4.4: $525^{\circ} \mathrm{C} \mathrm{CPF}$ Inlet Temperature B20 and ULSD Tests using In-cylinder and

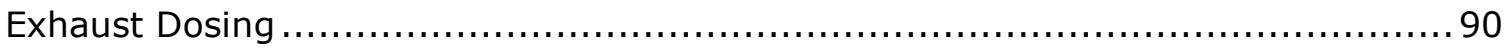


Figure 4.5: Averaged Particle Size Distribution by Particle Numbers by Fuel Type during Active Regeneration sampled DDOC and DCPF . 91 Figure 4.6: Radial Temperature Gradients at Four Axial Locations (Distance from CPF Inlet) during ULSD-4 Active Regeneration $\left(525^{\circ} \mathrm{C}\right.$ CPF Inlet Temperature Target, InCylinder Dosing) 93

Figure 4.7: Average-radial Axial Temperature Gradients during Active Regeneration with In-cylinder Dosing . 95

Figure 4.8: Optimized Results with All Tests Included in the Optimization 98 Figure 4.9: Grams of PM Oxidized per Equivalent Gallon of Fuel Injected during Dosing as a Function of Average CPF Temperature Including Data from Austin [1] 100 Figure 4.10: Grams of PM Oxidized per Equivalent Gallon of Fuel Injected during Dosing as a Function of Average CPF Temperature Including Data from Austin [1] Normalized by Exhaust Volumetric Flow Rate Ratio............................. 102 Figure B1: Copper Dilution Line Connected from the Heated Filter to the Dilution Box

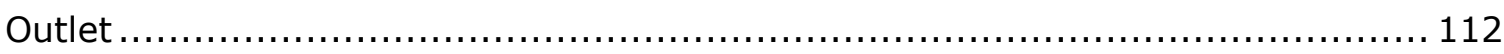

Figure B2: PSD Sample Line Connected to the DDOC Gaseous Emissions Port..... 113 Figure D1: Cummins 2007 ISL After-treatment System.......................... 116 Figure E1: A typical ISL AR experiment showing a) DOC and CPF pressure drops, b) Exhaust mass flow rate and c) CPF inlet temperature. 118

Figure G1: Example Auxiliary Doser Injector Calibration Curve with ULSD ........... 124 Figure H1: Air Flow Rate and CPF Pressure Drop for Run 2 (B20-2) ............... 126 Figure H2: Air Flow Rate and CPF Pressure Drop Profile for Run 3 (B20-5) .......... 126 Figure H3: CPF Pressure Drop Profile for Run 11 (B10-2) Measured by NI DAQ

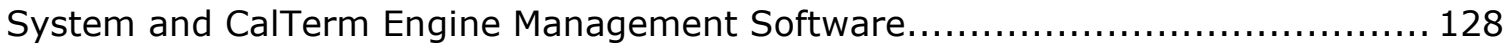
Figure H4: Air Flow Rate and CPF Pressure Drop Profile for Run 2 (B20-2)......... 129 Figure H5: Stage 2 Loading PM Concentration and Percent Oxidation for All Tests 130 Figure H6: Active Regeneration PM Oxidation for All Tests .... 133 Figure H7: Run 1 (B20-1) Experimental CPF Flow Resistance (subplot 1), Exhaust Viscosity and CPF Average Temperature (subplot 2), Exhaust Mass Flow Rate (subplot 3), and CPF Pressure Drop Profile (subplot 4).... 134

Figure H8: Run 1 (B20-1) NI and Corrected CalTerm Pressure Drop Profiles Including Linear Fit of NI Stage 1 and Stage 2 Loading and Pressure Drop Offset ............. 140 Figure H9: Run 1 (B20-1) Corrected and Experimental CPF Flow Resistance (subplot 1), Exhaust Viscosity and CPF Average Temperature (subplot 2), Corrected and 
Corrected Experimental Exhaust Mass Flow Rate (subplot 3), Corrected and Experimental CPF Pressure Drop Profile (subplot 4) .............................. 143

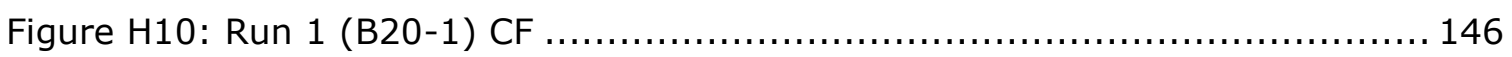

Figure H11: Run 1 (B20-1) Corrected and Experimental CPF Flow Resistance (subplot 1), Exhaust Viscosity and CPF Average Temperature (subplot 2), Experimental and Corrected Experimental Exhaust Mass Flow Rate (subplot 3), Corrected and

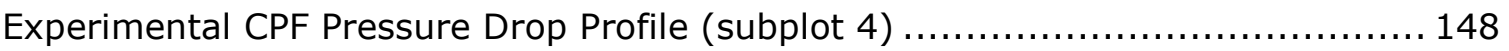

Figure H12: Run 2 (B20-2) Corrected and Experimental CPF Flow Resistance (subplot 1), Exhaust Viscosity and CPF Average Temperature (subplot 2), Experimental and Corrected Experimental Exhaust Mass Flow Rate (subplot 3), Corrected and Experimental CPF Pressure Drop Profile (subplot 4) ............................... 149 Figure H13: Run 3 (B20-5) Corrected and Experimental CPF Flow Resistance (subplot 1), Exhaust Viscosity and CPF Average Temperature (subplot 2), Experimental and Corrected Experimental Exhaust Mass Flow Rate (subplot 3), Corrected and

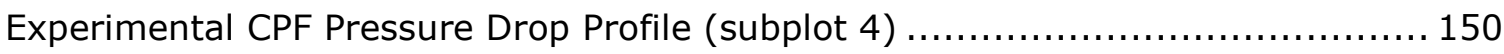
Figure H14: Run 4 (ULSD-3) Corrected and Experimental CPF Flow Resistance (subplot 1), Exhaust Viscosity and CPF Average Temperature (subplot 2), Experimental and Corrected Experimental Exhaust Mass Flow Rate (subplot 3), Corrected and Experimental CPF Pressure Drop Profile (subplot 4) ................ 151

Figure H15: Run 5 (ULSD-4) Corrected and Experimental CPF Flow Resistance (subplot 1), Exhaust Viscosity and CPF Average Temperature (subplot 2), Experimental and Corrected Experimental Exhaust Mass Flow Rate (subplot 3), Corrected and Experimental CPF Pressure Drop Profile (subplot 4) .................. 152 Figure H16: Run 6 (ULSD-5) Corrected and Experimental CPF Flow Resistance (subplot 1), Exhaust Viscosity and CPF Average Temperature (subplot 2), Exp. and Crrctd. Exp. Exhaust Mass Flow Rate (subplot 3), Corrected and Experimental CPF

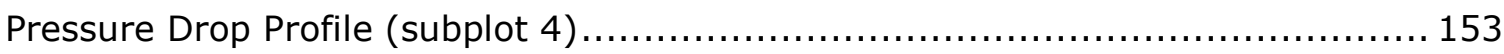
Figure H17: Run 7 (ULSD-6) Corrected and Experimental CPF Flow Resistance (subplot 1), Exhaust Viscosity and CPF Average Temperature (subplot 2), Experimental and Corrected Experimental Exhaust Mass Flow Rate (subplot 3), Corrected and Experimental CPF Pressure Drop Profile (subplot 4) ................. 154 Figure H18: Run 8 (B20-6) Corrected and Experimental CPF Flow Resistance (subplot 1), Exhaust Viscosity and CPF Average Temperature (subplot 2), Experimental and 
Corrected Experimental Exhaust Mass Flow Rate (subplot 3), Corrected and Experimental CPF Pressure Drop Profile (subplot 4) ............................ 155

Figure H19: Run 9 (B20-4) Corrected and Experimental CPF Flow Resistance (subplot 1), Exhaust Viscosity and CPF Average Temperature (subplot 2), Experimental and Corrected Experimental Exhaust Mass Flow Rate (subplot 3), Corrected and

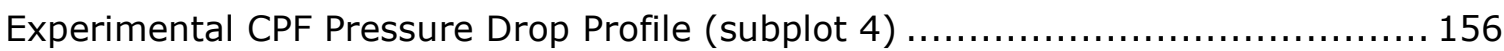

Figure H20: Run 10 (B10-1) Corrected and Experimental CPF Flow Resistance (subplot 1), Exhaust Viscosity and CPF Average Temperature (subplot 2), Experimental and Corrected Experimental Exhaust Mass Flow Rate (subplot 3), Corrected and Experimental CPF Pressure Drop Profile (subplot 4) ................ 157

Figure H21: Run 11 (B10-2) Corrected and Experimental CPF Flow Resistance (subplot 1), Exhaust Viscosity and CPF Average Temperature (subplot 2), Experimental and Corrected Experimental Exhaust Mass Flow Rate (subplot 3), Corrected and Experimental CPF Pressure Drop Profile (subplot 4) ................. 158 Figure H22: Run 12 (B10-3) Corrected and Experimental CPF Flow Resistance (subplot 1), Exhaust Viscosity and CPF Average Temperature (subplot 2), Experimental and Corrected Experimental Exhaust Mass Flow Rate (subplot 3), Corrected and Experimental CPF Pressure Drop Profile (subplot 4) 159

Figure H23: Run 13 (ULSD-1) Corrected and Experimental CPF Flow Resistance (subplot 1), Exhaust Viscosity and CPF Average Temperature (subplot 2), Experimental and Corrected Experimental Exhaust Mass Flow Rate (subplot 3), Corrected and Experimental CPF Pressure Drop Profile (subplot 4) ................. 160 Figure H24: Run 14 (ULSD-8) Corrected and Experimental CPF Flow Resistance (subplot 1), Exhaust Viscosity and CPF Average Temperature (subplot 2), Experimental and Corrected Experimental Exhaust Mass Flow Rate (subplot 3), Corrected and Experimental CPF Pressure Drop Profile (subplot 4) ................. 161 Figure H25: Run 15 (ULSD-9) Corrected and Experimental CPF Flow Resistance (subplot 1), Exhaust Viscosity and CPF Average Temperature (subplot 2), Experimental and Corrected Experimental Exhaust Mass Flow Rate (subplot 3), Corrected and Experimental CPF Pressure Drop Profile (subplot 4) ................... 162 Figure H26: Run 16 (B10-4) Corrected and Experimental CPF Flow Resistance (subplot 1), Exhaust Viscosity and CPF Average Temperature (subplot 2), Experimental and Corrected Experimental Exhaust Mass Flow Rate (subplot 3), Corrected and Experimental CPF Pressure Drop Profile (subplot 4) ................ 163 
Figure H27: Run 17 (ULSD-7R) Corrected and Experimental CPF Flow Resistance (subplot 1), Exhaust Viscosity and CPF Average Temperature (subplot 2), Exp. and Crrctd. Exp. Exhaust Mass Flow Rate (subplot 3), Corrected and Experimental CPF

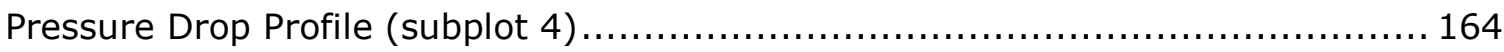

Figure H28: Run 18 (ULSD-2R) Corrected and Experimental CPF Flow Resistance (subplot 1), Exhaust Viscosity and CPF Average Temperature (subplot 2), Experimental and Corrected Experimental Exhaust Mass Flow Rate (subplot 3), Corrected and Experimental CPF Pressure Drop Profile (subplot 4) .................. 165

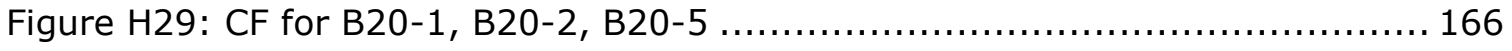

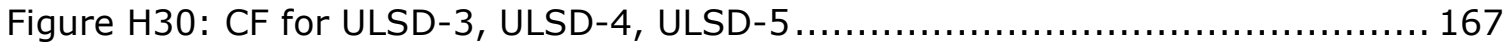

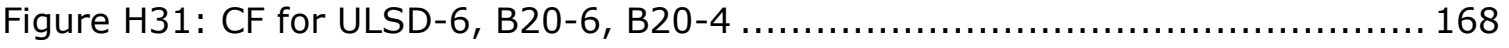

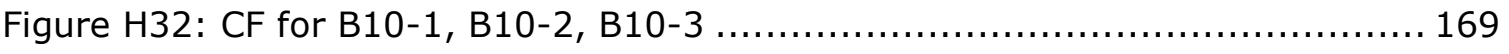

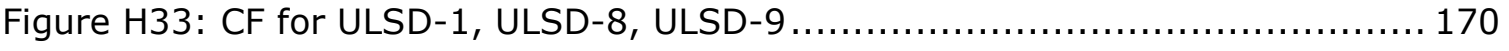

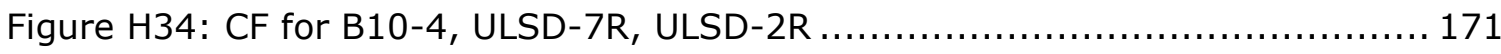

Figure I1: Average Engine-out Gaseous Emissions during Stage 2 Loading for Each

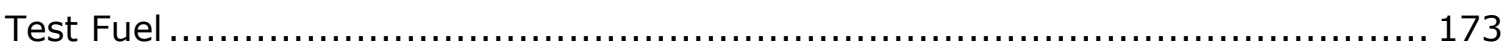

Figure I2: Stage 2 Loading Engine-Out and CPF-out Particle Size Distribution Weighed by Number for ULSD, B10, and B20.................................. 174

Figure I3: Stage 2 Loading Average Engine-Out PM Concentrations in Chronological

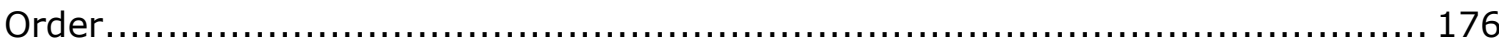

Figure I4: CPF Pressure Drop vs. CPF PM Loading at the Conclusion Stage 2 Loading 177

Figure J1: Average Engine-out Gaseous Emissions during Stage 4 Loading for Each

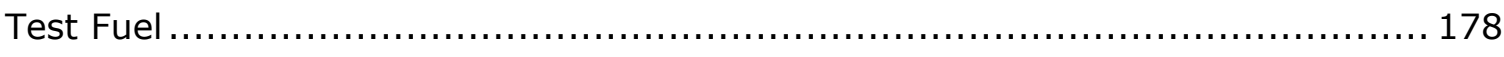

Figure J2: Particle Size Distribution by Particle Numbers Averaged by Fuel Type during Stage 4 Loading sampled DDOC and DCPF ............................. 180 Figure J3: CPF Pressure Drop at the Start and Stop of Stage 2 and Stage 4 Loading

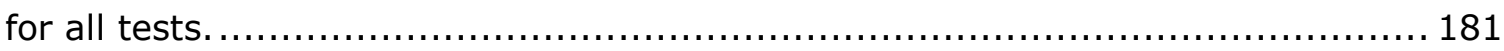

Figure J4: Stage 2 and Stage 4 Loading Reaction Rate Organized by Run Number 183 Figure N1: B20-1 Air Flow Rate (top) and CPF Pressure Drop Profile (bottom)..... 194 Figure N2: B20-2 Air Flow Rate (top) and CPF Pressure Drop Profile (bottom)...... 194 Figure N3: B20-5 Air Flow Rate (top) and CPF Pressure Drop Profile (bottom) ...... 195 Figure N4: ULSD-3 Air Flow Rate (top) and CPF Pressure Drop Profile (bottom) ... 195 Figure N5: ULSD-4 Air Flow Rate (top) and CPF Pressure Drop Profile (bottom) ... 196 
Figure N6: ULSD-5 Air Flow Rate (top) and CPF Pressure Drop Profile (bottom) ... 196 Figure N7: ULSD-6 Air Flow Rate (top) and CPF Pressure Drop Profile (bottom) ... 197 Figure N8: B20-6 Air Flow Rate (top) and CPF Pressure Drop Profile (bottom) ...... 197 Figure N9: B20-4 Air Flow Rate (top) and CPF Pressure Drop Profile (bottom)..... 198 Figure N10: B10-1 Air Flow Rate (top) and CPF Pressure Drop Profile (bottom) .... 198 Figure N11: B10-2 Air Flow Rate (top) and CPF Pressure Drop Profile (bottom) .... 199 Figure N12: B10-3 Air Flow Rate (top) and CPF Pressure Drop Profile (bottom) .... 199 Figure N13: ULSD-1 Air Flow Rate (top) and CPF Pressure Drop Profile (bottom).. 200 Figure N14: ULSD-8 Air Flow Rate (top) and CPF Pressure Drop Profile (bottom) .. 200 Figure N15: ULSD-9 Air Flow Rate (top) and CPF Pressure Drop Profile (bottom) .. 201 Figure N16: B10-4 Air Flow Rate (top) and CPF Pressure Drop Profile (bottom) .... 201 Figure N17: ULSD-7R Air Flow Rate (top) and CPF Pressure Drop Profile (bottom) 202 Figure N18: ULSD-2R Air Flow Rate (top) and CPF Pressure Drop Profile (bottom) 202 Figure N19: ULSD-10 Air Flow Rate (top) and CPF Pressure Drop Profile (bottom) 203 Figure 01: Modeled CPF PM Mass Retained in the CPF during Active Regeneration for

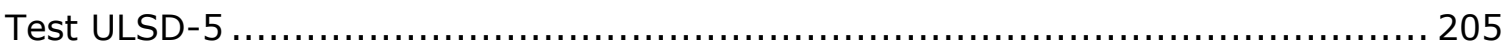

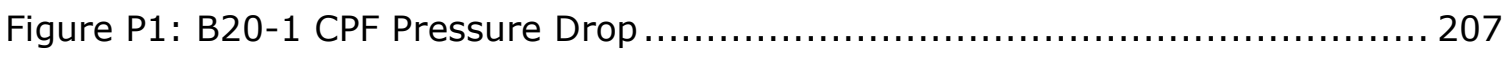

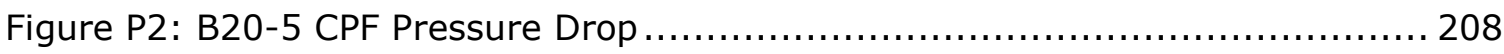

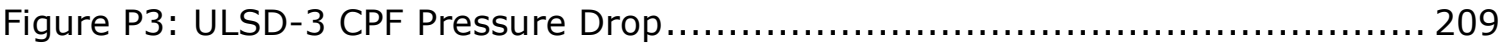

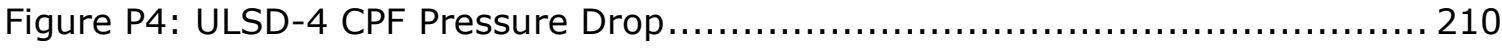

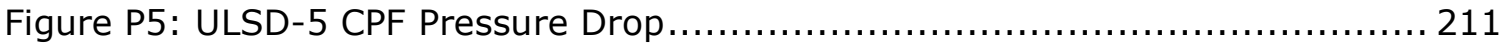

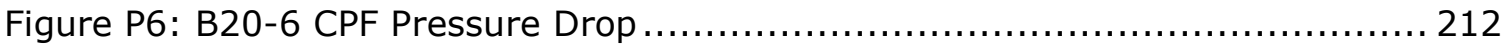

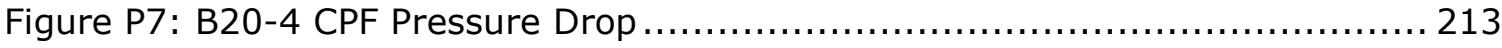

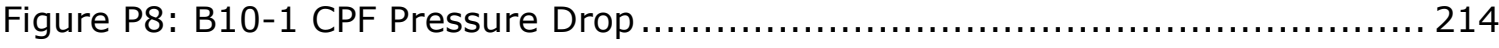

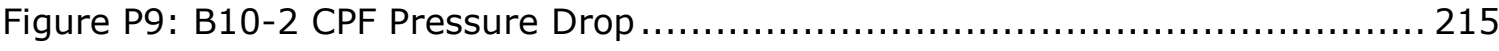

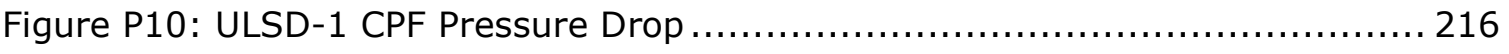

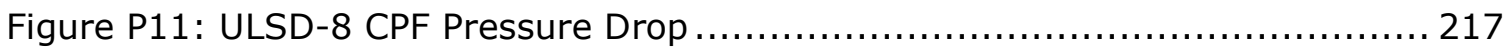

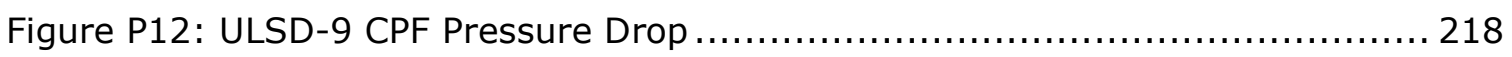

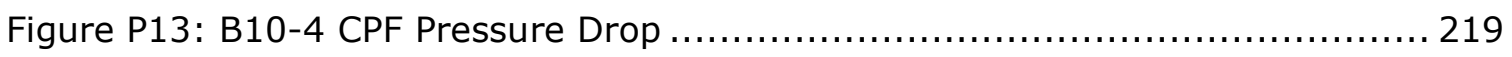

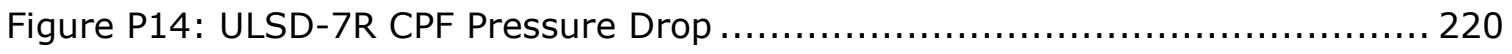

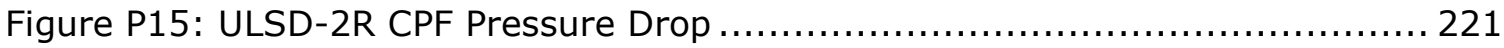

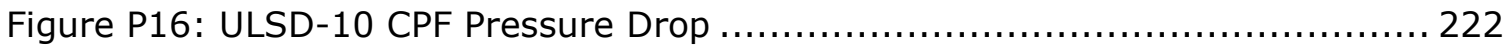




\section{List of Tables}

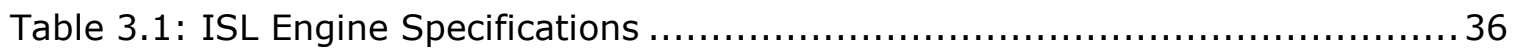

Table 3.2 Fuel Properties for Experimental Test Fuels* ............................... 37

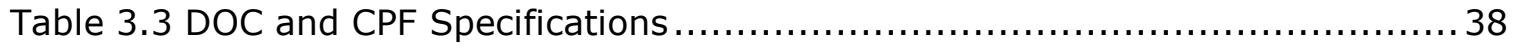

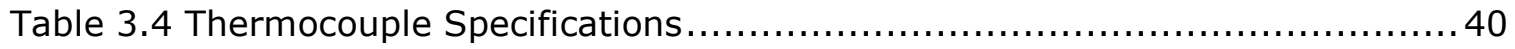

Table 3.5: Engine Operating Points for Initial Warm-Up Sequence .....................53

Table 3.6: Engine Speed and Load for Stage 2 Engine Warm Up .....................56

Table 3.7: Engine Speed and Load for Stage 4 Engine Warm Up .....................63

Table 3.8: Active Regeneration Test Matrix ..................................... 65

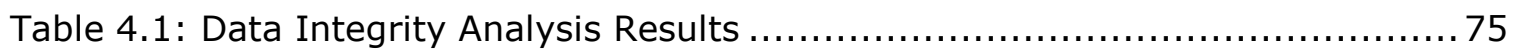

Table 4.2: Selected Active Regeneration Test Data ................................ 79

Table 4.3: HC Measurements Recorded during Active Regeneration Point Validation85

Table 4.4: $\mathrm{HC}, \mathrm{CO}$, and $\mathrm{NO}_{2}$ Conversion Efficiencies for All Tests ..................... 86

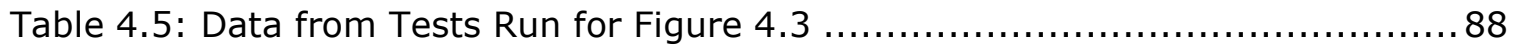

Table 4.6: Average CPF Temperature as a Function of Dosing Method for USLD and

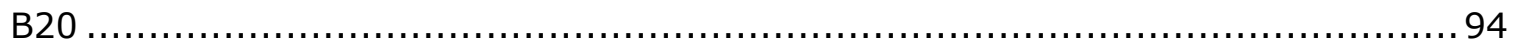

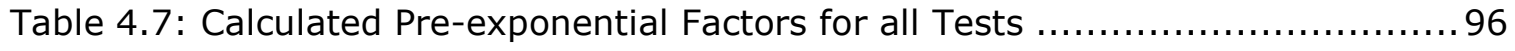

Table 4.8: Calculated Reaction Rate and Pre-exponential Factor Values for All Tests

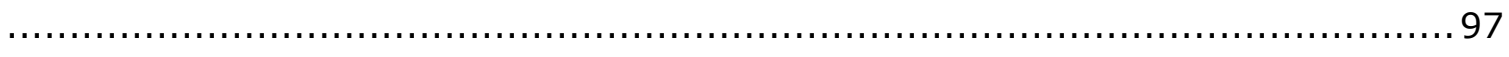

Table 4.9: Optimization Results using All Tests $\ldots \ldots \ldots \ldots \ldots \ldots \ldots \ldots \ldots \ldots \ldots \ldots \ldots \ldots$

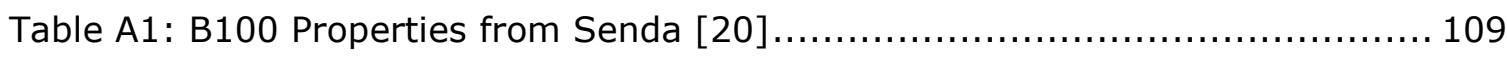

Table A2: Computed B100 Molecular Components .............................. 109

Table A3: H/C and O/C Ratios for B100 ....................................... 110

Table A4: Mole Fraction of Biodiesel for B10 and B20 Blends..................... 110

Table A5: Calculated Properties for B10 and B20 Biodiesel Blends with ULSD Data 111

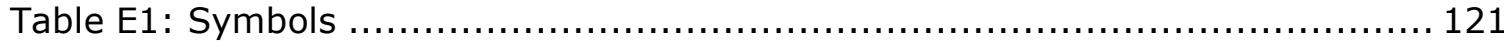

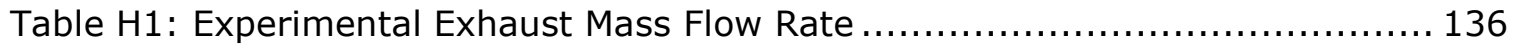

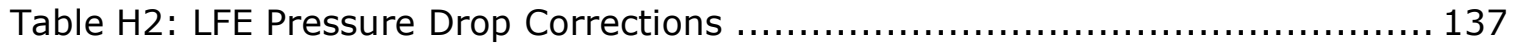

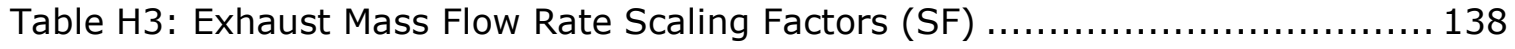

Table H4: Stage 1 Loading CPF Pressure Drop Offset Corrections $\ldots \ldots \ldots \ldots \ldots \ldots \ldots \ldots \ldots \ldots \ldots$

Table H5: Active Regeneration Ramp and Active Regeneration CF .................. 145

Table K1: Stage 1 Loading CPF Mass Balance..................................... 184

Table K2: Stage 2 Loading CPF Mass Balance................................. 185

Table K3: Active Regeneration CPF Mass Balance .............................. 186 
Table K4: Stage 3 Loading CPF Mass Balance................................... 187

Table K5: Stage 4 Loading CPF Mass Balance.................................. 188

Table L1: DOC Energy Balance Results..................................... 190

Table M1: Pre-test Preparation Phase Gaseous Emissions .......................... 191

Table M2: Stage 1 Loading Gaseous Emissions ................................. 191

Table M3: Stage 2 Loading Gaseous Emissions .................................. 192

Table M4: Active Regeneration Gaseous Emissions ............................. 192

Table M5: Stage 3 Loading Gaseous Emissions .................................... 193

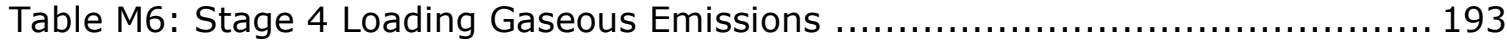

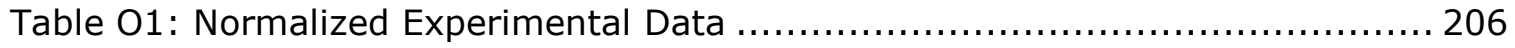




\section{Acknowledgements}

There are a number of individuals and organizations who are responsible for my ability to complete the work presented in this thesis. To each and every one of you, I say thank you, as there is no way I could have done it without you.

I would like to thank my advisors, Dr. John Johnson and Dr. Jeff Naber, for granting me the research opportunity within the Heavy Duty Diesel Group at MTU and for the guidance they have provided me throughout the time spent working with them. I would also like to thank Dr. Jason Keith for participating as a member of my thesis defense committee.

I would also like to thank the team members within the Heavy Duty Diesel Group from the past, present, and future that have helped immensely in the pursuit of my Master's degree. I would also like to extend thanks to the staff at MTU whose daily responsibilities helped me in the pursuit of my Master's degree.

I would also like to thank Cummins, Inc. for providing the engine and aftertreatment system used in this study and would like to thank the consulting support of Joe Brault, Krishna Chilumukuru, and Arvind Suresh. Finally, I would like to thank the United States Department of Energy for their financial support under Award Number DE-EE0000204, as this research would not have been possible without it.

This material is based upon work supported by the Department of Energy National Energy Technology Laboratory under Award Number(s) DE-EE0000204. This material was prepared as an account of work sponsored by an agency of the United States Government. Neither the United States Government nor any agency thereof, nor any of their employees, makes any warranty, expressed or implied, or assumed any legal liability or responsibility for the accuracy, completeness, or usefulness of any information, apparatus, product, or process disclosed, or represents that its use would not infringe privately owned rights. Reference herein to any specific commercial product, process, or service by trade name, trademark, manufacturer, or otherwise does not necessarily constitute or imply its endorsement, recommendation, or favoring by the United States Government or any agency thereof. The views and opinions of authors expressed herein do not necessarily state or reflect those of the United States Government or any agency thereof. 


\section{List of Abbreviations}

\begin{tabular}{|c|c|}
\hline 1D & 1 Dimensional \\
\hline $\mathbf{A}$ & Pre-exponential Factor; sec $^{-1}$ \\
\hline B10 & $10 \%$ blend of biodiesel with ULSD \\
\hline B20 & $20 \%$ blend of biodiesel with ULSD \\
\hline $\mathbf{C}_{\text {in }}$ & Engine-out PM concentration; $\mathrm{mg} / \mathrm{scm}$ \\
\hline $\mathrm{CO}_{2}$ & Carbon Dioxide \\
\hline CPF & Catalyzed Particulate Filter \\
\hline DCPF & Downstream CPF \\
\hline DDOC & Downstream DOC \\
\hline DOC & Diesel Oxidation Catalyst \\
\hline Ea & Activation energy; kJ. $\mathrm{gmol}^{-1}$ \\
\hline EGR & Exhaust Gas Recirculation \\
\hline EPA & Environmental Protection Agency \\
\hline FBP & Final Boiling Point \\
\hline FID & Flame Ionization Detector \\
\hline HC & Hydrocarbons \\
\hline HHV & Higher Heating Value \\
\hline IBP & Initial Boiling Point \\
\hline LFE & Laminar Flow Element \\
\hline LHV & Lower Heating Value \\
\hline MTU & Michigan Technological University \\
\hline NMHC & Non-methane hydrocarbons \\
\hline NO & Nitric Oxide \\
\hline $\mathbf{N O}_{2}$ & Nitrogen Dioxide \\
\hline $\mathbf{N O}_{\mathbf{x}}$ & $\mathrm{NO}+\mathrm{NO}_{2}$ \\
\hline PM & Particulate Matter \\
\hline Pt & Elemental Platinum \\
\hline $\mathbf{R}$ & Universal gas constant; J.(gmol.K) ${ }^{-1}$ \\
\hline RRo & $\mathrm{PM}$ reaction rate; $\mathrm{sec}^{-1}$ \\
\hline scm & Standard Cubic Meter \\
\hline SCR & Selective Catalytic Reduction \\
\hline SME & Soy Methyl Ester \\
\hline SOF & Soluble Organic Fraction \\
\hline TPO & Temperature Programmed Oxidation \\
\hline U.S. & United States \\
\hline UDOC & Upstream DOC \\
\hline ULSD & Ultra Low Sulfur Diesel \\
\hline$\Delta \mathbf{P}$ & Pressure drop; kPa \\
\hline
\end{tabular}




\section{Abstract}

Active regeneration experiments were carried out on a production 2007 Cummins 8.9L ISL engine and associated DOC and CPF aftertreatment system. The effects of SME biodiesel blends were investigated in this study in order to determine the PM oxidation kinetics associated with active regeneration, and to determine the effect of biodiesel on them. The experimental data from this study will also be used to calibrate the MTU-1D CPF model. Accurately predicting the PM mass retained in the CPF and the oxidation characteristics will provide the basis for computation in the ECU that will minimize the fuel penalty associated with active regeneration.

An active regeneration test procedure was developed based on previous experimentation at MTU. During each experiment, the PM mass in the CPF is determined by weighing the filter at various phases. In addition, DOC and CPF pressure drop, particle size distribution, gaseous emissions, temperature, and PM concentration data are collected and recorded throughout each experiment. The experiments covered a range of CPF inlet temperatures using ULSD, B10, and B20 blends of biodiesel. The majority of the tests were performed at CPF PM loading of $2.2 \mathrm{~g} / \mathrm{L}$ with in-cylinder dosing, although $4.1 \mathrm{~g} / \mathrm{L}$ and a post-turbo dosing injector were also used. The PM oxidation characteristics at different test conditions were studied in order to determine the effects of biodiesel on PM oxidation during active regeneration.

A PM reaction rate calculation method was developed to determine the global activation energy and the corresponding pre-exponential factor for all test fuels. The changing sum of the total flow resistance of the wall, cake, and channels, based on calculating $\Delta \mathrm{P} / \mu \bullet \dot{\mathrm{V}}$, was also determined as part of the data analysis process in order to check on the integrity of the data and to correct input data to be consistent with the expected trends of the resistance based on the engine conditions used in the test procedure.

It was determined that increasing the percent biodiesel content in the test fuel tends to increase the PM reaction rate and the regeneration efficiency of fuel dosing, i.e., at a constant CPF inlet temperature, B20 test fuel resulted in the highest PM reaction rate and regeneration efficiency of fuel dosing. Increasing the CPF inlet temperature also increases PM reaction rate and regeneration efficiency of fuel dosing. Performing 
active regeneration with B20 as opposed to ULSD allows for a lower CPF temperature to be used to reach the same level of regeneration efficiency, or it allows for a shorter regeneration time at a constant CPF temperature, resulting in decreased fuel consumption for the engine during active regeneration in either scenario. 


\section{Chapter 1 Introduction}

The diesel engine is important to many industries around the world since its introduction over a century ago. The durability, thermal efficiency, and increased torque over spark-ignition engines make diesel engines ideal for stationary power generation, on highway trucks, construction, agriculture, and a multitude of other applications worldwide including light-duty vehicles.

U.S. EPA emissions standards for heavy-duty diesel engines for model year 2007 resulted in many diesel engine equipped vehicles being outfitted with aftertreatment systems. These aftertreatment systems commonly consist of exhaust gas recirculation (EGR) with an oxidation catalyst (diesel oxidation catalyst or DOC) and particulate filter which may be catalyzed (catalyzed particulate filter or CPF) to reduce the tailpipe $\mathrm{NO}_{x}$ and particulate matter (PM) emissions from the engine.

As the filter is loaded with retained PM, active regeneration is periodically required to oxidize the PM in the filter. Active regeneration consists of injecting diesel fuel into the exhaust stream via in-cylinder or post-turbo fuel injection methods, which undergoes exothermal oxidation in the DOC, thereby increasing the exhaust gas temperature into the PM filter, and subsequently regenerating it through thermal oxidation. The fuel injected results in a direct fuel penalty because the injected fuel produces no useful work. In order to maximize the vehicle's fuel efficiency, high fidelity DOC and CPF models need to be developed, allowing the most fuel efficient engine control strategies to be implemented. Along with the emissions regulations, new OBD standards related to aftertreatment system functionality monitoring also need to be met. These OBD standards result in the necessity for sensors to be integrated for purposes such as monitoring the CPF outlet PM concentration to alert when failure exists in CPF PM filtering or when the DOC, CPF, and selective catalytic reduction (SCR) are not functioning and reducing the $\mathrm{PM}$ and $\mathrm{NO}_{\mathrm{x}}$ emissions according to the OBD standards.

In order to help reduce the United States' dependency on foreign oil, the use of up to $20 \%$ blends, by volume, of biodiesel has been approved by most manufacturers. The motivation behind this research is to better understand the active regeneration process with diesel and biodiesel fuels, to aid in the development of the DOC and CPF models and subsequent OBD and engine control strategies. As such, the specific 
objectives and an overview of the research described are presented in the following sections.

\subsection{Introduction}

A 2007 Cummins production aftertreatment system was used in this study consisting of a diesel oxidation catalyst (DOC) and a catalyzed particulate filter (CPF). As the engine out exhaust flows through the DOC channels, and subsequently over the precious metal wash coat within the DOC, the carbon monoxide (CO), hydrocarbons (HC), and nitric oxide (NO) are oxidized via chemical reactions occurring in the DOC.

The DOC also oxidizes the hydrocarbons injected via in-cylinder or post-turbo exhaust dosing during active regeneration, which generates the exothermic oxidation reaction that elevates the temperature of the exhaust before entering the CPF. The exotherm generated by the DOC, dependent upon flow rates of exhaust and fuel, produced $\mathrm{CPF}$ inlet temperatures ranging from 475 to $600^{\circ} \mathrm{C}$ to oxidize the particulate matter (PM) retained within the CPF during active regeneration. Active regeneration is periodically required to decrease the back pressure exerted on the engine which increases with CPF PM loading as well as maintaining save PM levels to avoid excessive temperature which could damage the substrate.

The fuel injected during active regeneration results in an overall fuel consumption penalty because the fuel injected in the exhaust produces no useful work. As such, active regeneration is not the preferred method of PM oxidation within the CPF, but it is a necessity because the engine will not always be operating at conditions that are suitable for passive oxidation of the PM. In order to minimize this fuel penalty, understanding the variables that affect the effectiveness of active regeneration is needed to develop fuel efficient engine operation strategies for active regeneration. These variables include, but are not limited to, CPF inlet temperature, PM loading within the CPF, fuel type, and fuel dosing method. CPF inlet temperatures ranging from 475 to $600^{\circ} \mathrm{C}, 2.2 \pm 0.2 \mathrm{~g} / \mathrm{L} \mathrm{CPF} \mathrm{PM} \mathrm{loading,} \mathrm{and} \mathrm{two} \mathrm{blends} \mathrm{of} \mathrm{biodiesel} \mathrm{were}$ used in this study. Blends of biodiesel with ultra-low sulfur diesel (ULSD) are characterized by their ' $\mathrm{B}$ ' factor, which represents the volume percent of biodiesel present in the ULSD-biodiesel blend, i.e., 10 and 20\% biodiesel blended with ULSD are denoted as B10 and B20, respectively. The different fuels tested in this study were ULSD, B10, and B20. 
Biodiesel refers to renewable fuel derived from vegetable oil, animal fat, or waste cooking oil and consists of the methyl esters of fatty acids, which is typically used with ULSD to produce various blends of biodiesel [3]. Most manufacturers state that no modifications to the engine are necessary if 20 volume percent or less is blended with ULSD, as long as the fuel meets the requirements stated in ASTM D7467 [4].

Increasing the CPF inlet temperature during active regeneration increases the PM reaction rate. Also, the reaction rate increases with increasing the percent biodiesel in the test fuels as observed by Austin [1]. Austin [1] concluded that at a constant target CPF inlet temperature, as the percent biodiesel increases, the amount of PM oxidized per gallon of dosing fuel used increases as well. At a constant level of PM oxidized per gallon of dosing fuel used, increasing the percent biodiesel decreases the required $\mathrm{CPF}$ inlet temperature.

Increasingly stringent regulations related to monitoring of the functionality of the CPF are going into effect as part of new OBD requirements for the model year 2013 [5]. In order to fulfill the requirements for monitoring CPF functionality, new sensors are required that directly measures the PM emissions after the CPF outlet, as well as survives the high temperatures (over $600^{\circ} \mathrm{C}$ ) seen after the CPF (i.e., during active regeneration). These new sensors are required because the PM concentration detection limits required for the new OBD legislation cannot be determined by the other sensors currently in use.

This work is part of a DOE project and the results will also be published in a 2013 SAE paper [2] currently in review.

\subsection{Research Goal and Objectives}

The goal of this research was to further refine the active regeneration test procedure developed by Austin [1] on the Cummins ISM engine and to quantify active regeneration as conducted on a 2007 Cummins ISL engine operated on ULSD and 10 and $20 \%$ blends of methyl-ester biodiesel fuels. In order to achieve this goal, quantification of the effects of CPF PM loading, CPF temperature, dosing method (incylinder or post-turbo dosing injection methods), and fuel type was required using the collected experimental data. The objectives used to accomplish the goal were as follows: 
1. Conduct a literature review on past PM thermal oxidation studies and relate this to the current studies,

2. Develop an improved procedure to collect high quality data that can support the active regeneration experimental analysis and modeling efforts,

3. Develop a method to calculate the PM reaction rate through the entire active regeneration period based on CPF PM loading and CPF temperature,

4. Determine the effects of CPF temperature, biodiesel blended fuels, and dosing method on the PM oxidation in the CPF during active regeneration including fitting the PM reaction rate to an Arrhenius model and optimization of rate parameters ( $A$ and Ea) for each test fuel,

5. Analyze the total of the filter wall, cake, and channel resistances by calculating $\Delta \mathrm{P} /(\mu \cdot \dot{\mathrm{V}})$ during the entire active regeneration test procedure.

High quality experimental data is vital to accomplishing this goal, and as such, a consistent experimental procedure throughout every test was developed and used which limits the variations between individual tests.

Along with the experimental portion of the research, a modeling effort is proceeding in parallel which uses the experimentally collected active regeneration data for calibration of a 1D CPF computer simulation (the MTU-1D CPF model). As stated above, the modeling effort is proceeding in parallel with the experimental work to develop and calibrate the MTU-1D CPF model. As thus an objective of this research with respect to the modeling effort was to assist in data compilation and explanation. Gaseous emissions, exhaust flow rate, CPF PM loading, engine-out and CPF-out PM concentration, and temperature data has been compiled and processed for each phase of each active regeneration experiment performed on the 2007 Cummins ISL engine. The calibration of the MTU-1D CPF model is underway and will be used to determine and model the PM oxidation kinetics within the CPF during active regeneration under each set of experimental conditions.

\subsection{Outline of Thesis}

This chapter provides a brief overview of the material included in this study. The introduction section has provided an overview of the aftertreatment system and PM oxidation via active regeneration. Quantifying the effects of biodiesel blends as 
compared to ULSD on PM oxidation during active regeneration is the primary goal of this study. The six more specific objectives have been described.

Chapter 2 is devoted to providing background information as well as a synopsis of the literature that has already been published relative to the research goal in this study. Literature from past research projects at Michigan Technological University as well as technical papers published by various organizations relative to this study are summarized in this chapter.

Chapter 3 describes the test cell and data acquisition instruments used to gather temperature, pressure, gaseous concentrations, PM concentrations, and other types of data vital for reaching the research goals and objectives. The engine, aftertreatment system, and dynamometer specifications are presented as well as the overall active regeneration test procedure and active regeneration test matrix.

Chapter 4 begins with the experimental results from active regeneration tests performed in this study. Data from active regeneration pertaining to PM reaction rate and fuel efficiency of PM oxidation is presented along with temperature, gaseous and PM concentrations, and other data. The effects of biodiesel blends on these data are also presented.

Chapter 5 presents a summary, conclusions from this study, and recommendations for future research. Appendices detailing various aspects of this study are also presented following Chapter 5 . 


\section{Chapter 2 Background and Literature Review}

This chapter focuses on the published literature pertaining to the research goals of this thesis. First, papers are reviewed about ULSD and biodiesel emissions related to diesel engines. In this section, emissions regulations are presented along with changes to engine emissions when changing from ULSD to biodiesel blended fuel. Next, mechanisms for PM oxidation are presented, where the findings are based off reactor data from past PM oxidation experimentation. The PM oxidation review leads into the next section, where the results of active regeneration experimentation are reviewed. Finally, a section devoted to PM concentration sensor technology is presented.

\subsection{ULSD and Biodiesel Emissions}

The diesel engine has been in a state of constant development for the past 75 years. One of the reasons it has seen this effort is its ability to provide reliable power for many applications, at a higher thermal efficiency than the gasoline fueled spark ignition engines. During the past 40 years, the United States EPA regulations regarding the tailpipe emissions of $\mathrm{PM}$ and gaseous species of $\mathrm{CO}, \mathrm{HC}$, and $\mathrm{NO}_{\mathrm{x}}$, have become more restrictive. Beginning in 2007, the PM emissions regulations were such that manufacturers had to use DOC and CPF aftertreatment devices to reduce the engine-out PM emissions to the levels required by the EPA. In 2010, the EPA heavy duty diesel emissions are regulated to $0.2 \mathrm{~g} / \mathrm{bhp}-\mathrm{h}$ for $\mathrm{NO}_{\mathrm{x}}, 0.14 \mathrm{~g} / \mathrm{bhp}-\mathrm{h}$ for $\mathrm{NMHC}$, $15.5 \mathrm{~g} / \mathrm{bhp}-\mathrm{h}$ for CO, and $0.01 \mathrm{~g} / \mathrm{bhp}-\mathrm{h}$ for PM which has been in effect since 2007. The DOC provides for the oxidation of $\mathrm{NO}$ to $\mathrm{NO}_{2}$ which then increases the passive $\mathrm{NO}_{2}$ assisted oxidation of PM in the CPF and its second function is to oxidize the injected hydrocarbons for periodic active regeneration of the retained PM in the CPF.

In the design of a diesel engine, there is a direct tradeoff between $\mathrm{PM}$ and $\mathrm{NO}_{\mathrm{x}}$ engine-out emissions. Depending on the aftertreatment system components being used, one can tune an engine to produce little PM with elevated $\mathrm{NO}_{\mathrm{x}}$ levels (useful when utilizing $\mathrm{NO}_{x}$ reduction aftertreatment technology) or produce more PM with reduced $\mathrm{NO}_{\mathrm{x}}$ levels. The approach of using high engine out $\mathrm{NO}_{\mathrm{x}}$ levels and a $\mathrm{NO}_{\mathrm{x}}$ aftertreatment system allows the reduction of fuel consumption for the engine. Increasing $\mathrm{NO}_{x}$ and decreasing $\mathrm{PM}$ emissions results in increased engine efficiency with decreased power and vice versa. The use of a CPF is primarily responsible for 
retaining and oxidizing the PM emitted from the engine. The DOC-CPF is the aftertreatment system used in this study. Complete understanding of the loading and oxidation of the PM retained within the CPF allows for the most fuel efficient engine tuning and control strategies to be used.

The DOC serves two purposes; first, it is a flow through chemical reactor which oxidizes $\mathrm{CO}, \mathrm{HC}$, and $\mathrm{NO}$ emissions into $\mathrm{CO}_{2}, \mathrm{NO}_{2}, \mathrm{H}_{2} \mathrm{O}, \mathrm{N}_{2}$ and $\mathrm{O}_{2}$. $\mathrm{NO}$ emissions are oxidized to $\mathrm{NO}_{2}$, which is the primary component responsible for the passive oxidation of PM within the CPF. Second, the DOC is used for oxidizing excess HCS injected into the exhaust stream to produce the exotherm required for active regeneration of the PM within the CPF. The concept of active regeneration will be discussed later. Figure 2.1 depicts the conversion of $\mathrm{NO}$ to $\mathrm{NO}_{2}$, as well as the oxidation of $\mathrm{HC}$ and $\mathrm{CO}$ gaseous species at various temperatures [6].

The most common CPF is a wall flow filter that retains the majority (up to $97 \%$ ) of PM emissions from the diesel engine. The term wall flow comes from the fact that every other channel in the substrate is blocked, so that the exhaust flows down the inlet channel, through the wall of the substrate, and out the outlet channel. The flow through the substrate wall is where the filtration of PM from the exhaust stream is accomplished. Figure 2.2 depicts the characteristics of a wall flow CPF substrate. The filter undergoes active regeneration to reduce the PM mass, and subsequently, the back pressure on the engine, after an amount of PM, such as $4 \mathrm{~g} / \mathrm{L}$, is retained in the filter. The PM is oxidized using passive or active regeneration, as mentioned previously, with active regeneration being the focus of this study.

The use of biodiesel is occurring more as the need for reducing the dependence on petroleum based fuel increases. Biodiesel is the name given to fuels derived from the esterification of renewable oils, fats, and fatty acids as described in Austin [1], and is manufactured from plant oils, recycled cooking grease and oil, or animal fats. As of today, most major engine manufacturers have approved the use of $20 \%$ biodiesel blends in their engines as long as the fuel meets the requirements stated in ASTM D7467 [4]. 


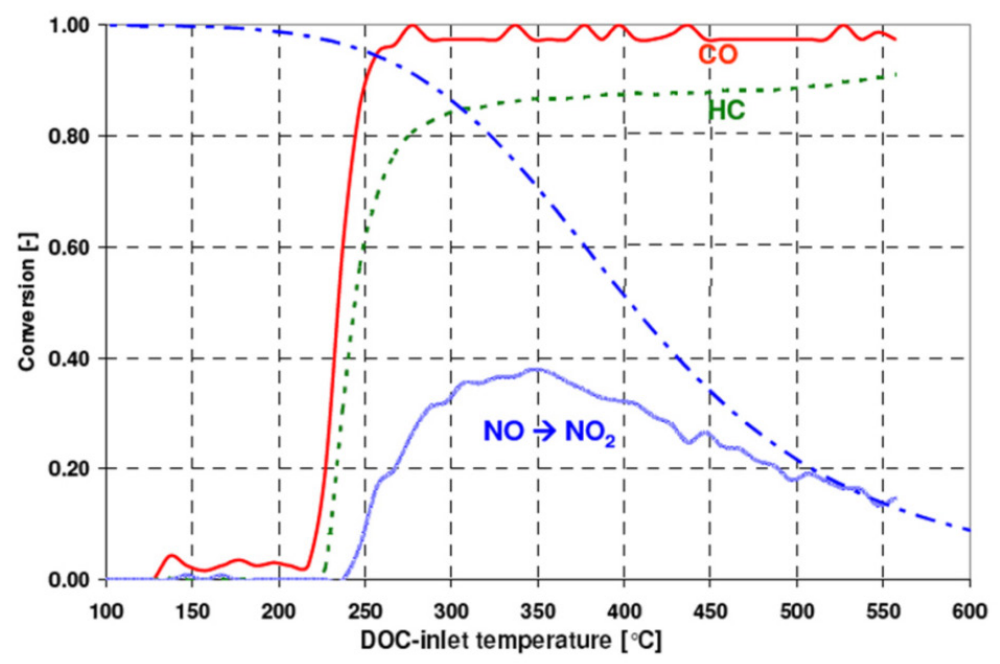

Figure 2.1: DOC Conversion Efficiencies for Various Gaseous Species [6]

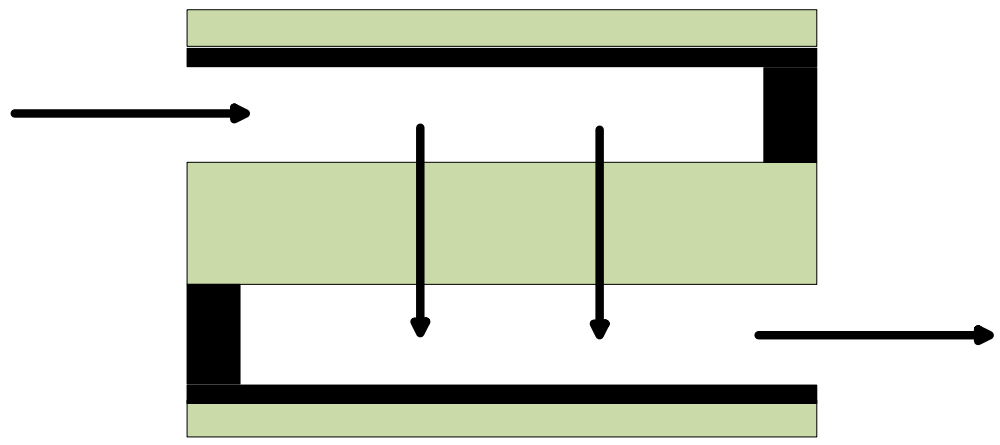

Figure 2.2: Example of CPF Wall Flow Substrate Structure

The effect of biodiesel on engine emissions is such that, in general, $\mathrm{HC}, \mathrm{CO}$, and PM emissions are reduced, while $\mathrm{NO}_{\mathrm{x}}$ emissions are slightly elevated or reduced, depending on the fuel blend and engine control strategy. A study by Poitras et al. [7] reported that with biodiesel fuels, $\mathrm{NO}_{\mathrm{x}}$ levels were increased at high engine loads but were decreased at low engine loads, with increasing biodiesel concentrations in the test fuel. The maximum reported increase and decrease was 7.3 and 25\%, respectively, using $\mathrm{B} 100$. No significant changes in the $\mathrm{NO}_{2}$ concentrations were reported, regardless of biodiesel blend used. Figure 2.3, from Poitras et al. [7], depicts the relative change of engine-out $\mathrm{NO}_{x}$ emissions across 3 test modes with varying blends of soy methyl ester (SME) biodiesel. $\mathrm{NO}_{\mathrm{x}}$ emissions increased and decreased based on the test mode and fuel blend being used, with no apparent pattern being visible. The largest changes were seen with B50 and B100 blends. 


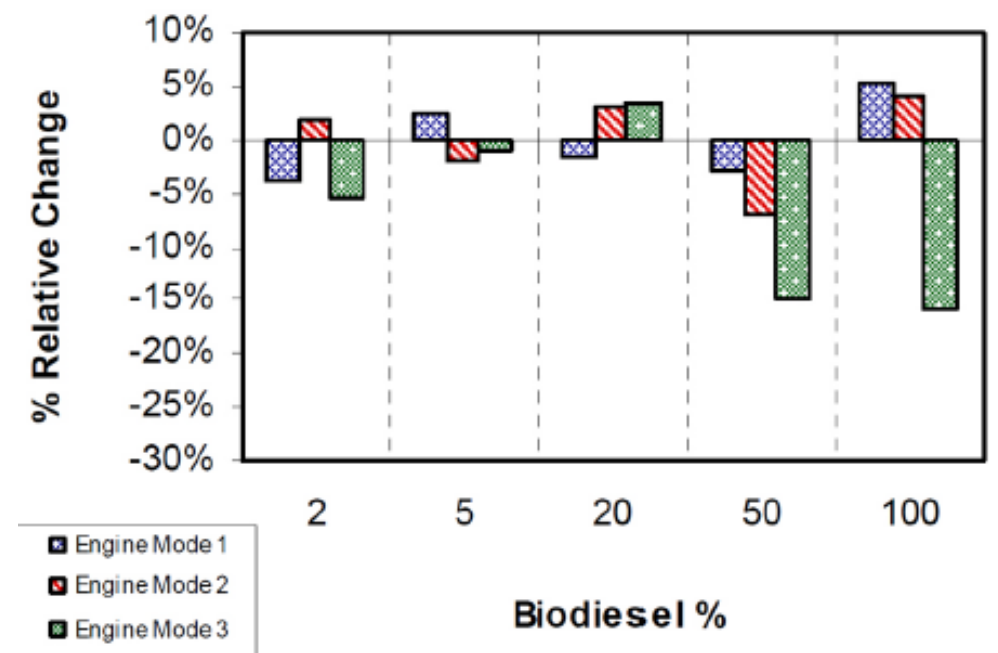

Figure 2.3: Relative Change of $\mathrm{NO}_{x}$ Emissions with SME Biodiesel Blends Compared to ULSD [7]

A study by Kawano et al. [8] on the exhaust characteristics of commercial vehicles fueled with biodiesel confirms those effects. This is partially due to the oxygen in the fuel, where more combustion sites are present in the combustion chamber, reducing the total engine-out emissions due to increased combustion efficiency. A study by Parihar et al. [9] described a reduction of PM mass emissions for $20 \%$ biodiesel blends for the complete particulate size range measured.

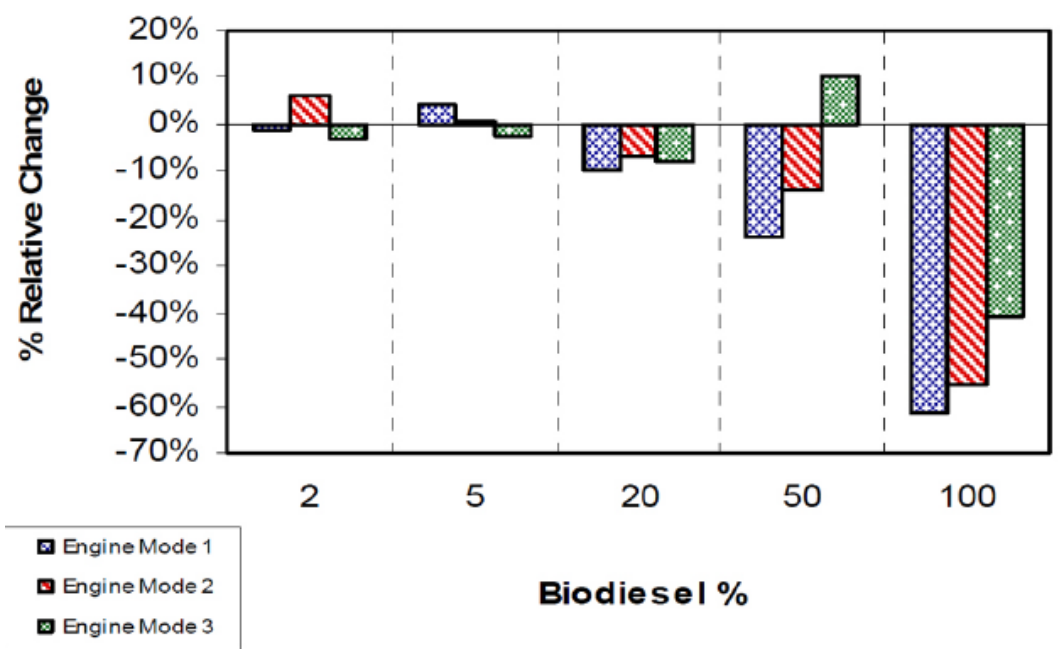

Figure 2.4: Relative Change of TPM Emissions with SME Biodiesel Blends Compared to ULSD [7] 
Poitras et al. [7] also reported lower PM emissions with increasing biodiesel blends, even though the $\mathrm{NO}_{\mathrm{x}}$ emission results were mixed. Total PM (TPM) emissions decreased 24 and $62 \%$ for B50 and B100 SME biodiesel, respectively, when compared to ULSD, with the results shown in Figure 2.4.

In general, the use of biodiesel blends results in a decrease of PM emissions, while some experiments resulted in a decrease of $\mathrm{NO}_{x}$ emissions and an increase of $\mathrm{NO}_{x}$ emissions in other experiments. Eckerle et al. [10] reported that the higher cetane number associated with biodiesel blends causes an increased ignition delay, which leads to higher $\mathrm{NO}_{\mathrm{x}}$ emissions at low load conditions due to increased diffusion combustion within the combustion chamber. Other factors which can influence the $\mathrm{NO}_{\mathrm{x}}$ emissions from an engine fueled with biodiesel is the fuel flow rate. Since biodiesel has a lower energy content than ULSD, more fuel is required to produce the same power. Since the fuel flow rate is commonly used to estimate the torque output of the engine, the control strategy determines that the engine is operating at a different load point and may adjust parameters such as fuel injection timing and duration, boost pressure, or exhaust gas recirculation (EGR) rate to maintain the desired power output of the engine, which leads to $\mathrm{NO}_{\mathrm{x}}$ emission variability.

\subsection{PM Oxidation}

\subsubsection{Introduction}

The CPF collects approximately $97 \%$ of the engine out PM, on a mass basis, from the exhaust stream before exiting the tailpipe. As PM accumulates in the CPF, a cake layer of PM builds up on the substrate walls, which serves as a secondary filtering medium, removing up to $95 \%$ of the PM before reaching the substrate wall which has approximately $50 \%$ filtration efficiency.

As the PM is retained in the CPF, the back pressure on the engine gradually increases, which gradually decreases fuel efficiency. Periodically, the PM needs to be oxidized with active regeneration from the CPF to reduce this back pressure. The PM within the CPF is oxidized in one of two ways;

1. Passive oxidation - using the engine-out $\mathrm{NO}_{\mathrm{x}}$ concentrations and exhaust temperature with a $\mathrm{DOC}$ to produce $\mathrm{NO}_{2}$, which oxidizes the PM within the CPF. 
2. Active regeneration - using fuel injected either in-cylinder or post-turbo and a DOC to elevate exhaust temperatures entering the CPF, which oxidized the PM within the CPF.

For passive oxidation there are no direct fuel penalties, because the engine operating conditions and DOC are what cause the oxidation of the PM within the CPF. Experimentation by Shiel [11] showed passive oxidation to be an effective oxidation technique with exhaust temperatures ranging from 250 to $400^{\circ} \mathrm{C}$ (corresponding to 1.38 and 1.91 on the horizontal axis in Figure 2.5), where the engine speed and load combinations, along with the DOC, were responsible for the $\mathrm{NO}_{2}$ production and subsequent PM oxidation within the CPF. Another benefit of passive oxidation is that the PM does not require any contact with the catalyst coating on the CPF substrate; the gaseous $\mathrm{NO}_{2}$ and temperatures in the exhaust stream passing through the PM cake layer is all that is required for PM oxidation to occur.

Active regeneration is the least desirable method of PM oxidation because of the direct fuel penalty associated with injecting fuel into the exhaust stream, usually diesel fuel from the engine's fuel system. Understanding the factors that affect PM oxidation during active regeneration is important because the most fuel efficient active regeneration control strategies can be produced once a complete understanding of PM oxidation characteristics is determined.

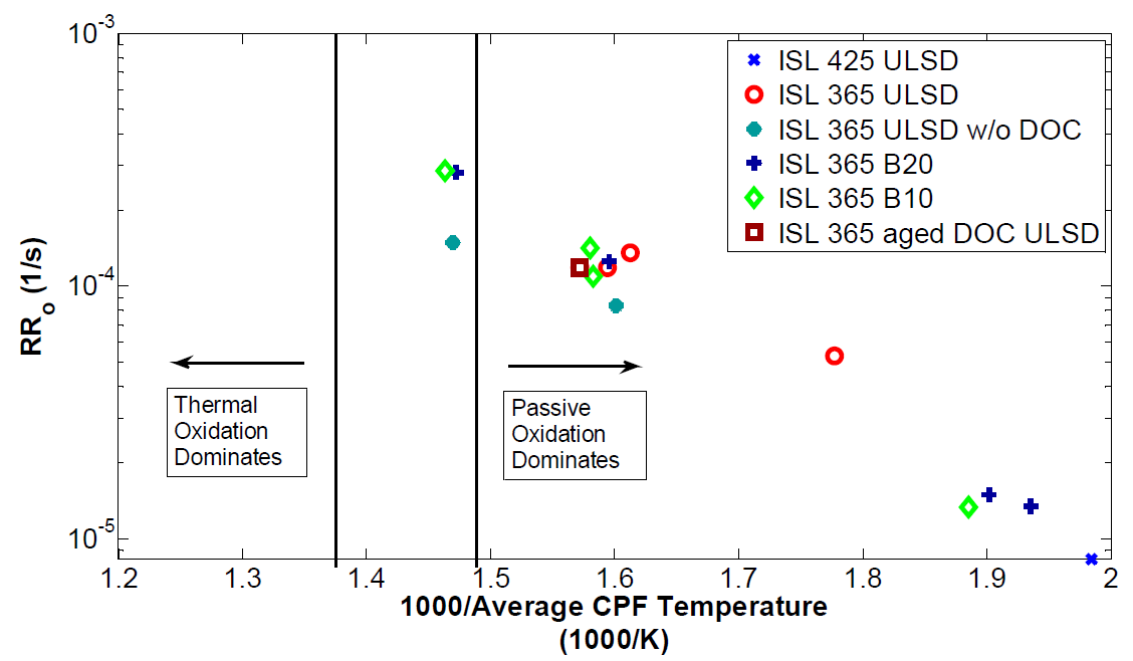

Figure 2.5: Passive Oxidation CPF PM Reaction Rate vs. 1000/Average CPF Temperature (Kelvin) [11] 


\subsubsection{Reactor PM Oxidation Studies}

There are many factors that influence the oxidation of PM within the CPF during active regeneration, such as temperature, filter substrates, catalyst coatings, and many others. In a study by Yezerets et al. [12], carbon black and diesel PM oxidation characteristics were examined. They concluded that diesel PM oxidation was enhanced with the addition of up to $10 \%$ water within the reactor while the carbon black was not affected. It is stated that the presence of water does not change the nature of the oxidation process, but enhances the probability of the reaction event, due to the increase in pre-exponential factor of the Arrhenius equation that was observed. With the presence of water, the activation energy for diesel PM remained in the range of $95 \pm 3 \mathrm{~kJ} / \mathrm{gmol}$ and $105 \pm 3 \mathrm{~kJ} / \mathrm{gmol}$ for the carbon black.

In another study by Yezerets et al. [13], un-catalyzed isothermal, temperature programmed oxidation (TPO), and serial TPO experiments on two samples of PM that were obtained from different engines and duty cycles were conducted. This was done in order to evaluate the possible variations in soot reactivity based on PM origin. As such, the samples were found to contain different amounts of the soluble organic fraction (SOF) and ash. It was observed that the kinetic parameters describing PM oxidation are rapidly changing during the first $10-25 \%$ of PM oxidation, and that this phenomenon is not related to temperature. It was found that the activation energy changes from 45-65 kJ/gmol for the initial PM oxidation to $125-145 \mathrm{~kJ} / \mathrm{gmol}$ for the remainder. Yezerets et al. [13] determined that the linearity of the Arrhenius curves produced from PM oxidation after the initial 25\% was excellent between 330 and $610^{\circ} \mathrm{C}$, as shown in Figure 2.6, where the oxidation rate constant $(\mathrm{k})$ is plotted

against 1000/temperature. Realizing this, they were able to determine the kinetic parameters of PM oxidation by $\mathrm{O}_{2}$ with high confidence. It was also concluded that the PM oxidation was uniform after the initial $25 \%$ was oxidized. The activation energy for the two PM samples were determined to be $126 \pm 3 \mathrm{~kJ} / \mathrm{gmol}$ and $146 \pm 3$ $\mathrm{kJ} / \mathrm{gmol}$, with a difference of $30^{\circ} \mathrm{C}$ in light-off temperature. These activation energies were calculated following SOF desorption and oxidative pre-treatment.

In a study by Oki et al. [14], PM emitted from a diesel fired lamp was used in the visualization experimentation. They concluded that the activation energy for the PM trapped on an un-catalyzed DPF membrane resulted in activation energies between 110 and $180 \mathrm{~kJ} / \mathrm{gmol}$. 


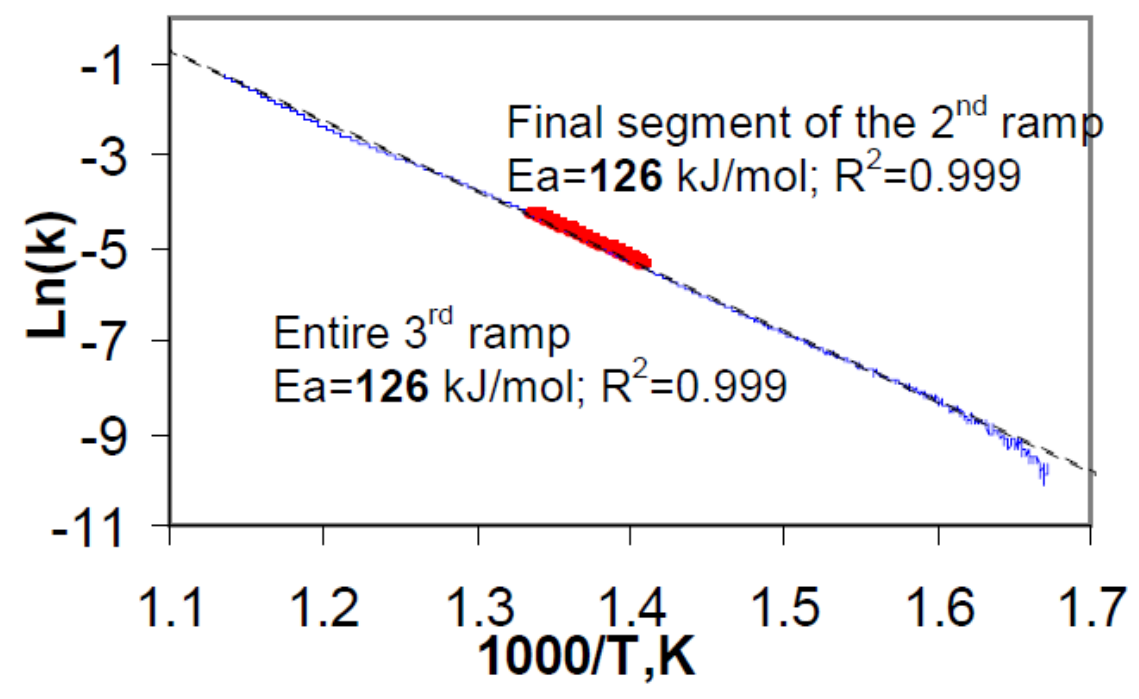

Figure 2.6: Soot Reactivity Measured During Temperature Ramps [13]

\subsection{Active Regeneration}

Active regeneration of the PM within the CPF results in a direct fuel penalty because the fuel is injected either late in the cylinder or directly into the exhaust downstream of the turbocharger. The fuel injected produces no useful work for the engine, resulting in decreased fuel efficiency. The main benefit of active over passive oxidation is the rate at which PM is oxidized.

As stated previously, active regeneration is the least desirable PM oxidation method due to the direct penalty associated with injecting diesel fuel into the exhaust gases. The fuel is required for the DOC to oxidize it and to raise the exhaust temperature entering the CPF into the thermal oxidation regime. The thermal oxidation regime is generally said to be at CPF temperatures above $400^{\circ} \mathrm{C}$. The DOC is subjected to $\mathrm{HC}$ concentrations up to 21,000 ppmC according to Chilumukuru [15], so it is important that the DOC has the capability for oxidizing this concentration of HC. DOC's are commonly coated with a Pt-based catalyst that exhibit HC conversion efficiencies based on exhaust gas temperature.

The point at which $50 \% \mathrm{HC}$ conversion efficiency is reached is termed the DOC's light-off temperature. Attempting active regeneration below the light off temperature can result in DOC face plugging. Attempting active regeneration below the DOC lightoff temperature also results in an overall waste of fuel, due to the reduced $\mathrm{HC}$ 
conversion efficiency below the light-off point. Injecting fuel below the light off point also requires additional fuel to reach the same CPF inlet exhaust temperature, which is a key factor related to CPF PM oxidation during active regeneration.

CPF inlet temperature is one of the most significant influences on the efficiency of PM oxidation during active regeneration. Lower CPF inlet temperatures require less fuel to achieve, but the regeneration process takes longer to reach the same level of PM oxidation. Experimentation by Austin [1] with B20 resulted in an efficiency of PM oxidation of 40 grams of PM oxidized per gallon of fuel injected at a CPF temperature of $520^{\circ} \mathrm{C}$ compared to 120 grams of PM oxidized per gallon of fuel injected at a CPF temperature of $575^{\circ} \mathrm{C}$, corresponding to a PM oxidation efficiency increase of $200 \%$ for a $55^{\circ} \mathrm{C}$ temperature increase. Figure 2.7 depicts the efficiency of PM oxidation resulting from experimental studies conducted by Austin [1].

Maintaining exhaust flow during active regeneration is also important. Once active regeneration has been initiated, a sudden drop in exhaust flow could lead to an uncontrolled regeneration. An uncontrolled regeneration occurs when the PM within the CPF begins to rapidly oxidize on its own, creating large thermal gradients within the CPF, which have the potential to damage the CPF substrate. This occurred during experimentation by Austin [1] where an uncontrolled regeneration resulted in a cracked CPF. The only noticeable change in performance was decreased PM filtration efficiency, with the crack being discovered after investigation into the CPF performance was carried out. 


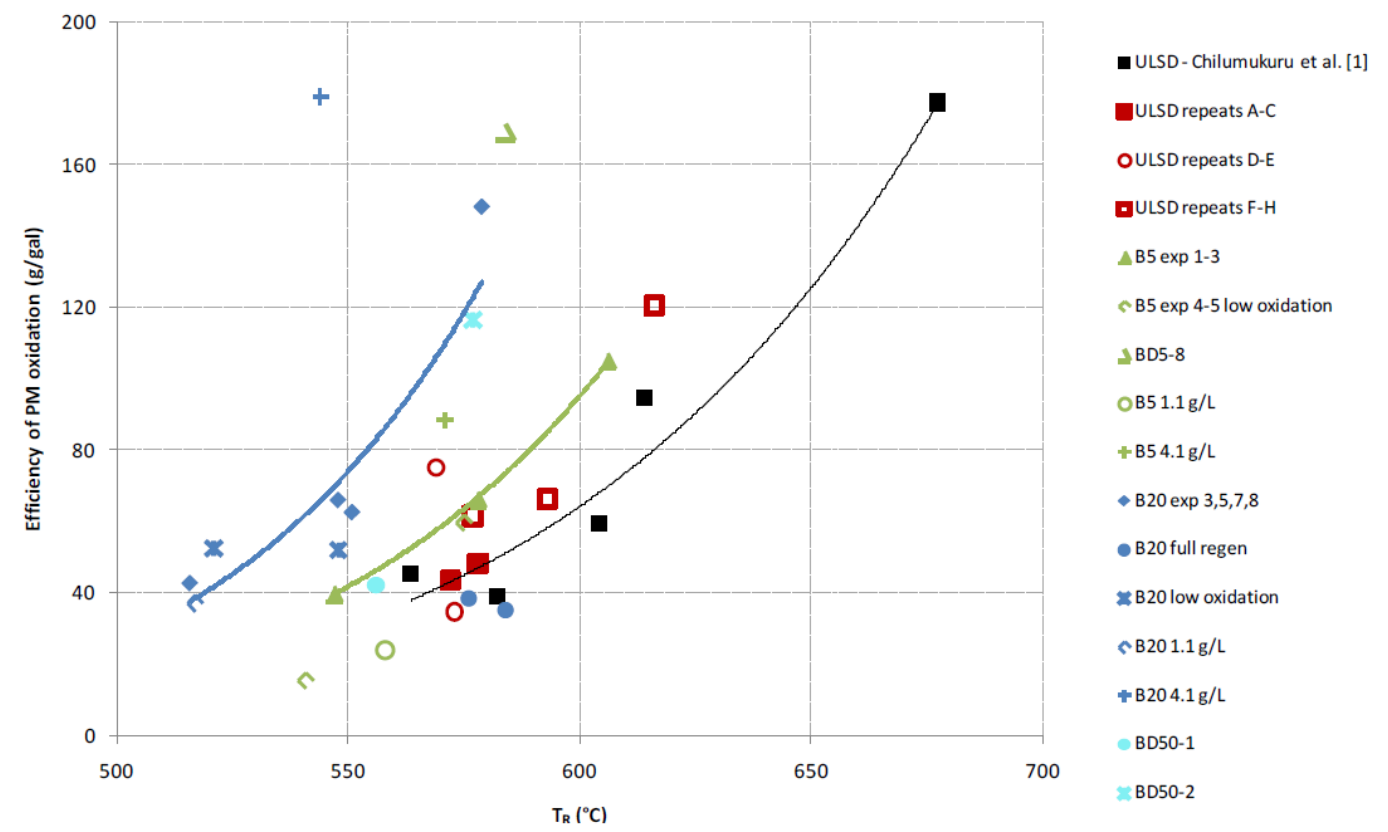

Figure 2.7: Efficiency of PM Oxidation as a Function of Average CPF Temperature $\left(T_{R}\right)[1]$

\subsection{Downstream PM Concentration Sensor}

As discussed previously, emissions regulations for the 2007 model year for U.S. heavy duty on-highway diesel engines resulted in diesel engine manufacturers using a DOC and CPF, to meet the PM emission standards. The DOC and CPF remain vital for the reduction of tailpipe PM emissions, but OBD regulations require the monitoring of the functionality of the CPF for the model year 2013 [5]. In order to fulfill the requirements for monitoring CPF functionality, new sensors are required that directly measure the PM emissions after the CPF outlet, as well as survive the harsh environment seen after the CPF (i.e., during active regeneration). These new sensors are required for the new OBD standards since this is the most effective way to sense failed PM filters.

Delphi has begun the development of a downstream PM sensor that uses technology similar to that of Bosch Lambda sensors [5], where the collecting sensing element is based existing multi-layer ceramic sensor technology. According to Ochs et al. [5] and Bender et al. [16], the sensing element is composed of two inter-digitated comb-like electrodes (IDE) with an infinite electrical resistance, an internal heater, and a temperature measuring element. 
As PM is deposited on the electrodes, an electrical contact forms between them, and the resistance between electrodes begins to decrease. After a certain amount of PM collection, a pre-defined current threshold is reached, where the heater is activated to heat the electrodes above $600^{\circ} \mathrm{C}$, thereby regenerating the sensor. The response time of the sensor is defined as the amount of time between the start of measurement and start of the sensor regeneration. The response time correlates with the exhaust PM concentration; it is the response time that is used to monitor the CPF's functionality within the OBD system. The sensor is connected to a sensor control unit (SCU), which transmits the sensor signal to the engine control unit (ECU) via CAN-bus. According to Ochs et al. [5], the sensor management, regeneration control, signal processing, and sensor signal verification are all controlled by the SCU. Figure 2.8 depicts the sensor functionality as well as PM accumulation on the sensor electrodes as described by Ochs et al. [5]. The blue line represents the sensor current between the electrodes during the PM deposition phase. The images show PM deposition across the electrodes, where the dark areas are the electrodes and the white areas are the isolating aluminum oxide. The left image shows the beginning of the measurement where no connections are formed, and the right image shows the connection between the electrodes by the deposited PM.

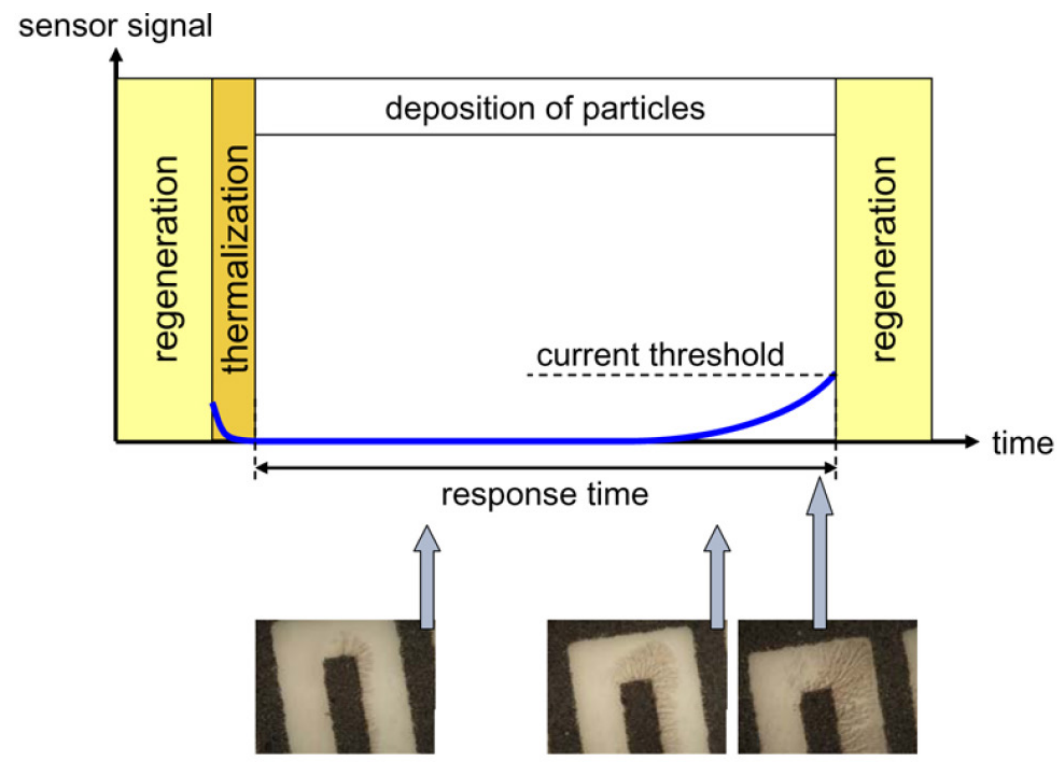

Figure 2.8: Signal Characteristics of the Resistive Particulate Matter Sensor and Images Showing PM Deposition on Electrodes [5], Copyright (C) SAE International, Reprinted with permission 
The CPF OBD model concept utilizes simulated PM mass flow of the engine (available for DPF load calculations) and calculates PM mass flow out of the CPF by utilizing a limit CPF model [5]. The model predicts the expected response time of the sensor and compares it with the actual response time. If the measured response time is greater than the predicted response time, the OBD function declares that the CPF is functioning properly. If the measured response time is lower than the predicted response time, the $\mathrm{OBD}$ functions declare that there is a problem with the CPF functionality.

Bender et al. [16] tested six Delphi PM sensors simultaneously, installed at various locations downstream of a CPF in order to assess part-to-part variations and location dependencies over two sets of experiments. The first set utilized a healthy CPF while the second set of experiments utilized simulation of a failed CPF to produce downstream concentration targets of $0.03 \mathrm{~g} / \mathrm{bhp}-\mathrm{hr}$. It was concluded that there was no obvious location dependency on the sensor output and that the differences in output trends could be related to PM morphology or deposited particle size and that the sensor output voltage should not be used as a direct measure of exhaust PM concentrations. Bender et al. [16] also concluded that the computed PM resistance is inversely proportional to accumulated PM on the sensor, resulting in a diminishing sensor 'gain' with accumulating PM.

\subsection{Summary}

The diesel engine has been in a state of constant development for the past 50 years, or more, because of its ability to provide reliable power for many applications, at a more efficient level than the gasoline fueled SI engines. Emission standards required for diesel engine equipped vehicles have resulted in the widespread use of DOC and CPF aftertreatment devices to reduce PM emissions. In the world of diesel engine calibration, a direct tradeoff between PM and $\mathrm{NO}_{x}$ emissions is apparent, where decreased $\mathrm{NO}_{x}$ engine-out emissions result in increased engine-out PM emissions and vice versa.

As interest in reducing the dependency on petroleum based fuels has increased, many manufacturers are certifying their engines with use of up to $20 \%$ volume blends of biodiesel (B20). In general, the use of biodiesel reduces engine-out HC, 
$\mathrm{CO}$, and $\mathrm{PM}$ emissions, while $\mathrm{NO}_{\mathrm{x}}$ emissions have been shown to increase or decrease, depending on fuel blend and engine control strategy $[1,7,11]$.

Since the CPF is able to retain up to $97 \%$ of the engine-out PM in the exhaust stream, the back pressure on the engine gradually increases as the filter is loaded over time since the passive oxidation rate is typically not equal to the engine-out PM rate for many applications. Oxidation of the PM by periodic active regeneration within the CPF is necessary to reduce this back pressure.

Passive oxidation utilizes engine-out $\mathrm{NO}_{2}$ concentrations to oxidize the PM within the CPF gradually with no direct fuel penalty. Active regeneration utilizes excess HC (fuel) injected into the exhaust to drive the temperature of exhaust entering the CPF to levels suitable for thermal PM oxidation. Active regeneration is less desirable because the injection of fuel into the exhaust stream poses a direct fuel penalty, since the fuel being injected produces no useful work. CPF inlet temperature is one of the most significant influences on the efficiency of PM oxidation during passive and active regeneration. Increasing the CPF inlet temperature from 520 to $575^{\circ} \mathrm{C}$ has shown to increase the PM oxidation efficiency of $200 \%$ [1].

With OBD standards in effect for the 2013 model year related to the monitoring of CPF functionality, new sensor technologies are being explored to measure the exhaust PM concentration in the CPF outlet. One such technology is being explored by Delphi where the sensing element is composed of two inter-digitated comb-like electrodes (IDE) with an infinite electrical resistance, an internal heater, and a temperature measuring element $[5,16]$. As PM is deposited on the electrodes, an electrical contact forms between them, and the resistance between electrodes begins to decrease. The response time of the sensor is defined as the amount of time between the start of measurement and start of the sensor regeneration, where the response time is used to monitor CPF functionality. 


\section{Chapter 3 Experimental Setup and Test Procedures}

Eighteen active regeneration experiments using ULSD, B10, and B20 biodiesel blends were conducted on a 2007 Cummins 8.9L 365 HP ISL (ISL 365) and one experiment was conducted on the $425 \mathrm{HP}$ (ISL 425) engine rating. Specifically, ten ULSD, four B10, and five B20 tests were performed between February 2011 and July 2012, with one of the ULSD tests being the one which was performed on the ISL 425 . The tests run with ULSD provide baseline data while the data from biodiesel tests allows for the comparison of the PM loading and oxidation characteristics with varying blends of biodiesel.

\subsection{Engine and Dynamometer}

The specifications for the 2007 Cummins ISL used in this study are shown in Table 3.1. While the ISL 425 was being used during passive oxidation studies by Shiel [11], an active regeneration experiment was performed to determine if any differences were apparent in the PM oxidation characteristics due to the larger turbocharger and the calibration changes in the ECU.

Engine manufacturers often build a base engine and offer a range of power outputs to widen the markets which can utilize the engine for their specific needs. Based on the requirements of the engine, it can be outfitted from a selection of turbochargers and engine calibrations to meet the needs of industries such as mobile power generation, heavy duty trucks of various sizes, buses, and a variety of others.

\section{Table 3.1: ISL Engine Specifications}

\begin{tabular}{|l|c|}
\hline Model & Cummins ISL $-272 \mathrm{~kW}(365 \mathrm{HP})$ and $317 \mathrm{~kW}(425 \mathrm{HP})^{*}$ \\
\hline Year of Manufacture & 2007 \\
\hline Cylinders & 6, inline \\
\hline Bore \& Stroke & $114 \times 144.5 \mathrm{~mm}$ \\
\hline Displacement & $8.9 \mathrm{~L}$ \\
\hline Aspiration & Turbocharged \\
\hline Aftercooling & Cummins Charge Air Cooler \\
\hline Turbocharger & $2100 \mathrm{RPM}$ and 272 kW \\
\hline Rated Speed and Power & $1695 \mathrm{Nm} @ 1400 \mathrm{RPM}$ \\
\hline Peak Torque & 160 Mpa \\
\hline Common Rail Pressure (peak) & Electronically Controlled and Cooled \\
\hline EGR System & \\
\hline *Change of turbocharger and ECU &
\end{tabular}


The engine dynamometer that connects to the 2007 ISL is a Dyne Systems Dynamatic unit, model number 8121, wet gap/low inertia eddy current dynamometer. The engine speed and torque were regulated by a Digalog Model 1022A dynamometer controller which can be operated in 'speed' and 'load' control modes. For the active regeneration engine testing, the controller was operated in the 'speed mode' where the controller holds a set speed and the user controls the load by operating the engine's throttle controls.

\subsection{Fuel Properties}

One batch of each biodiesel blend and two batches of ULSD were used for the active regeneration tests in this study, and samples of the fuels were tested with the results shown in Table 3.2. The hydrogen to carbon $(\mathrm{H} / \mathrm{C})$ and oxygen to carbon $(\mathrm{O} / \mathrm{C})$ ratios were calculated for each fuel (not included in the fuel analysis) and are also shown in Table 3.2, with the calculation methodology used to determine them in Appendix A.

Table 3.2 Fuel Properties for Experimental Test Fuels*

\begin{tabular}{|c|c|c|c|c|c|}
\hline & & ULSD-1 & ULSD-2 & B10 & $\mathrm{B} 20$ \\
\hline Sulfur [ppm] & & 7 & 12 & 4 & 4 \\
\hline Viscosity @ $40^{\circ} \mathrm{C}$ [cst] & & 2.290 & 2.609 & 2.368 & 2.533 \\
\hline API Gravity & & 35.6 & 33.4 & 36.5 & 35.5 \\
\hline Specific Gravity & & 0.847 & 0.858 & 0.842 & 0.847 \\
\hline Cetane Index & & 39.83 & 40.16 & 45.38 & 45.52 \\
\hline \multirow{2}{*}{ Distillation } & $\mathrm{IBP}\left[{ }^{\circ} \mathrm{C}\right]$ & 168 & 172 & 168 & 168 \\
\hline & $\mathrm{FBP}\left[{ }^{\circ} \mathrm{C}\right]$ & 340 & 359 & 343 & 345 \\
\hline Water [ppm] & & 92 & 348 & 415 & 553 \\
\hline ICP for Metals [ppm] & & $<1 * *$ & $<1 * *$ & $<1 * *$ & $<1 * *$ \\
\hline IR for \% Biodiesel & & 0 & $<0.1$ & 10.1 & 19.4 \\
\hline Higher Heating Value $[\mathrm{MJ} / \mathrm{kg}]$ & & 45.60 & 45.21 & 45.09 & 44.48 \\
\hline Lower Heating Value [MJ/kg] & & 42.80 & 42.55 & 42.47 & 42.03 \\
\hline $\mathrm{H} / \mathrm{C}$ & & 1.833 & 1.833 & 1.828 & 1.826 \\
\hline $\mathrm{O} / \mathrm{C}$ & & - & - & 0.01 & 0.02 \\
\hline
\end{tabular}

** All metal content less than 1 ppm

IBP: Initial Boiling Point

FBP: Final Boiling Point

*Fuel analyzed by Cummins laboratory 


\section{Table 3.3 DOC and CPF Specifications}

\begin{tabular}{|l|c|c|}
\hline Specification & DOC & CPF \\
\hline Part \# & $\begin{array}{c}\text { EPN Q621300 (ISL 365) } \\
\text { EPN Q629360-10 (ISL 425) }\end{array}$ & EPN Q623316 \\
\hline Substrate & Cordierite & Cordierite \\
\hline Cell Geometry & Square & Square \\
\hline Diameter [mm] & 267 & 267 \\
\hline Length [mm] & 102 & 305 \\
\hline Total Volume [L] & 5.7 & 17.1 \\
\hline $\begin{array}{l}\text { Cell Density [cells/cm }{ }^{2}, \\
\text { cells/in }{ }^{2} \text { ] }\end{array}$ & 62,400 & 31,200 \\
\hline Cell Width [mm] & 1.09 & 1.49 \\
\hline Frontal Area [\%] & 91 & 69 \\
\hline Channel Wall Thickness [mm] & 0.114 & 0.305 \\
\hline Wall Density [g/cc] & N/A & 0.45 \\
\hline Specific Heat [J/kg K] & N/A & 891 \\
\hline Thermal Conductivity [W/m K] & N/A & 0.84 \\
\hline Porosity [\%] & 35 & 52 \\
\hline Mean Pore Size [micron] & N/A & 13 \\
\hline
\end{tabular}

\subsection{Aftertreatment System}

A 2007 Cummins aftertreatment system was used for all active regeneration tests which consisted of a diesel oxidation catalyst (DOC) upstream of a catalyzed particulate filter (CPF). Table 3.3 lists the specifications for the DOC and CPF. After the switch from the ISL 365 to ISL 425, a 2010 Cummins DOC was implemented due to the original DOC being prone to face plugging. No noticeable difference from an active regeneration stand point was noticed with the new DOC, with the exception of the reduced frequency of face plugging.

\subsection{Test Cell Setup}

The test cell layout can be seen in Figure 3.1, which details the engine, dynamometer, exhaust, instrumentation, and dosing methods that were used in this study. The test cell includes two available exhaust paths for use during testing which provide the ability to start or stop a test phase without adverse effects on the engine or aftertreatment system. The path which bypasses the aftertreatment system is named the baseline while the path which utilizes the aftertreatment system is called the trapline. For startup of the engine and during warm up periods, the exhaust travels through the baseline, allowing the engine to warm up completely before exhaust is allowed to flow through the aftertreatment system, thereby reducing 
experimental data variability. Once the engine has stabilized at the desired operating conditions, two pneumatically controlled valves are actuated to divert the exhaust through the trapline. The first valve closes the baseline while the second valve opens the trapline. The instant that the trapline valve is opened marks the beginning of that particular phase in the experiment.

\subsubsection{Data Acquisition System}

A data acquisition system from National Instruments was used with LabVIEW to monitor and record temperature and pressure data throughout the test cell. Experimental data was recorded at $5 \mathrm{~Hz}$ for all active regeneration tests conducted in this study. Tests conducted on the 365 and 425 HP rated ISL engines will be referred to as ISL 365 and ISL 425 tests throughout this thesis.

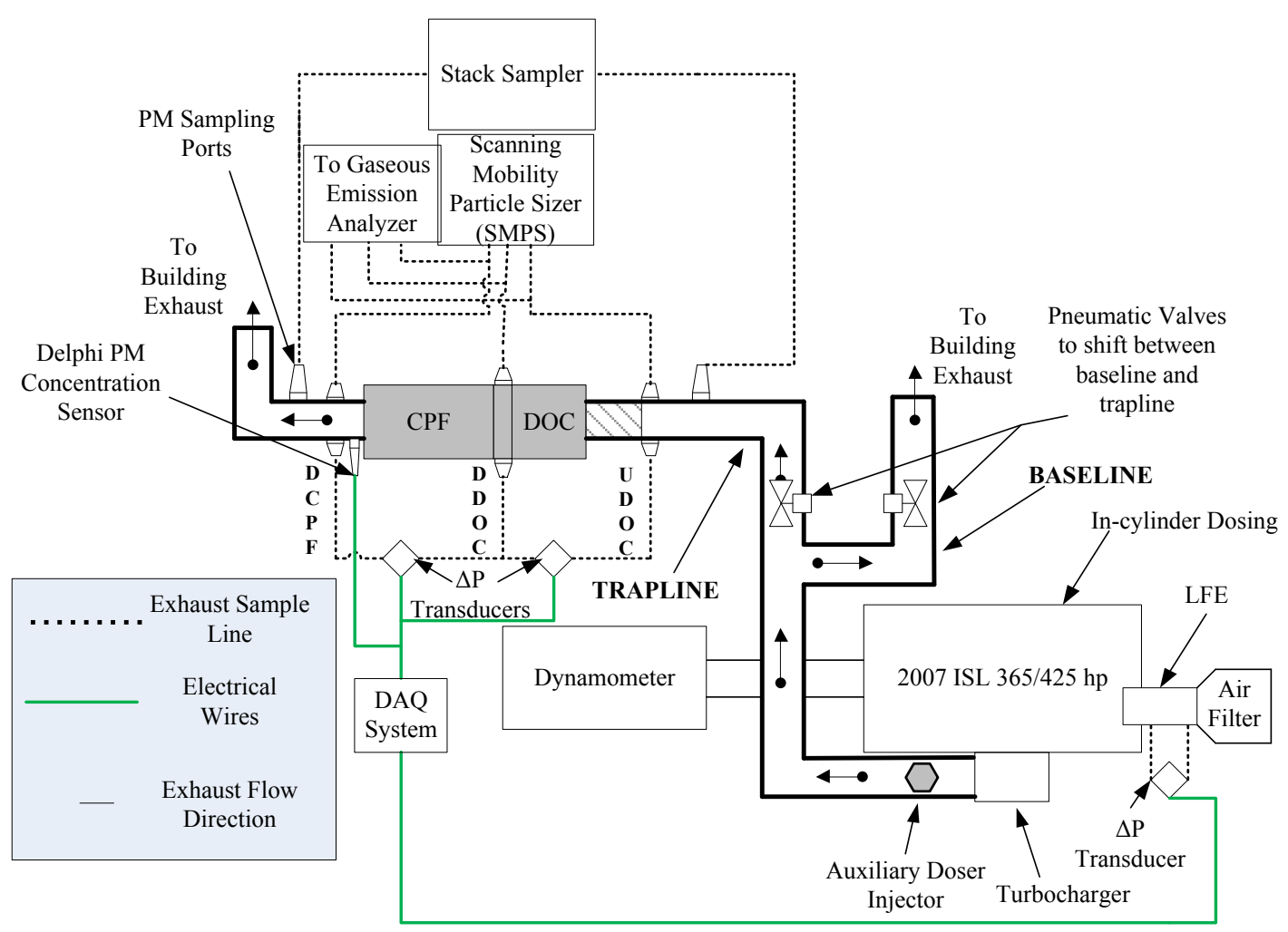

Figure 3.1 Test Cell Schematic for 2007 Cummins ISL 


\subsubsection{Temperature Measurements}

Temperature measurements were recorded using three diameters of ungrounded type $\mathrm{K}$ thermocouples, provided by Watlow, located throughout the aftertreatment system. The diameter of thermocouples used depends on the location that the temperature was being recorded. Thermocouple locations, descriptions, and part numbers can be seen in Table 3.4. Gaseous temperatures were measured with 0.125 in. diameter thermocouples. The DOC and CPF required 0.020 and 0.032 in. diameter thermocouples to measure internal substrate temperatures, respectively. The DOC and CPF thermocouple layout can be seen in Figures 3.2 and 3.3, respectively. During the analysis of experimentally collected test data, the average CPF temperature required calculation. The volume averaged CPF temperature was found by applying a weighting factor to certain sets of thermocouples. The weighing factor for $\mathrm{C} 1-\mathrm{C} 4, \mathrm{C} 5-\mathrm{C} 8, \mathrm{C} 9-\mathrm{C} 12$, and $\mathrm{C} 13-\mathrm{C} 16$ are 0.303, 0.287, 0.197, and 0.213, respectively. The weighting factors were calculated by taking the ratio of the CPF length occupied by each axial set of thermocouples by the overall length of the CPF. For example, for C1-C4, the amount of axial area occupied by them in the CPF is assumed to be $92.5 \mathrm{~mm}$. This comes from the addition of the $32 \mathrm{~mm}$ distance from the inlet to the C1-C4 axial row and the midway distance from C1-C4 to C5-C8 of $60.5 \mathrm{~mm}$. This length is then divided by the total length of $305 \mathrm{~mm}$ to give the 0.303 weighting factor. For the calculations in this study, the volume averaged CPF temperature was calculated using thermocouples C1-C3, C5-C7, C9-C11, C13-C15, or all thermocouples within the CPF except those at the outermost radial location. Hutton [6] further explains the concept of the volume averaged CPF temperature.

\section{Table 3.4 Thermocouple Specifications}

\begin{tabular}{|c|c|c|c|c|c|}
\hline Location & Type & $\begin{array}{c}\text { Diameter } \\
{[\mathrm{in}]}\end{array}$ & $\begin{array}{c}\text { Length(s) } \\
{[\mathrm{in}]}\end{array}$ & Watlow P/N & Body Material \\
\hline $\mathrm{DOC}$ & $\mathrm{K}$ & 0.02 & 12,17 & $\begin{array}{c}\text { AX1078701, PT- } \\
227664-001\end{array}$ & Inconel \\
\hline CPF & $\mathrm{K}$ & 0.032 & 12,17 & $\begin{array}{c}\text { AX1078801, Special } \\
\text { Order }\end{array}$ & Inconel \\
\hline $\begin{array}{c}\text { Engine } \\
\text { Exhaust }\end{array}$ & $\mathrm{K}$ & 0.125 & 6 & ACGF00Q060U40000 & Inconel \\
\hline
\end{tabular}




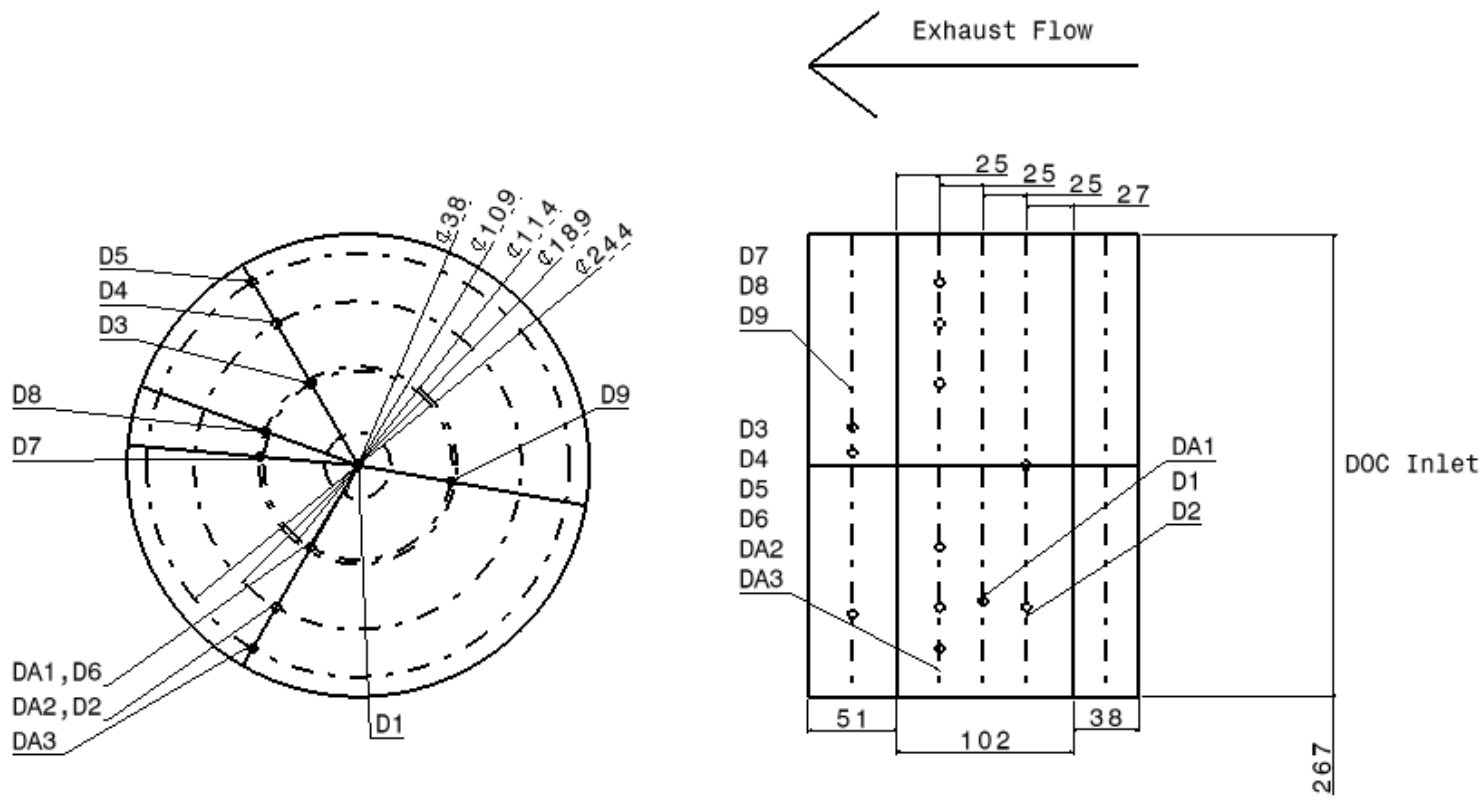

Figure 3.2 DOC Thermocouple Layout

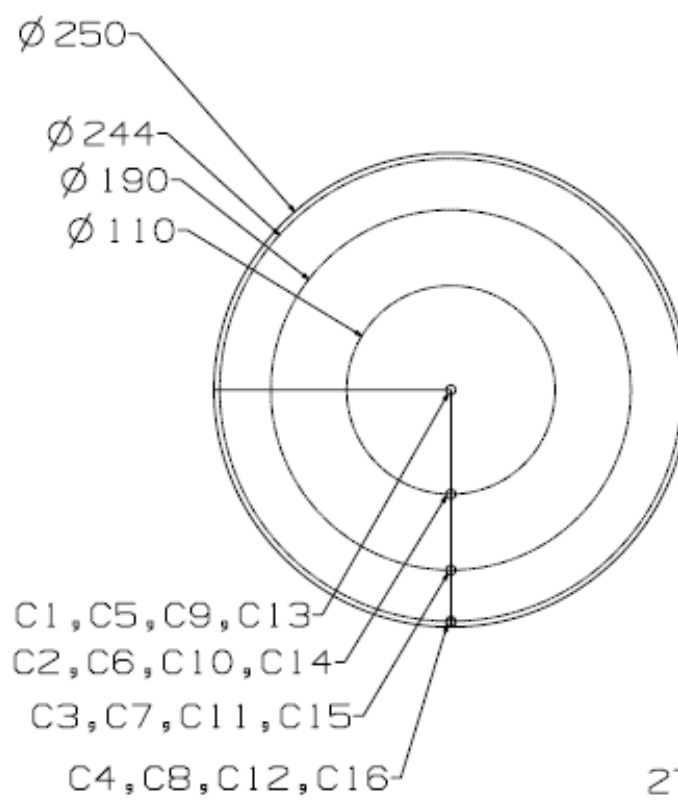

Exhaust Flow

DIMENSIONS IN MM

Figure 3.3 CPF Thermocouple Layout 


\subsubsection{Pressure Measurements}

Differential pressure measurements were monitored and recorded on the DOC, CPF, and laminar flow element (LFE). The DOC and CPF differential pressure measurements aid in monitoring the status of the aftertreatment system and are important data for the MTU DOC and CPF modeling studies. The differential pressure across the LFE is used to calculate the air mass flow rate into the engine. The barometric pressure at the LFE is measured by a fourth pressure sensor, with the humidity and test cell temperature being recorded at the LFE as well. These measurements allow for density and viscosity corrections to the air mass flow rate during each test.

\subsubsection{Air and Fuel Flow Measurements}

A LFE manufactured by Meriam Instruments (Cleveland, $\mathrm{OH}$ ), was used to determine the air mass flow rate into the engine during each test. The LFE was paired with a 0.5 psig differential pressure transducer to measure the differential pressure across the LFE, which was used to determine the air mass flow rate into the engine. The fuel flow rate was measured by an AVL (Plymouth, MI) fuel mass balance, model number 703G, where the device measures the amount of time it takes for the engine to consume a known mass of fuel $(0.4 \mathrm{~kg}$ for all tests in this study), and subsequently, the fuel mass flow rate into the engine is known. The total exhaust flow rate is calculated by the summation of the air and fuel mass flow rates determined by the two instruments.

\subsubsection{Gaseous Emissions Measurements}

Gaseous emissions were measured using an AVL (Plymouth, MI) Pierburg emissions bench, model number AMA 4000. The AMA 4000 emissions bench has the capability to simultaneously measure total hydrocarbons (THC), carbon monoxide (CO), carbon dioxide $\left(\mathrm{CO}_{2}\right)$, oxygen $\left(\mathrm{O}_{2}\right)$, and can sample either nitric oxides $\left(\mathrm{NO}_{\mathrm{x}}\right)$ or nitrogen oxide (NO) concentrations in the exhaust. In this study, exhaust $\mathrm{NO}_{2}$ concentrations were determined by taking the difference between the measured $\mathrm{NO}_{\mathrm{x}}$ and $\mathrm{NO}$ concentrations at any sampling location. Total gaseous emissions measurements consisted of sampling raw and wet exhaust gas from three locations in the aftertreatment system; upstream of the DOC (UDOC), downstream of the DOC (DDOC), and downstream of the CPF (DCPF), as seen previously in Figure 3.1. After 
the exhaust is sampled from any of the three locations, it passes through a heated filter and a sample line maintained at $185^{\circ} \mathrm{C}$.

\subsubsection{PM Concentration Measurements}

Particulate matter (PM) concentrations were obtained using a manual sampling train from Andersen Instruments Inc. (Smyrna, GA). Raw, hot $\left(260-350^{\circ} \mathrm{C}\right)$ exhaust gas was drawn through a Pall Corporation (Ann Arbor, MI) type A/E 47mm glass fiber filter. These PM samples were collected multiple times throughout each test, during loading and at the active regeneration engine condition, to determine average exhaust PM concentrations for the various phases of each test. During active regeneration testing, three samples were collected UDOC at the active regeneration engine condition, eight samples were collected UDOC during the loading states, and one sample was collected DCPF during loading as well. All UDOC samples were collected over five minutes, while the DCPF samples were collected over one hour due to the low PM concentrations measured DCPF. The average PM concentrations are used in calculations during post processing of the experimental data. The concentrations are used in the experimental mass balances and as an input for the MTU-1D CPF model. The average engine out PM concentrations are calculated using multiple samples taken during the loading phases and active regeneration engine condition prior to the start of each test. The CPF steady state filtration efficiency was calculated using PM concentrations UDOC and DCPF in conjunction with Eqn. 1; additional information on this process is available in reference [6].

$$
\eta_{\mathrm{f}}=\frac{\mathrm{C}_{\text {in }}-\mathrm{C}_{\text {out }}}{\mathrm{C}_{\text {in }}} \cdot 100 \%
$$

Eqn. 1

$\eta_{\mathrm{f}}=\mathrm{CPF}$ filtration efficiency $[\%]$

$\mathrm{C}_{\text {in }}=\mathrm{CPF}$ inlet PM concentration $[\mathrm{mg} / \mathrm{scm}]$

$\mathrm{C}_{\text {out }}=\mathrm{CPF}$ outlet PM concentration $[\mathrm{mg} / \mathrm{scm}]$

\subsubsection{Particle Size Distribution Measurements}

Particle size distribution (PSD) data were collected during the loading and active regeneration portions of the experiments on all experiments when the equipment was in operation. The data were collected using a set of four instruments collectively termed the Scanning Mobility Particle Sizing (SMPS) System, all manufactured by TSI Inc. (Shoreview, MN). The first of the instruments was a mini dilution system which 
was manufactured in-house. This dilution system used filtered, compressed air heated to a temperature of $230^{\circ} \mathrm{C}$ to condition the exhaust gas. The dilution ratios for the active regeneration tests were found to depend on the pressure drop across the aftertreatment components as well as the compressed air pressure. To compensate for these differences, the compressed air pressure was regulated at 30 psig and the dilution ratio was calculated at each engine operating condition used during testing with all test fuels for the post processing of the PSD data. A detailed description of the dilution ratio data collection method can be found in Appendix $B$.

The sampling locations for PSD measurements were UDOC, DDOC, and DCPF, as shown in Figure 3.1. Filtration efficiency of the CPF was calculated for loading and active regeneration portions of each experiment. The filtration efficiency, $\eta_{\text {filt, }}$ is calculated by using Eqn. 2, and the sum of all the particles from sampling DDOC and DCPF, after corrections to the PSD data have been applied. The PSD Data correction method can be found in Appendix $C$ with the equations and methodology being developed by Hutton [6].

$$
\eta_{\text {filt }}=\frac{\left(\text { DDOC }_{\text {total }}-\mathrm{DCPF}_{\text {total }}\right)}{\text { DDOC }_{\text {total }}}
$$

The filtration efficiency obtained by PM mass measurements and Eqn. 1 were also calculated to maintain consistency between active regeneration tests conducted on the ISL and tests from references $[1,15]$.

\subsubsection{CPF PM Mass Retained Measurements}

The DOC and CPF used in this study are mounted with stainless steel cans which included flanges and clamps allowing for easy removal from the exhaust line during the CPF weighing portion of each experiment. The scale used for measuring the CPF mass at the various times throughout each experiment was an Ohaus Ranger model $35 \mathrm{LM}$ with a readability of $0.1 \mathrm{~g}$ and a repeatability of $0.3 \mathrm{~g}$. Experimentation and analysis from Austin [1] showed that the mass of the CPF can be heavily influenced by the temperature at which it is weighed. As a result, care was taken to ensure that the CPF was weighed at approximately the same temperature each time it was weighed in the experiment. In order to ensure that the CPF was weighed at approximately the same temperature, the temperature reading from each thermocouple in the CPF substrate was taken prior to CPF weighing. Individual 
thermocouples are measured because the individually measured substrate temperatures can vary widely. For example, measured temperatures within the CPF after a given time with the engine operating at loading conditions (2100 RPM, 195 $\mathrm{Nm}$ ) can range from 180 to $290^{\circ} \mathrm{C}$. Due to these temperature gradients, it is not practical to specify an average CPF temperature at which weighing occurs for each test. Instead, it is preferred that the individual temperature measurements vary by no more than $\pm 15^{\circ} \mathrm{C}$ for each weighing. The detailed CPF mass measurement procedure can be found in Appendix D.

Active regeneration testing is broken up into eight phases of varying length. Figure 3.4 outlines the various phases for each active regeneration test.

The rate at which PM is deposited within the CPF is assumed to be constant, and for this to hold true, the exhaust mass flow rate, exhaust temperature, engine-out PM concentration, and CPF filtration efficiencies all must be assumed to be constant, or very similar at each phase of active regeneration testing; i.e., average CPF temperatures normally did not fluctuate beyond $\pm 5^{\circ} \mathrm{C}$ between loading phases in a specific active regeneration test.

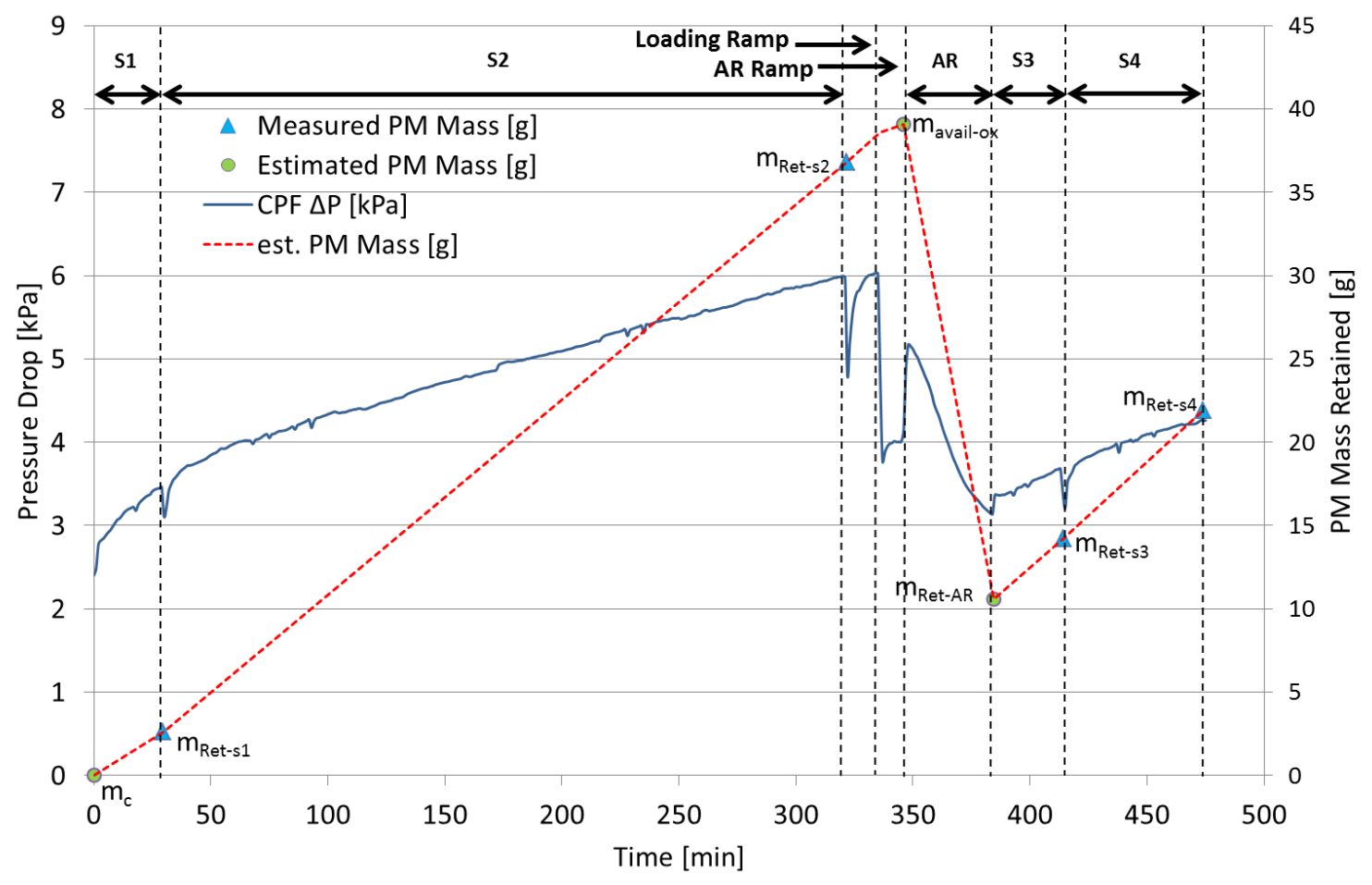

Figure 3.4: Overview of the ISL Active Regeneration Test Procedure 
The rate at which PM is deposited within the CPF is assumed to be constant, and for this to hold true, the exhaust mass flow rate, exhaust temperature, engine-out PM concentration, and CPF filtration efficiencies all must be assumed to be constant, or very similar at each phase of active regeneration testing; i.e., average CPF temperatures normally did not fluctuate beyond $\pm 5^{\circ} \mathrm{C}$ between loading phases in a specific active regeneration test.

Shiel [11] conducted an experiment to determine the time required to achieve steady state filtration efficiency following a CPF clean out, measured by the SMPS system. He concluded that the clean CPF filtration efficiency reaches steady state values in a minimal amount of time; therefore, constant filtration efficiency similar to the measured values from Stage 2 loading may be used during Stage 1 loading PM deposition calculations.

For phases of the test where the CPF mass was measured at the beginning and end, such as Stages 2 and 4, the PM mass retained within the CPF is a straight forward calculation. For phases where CPF mass measurements cannot be determined this way, they require separate calculation methodology. The calculation methodology used to determine CPF PM mass retained during Stage 1, Stage 3, loading Ramp, and the Active Regeneration (AR) Ramp phases is detailed below. The calculation methodology assumes that the rate of PM mass deposition during Stage 2 is constant during the loading Ramp (Eqn. 3) and the rate of PM mass deposition during Stage 4 is constant during Stage 3 (Eqn. 4). Eqn. 5 is used to determine the AR Ramp CPF PM mass deposition; due to the nature of the engine operating condition during active regeneration, the $\mathrm{CPF}$ is near its balance point. During extended periods of run time at the active regeneration engine condition, the change in the CPF pressure drop was negligible. For this reason, it is assumed that $90 \%$ of the engine-out PM is oxidized, $3 \%$ is passed through, and the remaining $7 \%$ is retained. Eqn. 6 is used to determine the Stage 1 PM mass deposition, with the detailed calculation methodology available in Appendix E. 


$$
\mathrm{m}_{\text {load-ramp }}=\left(\frac{\mathrm{m}_{\mathrm{s} 1}-\mathrm{m}_{\mathrm{s} 2}}{\text { time }_{\mathrm{s} 2}}\right) \cdot \text { time }_{\text {load-ramp }}
$$

$\mathrm{m}_{\text {load-ramp }}=$ Predicted CPF PM Mass Retained during the Loading Ramp [g]

$\mathrm{m}_{\mathrm{s} 1}=$ Measured CPF mass at the end of Stage 1 loading [g]

$\mathrm{m}_{\mathrm{s} 2}=$ Measured CPF mass at the end of Stage 2 loading [g]

time $_{\mathrm{s} 2}=$ Time of Stage 2 loading [min]

time $_{\text {Ioad-ramp }}=$ Time of Loading Ramp [min]

$$
\mathrm{m}_{\text {add_s3 }}=\left(\frac{\mathrm{m}_{\mathrm{s} 3}-\mathrm{m}_{\mathrm{S} 4}}{\text { time }_{\mathrm{s} 4}}\right) \cdot \mathrm{time}_{\mathrm{s} 3}
$$

Eqn. 4

$\mathrm{m}_{\text {add_s3 }}=$ Predicted CPF PM Mass Retained during Stage 3 loading[g]

$\mathrm{m}_{\mathrm{s} 3}=$ Measured CPF mass at the end of Stage 3 loading [g]

$\mathrm{m}_{\mathrm{s} 4}=$ Measured CPF mass at the end of Stage 4 loading [g]

time $_{\mathrm{s} 3}=$ Time of Stage 3 loading [min]

time $_{\mathrm{s} 4}=$ Time of Stage 4 loading $[\mathrm{min}]$

$$
\mathrm{m}_{\mathrm{AR} \_ \text {ramp }}=\mathrm{m}_{\mathrm{in,AR \_ ramp}} \cdot 0.07
$$

Eqn. 5

$\mathrm{m}_{\mathrm{AR} \_ \text {ramp }}=$ Predicted CPF PM Mass Retained during AR Ramp [g]

$\mathrm{m}_{\text {in,AR_ramp }}=\mathrm{PM}$ mass into the CPF during AR Ramp [g]

$$
\mathrm{m}_{\mathrm{add} \_\mathrm{s} 1}=\eta_{\mathrm{s} 1} \cdot \mathrm{m}_{\mathrm{in,s} 1}-\left(\eta_{\mathrm{s} 2}-\frac{\mathrm{m}_{\mathrm{s} 2}-\mathrm{m}_{\mathrm{s} 1}}{\mathrm{~m}_{\mathrm{in}, \mathrm{s} 2}}\right) \cdot \mathrm{m}_{\mathrm{in,s1}}
$$

Eqn. 6

$\mathrm{m}_{\text {add_s1 }}=$ Predicted CPF PM Mass Retained during Stage 1 loading $[\mathrm{g}]$

$\eta_{\mathrm{s} 1}=$ Average CPF filtration efficiency during Stage 1 loading [g]

$\eta_{\mathrm{s} 2}=$ Average CPF filtration efficiency during Stage 2 loading [g]

$\mathrm{m}_{\mathrm{s} 1}=$ Measured CPF mass at the end of Stage 1 loading [g]

$\mathrm{m}_{\mathrm{s} 2}=$ Measured CPF mass at the end of Stage 2 loading [g]

$\mathrm{m}_{\mathrm{in}, \mathrm{s} 1}=\mathrm{PM}$ mass into the CPF during Stage 1 loading [g]

$\mathrm{m}_{\mathrm{in}, \mathrm{s} 2}=\mathrm{PM}$ mass into the CPF during Stage 2 loading [g]

The MTU-1D CPF model will be used to account for varying exhaust gas concentrations and temperatures recorded during each experiment. Eqn. 3-6 will be used for the mass balances included in this thesis while the MTU modeling team will calibrate the MTU-1D CPF model and use it for determination of the final mass balances. As previously mentioned, the CPF filtration efficiency is determined by physical PM mass measurements upstream and downstream of it. The PM mass into 
the CPF is calculated using engine-out PM concentrations and exhaust flow data. The PM mass out of the CPF is calculated for each stage using the measured filtration efficiency. The remainder of the engine-out PM is assumed to be oxidized.

\subsection{Experimental DCPF PM Concentration Sensor}

A downstream CPF PM concentration sensor manufactured by Delphi (Troy, MI) was installed and evaluated on the ISL 365 engine following the ISL 425-ISL 365 changeover. Regulations related to monitoring the functionality of the CPF is in effect as part of new OBD requirements for the model year 2013 [5], which require the use of sensors to directly measure the PM emitted from the CPF. These sensors are also required to withstand the high temperatures seen at the CPF outlet during active regeneration. These new sensors are required because the concentration detection limits required for the new OBD regulations cannot be determined by other sensors currently in use.

The PM sensor measures the PM resistance in real time. Once a preset threshold for the PM resistance is reached, regeneration of the sensor is performed. The time between regenerations is defined as the sensor's response time. The response time correlates with the exhaust PM concentration; it is the response time that is used to monitor the CPF's functionality within the OBD. The goal is that modeling within the OBD will be used to predict the sensor's response time and compare it with the actual sensor response time. If the measured response time is greater than predicted, the OBD declares that the CPF is functioning normally. If the measured response time is lower than predicted, the OBD declares that there is a problem with the functionality of the CPF.

\subsubsection{PM Conductivity Study}

The goal of the Delphi sensor testing with respect to the PM conductivity study is to analyze the PM voltage measured by the sensor with ULSD compared to B20 test fuels. Since the sensors are normally operating in extremely low DCPF PM concentrations, the sensor response time can typically be measured in hours or days. In order to effectively study the conductivity of the PM emitted from various test fuels, a CPF with $25 \%$ of the inlet channel plugs opened was implemented in the test cell to allow between 2 and 6 (depending on test fuel and test cell conditions) $\mathrm{mg} / \mathrm{scm}$ of PM to be subjected to the PM sensor. 
The CPF modifications were accomplished by milling a pocket with $125 \mathrm{~mm}$ diameter and $25 \mathrm{~mm}$ depth into the outlet face of the substrate. The visible portion of the outlet face is $250 \mathrm{~mm}$ in diameter, so the $125 \mathrm{~mm}$ diameter pocket corresponds to $25 \%$ of the surface area, thereby producing a CPF with approximately $75 \%$ filtration efficiency.

Measuring the changes in PM voltage with respect to time between the two test fuels will determine whether PM conductivity differences between PM emitted from the ISL fueled with ULSD and B20 exists or not.

\subsubsection{Sensor Loading Study}

Another area of interest with respect to the Delphi DCPF PM sensor is to determine whether sensor PM loading has an effect on the measurement of PM accumulation on the sensor or not.

The first area of interest is whether PM accumulation occurs at an accelerated rate following CPF regeneration or not. Analyzing the PM voltage measured by the sensor before and immediately after CPF regeneration is the preferred method for determining if these differences exist.

The second area of interest is whether PM accumulation rate is affected by PM sensor loading or not. Similarly to the first area of interest, the PM voltage measured by a clean and partially loaded sensor will be analyzed during CPF loading before and immediately after CPF regeneration.

\subsection{Active Regeneration Test Procedure}

The main objective of the active regeneration testing is to determine the reaction rate of the PM inside the CPF during active regeneration. In order to accomplish this, a combination of CPF modeling paired with several CPF mass measurements are required. CPF models are used in phases where mass measurements are subject to error, i.e., during the temperature stabilization periods before CPF mass measurements which occur after the CPF clean out and active regeneration phases of each experiment.

By using CPF models during the first 30 minutes of the test, following the CPF clean out, the clean weight of the CPF can be calculated without having to measure the 
CPF immediately following the CPF clean out when the temperature is elevated, which is where mass measurement error may be introduced. The estimated clean weight of the CPF is used for the remaining calculations to determine the CPF loading and $\mathrm{PM}$ reaction rates during the test.

By using CPF models during the pre-active regeneration ramp periods as well as the 30 minutes of operation following active regeneration, the PM loading in the CPF after active regeneration can be determined, allowing for the calculation of the PM reaction rate during active regeneration.

Changes to the active regeneration test procedure on the ISL have been made from the procedure used on the ISM in references $[1,15]$. These changes include the predosing ramp at loading conditions for 15 minutes, the pre-active regeneration ramp at active regeneration conditions for 10 minutes, as well as the additional hour of operation at loading conditions following the CPF weighing after active regeneration. Along with the changes to the testing procedure used in references $[1,15]$, the engine operating condition during active regeneration was changed to allow the use of in-cylinder dosing on the ISL. Experiments from references $[1,15]$ used an engine operating condition of 2100 RPM and $470 \mathrm{Nm}, 40 \%$ load, which results in a space velocity (the relation between volumetric flow and the $17.1 \mathrm{~L}$ aftertreatment volume) that is too high for in-cylinder dosing to raise CPF inlet exhaust temperature to $600^{\circ} \mathrm{C}$. Therefore, the engine operating condition chosen for experiments run on the ISL was 1400 RPM and $460 \mathrm{Nm}$, corresponding to an exhaust flow rate of $8.0 \mathrm{~kg} / \mathrm{min}$ and a DOC space velocity ranging from 177-180 1/khr, which allows in-cylinder dosing to be used and provides a DOC inlet temperature of $325 \pm 10^{\circ} \mathrm{C}$, which is above the DOC lightoff point.

Prior to the start of each test, twelve PM sample filters must be prepared at least 24 hours before the test is to begin. The procedure for preparing PM sample filters can be found in Appendix F.

The MTU-1D CPF model should be run to gather base line information for the amount of time the engine is operated in the loading condition to reach a PM loading in the CPF of $2.2 \pm 0.2 \mathrm{~g} / \mathrm{L}$.

Since time of active regeneration varies depending on the CPF inlet temperature and fuel type being used during any particular test, an active regeneration model 
developed by Pidgeon [2] was used to gather base line information for the length of active regeneration required to oxidize $70 \%$ of the PM inside the CPF based on experimental test conditions.

The phases of an active regeneration test are:

1. Pre-test preparation: Prior to the CPF cleanout, the engine is operated at the active regeneration engine condition to collect PM samples, since PM samples cannot be collected during active regeneration due to fuel dosing.

2. CPF Clean out: Active regeneration is performed to oxidize the PM inside the CPF to begin with the DOC/CPF in the same state.

3. Stage 1 loading (S1): After the CPF cleanout is complete, the engine is switched to the loading condition for thirty minutes to ensure that the CPF has reached a repeatable temperature for weighing.

4. Stage 2 loading (S2): The engine is operated at the loading condition until a CPF particulate matter (PM) loading of $2.2 \pm 0.2 \mathrm{~g} / \mathrm{L}$ is achieved.

5. Pre-active Regeneration Ramps: The engine is operated at loading conditions for fifteen minutes and the active regeneration condition for ten minutes to stabilize the CPF temperature prior to active regeneration.

6. Active Regeneration (AR): For the active regeneration portion of the experiment, the engine is switched to the active regeneration engine condition.

a. Active regeneration can be performed using one of two dosing methods:

i. In-cylinder dosing

ii. Auxiliary fuel dosing injector; with the injector located downstream of turbocharger.

b. The amount of fuel injected (in-cylinder dosing) or the duty cycle of the injector (auxiliary injector) is set to a base value found in the pretest preparation phase to reach the desired CPF inlet temperature. Once the desired CPF inlet temperature is reached, the amount of fuel being injected is adjusted to maintain the desired CPF inlet temperature within $\pm 10^{\circ} \mathrm{C}$. After a pre-determined amount of time at the specified CPF inlet temperature or if the slope of the pressure drop 
profile across the CPF decreases significantly, the active regeneration portion of the test is stopped and the transition to Stage 3 loading is made. If the slope of the pressure drop profile across the CPF decreases significantly and active regeneration is allowed to continue, there will not be enough PM within the CPF to obtain an accurate mass measurement, due to the mass of PM related to the mass of the CPF (typical PM mass of $2.2 \mathrm{~g} / \mathrm{L}$ or $37.6 \mathrm{~g}$ compared to CPF mass of $17.8+$ $\mathrm{kg})$.

7. Stage 3 loading (S3): This follows the active regeneration; the engine is switched back to the loading condition for thirty minutes to ensure that the CPF has reached a repeatable temperature for weighing.

8. Stage 4 loading (S4): The engine is operated at the loading condition for sixty minutes to determine differences in the performance of a clean CPF and a CPF that has been partially regenerated. The experiment is concluded after the CPF weighing following Stage 4 loading has been completed.

\subsubsection{Pre-test Preparation Phase}

If the auxiliary fuel dosing injector is the method of dosing for the test, calibration of the injector is required prior to the start of this phase. The calibration procedure for the auxiliary dosing injector can be found in Appendix G. The pre-test preparation phase begins by starting the engine and allowing it to reach operating temperatures using the warm-up sequence seen in Table 3.5. During the warm up sequence, the exhaust is allowed to travel through the trapline, and subsequently, through the DOC and CPF to allow them to warm up as well.

After the engine and aftertreatment system are warmed up, the engine is switched to the active regeneration operating point of $1400 \mathrm{RPM}$ and $465 \mathrm{Nm}$ and is allowed to reach steady state.

Once the DOC inlet temperature has stabilized to $325 \pm 10^{\circ} \mathrm{C}$, gaseous emissions are sampled at all 3 sampling locations (UDOC, DDOC, and DCPF) for 10 minutes. 5 minutes are devoted to NOx sampling and the remainder is devoted to NO sampling, since they cannot be simultaneously measured on the gaseous emissions analyzer. Figure 3.5 depicts the gaseous emissions sampling strategy for the pre-test preparation phase. 
Three engine-out PM samples are also recorded during this phase, because engineout PM samples cannot be collected during active regeneration. The UDOC gaseous emissions are also used in the post-processing of data because the engine-out gaseous emissions cannot be measured during active regeneration due to possible damage to the analyzer.

Table 3.5: Engine Operating Points for Initial Warm-Up Sequence

\begin{tabular}{|c|c|c|}
\hline Engine Speed & Engine Load & Time \\
\hline$[$ RPM $]$ & {$[\mathrm{Nm}]$} & {$[\mathrm{min}]$} \\
\hline 750 & 0 & 1 \\
\hline 1200 & 220 & 5 \\
\hline 1800 & 220 & 5 \\
\hline 2100 & 440 & 5 \\
\hline 2100 & 840 & 5 \\
\hline
\end{tabular}

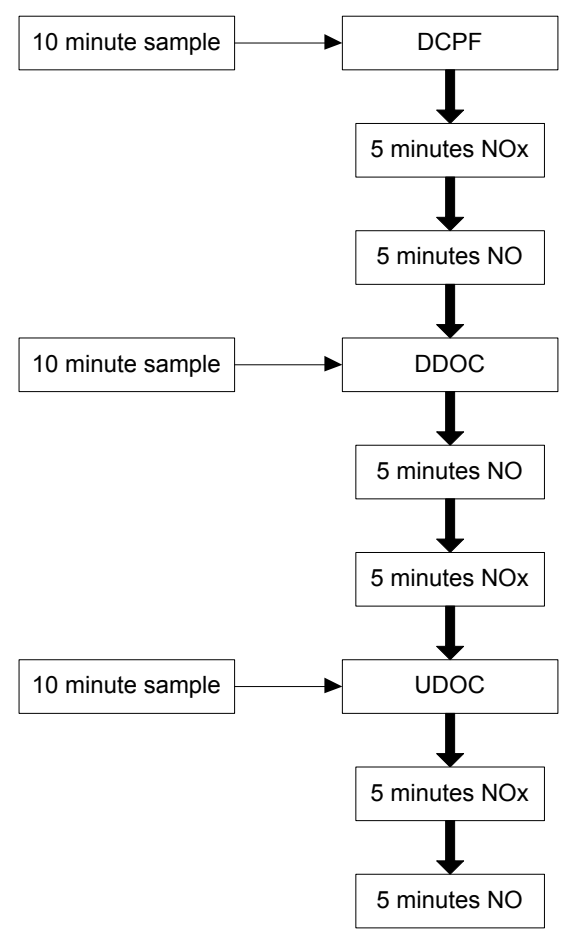

Figure 3.5: Pre-test Preparation Phase Gaseous Emissions Sampling Strategy 
Following the completion of the required PM and gaseous emissions measurements, the CPF clean-out phase can begin by initializing fuel dosing and determining the amount of fuel injected that is required to reach the target CPF inlet temperature to be used during the active regeneration phase.

\subsubsection{CPF Clean Out Phase}

At the completion of the data collection during the pre-test preparation phase, the engine is allowed to continue running at the active regeneration test condition if incylinder dosing is to be used, or the engine can be brought to 2100 RPM and $840 \mathrm{Nm}$ if the auxiliary dosing injector is used. If the engine is switched to 2100 RPM and 840

$\mathrm{Nm}$, the DOC inlet exhaust temperature must stabilize to $380 \pm 10^{\circ} \mathrm{C}$ before proceeding.

Once the desired engine operating point and steady state DOC inlet temperature are reached, dosing is activated and adjusted to reach a CPF inlet temperature of $600^{\circ} \mathrm{C}$. After $600^{\circ} \mathrm{C} \mathrm{CPF}$ inlet temperature is achieved, it is maintained for approximately fifteen minutes, ensuring that a constant CPF pressure drop profile is observed. If fifteen minutes passes and the pressure drop profile has not stabilized, the CPF clean out continues until the pressure drop profile is stable for an extended period of time. Once the CPF pressure drop profile is stable, dosing is halted and the CPF pressure drop profile is allowed to stabilize once again, after which the transition to Stage 1 loading is made.

\subsubsection{Stage 1 Loading Phase}

At the transition to Stage 1 loading, the engine is switched to 2100 RPM and 195 $\mathrm{Nm}$, with a DOC inlet temperature of $265^{\circ} \mathrm{C} \pm 10^{\circ} \mathrm{C}$ for Stage 1 loading of the CPF. The engine is allowed to run at the loading condition for approximately thirty minutes to allow the temperature of the CPF to stabilize. By weighing the CPF at a similar temperature during all portions of the test, the buoyancy effect that results from the thermal mass of the CPF is maintained at a constant level. Ultimately, this technique reduces variability between CPF weight measurements from different phases in the experiment. 
During Stage 1 loading, gaseous emissions are sampled constantly using the same strategy that was used in the pre-test preparation phase, where samples are taken DCPF, DDOC, and UDOC, in that order.

Exhaust particle size distribution (PSD) samples are also collected DCPF, DDOC, and UDOC. One sample at each location is taken during Stage 1 loading, with each sample being in the range from 20 seconds to 2 minutes in sampling time. The sampling time is set by the user, and can be varied depending on the resolution of data desired. The PSD samples must be taken at a different location than the gaseous emissions to allow each analyzer to receive the full exhaust sample at that location. For example, if gaseous emissions are being sampled DCPF, PSD must be sampled UDOC or DDOC until the DCPF gaseous emissions sampling has been finished.

One PM sample is collected UDOC for five minutes during Stage 1 loading along with the continuous monitoring of temperature, exhaust flow, fuel flow, and pressure drop profiles across the DOC and CPF.

After thirty minutes of Stage 1 loading, the engine out exhaust is switched to the bypass line which diverts the exhaust around the after-treatment system and the engine is shut down. Once the engine is shut down, the aftertreatment system is disassembled to allow the weighing of the CPF. The CPF weighing procedure is explained in detail in Appendix D.

The weighing of the CPF provides for the mass measurement $m_{s 1}$ which is used with $m_{\text {Ret-s } 1}$ to determine the clean weight of the filter $\left(m_{c}\right)$ using Eqn 1 . The value $m_{\text {Ret-s1 }}$ is obtained twice, once prior to the start of the experiment using preliminary test data. This value is used to predict the CPF PM loading during the test.

$$
\mathrm{m}_{\mathrm{c}}=\mathrm{m}_{\mathrm{s} 1}-\mathrm{m}_{\mathrm{Ret}-\mathrm{S} 1}
$$

$m_{c}=$ Calculated clean weight of the CPF, [g]

$\mathrm{m}_{\mathrm{s} 1}=$ Measured mass of the CPF after Stage 1 loading, [g]

$\mathrm{m}_{\text {Ret-S1 }}=$ MTU-1D model predicted PM added during Stage 1 loading, [g] 


\section{Table 3.6: Engine Speed and Load for Stage 2 Engine Warm Up}

\begin{tabular}{|c|c|c|}
\hline Engine Speed & Engine Load & Time \\
\hline$[$ RPM $]$ & {$[\mathrm{Nm}]$} & {$[\mathrm{min}]$} \\
\hline 750 & 0 & 1 \\
\hline 1200 & 195 & 5 \\
\hline 1800 & 195 & 5 \\
\hline 2100 & 195 & 5 \\
\hline
\end{tabular}

\subsubsection{Stage 2 Loading Phase}

After the aftertreatment system is reassembled and installed in the exhaust system, and while the exhaust is still routed through the baseline, the engine is started and brought to idle. Table 3.6 shows the warm up procedure after Stage 1 loading is complete, and warm up is complete when a steady exhaust manifold temperature is achieved.

Once the exhaust manifold temperature has stabilized, the exhaust is switched to the trapline which marks the beginning of Stage 2 loading.

Stage 2 loading takes place at 2100 RPM and $195 \mathrm{Nm}$, with a DOC inlet temperature of $265^{\circ} \mathrm{C} \pm 10^{\circ} \mathrm{C}$, which is the same operating condition as Stage 1 loading. The time of Stage 2 loading is based on preliminary modeling predictions, and has been shown to vary based upon the engine out PM concentration.

The same measurements and samples that were taken during Stage 1 loading are also taken during Stage 2 loading, but on a more frequent basis.

The strategy for gaseous sampling is modified from Stage 1 loading with initial sampling occurring DDOC. This location was given first priority in order to facilitate the modeling effort as it was deemed important from a modeling perspective to record the CPF inlet concentrations during the start of Stage 2 loading. The second sampling location is DCPF with the final location being UDOC. Gaseous sampling is cycled through these locations during the test with the time at each location split equally dependent upon the length of the test.

Figure 3.6 depicts the gaseous emissions sampling strategy for Stage 2 loading. 


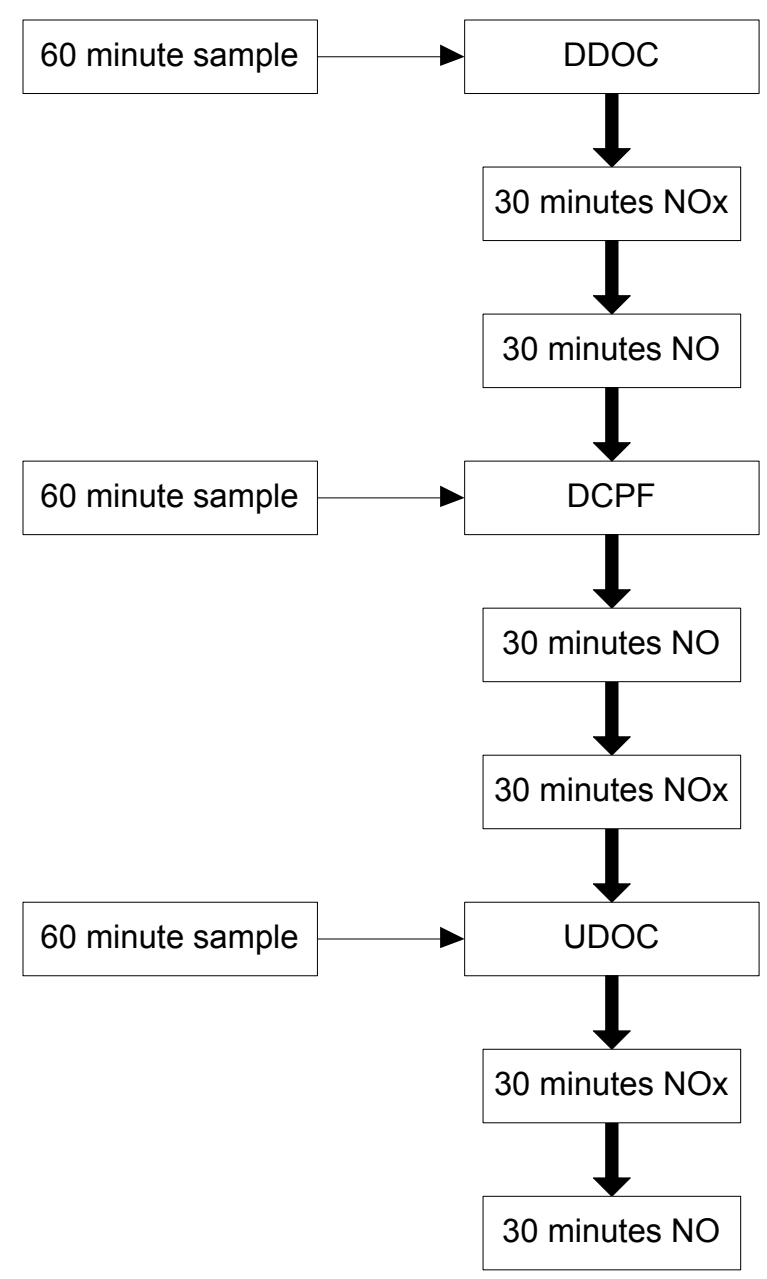

Figure 3.6: Gaseous Emissions Sampling Strategy for Stage 2 Loading Phase

The strategy for PSD sampling is the same as the strategy used for Stage 1 loading, in that PSD samples cannot be taken at the same location as gaseous emissions sampling at the same time.

Four PM samples are collected UDOC and one PM sample is taken DCPF during Stage 2 loading. Only one DCPF PM sample is collected because the PM concentration DCPF is so low that a one hour sample time is required to collect a measureable amount of PM. The sample time for the UDOC PM samples is five minutes, which is the same strategy that was used during Stage 1 loading.

After a predetermined amount of loading time has passed, the exhaust is diverted through the bypass line and the engine is brought to idle and shut down. The aftertreatment system is removed from the exhaust system and then disassembled for 
$\mathrm{CPF}$ weighing. The weighing of the CPF provides for the mass measurement $\mathrm{m}_{\mathrm{s} 2}$ which is used with $m_{c}$ in Eqn. 8 to determine $m_{\text {Ret-s2 }}$, the PM mass retained in the CPF after Stage 2 loading.

$$
\mathrm{m}_{\text {Ret-s2 }}=\mathrm{m}_{\mathrm{s} 2}-\mathrm{m}_{\mathrm{c}}
$$

Eqn. 8

$\mathrm{m}_{\text {Ret-s2 }}=$ Calculated PM mass retained in the CPF at end of Stage 2 loading, [g]

$\mathrm{m}_{\mathrm{s} 2}=$ Measured mass of the CPF at end of Stage 2 loading, [g]

$\mathrm{m}_{\mathrm{c}}=$ Calculated clean weight of the CPF, from Eqn. 7, [g]

The PM loading of the filter is verified by using the value $\mathrm{m}_{\text {Ret-s2, }}$ which is the mass of the accumulated PM in the filter, and dividing this mass value by the volume of the $\mathrm{CPF}, 17.1 \mathrm{~L}$. If $2.2 \pm 0.2 \mathrm{~g} / \mathrm{L}$ has not been achieved, the after-treatment system must be re-installed in the exhaust system and additional loading will be required.

After verifying that the CPF loading of $2.2 \pm 0.2 \mathrm{~g} / \mathrm{l}$ has been achieved, the aftertreatment system is reassembled and reinstalled into the exhaust system and subsequently, Stage 2 loading has been completed.

\subsubsection{Active Regeneration Phase}

Prior to the start of the Active Regeneration portion of the experiment, the gaseous emissions analyzer bench $\mathrm{HC}$ concentration range must be increased in order for the analyzer to accurately measure the increased $\mathrm{HC}$ concentrations that are found DDOC during fuel dosing. This is done by selecting the Hydrocarbon tab on screen 2 of the Pierburg bench. Touch the Parameters button, and select Range 4 for the hydrocarbon measurement range. Then span, zero, and adjust the hydrocarbon channel by itself, and confirm that the adjusted hydrocarbon measurement reaches 4200 ppm before finishing the adjust stage; if it does not reach 4200 ppm, re-zero and re-adjust it.

After the after-treatment system has been re-installed, the engine is warmed up in the baseline in the same manner prior to Stage 2 loading. The warm up is complete when a steady state exhaust manifold temperature is achieved.

After a steady exhaust manifold temperature is achieved, the exhaust is switched to the trapline and the aftertreatment system is allowed to warm up at the loading condition for approximately 15 minutes or until the DOC inlet temperature has 
stabilized at $265^{\circ} \mathrm{C} \pm 10^{\circ} \mathrm{C}$. Once the DOC inlet temperature is stable at the loading condition, the engine is switched to the active regeneration condition, 1400 RPM and $460 \mathrm{Nm}$, for approximately 10 minutes or until the DOC inlet temperature has stabilized at $325^{\circ} \mathrm{C} \pm 10^{\circ} \mathrm{C}$.

After a steady DOC inlet temperature at the active regeneration engine condition is achieved, fuel dosing is activated by the pre-determined injection method (incylinder or auxiliary fuel dosing injector), which marks the start of the Active Regeneration portion of the experiment. A base line length of the Active Regeneration phase for the experiment being conducted was found using the model developed by Pidgeon [2] prior to testing day. The amount of fuel required to be injected to reach the desired CPF inlet temperature was determined during the Pretest Preparation phase of the test, and is used as the initial fuel injection value at the start of active regeneration. The amount of fuel being injected is adjusted to maintain the desired $\mathrm{CPF}$ inlet temperature $\pm 10^{\circ} \mathrm{C}$ for the duration of active regeneration.

Gaseous emissions during active regeneration are collected DDOC for six minutes, with three minutes dedicated to NOx and three minutes dedicated to NO collection. Gaseous measurements should not be taken UDOC during fuel dosing due to the possibility of damage occurring to the analyzer. For the Active Regeneration phase of the test, it is assumed that the UDOC gaseous concentrations, other than hydrocarbon concentration, remain the same as what was found in the pre-test portion of the experiment.

At the same time that gaseous emissions are being collected, a PSD sample is taken DCPF. If the Active Regeneration portion of the experiment is long enough, gaseous emissions will be sampled for 6 minutes DCPF and a PSD sample will be taken DDOC.

The total gaseous sampling time at each location may need to be adjusted depending on the length of active regeneration.

Figure 3.7 is the visual representation for gaseous and PSD sampling during the active regeneration phase. 


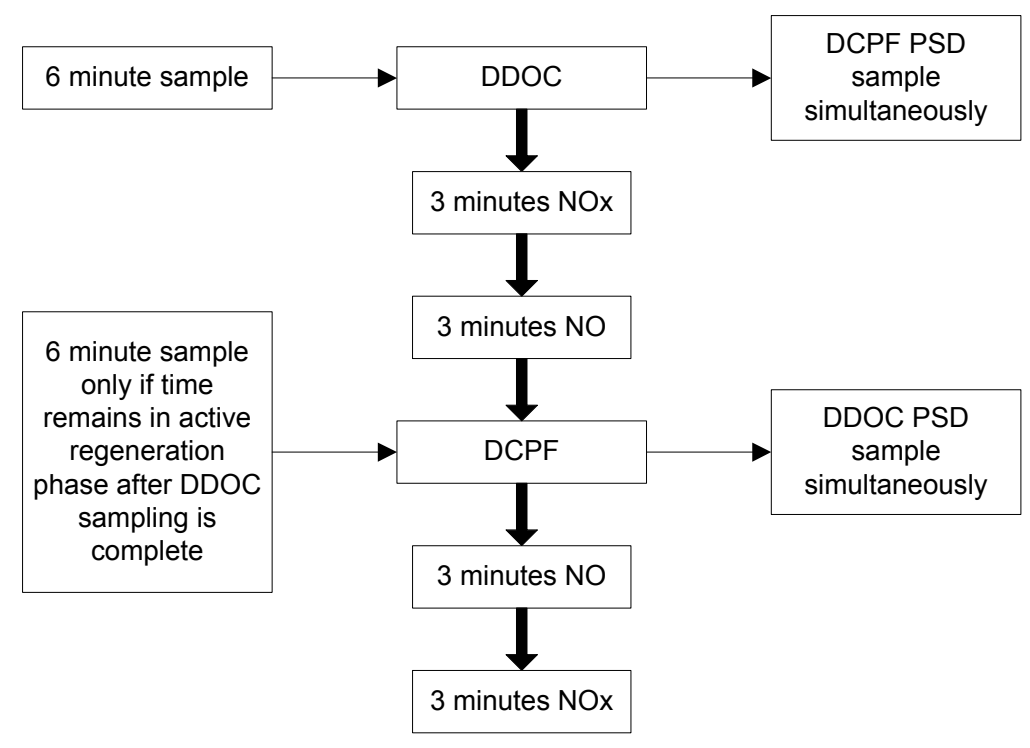

\section{Figure 3.7: Gaseous Emissions and PSD Sampling Strategy for Active Regeneration Phase}

After a predetermined amount of time, or if the slope of the pressure drop profile across the CPF decreases significantly, the Active Regeneration phase of the experiment is halted and the transition is made to Stage 3 loading.

\subsubsection{Stage 3 Loading Phase}

After the Active Regeneration portion of the test is concluded, the transition to Stage 3 loading begins. The engine is brought to the same engine conditions used during Stage 1 and Stage 2 loading, 2100 RPM and 195 Nm, with a DOC inlet temperature of $265^{\circ} \mathrm{C} \pm 10^{\circ} \mathrm{C}$.

The collection of experimental data occurs in the same manner as the Stage 1 loading portion of the experiment, because continuing the sampling of exhaust gases DCPF after active regeneration prevents any false $\mathrm{HC}$ concentration readings due to analyzer hang up. Stage 3 loading is thirty minutes long which allows the temperature of the CPF to stabilize to the values that were experienced in Stage 1 and Stage 2 loading, allowing for the best calculation of total PM oxidized during active regeneration.

After thirty minutes of operating in Stage 3 loading, the exhaust is switched to the bypass line and the engine is brought to idle and shut down. The aftertreatment 
system is removed from the exhaust system and disassembled for weighing of the CPF.

The weighing of the CPF provides for the mass measurement $m_{s 3}$ which is used with $m_{c}$ in Eqn. 9 to determine the remaining amount of PM mass in the filter $\left(m_{\text {Ret-s }}\right)$.

$$
\mathrm{m}_{\mathrm{Ret}-\mathrm{s} 3}=\mathrm{m}_{\mathrm{s} 3}-\mathrm{m}_{\mathrm{c}}
$$

$\mathrm{m}_{\text {Ret-s3 }}=$ Calculated PM mass retained in the CPF after Stage 3 loading, [g]

$\mathrm{m}_{\mathrm{s} 3}=$ Measured mass of the CPF after Stage 3 loading, [g]

$\mathrm{m}_{\mathrm{c}}=$ Calculated clean weight of the CPF, from Eqn. 7, [g]

In order to determine the amount of PM mass present in the filter after the Active Regeneration portion of the experiment, Eqn. 4 is used to calculate the amount of PM

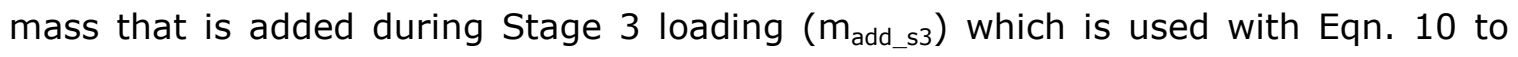
determine the amount of PM present in the filter ( $\left.m_{\text {Ret-AR }}\right)$ after the Active Regeneration portion of the experiment.

$$
\mathrm{m}_{\text {Ret-AR }}=\mathrm{m}_{\text {Ret-s3 }}-\mathrm{m}_{\text {add_s } 3}
$$

$\mathrm{m}_{\text {Ret-AR }}=$ Calculated PM mass retained in the CPF after Active Regeneration, [g]

$\mathrm{m}_{\text {Ret-s3 }}=$ Measured PM mass retained in the CPF after Stage 3 loading, [g]

$\mathrm{m}_{\text {add_s3 }}=$ Predicted (Eqn. 4) PM mass added to the CPF during Stage 3 loading, [g]

The amount of PM added to the CPF during the 10 minute ramp-up at the active regeneration engine condition can be calculated using the engine out PM concentration $\left(\mathrm{EO}_{\mathrm{PM}}\right)$ and exhaust flow rate $\left(\mathrm{Q}_{\mathrm{std}}\right)$ with Eqn. 11. 


$$
\mathrm{m}_{\text {AR_ramp }}=\mathrm{m}_{\text {in,AR_ramp }} \cdot 0.07
$$

$\mathrm{m}_{\mathrm{AR} \_ \text {ramp }}=$ Predicted CPF PM Mass Retained during AR Ramp [g]

$\mathrm{m}_{\text {in,AR_ramp }}=\mathrm{PM}$ mass into the CPF during AR Ramp [g]

The amount of PM oxidized during active regeneration is calculated using $m_{\text {Ret-s }}$, $m_{\text {Ret-AR }}, m_{A R-r a m p}$, and the PM mass added to the CPF during the loading ramp-up time estimated from the MTU-1D CPF model, $\mathrm{m}_{\text {load-ramp, with Eqn. } 12 .}$

$$
\mathrm{m}_{\mathrm{OX}}=\mathrm{m}_{\mathrm{Ret}-\mathrm{s} 2}+\mathrm{m}_{\text {load-ramp }}+\mathrm{m}_{\mathrm{AR}-\mathrm{ramp}}-\mathrm{m}_{\mathrm{Ret}-\mathrm{AR}}
$$

Eqn. 12

$\mathrm{m}_{\mathrm{Ox}}=$ Calculated PM mass oxidized in the CPF during Active Regeneration, [g]

$\mathrm{m}_{\text {Ret-s2 }}=$ Calculated PM mass retained in the CPF at end of Stage 2 loading, [g]

$\mathrm{m}_{\text {load-ramp }}=\mathrm{MTU}-1 \mathrm{D}$ model predicted $\mathrm{PM}$ mass added to the CPF during Pre-active Regeneration ramp up at the loading condition, [g]

$\mathrm{m}_{\mathrm{AR} \text {-ramp }}=\mathrm{PM}$ mass added to $\mathrm{CPF}$ during ramp up at Active Regeneration engine conditions, [g]

$\mathrm{m}_{\text {Ret-AR }}=$ Calculated PM mass retained in the CPF after Active Regeneration, [g]

After the CPF has been weighed, the after-treatment system is reassembled and installed in the exhaust system in preparation for Stage 4 loading.

\subsubsection{Stage 4 Loading Phase}

After the after-treatment system is reassembled and installed in the exhaust system, and while the exhaust is still routed through the baseline, the engine is started and brought to idle. Table 3.7 shows the warm up procedure after Stage 3 loading is complete, and warm up is complete when a steady exhaust manifold temperature is achieved.

Once the exhaust manifold temperature has stabilized, the exhaust is switched to the trapline which marks the beginning of Stage 4 loading. 


\section{Table 3.7: Engine Speed and Load for Stage 4 Engine Warm Up}

\begin{tabular}{|c|c|c|}
\hline Engine Speed & Engine Load & Time \\
\hline$[$ RPM] & {$[\mathrm{Nm}]$} & {$[\mathrm{min}]$} \\
\hline 750 & 0 & 1 \\
\hline 1200 & 195 & 5 \\
\hline 1800 & 195 & 5 \\
\hline 2100 & 195 & 5 \\
\hline
\end{tabular}

Stage 4 loading takes place at 2100 RPM and 195 Nm, with a DOC inlet temperature of $265^{\circ} \mathrm{C} \pm 10^{\circ} \mathrm{C}$, which is the same operating condition as the Stage 1 , Stage 2 , and Stage 3 loading phases. Stage 4 loading is sixty minutes long and allows the behavior of the CPF after a partial regeneration to be explored.

The collection of experimental data occurs in the same manner as the Stage 2 portion of the experiment, with the only differences being that two UDOC PM samples are collected and the total length of Stage 4 loading, which is only 60 minutes.

After sixty minutes of operating in Stage 4 loading, the exhaust is switched to the bypass line and the engine is brought to idle and shut down. The after-treatment system is removed from the exhaust system and disassembled for weighing of the CPF.

The weighing of the CPF provides for the mass measurement $m_{s 4}$ which is used with $m_{c}$ in Eqn. 13 to determine the remaining amount of PM mass in the filter $\left(m_{\text {Ret-s4 }}\right)$.

$$
\mathrm{m}_{\text {Ret }-\mathrm{s} 4}=\mathrm{m}_{\mathrm{s} 4}-\mathrm{m}_{\mathrm{c}}
$$

$\mathrm{m}_{\text {Ret-s4 }}=$ Calculated PM mass retained in the CPF after Stage 4 loading, [g]

$\mathrm{m}_{\mathrm{s} 4}=$ Measured mass of the CPF after Stage 4 loading, $[\mathrm{g}]$

$\mathrm{m}_{\mathrm{c}}=$ Calculated clean weight of the CPF, from Eqn. 7, [g]

After the mass retained in the CPF after Stage 4 is determined, the experiment has concluded.

\subsection{Active Regeneration Test Matrix}

In order to determine the dominant factors affecting the PM oxidation in the CPF during active regeneration, a series of tests were created which cover a range of CPF 
inlet temperatures using ULSD, B10, and B20. As well as changes in the test fuel, two higher PM loading cases $(4.1 \mathrm{~g} / \mathrm{L})$ and exhaust dosing cases were also factored into the test matrix. The engine operating point and percent PM oxidization targets were the constant factors associated with the entire test matrix. Table 3.8 illustrates the active regeneration tests that were completed in this study. The numbers represent the chronological order of the experiments for each fuel (i.e., the blue cell numbered 6 coincides with test B20-6). 

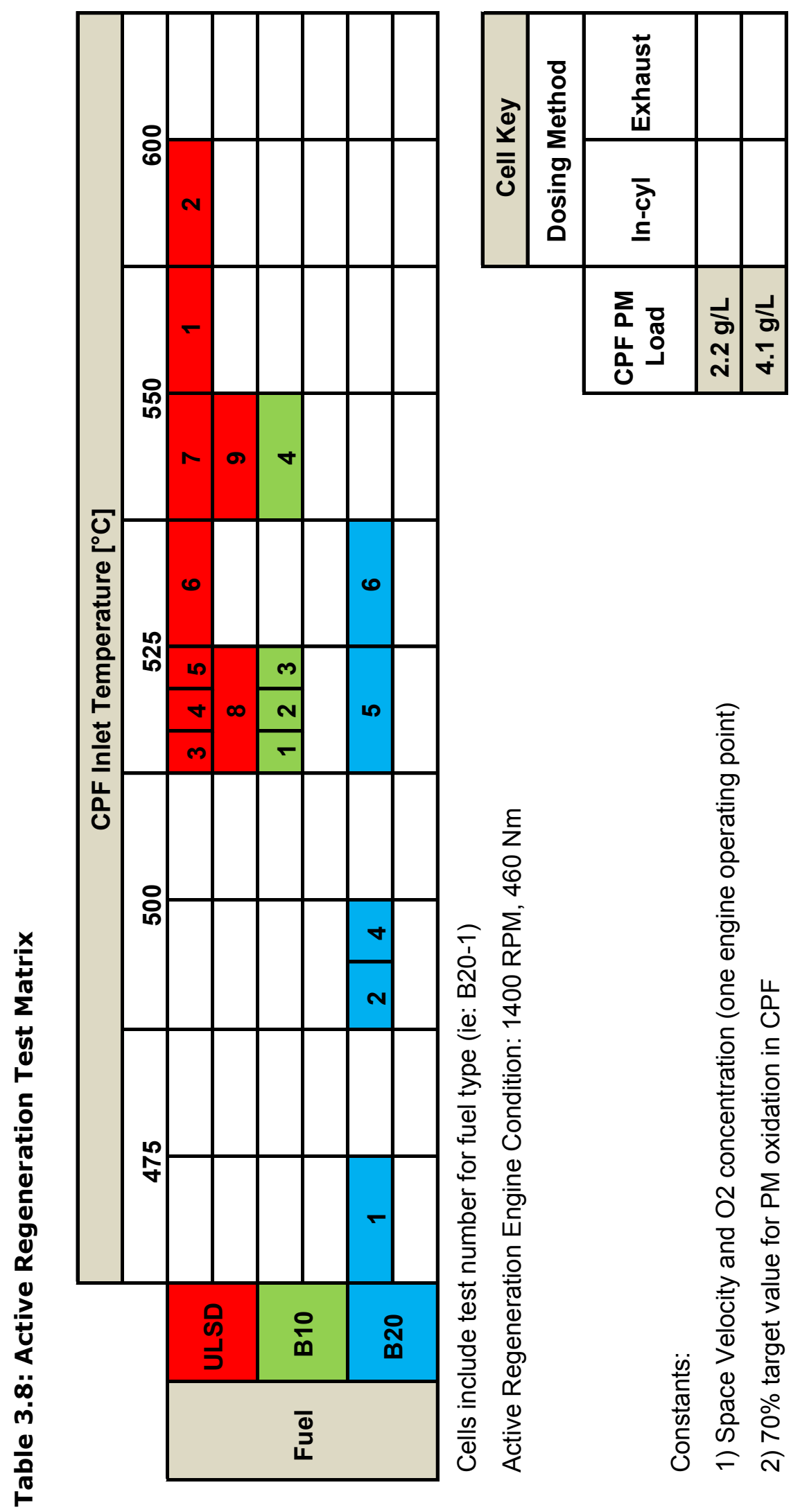

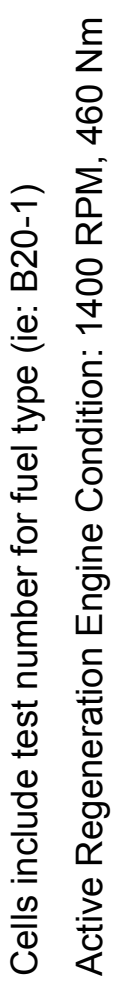

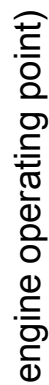

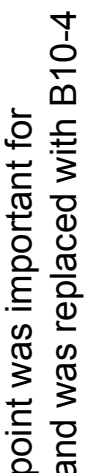

Ð ర్

离

ญำ

苟

क ⿱宀

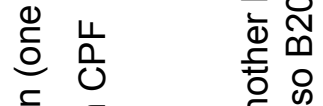

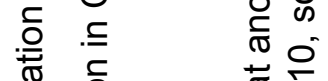

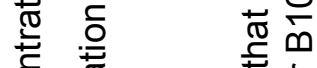

ঠ

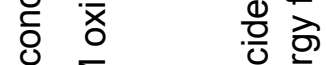

กิ

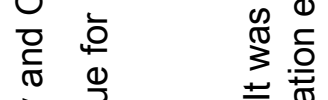

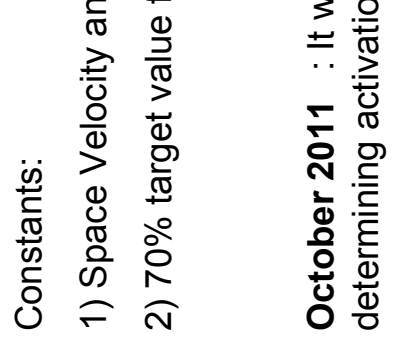




\subsection{PM Reaction Rate Calculation Method}

The method for calculating the reaction rate for active regeneration has been updated since the active regeneration experimentation performed by Austin [1] and Chilumukuru [15] in order to account for varying CPF temperatures. The method utilizes experimentally measured time dependent CPF temperatures, average PM concentrations, and PM loadings at the start and end of the active regeneration portion of the test. The time that fuel dosing was activated is considered the experimental active regeneration period. Conservation of mass in the CPF, with inlet PM concentrations of $C_{i n}$, and an initial PM loading of $m_{R}$, results in Eqn. 14, a first order ODE for change in PM mass retained $m_{R}$, over time $t$. It is assumed that everything in Eqn. 14 with the exception of the reaction rate (RRo) is constant, since RRo is temperature dependent, and the average CPF temperature changes with time.

$$
\frac{\mathrm{dm}}{\mathrm{dt}}=\eta_{\text {filt }} \cdot \mathrm{C}_{\mathrm{in}} \cdot \mathrm{Q}-\mathrm{m}_{\mathrm{R}} \cdot \mathrm{RRo}(\mathrm{T})
$$

Setting $\Delta \mathrm{m}=\mathrm{m}_{\mathrm{R}}(\mathrm{i})-\mathrm{m}_{\mathrm{R}}(\mathrm{i}-1)$ and $\mathrm{m}_{\mathrm{R}}=\mathrm{m}_{\mathrm{R}}(\mathrm{i}-1)$ in Eqn. 14, Eqn. 14 can be solved numerically for $m_{R}(i)$ after substituting $R R o(T)=A \cdot e^{[-E a /(R \cdot T(i))]}$ which yields Eqn. 15 .

$$
m_{R}(i)=\left[\eta_{\text {filt }} \cdot C_{\text {in }} \cdot Q-m_{R}(i-1) \cdot A \cdot e^{\left[-E_{a} /(R \cdot T(i))\right]}\right] \cdot \Delta t+m_{R}(i-1) \quad \text { Eqn. } 15
$$

$\mathrm{i}=$ Incremental point in time during active regeneration [-]

$\mathrm{m}_{\mathrm{R}}(\mathrm{i})=\mathrm{PM}$ mass in CPF at time i during active regeneration [ $\mathrm{g}$ ]

$\mathrm{m}_{\mathrm{R}}(\mathrm{i}-1)=\mathrm{PM}$ mass in CPF calculated at time $\mathrm{i}-1[\mathrm{~g}]$

$\eta_{\text {filt }}=$ CPF filtration efficiency $[-]$

$\mathrm{C}_{\text {in }}=$ Engine out PM concentration $[\mathrm{g} / \mathrm{scm}]$

$\mathrm{Q}=$ Exhaust volumetric flow rate $[\mathrm{scm} / \mathrm{sec}]$

$A=$ Pre-exponential factor $[1 / \mathrm{s}]$

Ea = Activation energy, $145000[\mathrm{~J} / \mathrm{gmol}]$

$\mathrm{R}=$ Universal gas constant, 8.315E-03 $[\mathrm{J} /(\mathrm{gmol} \cdot \mathrm{K})]$

$\mathrm{T}(\mathrm{i})=\mathrm{CPF}$ avg. temperature at time i during $\mathrm{AR}[\mathrm{K}]$

$\Delta \mathrm{t}=$ Time step through active regeneration, $1[\mathrm{sec}]$

Using Eqn. 15, the PM mass retained within the CPF is calculated at each time step during the active regeneration portion of the experiment. The experimental data from a performed test provides for the length of the active regeneration period along 
with the CPF filtration efficiency, engine out PM concentration, exhaust volumetric flow rate, and the average CPF temperature throughout the active regeneration period. The constants in Eqn. 15 are the activation energy (145 kJ/gmol [13]) and the universal gas constant. The pre-exponential factor, $A$, is fit by iteration until the actual PM mass retained at the end of the active regeneration is matched to the calculated PM mass retained at the end of active regeneration. The iteration is accomplished by comparing the final calculated PM mass retained to the experimental amount of PM mass retained in the CPF after active regeneration. If the calculated ending mass retained is too high (actual PM mass $0.1 \mathrm{~g}$ ), the preexponential factor is increased and the calculation runs again. Similarly, if the calculated ending mass retained is too low, the pre-exponential factor is decreased and the calculation runs again. The pre-exponential factor is iterated until the actual PM mass retained $00.1 \mathrm{~g}$ is matched to the calculated PM mass retained at the end of active regeneration. Once the PM mass retained is within limits, the pre-exponential factor is known.

With the pre-exponential factor known, the average CPF temperature matrix is used as an input to Eqn. 16, which assumes that the activation energy and preexponential factor remain constant.

$$
\left.\operatorname{RRo}=A \cdot e^{\left[-E_{a} /(R \cdot T)\right.}\right]
$$

$\mathrm{RRo}=$ reaction rate $[1 / \mathrm{s}]$

Using Eqn. 16, the reaction rate is calculated for each time step of the active regeneration portion of the experiment and then reported in matrix form. The reported reaction rate is the calculated value corresponding to the average CPF temperature during active regeneration.

\subsection{Activation Energy Determination Method}

The experimental data from all ISL 365 runs were used in conjunction with optimization methods, similar to those used by Surenahalli [17], to calculate a single value for the activation energy of each test fuel. The experimental reaction rate, average CPF temperature, and mole fraction of $\mathrm{O}_{2}\left(\mathrm{YO}_{2}\right)$ for each test case is input into the optimization. Upper and lower limits for the activation energy to be used by the optimization are input as well. 
The optimization calculates the reaction rates based on the experimental CPF temperature and oxygen concentration from Eqn. 17 and minimizes the difference between the experimental and the optimized reaction rates. The optimization uses

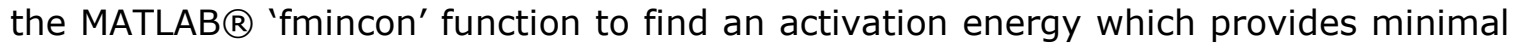
variation in pre-exponential factors and minimizes the cost function. The cost function for the optimization is defined at the percent difference between the experimental and optimized reaction rates, as shown in Eqn. 17.

$$
\operatorname{cost}=\sum_{\mathrm{i}=0}^{\mathrm{n}} \frac{\mathrm{RRo}_{\exp }-\mathrm{RRo}_{\mathrm{opt}}}{\mathrm{RRo}_{\exp }}
$$

$\mathrm{n}=$ number of tests.

After the cost function has been minimized, the corresponding activation energy is reported along with pre-exponential factors for each test input to the optimization.

\subsection{CPF Resistance Calculation Method}

In order to determine where any experimental problems occurred during data collection, the total CPF resistance can be calculated and used to determine if data problems occurred during the test. The total hydrodynamic flow resistance of the CPF is expected to increase during loading and decrease during active regeneration followed by an increase during post-loading due to the corresponding changes in the PM retained in the CPF. CPF resistance can be calculated using Eqn. 18 which comes from reference [18] where both sides of the equation represent the sum total of the CPF wall, PM cake, and channel resistances. The mass flow rate of exhaust through the CPF is assumed to be equal to the sum of the mass flow rate of air (measured by the pressure drop across the LFE) and mass flow rate of fuel (measured by the AVL fuel balance) into the engine. The density of the exhaust gas mixture is calculated using the ideal gas equation of state and it is a function of the exhaust pressure and temperature. The dynamic viscosity of the exhaust is calculated by Sutherland's law assuming air as the gas and is a function of temperature. Separate analysis conducted by Premchand [19] has shown that the difference in viscosity between engine exhaust and air is negligible. The weighted CPF average temperature is used in the calculation of CPF resistance on the left side of Eqn. 18 because the weighted 
CPF average temperature represents the overall CPF temperature and temperature is the variable that affects the viscosity and density of the exhaust gas.

$$
\left(\Delta \mathrm{P} \cdot \mathrm{V}_{\text {trap }} \cdot \rho_{\mathrm{exh}}\right) /\left(\mu \cdot \dot{\mathrm{m}}_{\mathrm{exh}}\right)=\frac{\left(\alpha+\mathrm{w}_{\mathrm{S}}\right)^{2}}{2}\left[\frac{\mathrm{w}_{\mathrm{S}}}{\mathrm{k}_{\mathrm{s}} \alpha}+\frac{1}{2 \mathrm{k}_{\text {soot }}} \ln \left(\frac{\alpha}{\alpha-2 \mathrm{w}}\right)+\frac{4 \mathrm{FL}^{2}}{3}\left(\frac{1}{(\alpha-2 \mathrm{w})^{4}}+\frac{1}{\alpha^{4}}\right)\right] \quad \text { Eqn. } 18
$$

$\Delta \mathrm{P}=\mathrm{CPF}$ pressure drop $[\mathrm{Pa}]$

$\mathrm{V}_{\text {trap }}=$ Total volume of the CPF $\left[\mathrm{m}^{3}\right]$

$\rho_{\text {exh }}=$ Density of exhaust $\left[\mathrm{kg} / \mathrm{m}^{3}\right]$

$\rho_{\text {exh }}=\left(\Delta \mathrm{P}+\mathrm{P}_{\text {barometric }}\right) /\left(\mathrm{R} \cdot \mathrm{T}_{\mathrm{avg}}\right)$

$\mathrm{T}_{\text {avg }}=$ Weighted average CPF temperature $[\mathrm{K}]$

$\mu=$ Exhaust dynamic viscosity $\left[(\mathrm{N} \cdot \mathrm{sec}) / \mathrm{m}^{2}\right]$

$m_{\text {exh }}=$ Mass flow rate of exhaust $[\mathrm{kg} / \mathrm{sec}]$

$\alpha=$ Channel width [m]

$\mathrm{w}_{\mathrm{s}}=$ Wall thickness $[\mathrm{m}]$

$\mathrm{k}_{\mathrm{s}}=$ Substrate wall permeability $\left[\mathrm{m}^{2}\right]$

$\mathrm{k}_{\mathrm{soot}}=$ Cake layer permeability $\left[\mathrm{m}^{2}\right]$

$\mathrm{w}=$ Particulate layer thickness $[\mathrm{m}]$

$\mathrm{F}=$ Factor $=28.454[18]$

$\mathrm{L}=$ Channel length $[\mathrm{m}]$

$\left(\Delta \mathrm{P} \cdot \mathrm{V}_{\text {trap }} \cdot \rho_{\text {exh }}\right) /\left(\mu \cdot \dot{\mathrm{m}}_{\text {exh }}\right)=$ Resistance $[-]$

The left-hand side of Eqn. 18 includes the CPF pressure drop, total substrate volume, the dynamic viscosity, mass flow rate, pressure, and exhaust temperature of the gas in the CPF, while the right-hand side is the equivalent CPF flow resistance based on dimensions of the substrate channels, channel walls, PM cake layer, and the permeability of the cake layer and the substrate wall. Eqn. 19 [19] describes the change in the substrate wall permeability as a function of the PM mass retained in the substrate wall and resulting change in the porosity and the unit collector diameter. The functions used to describe the change in substrate wall porosity and unit collector diameter are described in detail in reference [19]. 
$\mathrm{k}_{\mathrm{s}}=\mathrm{k}_{\mathrm{s} 0} \cdot\left(\frac{\mathrm{d}_{\mathrm{c}}}{\mathrm{d}_{\mathrm{c} 0}}\right)^{2} \cdot\left(\frac{\mathrm{f}(\varepsilon)}{\mathrm{f}\left(\varepsilon_{0}\right.}\right)$

Eqn. 19

$\mathrm{k}_{\mathrm{s} 0}=$ Clean substrate wall permeability $\left[\mathrm{m}^{2}\right]$

$\mathrm{d}_{\mathrm{c}}=$ Instantaneous diameter of a loaded unit collector [m]

$\mathrm{d}_{\mathrm{c} 0}=$ Diameter of a clean unit collector $[\mathrm{m}]$

$\varepsilon=$ Instantaneous substrate wall porosity $\left(=\mathrm{F}\left(\varepsilon_{0}\right.\right.$ and $\left.\left.\mathrm{m}_{\text {wall }}\right)\right)[-]$

$\mathrm{m}_{\text {wall }}=$ Substrate wall PM mass retained

$\varepsilon_{0}=$ Clean substrate wall porosity [-]

The density of the exhaust is calculated using the ideal gas equation of state $(\rho=$ $P / R T$ ) where $P$ is equal to the pressure in the exhaust stream defined as the barometric pressure + CPF pressure drop. $\mathrm{R}$ is the universal gas constant and $\mathrm{T}$ is equal to the weighted average CPF temperature calculated using the methodology described in the Temperature Measurements section of Chapter 3. As previously mentioned, the weighing factor for $\mathrm{C} 1-\mathrm{C} 4, \mathrm{C} 5-\mathrm{C} 8, \mathrm{C} 9-\mathrm{C} 12$, and $\mathrm{C} 13-\mathrm{C} 16$ are 0.303 , $0.287,0.197$, and 0.213 , respectively.

The viscosity is also based on the average CPF temperature, and the total CPF flow resistance is evaluated at every time point through the active regeneration experiments. The weighted average CPF temperature is used throughout all the calculations related to the CPF resistance because the weighted average CPF temperature is the best representation of the temperature state of the CPF at any time point of the experiment. The average CPF temperature also produces the best CPF resistance response relative to all other thermocouple measurements and is closely related to the trends seen when analyzing CPF resistance with thermocouple C3, which produced the best resistance trends when calculated using a single thermocouple as the temperature input.

During loading of the CPF, the substrate wall permeability is decreasing and the particulate layer thickness is increasing due to the addition of PM into the substrate wall and PM cake layer, thereby increasing the magnitude of the $1^{\text {st }}$ and $2^{\text {nd }}$ terms of the right-hand side of Eqn. 18 and in turn, increasing the total flow resistance of the CPF.

The opposite is true during regeneration, where the substrate wall permeability increases due to the oxidation of the PM retained in the substrate wall, thereby causing the substrate wall porosity to increase toward the 'clean' substrate value. 
The particulate layer thickness decreases as PM retained in the cake layer is oxidized over time, thereby decreasing the magnitude of the $1^{\text {st }}$ and $2^{\text {nd }}$ terms of the righthand side of Eqn. 18 and in turn, decreasing the total flow resistance of the CPF.

During post loading, the substrate wall permeability is constant (unless the PM cake layer is completely oxidized after active regeneration) and the particulate layer thickness increases because the oxidation rate is less than the PM addition rate from the engine.

The constants in the right-hand side of Eqn. 18 are the cake layer permeability, channel width and length, channel wall thickness, the Fanning friction factor for square channels equal to 28.454 (from reference [18]), and the variables are the substrate permeability and the cake layer thickness. Figure 3.8 graphically displays the raw experimental data pertaining to CPF resistance calculations for test $\mathrm{B} 20-1$. Subplot 1 is the calculated CPF resistance over the course of the entire test, subplot 2 is the exhaust viscosity and weighted average CPF temperature, subplot 3 is the exhaust mass flow rate, and subplot 4 is the CPF pressure drop profile.

The vertical drops in resistance at $t=5.8$ and 5.9, and the vertical increase at 6.5 hours are not plausible since neither the PM cake layer thickness nor substrate wall permeability can change that rapidly for the given engine conditions of temperature and $\mathrm{NO}_{2}$ concentration. The only variables that affect the change in CPF flow resistance between consecutive points in time would be the PM cake layer thickness and substrate wall permeability (due to changing PM mass), and at times where these variables are not changed (such as when switching engine conditions as shown at $t=5.8$ hours in Figure 3.8), no change in CPF resistance should be present.

In order to correct the vertical shifts in the CPF flow resistance, a correction factor (CF) was applied to the denominator of the left-hand side of Eqn. 18 as indicated in Eqn. 20.

$$
\text { Resistance }=\frac{\Delta \mathrm{P} \cdot \mathrm{V}_{\mathrm{t}} \cdot \rho_{\mathrm{exh}}}{\dot{\mathrm{m}} \mu \cdot \mathrm{CF}}
$$

$\mathrm{CF}=$ Correction factor [ fraction] 

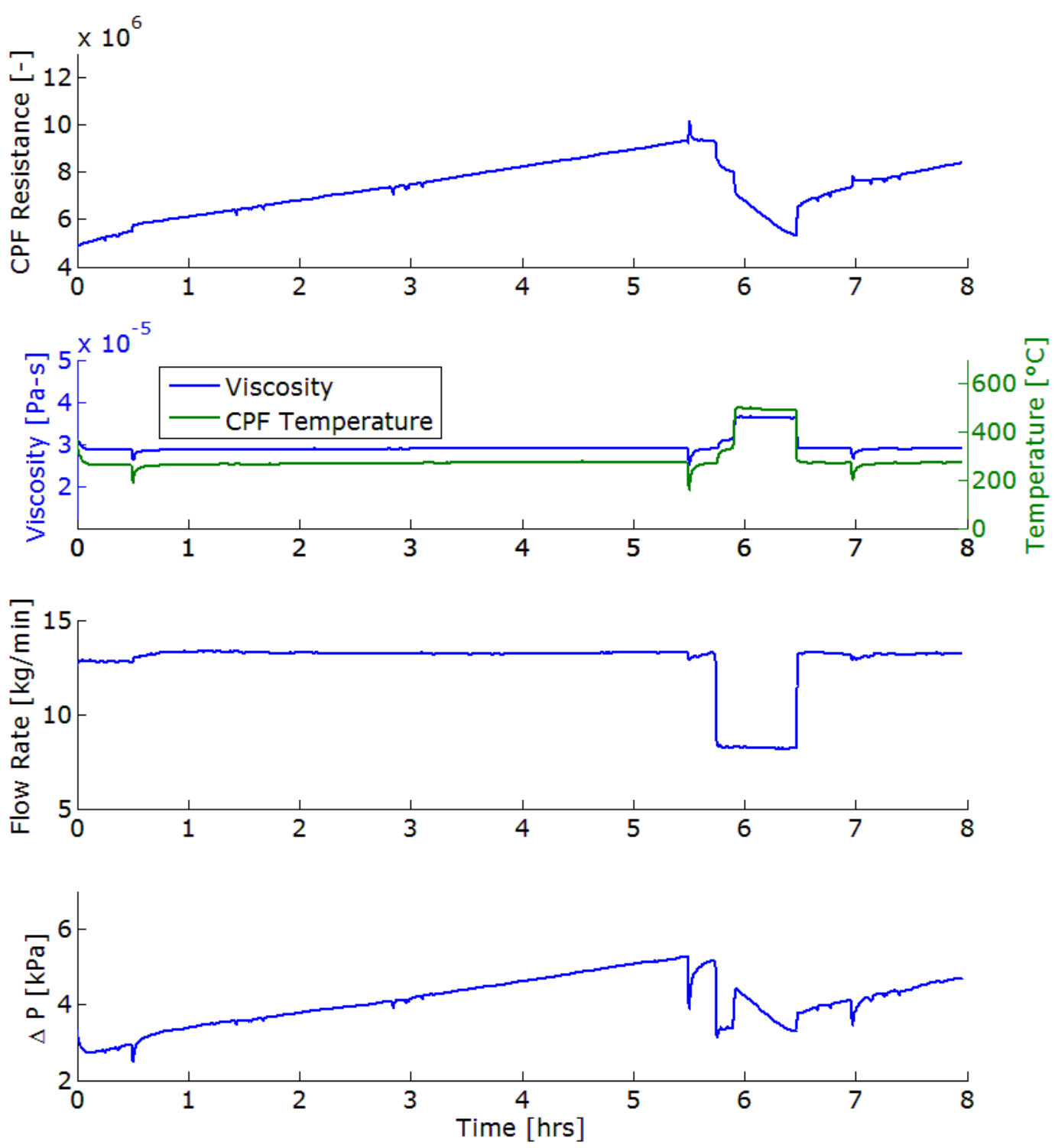

Figure 3.8: B20-1 Experimental CPF Flow Resistance (subplot 1), Exhaust Viscosity and CPF Average Temperature (subplot 2), Exhaust Mass Flow Rate (subplot 3), and CPF Pressure Drop Profile (subplot 4).

The engine-out exhaust mass flow rate is calculated based on a pressure transducer reading on the LFE and is assumed to be equal to the mass flow rate at the CPF inlet. It is believed that the correction factor accounts for PM and temperature maldistribution within the CPF (that may not be accounted for using the weighted average CPF temperature) as well as exhaust flow maldistribution at the CPF inlet. Although it is currently modeled as a constant, the PM cake layer permeability could 
also change because of the change in pressure and as a result of the oxidation process during active regeneration, which the correction factor would also account for. The correction factor also compensates for the phasing differences that may be present between the mass flow rate, temperature, or pressure drop signals. The correction factor in Eqn. 20 corrects for the above effects so that a plausible resistance vs. time plot is available to be used with the MTU-1D CPF Model. The specific methodology used to determine CF for every test case can be found in Appendix $\mathrm{H}$ along with corrections for DAQ errors involved with the LFE and CPF pressure transducers and exhaust bypass valve leaks. 


\section{Chapter 4 Experimental Results}

As previously discussed, an active regeneration experiment consists of several phases separated by CPF weighing events; Stage 1 loading, Stage 2 loading, Active Regeneration, Stage 3 loading, and Stage 4 loading are the phases of a typical active regeneration test. The following section details the experimental and modeling results from the Active Regeneration phase after a data integrity analysis of the experimental data that are used in the MTU-1D modeling effort [19]. The complete details of the analysis are in Appendix $\mathrm{H}$.

The results pertaining to Stage 2 and Stage 4 loading, and the effects of biodiesel blends on them can be found in Appendix I and J respectively. The CPF filtration efficiency by mass was determined during Stage 2 loading phases and was determined to be an average of $97 \%$.

\subsection{Data Integrity Analysis for Modeling}

From a modeling perspective, it is important that the integrity of the experimental data collected during active regeneration testing is good. This is important because inaccuracies with experimental data lead to difficulty in the modeling of the experimental data which can result in inaccurate models. By analyzing a set of key variables throughout the course of each active regeneration test, the integrity of the experimental data to be used in the modeling studies can be determined.

Using all the important variables that affect the model, Table 4.1 was created specifically outlining the specific variables used to analyze the integrity of the experimental data. The table includes simply Pass or Fail conditions for each variable as it relates to each individual test. Green cells indicate that the experimental data met the criterion. Yellow cells indicate that the experimental data can be used for model calibration after data corrections are implemented. The specific data corrections are explained later in this section as well as in Appendix $\mathrm{H}$. Red cells indicate that the experimental data failed one of the criterion and the experimental data needs further analysis. As explained later, the PM concentration data is believed to be the most likely source of error in the experimental data pertaining to Stage 2 PM oxidation after the data corrections were implemented. 
Table 4.1: Data Integrity Analysis Results

\begin{tabular}{|c|c|c|c|c|c|c|}
\hline Run \# & Test & Air Flow & CPF Pressure Drop & S2 PM Oxidation & AR PM Oxidation & Overall \\
\hline 1 & B20 1 & Pass & Pass & Pass & Pass \\
\hline 2 & B20 2 & Pass & Pass & Pass & Pass \\
\hline 3 & B20 5 & Fail & Fail & Pass & Fail \\
\hline 4 & ULSD 3 & Fail & Fail & Pail & Pass & Pass \\
\hline 5 & ULSD 4 & Fail & Fail & Pass & Pass & Pass \\
\hline 6 & ULSD 5 & Fail & Fail & Pass & Pass \\
\hline 7 & ULSD 6 & Pass & Pass & Pass & Pass \\
\hline 8 & B20 6 & Pass & Pass & Fail & Pass \\
\hline 9 & B20 4 & Pass & Pass & Pass & Pass \\
\hline 10 & B10 1 & Pass & Pass & Fail & Pass \\
\hline 11 & B10 2 & Pass & Pass & Pass & Pass & Pass \\
\hline 12 & B10 3 & Pass & Pass & Pass & Pail \\
\hline 13 & ULSD 1 & Fail & Pass & Pass & Pass & Pass \\
\hline 14 & ULSD 8 & Fail & Pass & Pass & Pass \\
\hline 15 & ULSD 9 & Fail & Pass & Fail & Pass & Pass \\
\hline 16 & B10 4 & Pass & Pass & Pass & Pass \\
\hline 17 & ULSD 7R & Pass & Pass & Fail & Pass \\
\hline 18 & ULSD 2R & Pass & Pass & Pass & & Fail \\
\hline 19 & ULSD 10 & Pass & & & Pass \\
\hline
\end{tabular}

The variables included in Table 4.1 are:

- Air Flow: Pass condition given if there are no significant errors in air flow rate into the engine at constant engine operating conditions. Fail conditions were the result of DAQ system error related to pressure transducer measurements for Stage 1 loading. The steady state exhaust flow rate was corrected for Stage 1 and other test phases in order for the experimental data to be suitable for modeling.

- CPF Pressure Drop: Pass condition given if there are no significant fluctuations in the CPF pressure drop between test phases. Fail conditions could be the result of a sticking bypass line exhaust valve, or DAQ system error related to pressure transducer measurements for any specific test phase. Pass condition exists if CalTerm pressure drop can be used to correct the DAQ system pressure drop. All runs were corrected with the exception of Run 12.

- S2 PM Oxidation: Pass condition given if the S2 loading phase PM oxidation is within $21 \pm 9 \%$ of the total PM entering the CPF. Fail conditions are most likely the result of inaccurate PM concentration. Further analysis of the data that affects the the 1D model was carried out and can be seen in Appendix $\mathrm{H}$.

- AR PM Oxidation: Pass condition given if the PM oxidation during active regeneration does not exceed $80 \%$ of the total PM mass available for oxidation at the start of active regeneration. Greater than $80 \%$ PM oxidation leaves the opportunity for CPF weighing errors due to the small amount of PM within the CPF at the time of weighing for higher levels of PM oxidation. 
The tests which failed the air flow criterion were the tests which showed a significant change in experimental flow rate between steady state phases at the same engine operating condition, such as test B20-5, where the air flow rate between Stage 1 and Stage 2 loading was measured 12.7 and $13.2 \mathrm{~kg} / \mathrm{min}$, respectively. The flow rate data were corrected based on the analysis in Appendix $\mathrm{H}$. With the corrections implemented, the data can be used for calibration of the MTU-1D CPF model, represented by the color yellow in the 'Air Flow' column of Table 4.1.

Failure of the pressure drop criterion was a result of visible variation in the pressure drop between test phases, such as test B20-5 where the pressure drop at the loading ramp started nearly $1.5 \mathrm{kPa}$ lower than the ending of Stage 2 and suddenly increases midway through. This is characteristic of the exhaust bypass valve sticking open and fully closing during the test, resulting in failure of the pressure drop criterion. The yellow cells marked 'Fail' in the 'CPF Pressure Drop' column of Table 4.1 represent the test cases which experienced a leaking exhaust bypass valve. With the air flow rate corrections implemented, this pressure drop data can be used for calibration of the MTU-1D CPF model, represented by the color yellow.

Test B10-3 was the only test which did not require any Stage 1 CPF pressure drop offset corrections due to DAQ system error with pressure transducer measurements. These data were corrected based on the analysis described in Appendix $\mathrm{H}$ and are the yellow cells marked 'Pass' in the 'CPF Pressure Drop' column of Table 4.1.

Failure of the S2 oxidation resulted if the measured PM oxidation during those phases was not between $21 \pm 9 \% .21 \pm 9 \%$ was the expected amount of PM oxidation to occur during loading phases, with variations likely due to PM concentration measurement errors. As detailed in Appendix $\mathrm{H}$, the PM concentration data is the most likely source of error associated with the S2 PM oxidation data.

PM oxidation during active regeneration above $80 \%$ can potentially result in CPF weighing errors due to the low levels of PM within the CPF at the time of weighing. Failures are shown by the color red in Table 4.1. The AR PM oxidation during test B20-5 approached 88\%; while this is above the $70 \%$ target, the CPF mass measurements are believed to be accurate and as such, the test data can be used for calibration of the MTU-1D CPF model. 
Overall failure resulted if any given test failed more than the air flow or CPF pressure drop criterion alone, because the air flow can be corrected, as stated previously. For all four test cases in the 'CPF Pressure Drop' column of Table 4.1, the exhaust bypass valve was leaking. The flow rate corrections allow for this pressure drop data to be used for model calibration.

In total, the experimental data from eight tests can be said to be well suited for modeling, where they are shown by the green cells in the 'Overall' column of Table 4.1.

The CPF resistance was calculated for each test case, as described in the CPF Resistance Calculation Method section of Chapter 3 (section 3.10), where the CPF mass flow rate scaling factors (SF), the CPF pressure drop offset corrections, and the correction factor (CF) for active regeneration phases are shown in Tables H3-H5. The un-corrected and corrected experimental data related to CPF resistance for each test case is also shown at the end of Appendix $\mathrm{H}$. The correction methods to be applied to the input data for the MTU-1D CPF model are also given at the end of Appendix $\mathrm{H}$.

The tests which can be used for calibration of the MTU-1D CPF model following the data corrections previously mentioned are shown by the yellow cells in the 'Overall' column of Table 4.1. With the data corrections implemented when necessary, a total of fourteen tests can be used for calibration of the CPF model.

In terms of the active regeneration data analysis, the main variables which are analyzed are the gaseous emissions, CPF pressure drop profile, CPF temperature, CPF mass measurements, active regeneration time, and engine-out PM concentration. 
The variables selected for Table 4.2 are the dosing method used during each test, active regeneration time, pre-active regeneration ramp times, DOC inlet temperature, CPF inlet temperature, average CPF temperature, exhaust mass flow rate, estimated dosing flow rate, estimated engine-out $\mathrm{HC}$ concentration, engine-out PM concentration, PM mass available for oxidation, and percent of the PM oxidized during active regeneration (which includes the retained PM within the CPF as well as the engine-out PM emitted during the active regeneration process).

\subsection{Active Regeneration}

The active regeneration of the CPF is the area of interest in this study. The Active Regeneration phase of the experiment is initiated after the CPF loading of 2.200 .2 (or $4.1 \mathrm{0} 0.2$ in two test cases) $\mathrm{g} / \mathrm{L}$ has been verified at the conclusion of Stage 2 loading. For the testing performed in this study, a range of CPF inlet temperatures from 475 to $600^{\circ} \mathrm{C}$ using in-cylinder and exhaust dosing methods with ULSD, B10, and B20 were selected for the test matrix to determine which factors affect the PM oxidation within the CPF during active regeneration.

A summary of the most important variables from the active regeneration testing are given in Table 4.2, with the complete mass balances for all phases for each test in Appendix $\mathrm{K}$. 


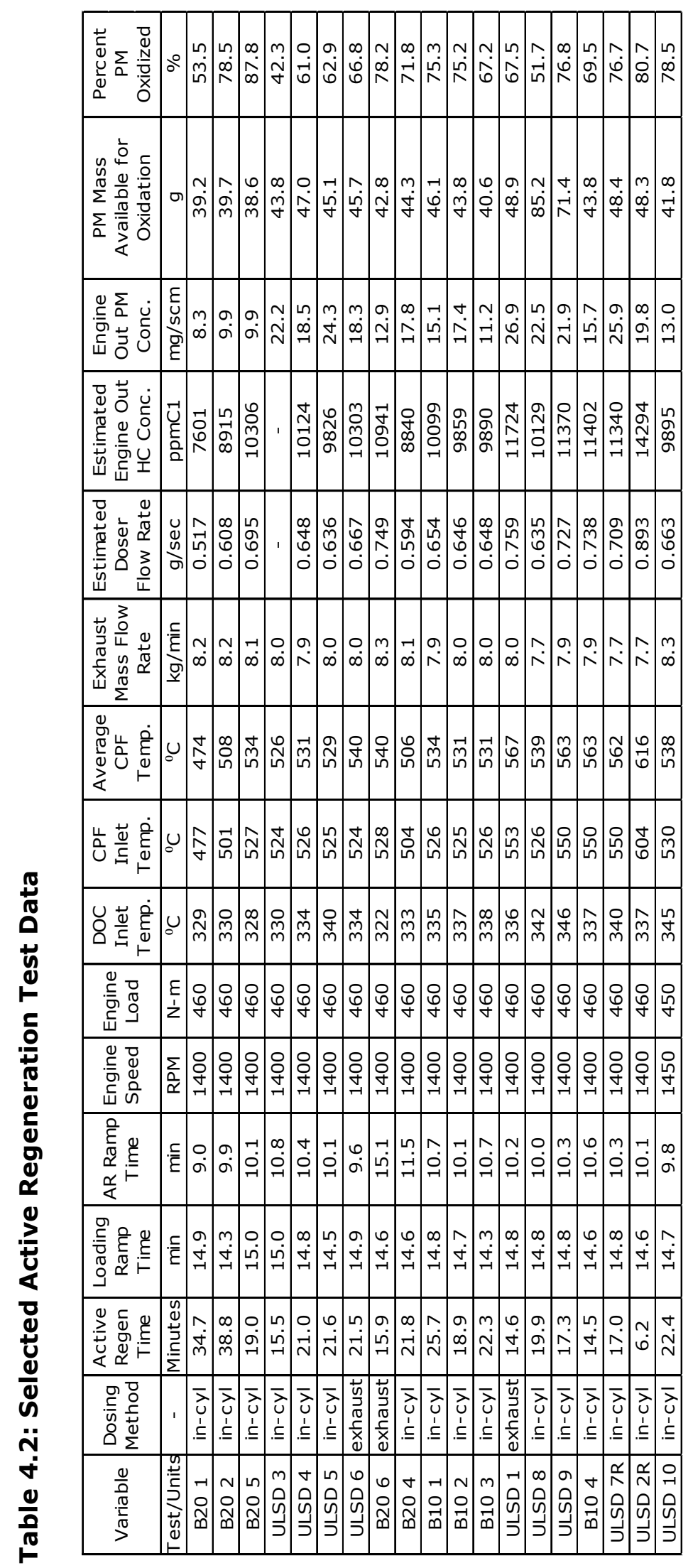


DOC inlet temperature was a direct measurement from the exhaust pipe located at the DOC inlet cone. Since this is not part of the DOC thermocouple layout (not located in any part of the DOC), it is excluded from Figure 3.2. Each experimentally measured and reported DOC inlet temperature is the result of the average over time of the points during the active regeneration portion of the test, since each temperature is calculated at every time step throughout the experiment during post processing of experimental data.

CPF inlet temperature was defined as the average of D7, D8, and D9 thermocouples, the locations of which can be seen in Figure 3.2.

Average CPF temperature was defined as the weighted average of all thermocouples located in the CPF in Figure 3.3 except the axial set of thermocouples located at the radial edge of the CPF. Thermocouples C1-C3, C5-C7, C9-C11, and C13-C15 carry weighing factors of $0.303,0.287,0.197$, and 0.213 respectively, due to their axial placement in the CPF substrate. These weighting factors were determined using the methodology described in the Temperature Measurements section of Chapter 3. The locations of these thermocouples was determined based on the method from references $[1,6]$, in order to allow for the determination of volume averaged CPF temperatures for each experiment.

The engine-out exhaust mass flow rate was calculated using the pressure drop across the laminar flow element (LFE) giving the air flow rate and the fuel flow rate consumed by the engine was calculated using an AVL fuel system. The exhaust mass flow rate is calculated at each time step throughout the experiment and is the result of the summation between the air and fuel mass flow rates. The reported exhaust mass flow rate is the average of all the calculated flow rates throughout each phase of the experiment.

The doser flow rate and engine out HC concentrations represented are the estimated values resulting from a DOC energy balance. There was significant variation in the experimentally determined doser flow rate, and subsequent engine out $\mathrm{HC}$ concentrations. A comparison of the experimental vs. estimated doser flow rates can be found in Appendix L. The DOC energy balance was carried out using the methods described in reference [17] in order to estimate the upstream DOC HC concentrations and doser flow rate. The energy balance used the experimentally 
measured downstream DOC HC concentrations and the measured temperature rise across the DOC to estimate the amount of $\mathrm{HC}$ required at the DOC inlet to produce the observed temperature change. The estimated DOC inlet HC concentrations were then converted back to dosing flow rate in the same manner that is used to calculate upstream DOC hydrocarbon concentrations from the experimental dosing rate (Eqn. 21). The data for estimated doser flow rate is missing for test ULSD-3 because the emissions bench was not operational during this test, which resulted in missing DDOC HC data to be used in the energy balance.

The percent PM oxidized (70\% target for all tests) is the calculated amount of PM that was oxidized during the Active Regeneration phase. The total amount of PM available for oxidation is defined as the PM mass within the CPF at the start of active regeneration in addition to the engine-out PM that flows into the CPF during the Active Regeneration phase. The total PM oxidized is calculated based on the CPF mass measurement following Stage 3 loading. Subtracting the estimated PM mass addition during Stage 3 loading from the PM within the CPF at the end of Stage 3 yields the PM mass remaining after active regeneration. Subtracting the mass of PM at the end of active regeneration from the total PM at the start of active regeneration yields the amount of PM mass oxidized during active regeneration. The percent PM oxidized is the percent of the total PM mass available for oxidation that was actually oxidized during the Active Regeneration phase calculated using $\left(\frac{P M \text { Oxidized during AR }}{\text { Total PM Available for Oxidation }}\right) \cdot 100$.

In Table 4.2, there are a few items from the experimental results that need to be explained.

Differences in PM concentrations between tests at the same experimental conditions were noticed. For example, the engine-out PM concentration during active regeneration for test $\mathrm{B} 10-2$ was $15 \%$ higher than test $\mathrm{B} 10-1$. Since the absolute humidity was 0.008 and $0.009 \mathrm{~kg}_{\text {water }} / \mathrm{kg}_{\text {air }}$ during test B10-2 and B10-1, respectively test cell humidity is not believed to be the cause of these differences.

PM concentrations were also affected by the percent biodiesel in the test fuel, which can be seen in Figure 4.1. In Figure 4.1, the average engine-out PM concentrations measured during the pre-test phase are displayed with error bars representing one standard deviation between all of the PM samples collected during the experiment. 
The data is displayed in the order of completion of the tests to see the trends in PM concentration throughout the testing period. The PM concentrations were shown to decrease with increasing concentrations of biodiesel in the test fuel as well as fluctuate due to test cell conditions.

In Figure 4.1, the larger error bars are associated with tests, i.e., Tests 15, 17 and 18 , in which individual PM samples may have been damaged during the sampling or weighing processes. These damaged filters introduce error into the filter mass measurements resulting in increased standard deviation of engine-out PM concentration. The damaged filters were subsequently removed from the calculated average engine-out PM concentration reported in the data.

Differences between in-cylinder and exhaust dosing methods regardless of fuel can be seen in the elevated average CPF temperatures during active regeneration. Tests B20-6 and ULSD-6, both of which used exhaust dosing, resulted in an average CPF temperature of $540^{\circ} \mathrm{C}$. The comparable B20 (B20-5) and ULSD (ULSD-3, 4, and 5) tests using in-cylinder dosing resulted in an average CPF temperature of 534 and $529^{\circ} \mathrm{C}$, respectively, resulting in an average CPF temperature increase of $6^{\circ} \mathrm{C}$ and $11^{\circ} \mathrm{C}$, respectively, when using exhaust dosing.

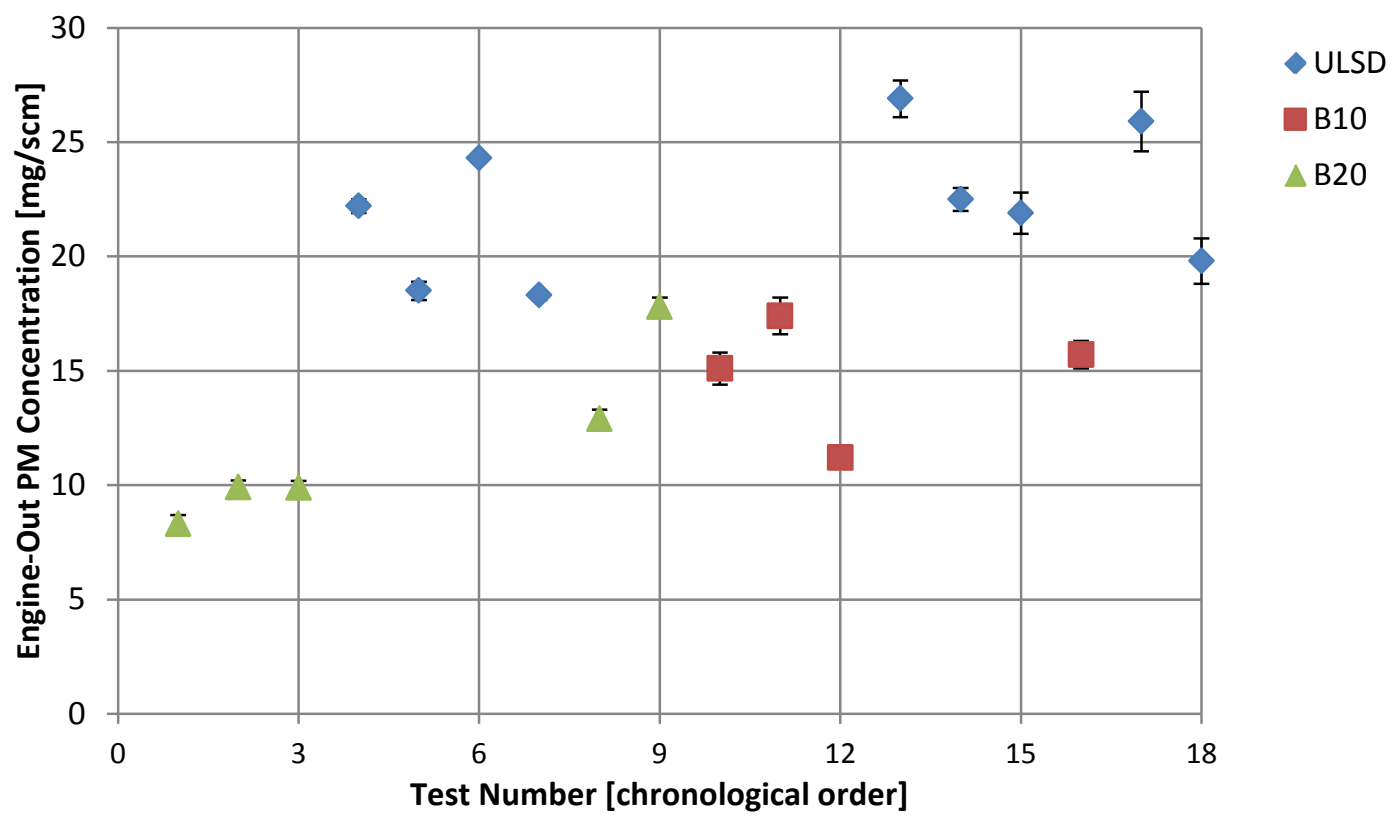

Figure 4.1: Pre-test Phase for Active Regeneration Average Engine-Out PM Concentrations in Chronological Order 


\subsubsection{Gaseous Emissions}

Complete gaseous emissions summaries for all active regeneration experiments can be found in Appendix M. During active regeneration, gaseous emissions are measured DDOC and DCPF only due to the increased HC concentration found UDOC during fuel dosing, regardless of dosing method. The increased $\mathrm{HC}$ concentrations found UDOC are out of the range of the gaseous emissions analyzer and could damage it, so the UDOC HC concentrations were calculated using the estimated dosing flow rate and exhaust flow rate with Eqn. 21.

$$
Y_{U D O C}=\frac{\frac{\dot{m}_{f}}{M W_{f}}}{\frac{\dot{m}_{f}}{M W_{f}}+\frac{\dot{m}_{\text {exh }}}{M W_{\text {exh }}}} \cdot e^{6}
$$

$\mathrm{Y}_{\mathrm{UDOC}}=\mathrm{UDOC} \mathrm{HC}$ concentration $[\mathrm{ppm} \mathrm{C}]$

$\dot{\mathrm{m}}_{\mathrm{f}}=$ Estimated dosing flow rate $[\mathrm{g} / \mathrm{sec}]$

$\dot{\mathrm{m}}_{\text {exh }}=$ Exhaust flow rate $[\mathrm{g} / \mathrm{sec}]$

$\mathrm{MW}_{\mathrm{f}}=$ Molecular weight of fuel $[\mathrm{g} / \mathrm{gmol}]$

$\mathrm{MW}_{\text {exh }}=$ Molecular weight of exhaust $=28.5$ (reference $\left.[15]\right)[\mathrm{g} / \mathrm{gmol}]$

The molecular weight for the B10 and B20 biodiesel blends were calculated based on fuel analysis data from tests performed on ULSD and B100. The molecular weights for ULSD, B10, and B20 were determined to be 166, 168, and $170 \mathrm{~g} / \mathrm{gmol}$, respectively, on a $\mathrm{C}_{12}$ basis. The computation methodology used to determine the molecular weights can be found in Appendix A.

Eqn. 21 is valid assuming all the dosing fuel was vaporized in the exhaust stream [15]. The other UDOC gaseous emissions were collected and are assumed unchanged from the pre-test phase of each experiment.

Since DDOC HC measurements are taken first during active regeneration, coupled with the length of the active regeneration times, DCPF HC measurements during active regeneration were influenced by $\mathrm{HC}$ absorption in the line to the FID when switching sampling locations of high $\mathrm{HC}$ concentration to low $\mathrm{HC}$ concentration. Figure 4.2 illustrates this graphically, which can be seen since the measured HC concentration never reaches a steady state value during the sample time. The HC concentration shown in Figure 4.2 is the DCPF HC measurement following 6 minutes of sampling $\mathrm{HC}$ in the DDOC location during active regeneration. 
The data for Figure 4.2 comes from test ULSD-3, but the same trend was present for all fuels. For this reason, the DCPF hydrocarbon concentration found during the active regeneration engine condition validation test was used in calculating CPF hydrocarbon conversion efficiencies. The point validation test was conducted with ULSD before the start of active regeneration testing, in order to map the DOC and $\mathrm{CPF}$ inlet temperatures for in-cylinder and exhaust dosing methods across the entire CPF inlet temperature range seen in Table 3.8, the experimental test matrix. Gaseous emissions were collected at all three sampling locations during the entire test, allowing enough time for the values to stabilize. Table 4.3 shows the results of the in-cylinder, $600^{\circ} \mathrm{C} \mathrm{CPF}$ inlet temperature case from the point validation test, which is where the DCPF HC concentration used for conversion efficiency calculations was derived from. The DCPF HC concentration was assumed to remain unchanged across all fuel types for $\mathrm{HC}$ conversion efficiency calculations.

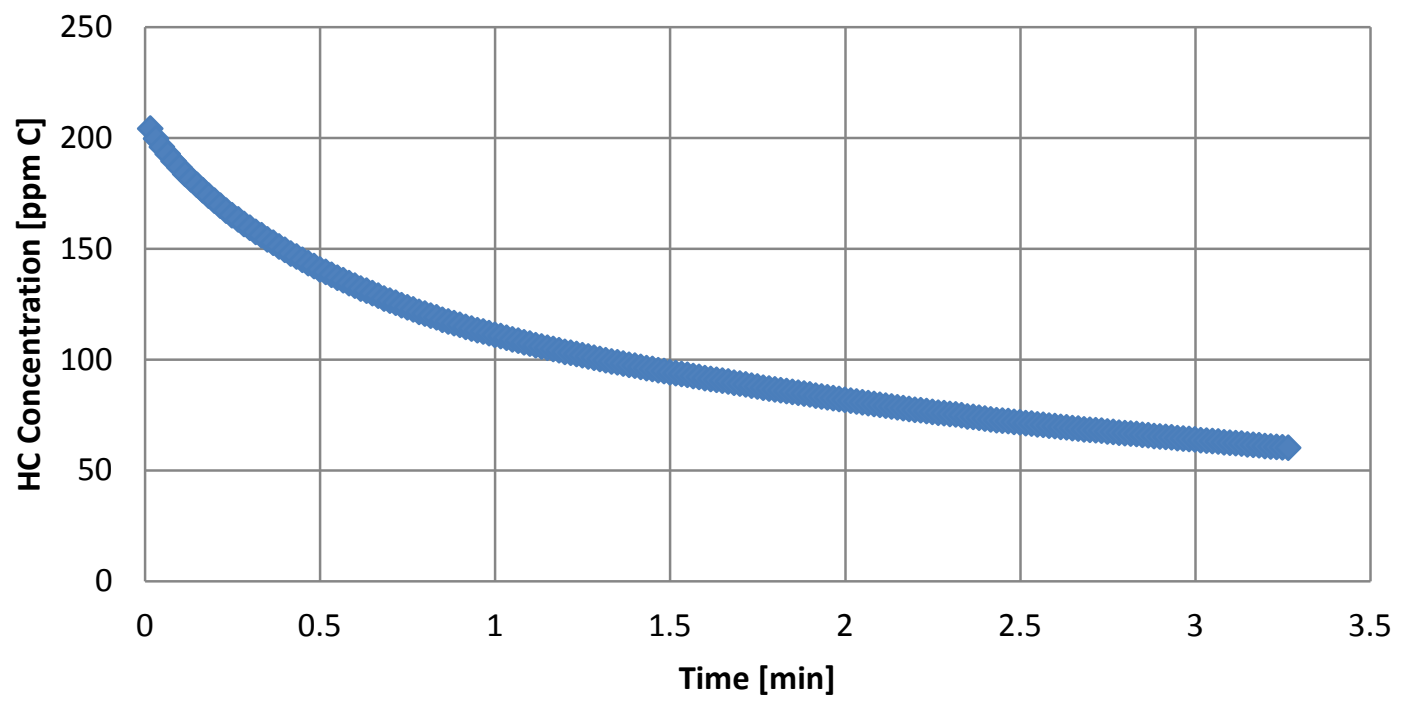

Figure 4.2: ULSD-3 DCPF HC Measurement during Active Regeneration (Incylinder Dosing Case) 
Table 4.3: HC Measurements Recorded during Active Regeneration Point Validation

\begin{tabular}{|c|c|c|c|c|c|}
\hline $\begin{array}{c}\text { DOC Inlet } \\
\text { Temp }\end{array}$ & $\begin{array}{c}\text { CPF Inlet } \\
\text { Temp }\end{array}$ & $\begin{array}{c}\text { CPF } \\
\text { Outlet } \\
\text { Temp }\end{array}$ & $\begin{array}{c}\text { UDOC HC } \\
\text { Conc. }\end{array}$ & $\begin{array}{c}\text { DDOC HC } \\
\text { Conc. }\end{array}$ & $\begin{array}{c}\text { DCPF HC } \\
\text { Conc. }\end{array}$ \\
\hline${ }^{\circ} \mathrm{C}$ & ${ }^{\circ} \mathrm{C}$ & ${ }^{\circ} \mathrm{C}$ & $\mathrm{ppm} \mathrm{C}$ & $\mathrm{ppm} \mathrm{C}$ & $\mathrm{ppm} \mathrm{C}$ \\
\hline 329 & 603 & 609 & 20829 & 512 & 4 \\
\hline
\end{tabular}

Table 4.4 shows the $\mathrm{HC}, \mathrm{CO}$, and $\mathrm{NO}_{2}$ conversion efficiencies across the DOC and CPF during active regeneration for all experiments. $A^{\prime}{ }^{\prime \prime}$ ' next to the test name indicates a test which used the exhaust dosing method.

The lowest and highest DOC HC conversion efficiencies measured were $94 \%$ and $98 \%$, respectively, while the CPF HC conversion efficiency remained between 98 and $99 \%$ for all experiments. The lowest and highest DOC CO conversion efficiencies measured were $53 \%$ and $96 \%$, respectively In general, it has been shown that the $\mathrm{CO}$ conversion efficiency decreases with increasing CPF inlet temperature due to the chemical reactions occurring within the DOC to oxidize the excess $\mathrm{HC}$. The negative $\mathrm{NO}_{2}$ conversion across the $\mathrm{DOC}$ indicates that $\mathrm{NO}_{2}$ is being consumed across the DOC, while the positive $\mathrm{NO}_{2}$ conversion across the CPF indicates that $\mathrm{NO}_{2}$ is being produced across the CPF, which was observed during all experiments regardless of fuel type. This is the opposite of the trends found in Chilumukuru [15] where $\mathrm{NO}_{2}$ concentrations across the DOC increased, but decreased across the CPF, indicating net $\mathrm{NO}_{2}$ consumption in the CPF for PM oxidation. 
Table 4.4: $\mathrm{HC}, \mathrm{CO}$, and $\mathrm{NO}_{2}$ Conversion Efficiencies for All Tests

\begin{tabular}{|c|c|c|c|c|c|c|}
\hline \multirow{2}{*}{ Test } & \multicolumn{2}{|c|}{$\begin{array}{c}\text { HC Conversion } \\
\text { Efficiency [\%] }\end{array}$} & \multicolumn{2}{c|}{$\begin{array}{c}\text { CO Conversion } \\
\text { Efficiency }[\%]\end{array}$} & \multicolumn{2}{c|}{$\begin{array}{c}\text { NO2 Conversion } \\
\text { Efficiency [\%] }\end{array}$} \\
\hline Location & DOC & CPF & DOC & CPF & DOC & CPF \\
\hline B20 1 & 96 & 98 & 91 & 100 & -4 & 26 \\
\hline B20 2 & 96 & 99 & 70 & 100 & -14 & 26 \\
\hline B20 5 & 97 & 99 & 72 & 100 & -14 & 18 \\
\hline ULSD 3 & - & - & 96 & 100 & -10 & 22 \\
\hline ULSD 4 & 98 & 99 & 91 & 100 & -17 & 21 \\
\hline ULSD 5 & 97 & 99 & 89 & 100 & -10 & 22 \\
\hline ULSD 6* & 95 & 99 & 87 & 100 & -9 & 22 \\
\hline B20 6* & 94 & 99 & 77 & 100 & -17 & 16 \\
\hline B20 4 & 97 & 99 & 83 & 100 & -12 & 32 \\
\hline B10 1 & 96 & 99 & 83 & 100 & -12 & 22 \\
\hline B10 2 & 98 & 99 & 83 & 100 & -21 & 22 \\
\hline B10 3 & 97 & 99 & 85 & 100 & -20 & 15 \\
\hline ULSD 1* & 95 & 99 & 83 & 100 & -16 & 11 \\
\hline ULSD 8 & 94 & 99 & 72 & 100 & -9 & 14 \\
\hline ULSD 9 & 94 & 100 & 69 & 100 & -19 & 9 \\
\hline B10 4 & 96 & 99 & 72 & 100 & -17 & 10 \\
\hline ULSD 7R & 96 & 99 & 66 & 100 & -6 & 11 \\
\hline ULSD 2R & 97 & 99 & 53 & 100 & -4 & 9 \\
\hline ULSD 10 & 97 & 99 & 77 & 100 & -107 & 25 \\
\hline
\end{tabular}

* Indicates post-turbo dosing test case

Gaseous emission data during active regeneration from Austin [1] for the ISM engine indicates that some tests resulted in net $\mathrm{NO}_{2}$ consumption across the CPF while others resulted in $\mathrm{NO}_{2}$ production, with the same test fuel.

Due to $\mathrm{NO}_{2}$ production across the CPF for experiments run on the ISL, $\mathrm{NO}_{2}$ is not believed to be a significant aid for PM oxidation within the CPF at the engine condition selected. $\mathrm{NO}_{2}$ based oxidation can occur at other engine conditions, which is the main focus in the study by Shiel [11].

HC measurements were unavailable during ULSD-3 due to the flame ionization detector (FID) in the gaseous emissions analyzer experiencing a failure which required repair by $A V L$. 


\subsubsection{CPF Pressure Drop Profile}

During active regeneration, the pressure drop across the CPF increases upon the start of fuel dosing due to the increase in the temperature of the exhaust, which increases the exhaust actual volumetric flow rate. The actual exhaust volumetric flow rate is given in Eqn. 22 with the equation for calculating density as a function of pressure and temperature in Eqn. 23.

$$
\dot{V}=\frac{\dot{m}}{\rho}
$$

$\dot{V}=$ Actual volumetric flow rate

$\dot{\mathrm{m}}=$ Mass Flow Rate $[\mathrm{kg} / \mathrm{min}]$

$\rho=$ Density $\left[\mathrm{kg} / \mathrm{m}^{3}\right]$

$$
\rho=\frac{P}{R \cdot T}
$$

$\mathrm{R}=$ Universal gas constant, 8.315E-03 $[\mathrm{J} /(\mathrm{gmol} \cdot \mathrm{K})]$

$\mathrm{T}=\mathrm{CPF}$ weighted avg. temperature $[\mathrm{K}]$

As the active regeneration progresses, PM in the cake and the wall oxidizes, and the pressure drop across the CPF decreases. If the regeneration were allowed to continue for an extended period of time, the pressure drop would asymptotically approach a constant value as the balance point (PM within the CPF is oxidized at the same rate that it is deposited from the engine) is reached.

The pressure drop profile for $525^{\circ} \mathrm{C}$ CPF inlet temperature runs using ULSD, B10, and B20 with in-cylinder dosing are shown in Figure 4.3. The active regeneration phase during ULSD-4, B10-1, and B20-5 resulted in total PM oxidation of $63 \%, 77 \%$, and $88 \%$, respectively, as shown in Table 4.5 .

In this plot, B10-1 had the longest regeneration, followed by ULSD-4 and B20-5. The amount of time that fuel dosing was activated, and subsequently the active regeneration time, is not an accurate representation of the oxidation rate of PM within the CPF because different amounts of PM were oxidized between all three tests. 
Table 4.5: Data from Tests Run for Figure 4.3

\begin{tabular}{|c|c|c|c|c|c|}
\hline \multirow{2}{*}{ Test/Units } & AR Time & $\begin{array}{c}\text { Average CPF } \\
\text { Inlet Temp. }\end{array}$ & $\begin{array}{c}\text { Estimated Doser } \\
\text { Flow Rate }\end{array}$ & $\begin{array}{c}\text { CPF Loading } \\
\text { Prior to AR }\end{array}$ & $\begin{array}{c}\text { Percent PM } \\
\text { Oxidized }\end{array}$ \\
\cline { 2 - 6 } & $\min$ & ${ }^{\circ} \mathrm{C}$ & $\mathrm{g} / \mathrm{sec}$ & $\mathrm{g} / \mathrm{L}$ & $\%$ \\
\hline ULSD 4 & 21.0 & 520 & 0.648 & 2.6 & 63 \\
\hline B10 1 & 25.7 & 521 & 0.654 & 2.5 & 77 \\
\hline B20 5 & 19.0 & 523 & 0.695 & 2.2 & 88 \\
\hline
\end{tabular}

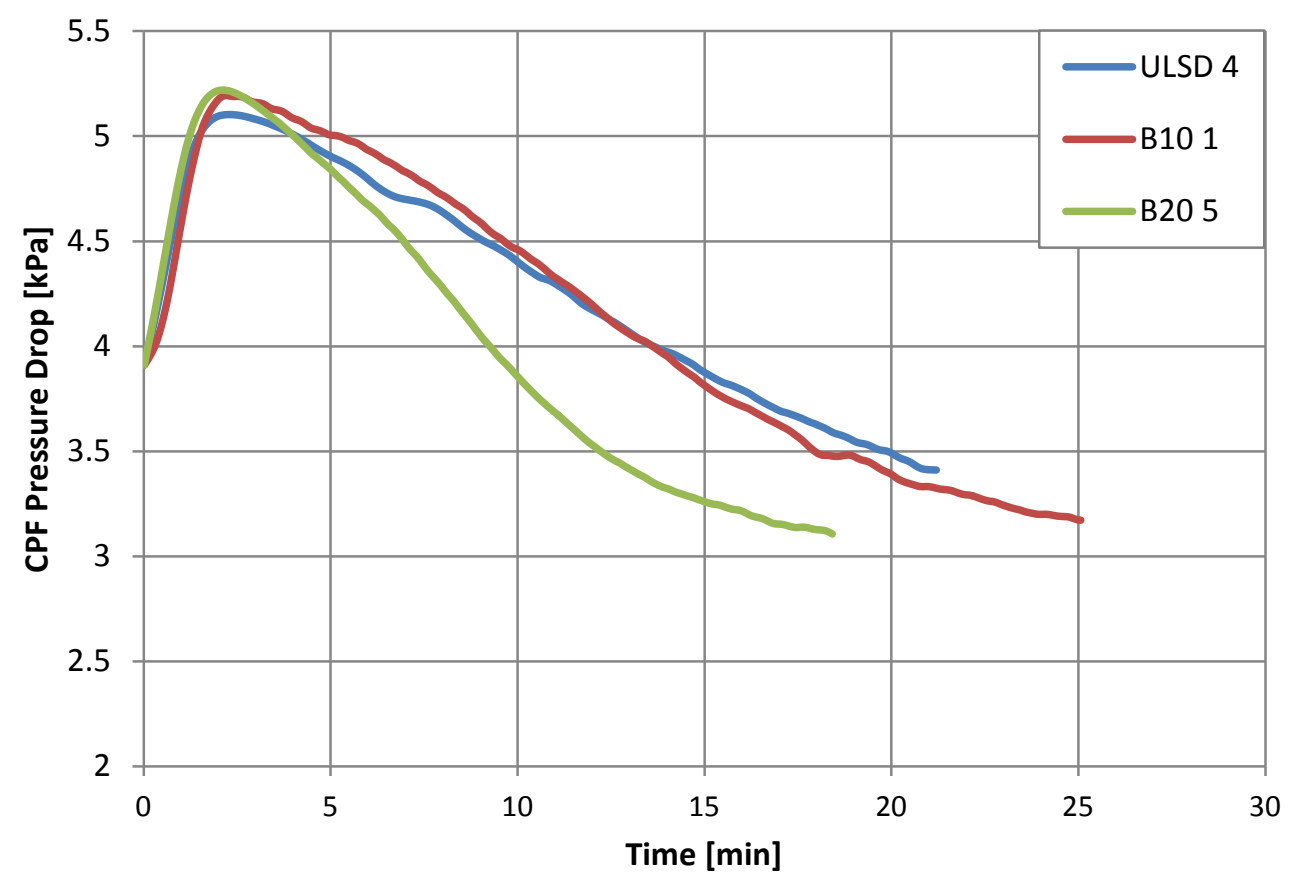

Figure 4.3: Comparison of CPF Pressure Drop for ULSD-4, B10-1, and B20-5, all at Nominal $525^{\circ} \mathrm{C}$ CPF Inlet Temperature using In-Cylinder Dosing

For tests at the same CPF inlet temperature, prior to the balance point of the CPF, the slope of the pressure drop profile across the CPF is representative of the PM oxidation rate in the wall and cake within the CPF. The balance point of the CPF is defined as the time during active where the CPF pressure drop does not fluctuate and appears as a horizontal time when displayed over time. Keeping this in mind, it can be seen in Figure 4.3 that B20 has the highest PM oxidation rate, followed by B10 and ULSD because the slope of the pressure drop profiles are steepest with B20, followed by B10 and ULSD. The wall pressure drop can have a significant effect on the overall pressure drop even though the mass of PM in the wall is significantly less 
than in the cake. Complete pressure drop profiles for all tests can be found in Appendix N.

It can be seen in Figure 4.3 that the peak pressure drop does not occur at the same point for all the tests. This could be due to a number of factors such as PM loading and amount of fuel being dosed during active regeneration, which can be found in Table 4.4. ULSD-4 had the highest PM loading with a dosing rate only slightly higher than that of $\mathrm{B} 10-1$, yet the peak pressure drop across the CPF occurred nearly 0.3 $\mathrm{kPa}$ lower than the two biodiesel tests. B20-5 had the lowest CPF PM loading with the highest fuel dosing rate while B10-1 had CPF PM loading $0.1 \mathrm{~g} / \mathrm{L}$ lower than ULSD-4, with the lowest fuel dosing rate, and the peak pressure drop for both tests occurred near $5.3 \mathrm{kPa}$.

Figure 4.4 shows tests completed with B20 and ULSD at the same CPF inlet temperature $\left(525^{\circ} \mathrm{C}\right)$ using in-cylinder and exhaust dosing methods. Blue lines indicate the ULSD tests, with the dashed line representing the exhaust dosing case. The same holds true for the B20 test cases, except the representative lines are orange.

The in-cylinder dosing tests in Figure 4.4 were B20-5 and ULSD-4 while B20-6 and ULSD- 6 were the post turbo dosing tests. In both post turbo dosing cases, the peak pressure drop is elevated from the in-cylinder dosing cases. The average CPF temperature was also elevated during these tests, which could account for the differences in the pressure drop peaks because increased temperature results in increased pressure drop due to increased actual exhaust volumetric flow rate. Figure 4.4 also re-iterates the fact that at a constant CPF inlet temperature, PM oxidation with B20 progresses at a significantly faster rate than with ULSD, as shown by the differences in the slope of the pressure drop profile. 


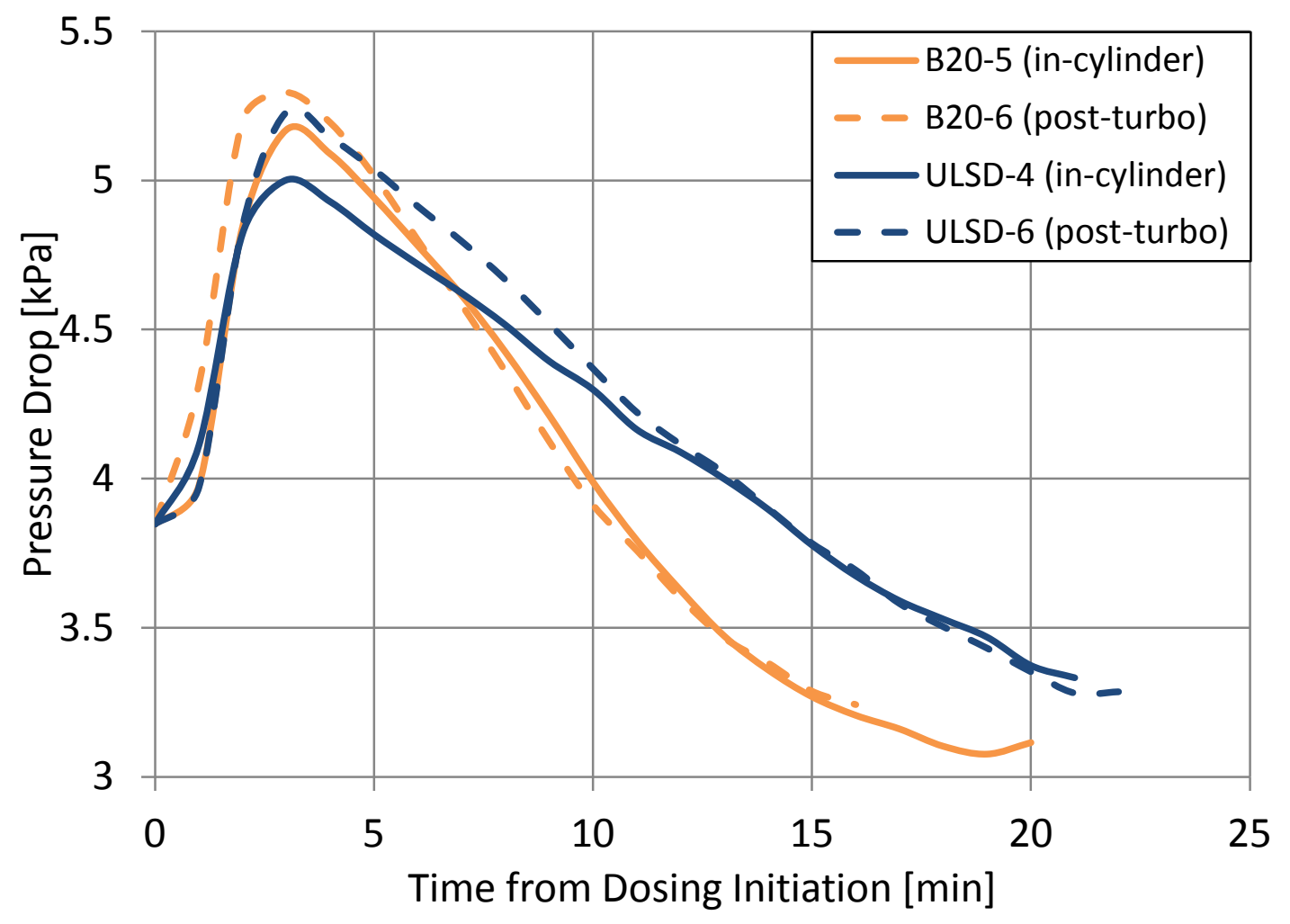

Figure 4.4: $525^{\circ} \mathrm{C}$ CPF Inlet Temperature B20 and ULSD Tests using Incylinder and Exhaust Dosing

\subsubsection{Particle Size Distribution}

Particle size distribution data were collected only DDOC and DCPF during the Active Regeneration phase due to the high levels of hydrocarbons UDIC during fuel dosing which could damage the SMPS system. DDOC and DCPF average particle size distribution data by number of particles, by fuel type can be seen in Figure 4.5. It is believed that a cracked fitting on the SMPS system occurred near the time that test B10-2 was performed, corresponding to run 11 of 19 , and as such, only the data collected before this test will be presented.

In Figure 4.5, it can be seen that the number of particles sampled in both locations is greatest with ULSD, followed by B10 and B20, which was expected based on the trends associated with decreasing particle count with increasing percent biodiesel in the test fuel as reported by Austin [1]. 


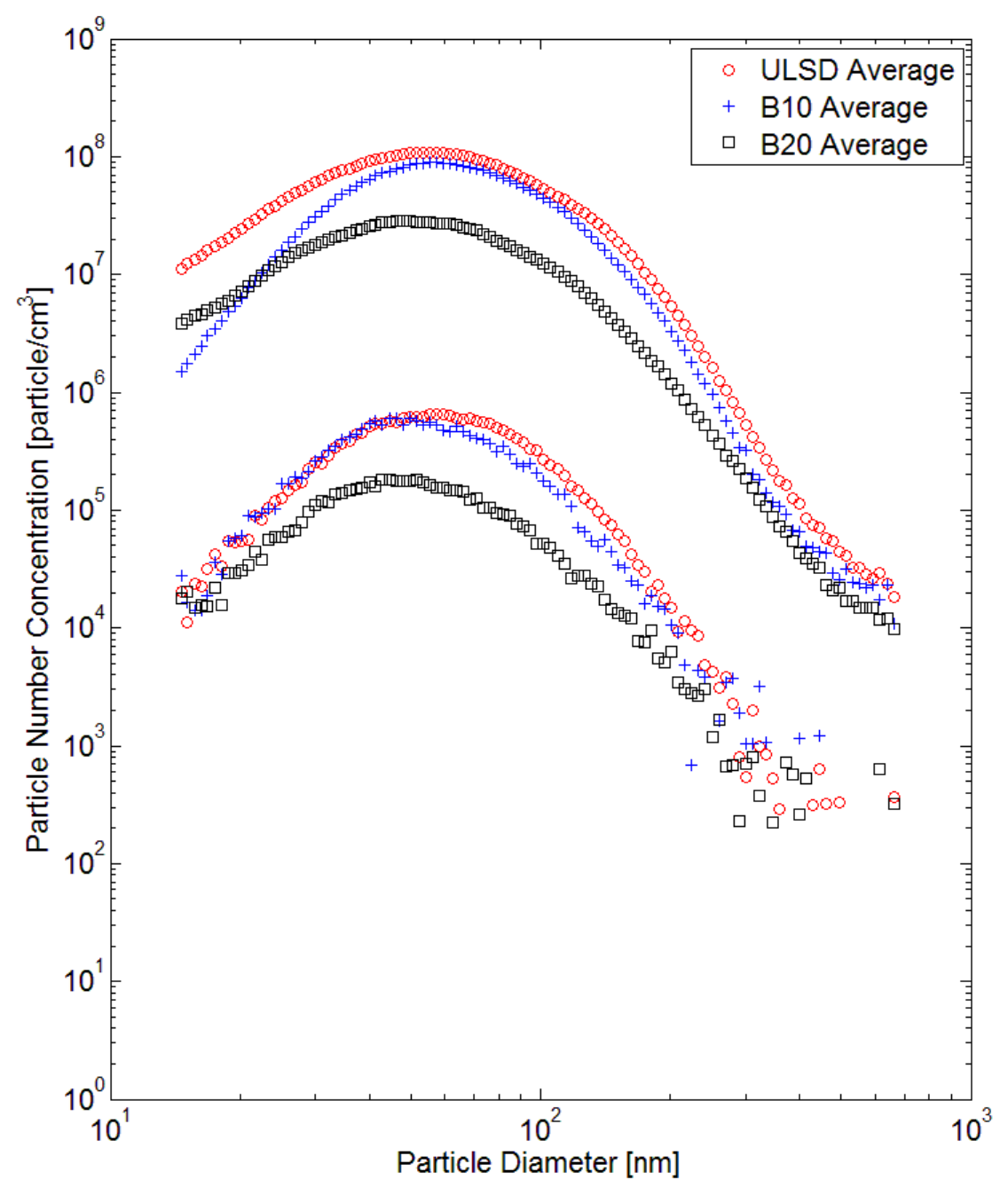

Figure 4.5: Averaged Particle Size Distribution by Particle Numbers by Fuel Type during Active Regeneration sampled DDOC and DCPF

\subsubsection{CPF Temperature Gradients}

The CPF thermocouple layout, as illustrated in Figure 3.3, is significantly different from the layout by Chilumukuru [15] and Austin [1] because it was not achievable due to physical limitations of the CPF. The modified layout incorporates 4 radial and 4 axial thermocouple placement positions and now includes an axial set of thermocouples located in the center of the CPF. Austin [1] and Chilumukuru [15] did not place any thermocouples in the center of the CPF. 
Figure 4.6 represents the radial temperature profiles during active regeneration for each axial set of thermocouples from test ULSD-4 $\left(2.2 \mathrm{~g} / \mathrm{L}\right.$ and $525^{\circ} \mathrm{C} \mathrm{CPF}$ inlet temperature targets, in-cylinder dosing). The temperatures measured by each thermocouple were averaged for the entire active regeneration portion of the experiment. Figure 4.6 represents the radial temperature gradient at each axial location that thermocouples are located (i.e., the $32 \mathrm{~mm}$ axial location consists of thermocouples C1, C2, C3, and C4 from Figure 3.3).

As seen in Figure 4.6, as the axial distance from the CPF inlet increases, the temperature measured by the thermocouples in those axial locations increases also. The increase in temperature in the axial direction, from the inlet of the CPF toward the outlet, is the result of hydrocarbon and PM oxidation within the CPF, with the hydrocarbon oxidation being the primary source of energy release according to reference [1]. As the radial distance from the CPF center increases, the temperatures measured by the thermocouples in those locations decreases, which was the same trend in all axial locations in the CPF. For the thermocouples located at 153 and 273 $\mathrm{mm}$ from the inlet face, the temperature gradient toward the outer edge of the CPF is greater than the other axial locations. The temperature at the CPF radius was estimated for each case using a $3^{\text {rd }}$ order polynomial fit of the data from all other thermocouple locations and is shown by the red vertical line in Figure 4.6.

The tests which were run with the post turbo dosing injector had elevated CPF temperatures when compared to tests run with in-cylinder dosing at the same test conditions. It can be seen in Table 4.6 that the ULSD and B20 cases had CPF inlet temperatures within $1^{\circ} \mathrm{C}$ and average CPF temperatures increased by 11 and $6^{\circ} \mathrm{C}$, respectively, for the exhaust dosing cases. This could have been caused by the increase in doser flow rate required for post-turbo regeneration to reach the same $\mathrm{CPF}$ inlet temperature, allowing more $\mathrm{HC}$ to reach the $\mathrm{CPF}$, thereby increasing the exotherm generated during active regeneration. Table 4.6 shows the average CPF temperature for ULSD and B20 in-cylinder dosing compared to post-turbo dosing test conditions. 


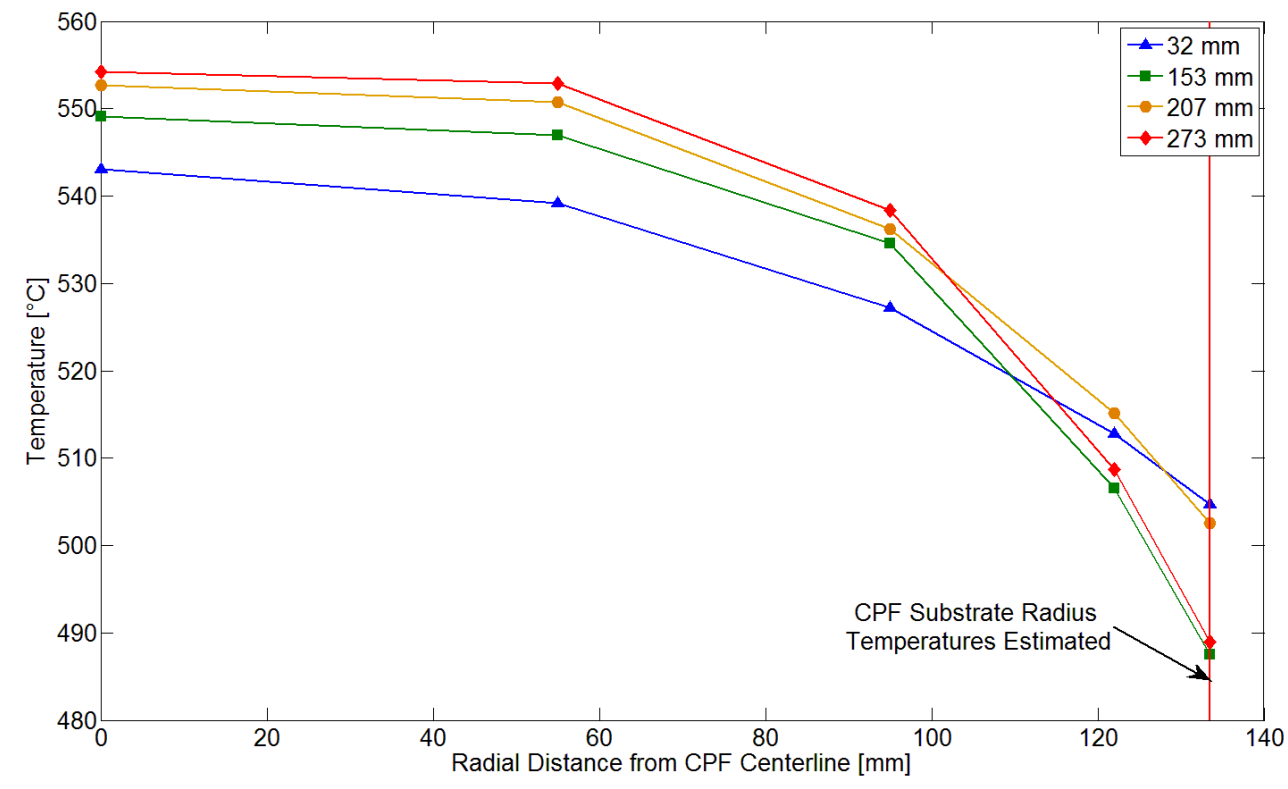

Figure 4.6: Radial Temperature Gradients at Four Axial Locations (Distance from CPF Inlet) during ULSD-4 Active Regeneration $\left(525^{\circ} \mathrm{C}\right.$ CPF Inlet Temperature Target, In-Cylinder Dosing) 
Table 4.6: Average CPF Temperature as a Function of Dosing Method for USLD and B20

\begin{tabular}{|c|c|c|}
\hline Variable & $\begin{array}{c}\text { CPF Inlet } \\
\text { Temp. } \\
{\left[{ }^{\circ} \mathrm{C}\right]}\end{array}$ & $\begin{array}{c}\text { Average } \\
\text { CPF Temp. } \\
{\left[{ }^{\circ} \mathrm{C}\right]}\end{array}$ \\
\hline ULSD in-cyl & 525 & 529 \\
\hline ULSD post-turbo & 524 & 540 \\
\hline B20 in-cyl & 527 & 534 \\
\hline B20 post-turbo & 528 & 540 \\
\hline
\end{tabular}

Figure 4.7 illustrates the axial temperature gradients within the CPF during active regeneration. The radial temperature measurements at each axial location were averaged (over the course of the entire active regeneration portion of each experiment) to show the effect of fuel and CPF temperature on the axial temperature gradient. All tests in Figure 4.7 were conducted using in-cylinder dosing.

As shown in Figure 4.7, the effect of fuel type on the axial temperature gradients are minimal, as the temperature gradient lines from tests ULSD-4, B10-1, and B20-5 all lay nearly on top of each other, and since each test had the same CPF inlet temperature target, it can be said that the effects of fuel type on the axial temperature gradients are negligible. As the CPF inlet temperature increases, the temperature change across the CPF also increases, which was expected, because higher $\mathrm{HC}$ concentrations required for elevated CPF inlet temperatures lead to higher temperatures in the axial direction from inlet to outlet. Regardless of test fuel type or $\mathrm{CPF}$ inlet temperature, the same average-radial temperature change from CPF inlet to outlet was observed at each axial location $\square 4^{\circ} \mathrm{C}$. 


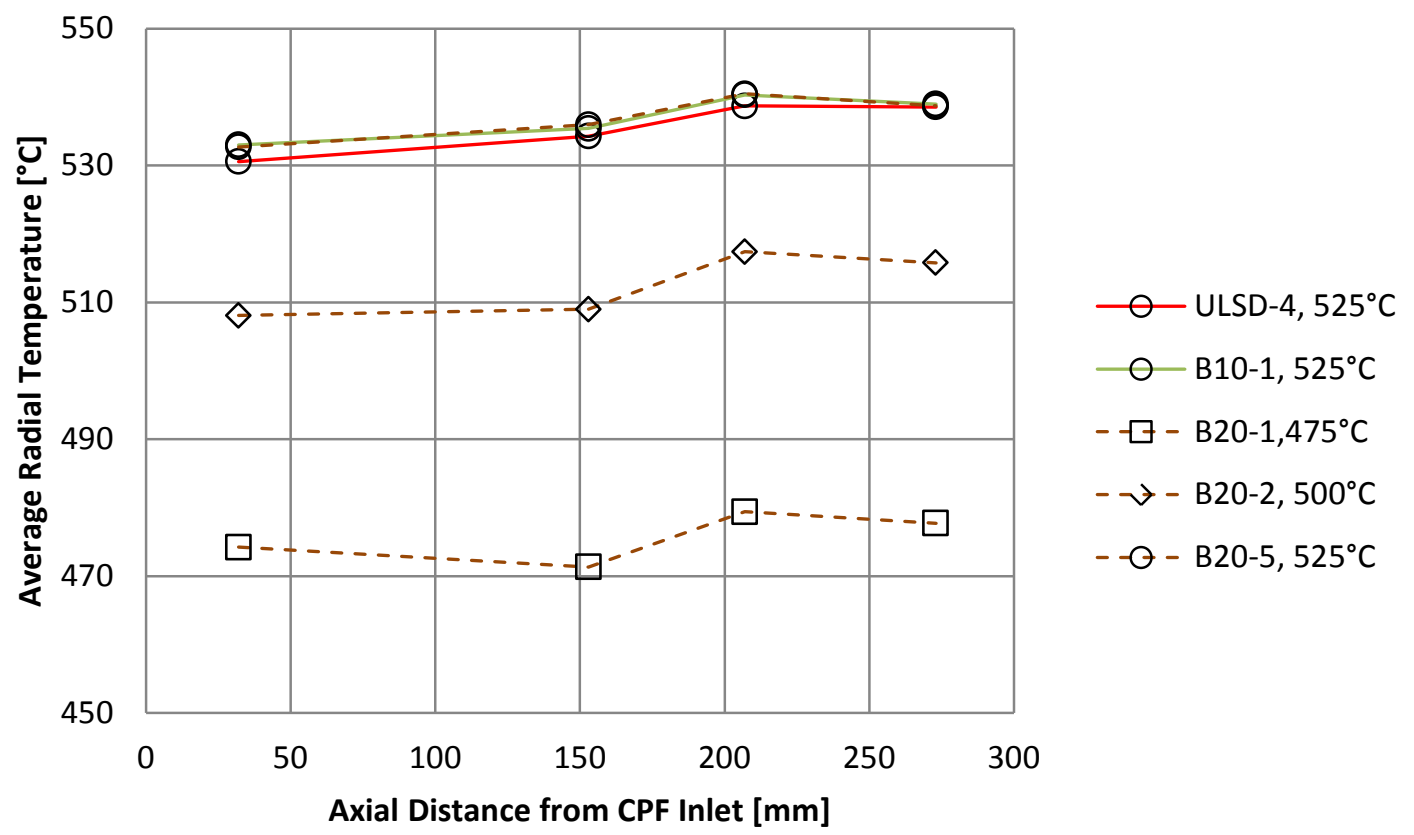

\section{Figure 4.7: Average-radial Axial Temperature Gradients during Active Regeneration with In-cylinder Dosing}

\subsubsection{PM Reaction Rate}

As described in Chapter 3, the PM reaction rate is calculated using a method that is different than what was used by Austin [1] and Chilumukuru [15] in order to account for varying CPF temperatures throughout active regeneration. The first step is using Eqn. 15 to solve for the pre-exponential by iteration until the PM mass within the CPF at the beginning and ending of active regeneration are matched within $\pm 0.1 \mathrm{~g}$. Table 4.7 is the result of this first step and shows the pre-exponential factors determined for each test case. 
Table 4.7: Calculated Pre-exponential Factors for all Tests

\begin{tabular}{|c|c|}
\hline Variable & $\begin{array}{c}\text { Pre-exponential } \\
\text { Factor } \cdot 10^{6}\end{array}$ \\
\hline Abbreviation & A \\
\hline Test/Units & $1 / \mathrm{sec}$ \\
\hline B20 1 & 5.08 \\
\hline B20 2 & 3.29 \\
\hline B20 5 & 4.62 \\
\hline ULSD 3 & 2.06 \\
\hline ULSD 4 & 2.04 \\
\hline ULSD 5 & 2.20 \\
\hline ULSD 6 & 1.76 \\
\hline B20 6 & 3.38 \\
\hline B20 4 & 5.43 \\
\hline B10 1 & 2.22 \\
\hline B10 2 & 3.24 \\
\hline B10 3 & 2.27 \\
\hline ULSD 1 & 1.46 \\
\hline ULSD 8 & 1.38 \\
\hline ULSD 9 & 1.80 \\
\hline B10 4 & 1.75 \\
\hline ULSD 7R & 1.77 \\
\hline ULSD 2R & 1.88 \\
\hline ULSD 10 & 2.71 \\
\hline & \\
\hline
\end{tabular}

With the pre-exponential factor known, the average CPF temperature matrix (CPF average temperature calculated at every time point in the experiment) is used as an input to Eqn. 16, which assumes that the activation energy and pre-exponential factor remain constant.

Using Eqn. 16, the reaction rate is calculated for each time step of the active regeneration portion of the experiment and then reported in matrix form. The reported reaction rate is the calculated value corresponding to the average CPF temperature during active regeneration. The calculated reaction rates and corresponding pre-exponential factors for all tests can be seen in Table 4.8. 
Table 4.8: Calculated Reaction Rate and Pre-exponential Factor Values for All Tests

\begin{tabular}{|c|c|c|c|c|}
\hline Variable & $\begin{array}{c}\text { Pre-exponential } \\
\text { Factor } \cdot 10^{6}\end{array}$ & Reaction Rate & $\begin{array}{c}\text { Average CPF } \\
\text { Temp. }\end{array}$ & $\begin{array}{c}\text { CPF Inlet O2 } \\
\text { Concentration }\end{array}$ \\
\hline Abbreviation & A & RRo & TCPF_AR_AVG $_{\text {CP_A }}$ & $\mathrm{YO}_{2}$ \\
\hline Test/Units & $1 / \mathrm{sec}$ & $1 / \mathrm{sec}$ & ${ }^{\circ} \mathrm{C}$ & $\%$ \\
\hline B20 1 & 5.08 & $4.23 \mathrm{E}-03$ & 474 & 8.8 \\
\hline B20 2 & 3.29 & $8.29 \mathrm{E}-03$ & 508 & 8.0 \\
\hline B20 5 & 4.62 & $2.34 \mathrm{E}-02$ & 534 & 8.2 \\
\hline ULSD 3 & 2.06 & $9.06 \mathrm{E}-03$ & 526 & 7.6 \\
\hline ULSD 4 & 2.04 & $1.03 \mathrm{E}-02$ & 531 & 7.6 \\
\hline ULSD 5 & 2.20 & $1.03 \mathrm{E}-02$ & 529 & 7.7 \\
\hline ULSD 6 & 1.76 & $1.11 \mathrm{E}-02$ & 540 & 7.7 \\
\hline B20 6 & 3.38 & $2.01 \mathrm{E}-02$ & 540 & 8.2 \\
\hline B20 4 & 5.43 & $1.25 \mathrm{E}-02$ & 506 & 8.3 \\
\hline B10 1 & 2.22 & $1.18 \mathrm{E}-02$ & 534 & 7.8 \\
\hline B10 2 & 3.24 & $1.61 \mathrm{E}-02$ & 531 & 7.7 \\
\hline B10 3 & 2.27 & $1.12 \mathrm{E}-02$ & 531 & 7.8 \\
\hline ULSD 1 & 1.46 & $1.96 \mathrm{E}-02$ & 567 & 7.2 \\
\hline ULSD 8 & 1.38 & $8.37 \mathrm{E}-03$ & 539 & 7.8 \\
\hline ULSD 9 & 1.80 & $2.18 \mathrm{E}-02$ & 563 & 7.3 \\
\hline B10 4 & 1.75 & $2.05 \mathrm{E}-02$ & 563 & 7.5 \\
\hline ULSD 7R & 1.77 & $2.07 \mathrm{E}-02$ & 562 & 7.3 \\
\hline ULSD 2R & 1.88 & $8.28 \mathrm{E}-02$ & 616 & 6.9 \\
\hline ULSD 10 & 2.71 & $1.47 \mathrm{E}-02$ & 538 & 8.5 \\
\hline
\end{tabular}

\subsubsection{Activation Energy Determination}

All tests were optimized using a range of activation energies of $120-150 \mathrm{~kJ} / \mathrm{gmol}$ which yielded the results in Table 4.9. In Table 4.9, the reported pre-exponential factors are the result of averaging the pre-exponential factors for each fuel type. The lowest average pre-exponential factor was found with ULSD, while the highest was found with B20, which was expected.

The upper and lower limits for the activation energy were adjusted until the preexponential factors reported for each fuel type correlated well with the experimental data. This correlation can be seen in Figure 4.8 where the experimentally determined reaction rate normalized by the molar fraction of oxygen into the CPF is plotted as a function of average CPF temperature in the Arrhenius form. 
Table 4.9: Optimization Results using All Tests

\begin{tabular}{|c|c|c|}
\hline Variable & Pre-exponential Factor & Activation Energy \\
\hline Abbreviation & $\mathrm{A}$ & $\mathrm{Ea}$ \\
\hline Fuel/Unit & $1 / \mathrm{sec}$ & $\mathrm{kJ} / \mathrm{gmol}$ \\
\hline ULSD & $9.8 \mathrm{E}+06$ & 139 \\
\hline B10 & $12.2 \mathrm{E}+06$ & \\
\hline B20 & $20.1 \mathrm{E}+06$ & \\
\hline
\end{tabular}

A statistical analysis between average pre-exponential factors was done using a two sample t-test in order to determine whether or not the average pre-exponential factors were statistically different between fuel types. It was determined, with 95\% confidence, that the average pre-exponential factors were statistically the same for ULSD vs. B10, but were statistically different between ULSD vs. B20 and B10 vs. B20.

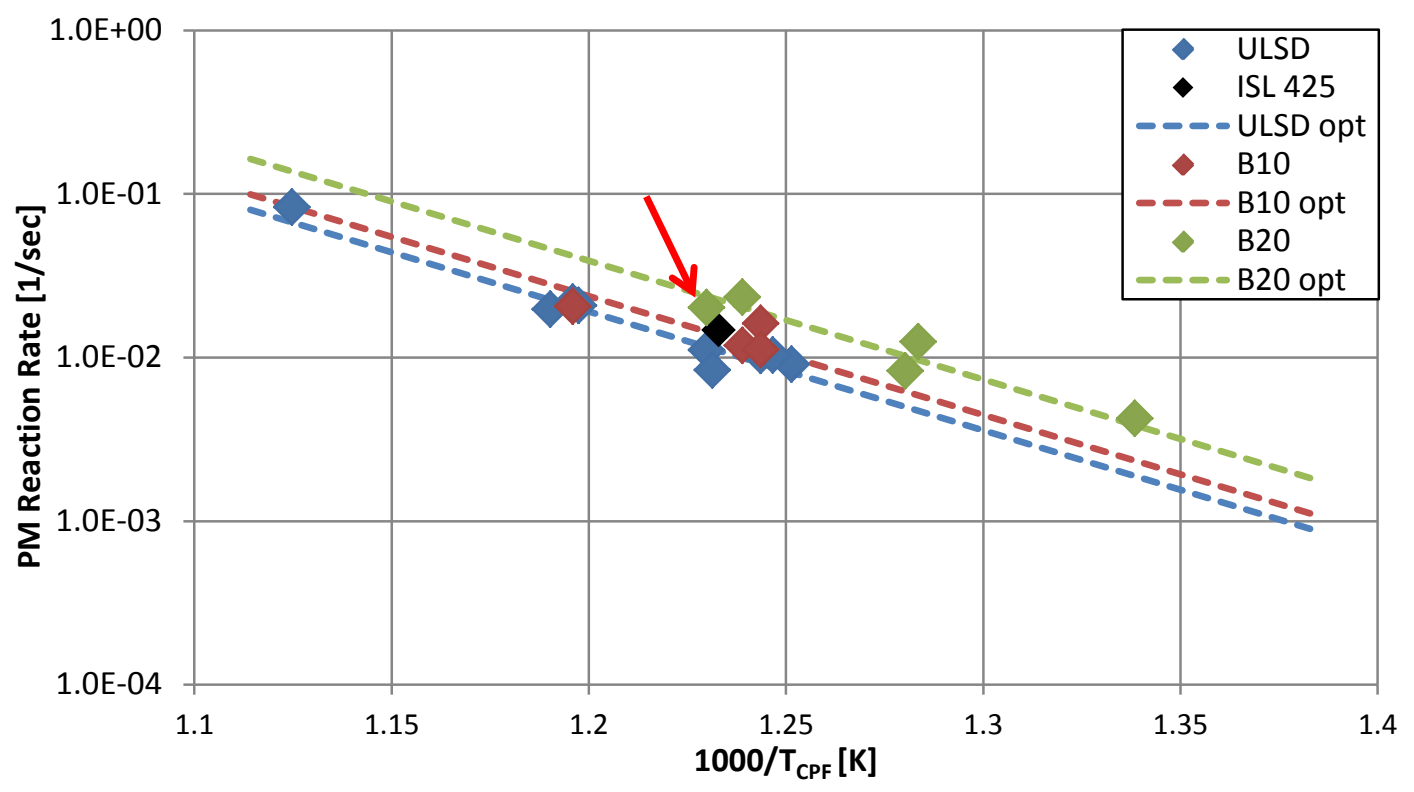

Figure 4.8: Optimized Results with All Tests Included in the Optimization 
As can be seen in Figure 4.8, the reaction rate increases with increasing CPF inlet temperature for all experiments run on the 2007 ISL. Reaction rate also increased with an increasing percentage of biodiesel in the test fuel (i.e., B20 had a higher reaction rate than $\mathrm{B} 10, \mathrm{~B} 10$ has a higher reaction rate than ULSD, with a constant CPF temperature). These trends were expected and are the same trends seen in the experimental data from Austin [1].

Tests ULSD-6 and B20-6 were conducted using the auxiliary dosing injector located in the exhaust rather than in-cylinder dosing which was used for all other tests. The B20 test utilizing the auxiliary dosing injector in Figure 4.8 has a red arrow marking it, to visualize the shift along the horizontal axis. This shift is a result of the change in average CPF temperature. The average CPF temperature during active regeneration was increased by $6^{\circ} \mathrm{C}$ in the $\mathrm{B} 20$ case and $11^{\circ} \mathrm{C}$ in the ULSD case. ULSD-10, conducted on the ISL 425 , is represented by a black marker in Figure 4.12. There is not a significant change in the reaction rate when compared to ISL 365 tests, although more ISL 425 active regeneration tests should be conducted in order to verify this result.

\subsubsection{Regeneration Efficiency of Fuel Dosing}

Maximizing the fuel efficiency during active regeneration is vital since the highest possible fuel efficiency is desirable for the customer. In order to maximize engine system fuel efficiency, the regeneration efficiency of PM oxidation during fuel dosing needs to be maximized. Regeneration at high temperatures as well as higher biodiesel levels both contributed to a reduced fuel penalty associated with active regeneration due to shorter regeneration times and more efficient PM oxidation, respectively, which is explained later in this section. Some of the data from Austin [1] and the data from this study are displayed in Figure 4.9. Trend lines were incorporated into the plot for each fuel type used (B5 and B20 for the data from Austin [1] and ULSD, B10, and B20 for the data from this study). 


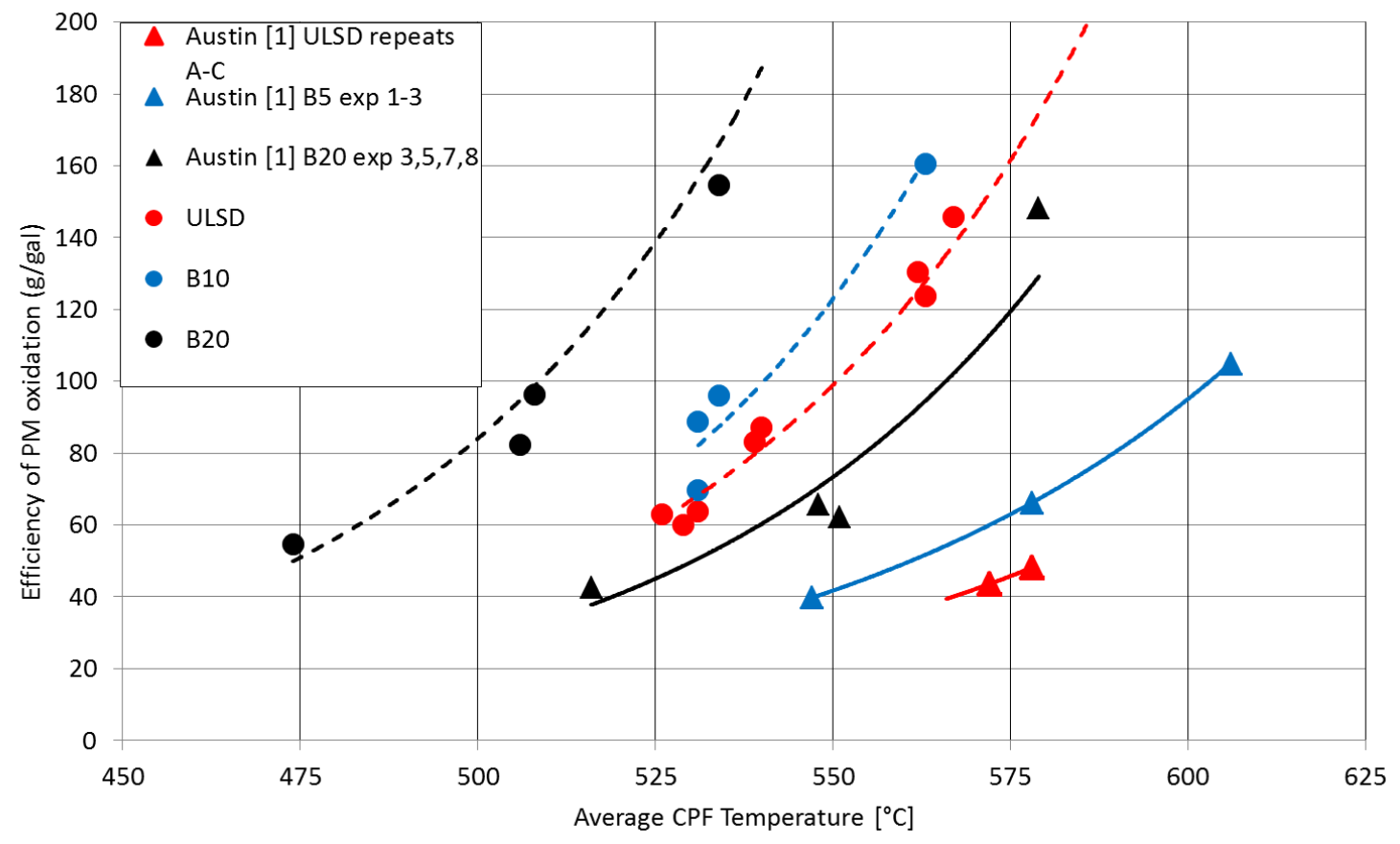

Figure 4.9: Grams of PM Oxidized per Equivalent Gallon of Fuel Injected during Dosing as a Function of Average CPF Temperature Including Data from Austin [1]

It is clearly visible in Figure 4.9 that the data from this study follows the general same trend as the data presented by Austin [1] in that at a constant average CPF temperature, B20 has the highest active regeneration fuel efficiency, and decreases with decreasing test fuel b-factor level. For example, the data from this study suggests that at an average $\mathrm{CPF}$ temperature of $525^{\circ} \mathrm{C}$, active regeneration with ULSD, B10, and B20 results in 63, 90, and 154 grams of PM oxidized per gallon of dosing fuel used, respectively, coinciding with an increase of $43 \%$ from ULSD to B10 and $144 \%$ from ULSD to B20.

Another way to interpret the data presented in Figure 4.9 is to look at the equivalent temperatures required to achieve a given PM oxidation/gallon of fuel dosed across all three fuels. For example, active regeneration with ULSD, B10, and B20 near a PM oxidized/fuel dosed value of 80 occurs at 540, 531 and $506^{\circ} \mathrm{C}$, respectively. Therefore, as higher blends of biodiesel are used, more PM is oxidized at a given temperature, or a lower CPF temperature is required to achieve the same level of PM 
oxidation/fuel dosed. The lower CPF temperature coincides with a lower dosing rate, resulting in increased engine fuel efficiency.

In order to accurately compare the data from Austin [1] and this study, the PM oxidation efficiency data from Austin [1] was normalized by multiplying each data point by the ratio of the standard exhaust volumetric flow rate between the two studies since Austin's [1] engine condition for active regeneration was at a higher flow rate condition than this study The ratio of the flow rates was $\dot{V}_{-} G T A / \dot{V}_{-} J M P$ where GTA denotes data from Austin [1] and JMP denotes data from this study. The data following this normalization process can be seen in Figure 4.10.

It can be seen in Figure 4.10 that the data from Austin [1] lies close to the data from this study after the application of the flow rate ratios described above. Since the exhaust flow rate used during active regeneration by Austin [1] was more than twice that which was used during active regeneration in this study, the exhaust volumetric flow rate ratio described above was between 2.0 and 2.3 for every data point from Austin [1].

As a result of the data normalization process, Figure 4.10 shows that the regeneration efficiency for any given temperature is more efficient with a lower exhaust flow rate. The efficiency of PM oxidation from this study was twice that which was reported in the study by Austin [1], regardless of test fuel type. This is due to the approximate 3 times increase in fuel required to raise the exhaust to a given temperature between Austin [1] and this study. At higher exhaust flow rates in the Austin [1] study, more fuel is consumed during active regeneration when compared to lower flow rates in this study due to the required increase in dosing fuel flow rate. 


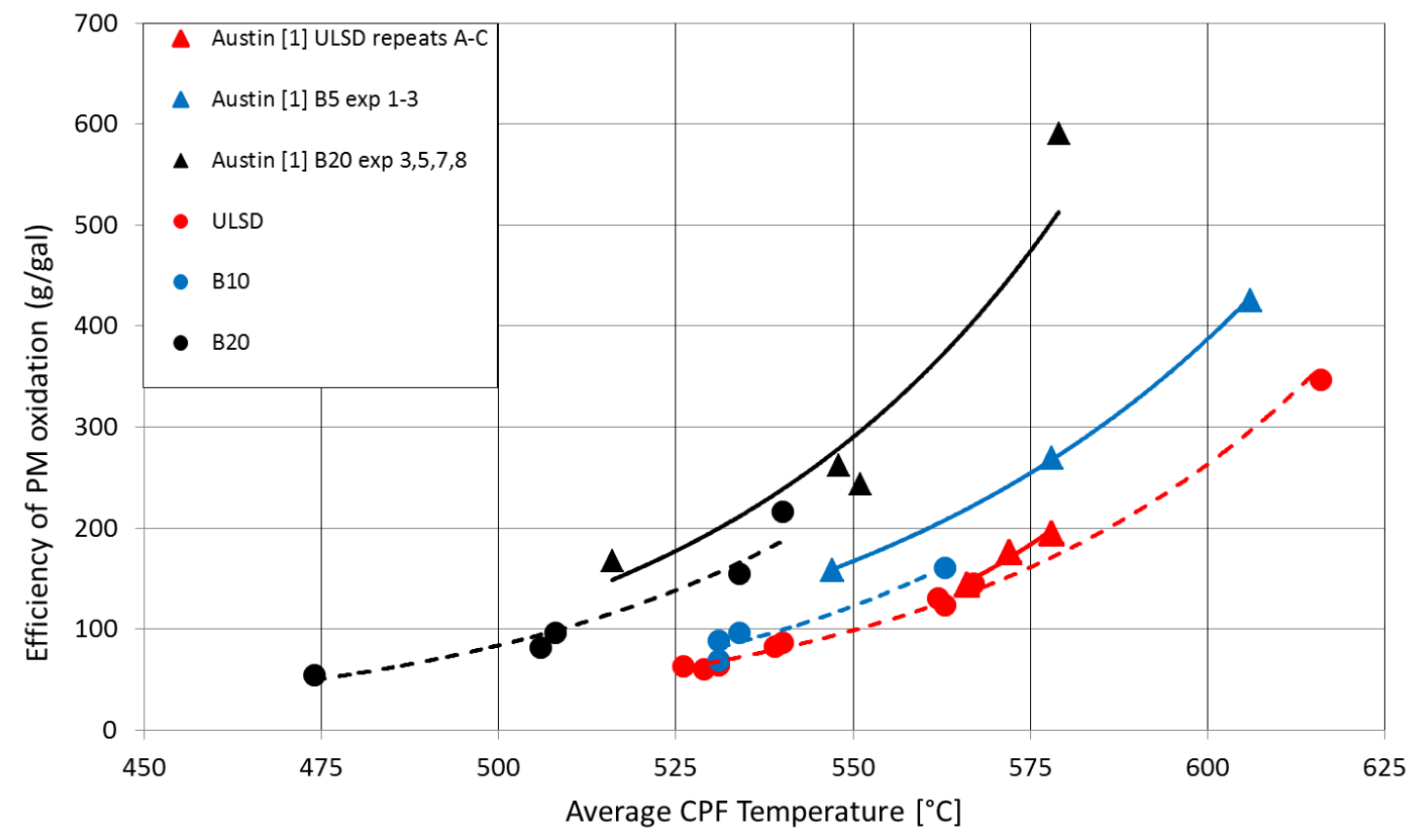

Figure 4.10: Grams of PM Oxidized per Equivalent Gallon of Fuel Injected during Dosing as a Function of Average CPF Temperature Including Data from Austin [1] Normalized by Exhaust Volumetric Flow Rate Ratio

The data from this study differs slightly from the data presented by Austin [1] in that the representative data points in Figure 4.10 are shifted along the CPF temperature axis as well as a slight shift up on the vertical axis for the representative temperature points. This could be possible by a number of factors including the CPF thermocouple layout changes that were explained earlier, differences between the experimental procedures used on the ISM $[1,15]$ and the ISL, or differences between the ISM and the ISL themselves since the ISM and ISL are two completely different engine platforms. Another possible difference could be related to in-cylinder vs. exhaust dosing methods, as the data in Figure 4.10 from this study was with incylinder and exhaust dosing, while data from Austin [1] used the exhaust dosing method only. The exhaust flow rate during active regeneration were much lower on the ISL compared to the ISM [1] in order for in-cylinder dosing to be used to reach a $\mathrm{CPF}$ inlet temperature of at least $600^{\circ} \mathrm{C}$, which may also have had an effect on the results of the regeneration efficiency of fuel dosing on the ISL.

The analysis methods with respect to the regeneration efficiency of fuel dosing were the same between the ISM and ISL and as such, are not believed to be a 
contributing factor in the differences between the data. The differences in engines and active regeneration engine conditions are believed to be the most likely cause for the differences in the experimental data between this study and the data presented by Austin [1].

The calculation and analysis method for determining the data presented in Figures 4.9 and 4.10 is shown in Appendix O.

\subsubsection{In-cylinder and Post-turbo Dosing Methods}

Tests ULSD-3, ULSD-4, ULSD-5, and ULSD-6 were test cases with experimental CPF inlet temperatures of $525 \pm 1^{\circ} \mathrm{C}$ using ULSD. B20-5 and B20-5 were test cases with experimental CPF inlet temperatures of $527 \pm 1^{\circ} \mathrm{C}$ using $\mathrm{B} 20$. Out of these 6 tests, ULSD-6 and B20-6 were the only test case which used the post-turbo dosing method.

From Table M4, the gaseous emissions summary during active regeneration, it can be seen that the CPF inlet HC concentration was 200-300 ppm higher for the postturbo dosing case. From Table 4.6, it can be seen that the volume average CPF temperatures were $6^{\circ} \mathrm{C}$ and $11^{\circ} \mathrm{C}$ higher for the post-turbo $\mathrm{B} 20$ and ULSD tests, respectively. From Figure 4.4, it can be seen that the peak CPF pressure drop during active regeneration was $0.2-0.3 \mathrm{kPa}$ higher for the post-turbo dosing cases with ULSD and B20.

Considering the fact that these tests were conducted at experimental CPF inlet temperatures from $525-528^{\circ} \mathrm{C}$, it can be said that performing active regeneration with the post-turbo dosing method requires more dosing fuel to achieve the same CPF inlet temperature.

The result is that the DOC HC conversion efficiency is greater with in-cylinder dosing when compared to post-turbo dosing methods, regardless of test fuel type. 


\section{Chapter 5 Conclusions and Recommendations}

The main goal of this research was to develop an active regeneration test procedure which was suitable for the use of in-cylinder dosing while determining effects of CPF PM loading, CPF temperature, dosing method (in-cylinder or post-turbo dosing injection methods), and fuel on PM oxidation via active regeneration in a CPF. This goal has been met through the completed testing and analysis of the data.

The method for calculating the reaction rate during active regeneration has been modified from Austin [1] and now includes the average CPF temperature at each time step during active regeneration in the calculation of the reaction rate. Changes to the experimental setup (A 2002 Cummins ISM engine was used in [1] while a 2007 Cummins ISL was used in this study) CPF thermocouple layout (and subsequent average CPF temperature calculation) from Austin [1] resulted in a shift in the grams of PM oxidized/gallon of dosing fuel injected data although the trends seen in Austin [1] were also seen in the ISL test data.

\subsection{Conclusions}

Conclusions from the analysis of the data are as follows.

- A literature review on past research related to PM oxidation during active regeneration and the effects of biodiesel blends on it has been accomplished.

- All experimental data was used in the analysis of PM reaction rate and rate parameter (Ea and A) optimization while 11 total test cases have been deemed suitable for calibration of the MTU-1D CPF Model.

- A method to calculate the PM reaction rate at each time step through the entire active regeneration phase of the experiments has been developed and shows good correlation between experimental test cases.

- The PM reaction rate was shown to increase with increasing test fuel percent biodiesel and CPF inlet temperature and an active regeneration model developed by Pidgeon [2] was used to predict the active regeneration time given a set of experimental test conditions.

- $\quad$ Optimization methods were used to determine a global activation energy of $139 \mathrm{~kJ} / \mathrm{gmol}$ for all test fuels as well as the pre-exponential factor for each test fuel where B20 was the highest, followed by B10 and ULSD. B20 
and ULSD were shown to be statistically different while B10 and ULSD were shown to be statistically similar.

- DOC HC conversion efficiency is increased with in-cylinder compared to post-turbo dosing methods.

- $\quad$ Regeneration efficiency of fuel dosing is increased as exhaust volumetric flow rate is decreased. This is due to the amount of dosing fuel that is required to achieve a given CPF inlet temperature decreases with decreasing flow rate.

- $\quad$ More PM is oxidized per gallon of dosing fuel consumed at a constant CPF temperature with B20 leading to shorter regeneration times and decreased fuel consumption during active regeneration

- A lower temperature is required to achieve the same level of regeneration efficiency of fuel dosing with B20 when compared to B10, and a lower temperature is required with B10 compared to ULSD. A lower CPF temperature requires less dosing fuel to be consumed during dosing, decreasing fuel consumption during active regeneration.

- The CPF resistance was calculated based on experimental data for each test case. LFE and CPF pressure drop offsets were implemented for S1 loading test phases where the measurements were subject to error due to test cell temperature rise. Exhaust flow rate scaling factors were implemented for test phases in which unknown errors with the LFE pressure drop measurements occurred. CF was determined using Eqn. 20 based on a re-constructed, plausible resistance curve, and will be applied to exhaust mass flow rate for simplicity in the input data preparation for the MTU-1D CPF model.

\subsection{Recommendations}

- Implementation of control of the engine intake air within the test cell would be beneficial to future research that collects data similar to this study because more consistent engine-out PM concentration data could be gathered. Controlling the test cell temperature would be beneficial for more consistent experimental data. 
- $\quad$ Complete additional active regeneration tests to cover a more broad range of CPF inlet temperatures with all test fuels used in this study (ULSD, B10, and B20).

- Repeat the tests in which the exhaust bypass line valve was shown to be sticking (Figures P2-P5 corresponding to tests B20-5, ULSD-3, ULSD-4, and ULSD-5).

- Perform additional ULSD tests with the ISL 425 rating to definitively determine whether differences exist, from an active regeneration stand point, between the two engine ratings.

- $\quad$ Changes to the National Instruments DAQ system to definitely negate the effects of test cell temperature on the pressure transducer readings as shown in Figure P8, where the increase in test cell temperature between the starting points of Stage 1 and Stage 2 loading affected the accuracy of the CPF pressure drop. The pressure drop was affected such that the steady state CPF pressure drop during Stage 1 loading was lower than it should have been, due to errors introduced as a result of the increase in test cell temperature from the first engine start-up to the end of Stage 1.

\section{References}

1. Austin G, Naber J, Johnson J, Hutton C, "Effects of Biodiesel Blends on Particulate Matter Oxidation in a Catalyzed Particulate Filter during Active Regeneration," SAE Technical Paper No. 2010-01-0557, 2010.

2. Pidgeon J, Naber J, Johnson J, "An Experimental Investigation into the Effects of Biodiesel Blends on Particulate Matter Oxidation in a Catalyzed Particulate Filter during Active Regeneration", SAE Technical Paper No. 2013-01-0521, 2013, currently under official review.

3. Williams A, McCormick R, Hayes R, Ireland J, Fang H, "Effect of Biodiesel Blends on Diesel Particulate Filter Performance", SAE Technical Paper No. 2006-01-3280, 2006.

4. Morcos M, Ayyappan P, Harris T, "Characterization of DPF Ash for Development of DPF Regeneration Control and Ash Cleaning Requirements", SAE Technical Paper No. 2011-01-1248, 2011.

5. Ochs T, Schittenhelm H, Genssle A, and Kamp B, "Particulate Matter Sensor for On Board Diagnostics (OBD) of Diesel Particulate Filters (DPF)", SAE Technical Paper No. 2010-01-0307, 2010. 
6. Hutton C, Johnson J, Naber J, Keith J, "Procedure Development and Experimental Study of Passive Particulate Matter Oxidation in a Diesel Catalyzed Particulate Filter", SAE Technical paper No. 2012-01-0851, 2012.

7. Poitras M, Rosenblatt D, Chan T, and Rideout G, "Impact of Varying Biodiesel Blends on Direct-Injection Light-Duty Diesel Engine Emissions", SAE Technical Paper No. 2012-01-1313, 2012.

8. Kawano D, Mizushima N, Ishii H, Goto $Y$, and Iwasa $K$, "Exhaust Emission Characteristics of Commercial Vehicles Fuelled with Biodiesel", SAE Technical Paper No. 2010-01-2276, 2010.

9. Parihar A, Sethi V, Parikh P, Radhakrishna D, Hashmi K, Gupta A, and Dar F, "Physical Characterization of Particulate Emissions from Compression Ignition Engine Operating on Diesel and Biodiesel Fuels", SAE Technical Paper No. 2011-26-0026, 2011.

10. Eckerle W, Lyford-Pike E, Stanton D, LaPointe L, Whitacre S, and Wall J, "Effects of Methyl Ester Biodiesel Blends on NOx Emissions", SAE Technical Paper No. 2008-01-0078, 2008.

11. Shiel K, Naber J, Johnson J, Hutton C, "Catalyzed Particulate Filter Passive Oxidation Study with ULSD and Biodiesel Blended Fuel", SAE Technical Paper No. 2012-01-0831, 2012.

12. Yezerets A, Currier N, Eadler H, Popuri S, Suresh A, "Quantitative FlowReactor Study of Diesel Soot Oxidation Process", SAE Technical Paper No. 2002-01-1684, 2002.

13. Yezerets A, Currier N, Eadler $H$, "Experimental Determination of the Kinetics of Diesel Soot Oxidation by $\mathrm{O}_{2}$ - Modeling Consequences", SAE Technical Paper No. 2003-01-0833, 2003.

14. Oki H, Karin P, and Hanamura, K, "Visualization of Oxidation of Soot Nanoparticles Trapped on a Diesel Particulate Membrane Filter", SAE Technical Paper No. 2011-01-0602, 2011.

15. Chilumukuru K, Arasappa R, Johnson J, Naber J, "An Experimental Study of Particulate Thermal Oxidation in a Catalyzed Particulate Filter during Active Regeneration", SAE Technical Paper No. 2009-01-1474, 2009.

16. Bender D, Jones J, Harshbarger D, "Analysis of Particulate Matter Sensor Signals", SAE Technical Paper No. 2012-01-0871, 2012. 
17. Surenahalli H, Premchand K, Johnson J, Parker G, "Modeling Study of Active Regeneration of a Catalyzed Particulate Filter Using One-Dimensional DOC and CPF Models", SAE Technical Paper No. 2011-01-1242, 2011

18. Konstandopoulos A, Kostoglou M, Skaperdas E, Papaioannou E, Zarvalis D, Kladopoulou E, "Fundamental Study of Diesel Particulate Filters: Transient Loading, Regeneration, and Aging", SAE Technical Paper No. 2000-01-1016, 2000.

19. Premchand K, Johnson J, Yang S, "Development of a 1-D Catalyzed Diesel Particulate Filter Model for Simulation of the Oxidation of Particulate Matter and Gaseous Species during Passive Oxidation and Active Regeneration", SAE Technical Paper No. 2013-01-1574, 2013, currently under review.

20. Senda, J., Okui, N., Suzuki, T., and Fujimoto, H., "Flame Structure and Combustion Characteristics in Diesel Combustion Fueled with Bio-diesel," SAE Technical Paper 2004-01-0084, 2004.

21. Yeliana Y, "Parametric Combustion Modeling for Ethanol-Gasoline Fuelled Spark Ignition Engines", Ph. D. Thesis, Michigan Technological University, 2010.

22. Pinturaud D, Charlet A, Caillol C, Higelin P, Girot $P$, and Briot A, "Experimental Study of DPF Loading and Incomplete Regeneration", SAE Technical Paper No. 2007-24-0094, 2007. 


\section{Appendix A Biodiesel Blend Molecular Formula Calculations}

In order to accurately calculate the hydrocarbon concentrations upstream of the DOC during active regeneration, the molecular weight of the fuel being used must be known. Since the molecular weight for the B10 and B20 test fuel was not included in the analysis results, molecular weights based upon the ULSD blended with $10 \%$ and $20 \%$, by volume, of B100 required computation. Calculations using ULSD assume that the ULSD empirical formula is $\mathrm{CH}_{1.833}$ (Chilumukuru [15] assumes $\mathrm{C}_{12} \mathrm{H}_{22}, \mathrm{H} / \mathrm{C}=$ 1.833). The density of ULSD comes from the fuel test results presented earlier in this report, and was given as $858 \mathrm{~kg} / \mathrm{m}^{3}$.

The density and percentages of carbon, hydrogen, and oxygen by mass of waste oil methyl-ester B100 was obtained in Senda [20] and are given below in Table A1.

\section{Table A1: B100 Properties from Senda [20]}

\begin{tabular}{|c|c|c|}
\hline Property & Units & Value \\
\hline Density & {$\left[\mathrm{kg} / \mathrm{m}^{3}\right]$} & 888 \\
\hline Carbon & $\%$ & 77.2 \\
\hline Hydrogen & $\%$ & 11.7 \\
\hline Oxygen & $\%$ & 11.1 \\
\hline
\end{tabular}

Using the data from Table A1 in conjunction with Eqn. A1, the moles of each atom in B100 was calculated which are given in Table A2.

$$
\mathrm{n}_{\mathrm{x}}=\frac{\mathrm{m}_{\mathrm{x}}}{\mathrm{MW}_{\mathrm{x}}}
$$

$\mathrm{nx}=$ number of moles of molecule $\mathrm{x}$

$\mathrm{mx}=$ mass percent of molecule $\mathrm{x}$ in fraction form (i.e., 0.772 , not 77.2 )

$\mathrm{MW}_{\mathrm{x}}=$ molecular weight of molecule $\times[\mathrm{g} / \mathrm{gmol}]$

Using the data from $A 2$, the hydrogen/carbon $(\mathrm{H} / \mathrm{C})$ and oxygen/carbon $(\mathrm{O} / \mathrm{C})$ ratios can be calculated by the division of the two molecules in question. The $\mathrm{H} / \mathrm{C}$ and $\mathrm{O} / \mathrm{C}$ ratios for B100 are given in Table A3.

\section{Table A2: Computed B100 Molecular Components}




\begin{tabular}{|c|c|c|}
\hline moles Carbon & mol & 0.0643 \\
\hline moles Hydrogen & mol & 0.1161 \\
\hline moles Oxygen & $\mathrm{mol}$ & 0.0069 \\
\hline
\end{tabular}

Table A3: H/C and O/C Ratios for B100

\begin{tabular}{|c|c|}
\hline Ratio & Value \\
\hline $\mathrm{H} / \mathrm{C}$ & 1.81 \\
\hline $\mathrm{O} / \mathrm{C}$ & 0.107 \\
\hline
\end{tabular}

Using the $\mathrm{H} / \mathrm{C}$ and $\mathrm{O} / \mathrm{C}$ ratios, the empirical formula for $\mathrm{B} 100$ can be expressed as $\mathrm{CH}_{1.81} \mathrm{O}_{0.107}$, subsequently allowing for the calculation of the molecular weight by $(12.01 \cdot 1)+(1.008 \cdot 1.81)+(16.0 \cdot 1.107)$, resulting in a molecular weight of 15.55 $\mathrm{g} / \mathrm{gmol}$. The molecular weight for ULSD was calculated similarly using the empirical formula referenced earlier, resulting in $13.85 \mathrm{~g} / \mathrm{gmol}$.

Eqn. A2, from Yeliana [21], is used to calculate the mole \% of biodiesel in the B10 and B20 blends, which are given in Table A4.

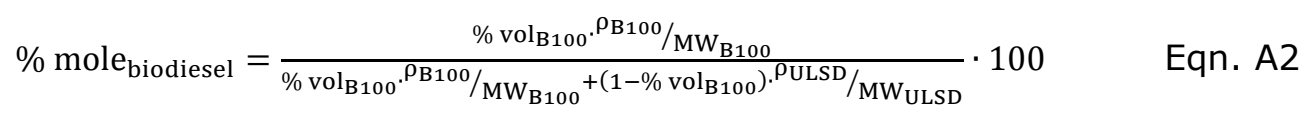

$\%$ mole $_{\text {biodiesel }}=$ mole fraction of biodiesel in the B10 or B20 blend [\%]

$\%$ vol $_{\mathrm{B} 100}=\%$ volume of $\mathrm{B} 100$ in the mixture, fraction form

$\rho_{\mathrm{B} 100}=$ Density of $\mathrm{B} 100\left[\mathrm{~kg} / \mathrm{m}^{3}\right]$

$\mathrm{MW}_{\mathrm{B} 100}=$ Molecular weight of $\mathrm{B} 100[\mathrm{~g} / \mathrm{gmol}]$

$\rho_{U L S D}=$ Density of ULSD $\left[\mathrm{kg} / \mathrm{m}^{3}\right]$

$\mathrm{MW}_{\mathrm{ULSD}}=$ Molecular weight of ULSD $[\mathrm{g} / \mathrm{gmol}]$

The empirical formula for the B10 and B20 biodiesel blends can be generally expressed as $\left(\mathrm{CH}_{\beta^{*}} \mathrm{O}_{z^{*}}\right)_{a^{*}}$, where $a^{*}, \beta^{*}$, and $z^{*}$ are calculated using Eqn. A3, A4, and A5, respectively [21].

Table A4: Mole Fraction of Biodiesel for B10 and B20 Blends

\begin{tabular}{|c|c|c|}
\hline Fuel & Mole Fraction & Unit \\
\hline B10 & 9.29 & $\%$ \\
\hline B20 & 18.73 & $\%$ \\
\hline
\end{tabular}




$$
\begin{aligned}
& \alpha^{*}=(1-\overline{\mathrm{E}}) \cdot \alpha_{\mathrm{ULSD}}+[\overline{\mathrm{E}}] \cdot \alpha_{\mathrm{B} 100} \\
& \beta^{*}=\frac{(1-\overline{\mathrm{E}}) \cdot \beta_{\mathrm{ULSD}} \cdot \alpha_{\mathrm{ULSD}}+[\overline{\mathrm{E}}] \cdot \mathrm{z}_{\mathrm{B} 100} \cdot \alpha_{\mathrm{B} 100}}{(1-\overline{\mathrm{E}}) \cdot \alpha_{\mathrm{ULSD}}+[\overline{\mathrm{E}}] \cdot \alpha_{\mathrm{B} 100}} \\
& \mathrm{z}^{*}=\frac{(1-\bar{E}) \cdot z_{U L S D} \cdot \alpha_{U L S D}+[\bar{E}] \cdot z_{B 100} \cdot \alpha_{B 100}}{(1-\bar{E}) \cdot \alpha_{U L S D}+[\bar{E}] \cdot \alpha_{B 100}}
\end{aligned}
$$

$\overline{\mathrm{E}}=$ mole fraction of biodiesel in blend

$a=$ carbon atoms

$\beta=H / C$ ratio

$z=O / C$ ratio

The calculated values for $a^{*}, \beta^{*}$, and $z^{*}$, the blend empirical formula, and blend molecular weights are given in Table $A 5$ on a $\mathrm{C}_{12}$ basis.

Table A5: Calculated Properties for B10 and B20 Biodiesel Blends with ULSD Data

\begin{tabular}{|c|c|c|c|c|c|c|c|}
\hline Fuel & $\alpha^{*}$ & $\beta^{*}$ & $z^{*}$ & Formula & Molecular Weight & $\mathrm{H} / \mathrm{C}$ & $\mathrm{O} / \mathrm{C}$ \\
\hline- & - & - & - & - & [g/gmol] & - & - \\
\hline B10 & 1 & 1.828 & 0.0099 & $\mathrm{CH}_{1.828} \mathrm{O}_{0.0099}$ & 168 & 1.828 & 0.010 \\
\hline B20 & 1 & 1.826 & 0.0200 & $\mathrm{CH}_{1.826} \mathrm{O}_{0.0200}$ & 170 & 1.826 & 0.020 \\
\hline ULSD & 1 & 1.833 & - & $\mathrm{CH}_{1.833}$ & 166 & 1.833 & - \\
\hline
\end{tabular}




\section{Appendix B Dilution Ratio Calculation Method}

The exhaust sampled by the SMPS is diluted with compressed air before PSD data is collected, so determining the dilution ratio for each engine condition, sampling location, and test fuel is important. The dilution ratio is defined as the ratio of $\mathrm{CO}_{2}$ in the exhaust to the $\mathrm{CO}_{2}$ after going through the SMPS dilution system, measured by the Pierburg emissions bench. The engine is operated at the condition during which PSD data will be collected. The copper dilution line shown in Figure B1 and is connected from the heated filter to the dilution box outlet as shown. The PSD sample line is then connected to the gaseous emissions port corresponding to the location to be sampled as shown in Figure B2.

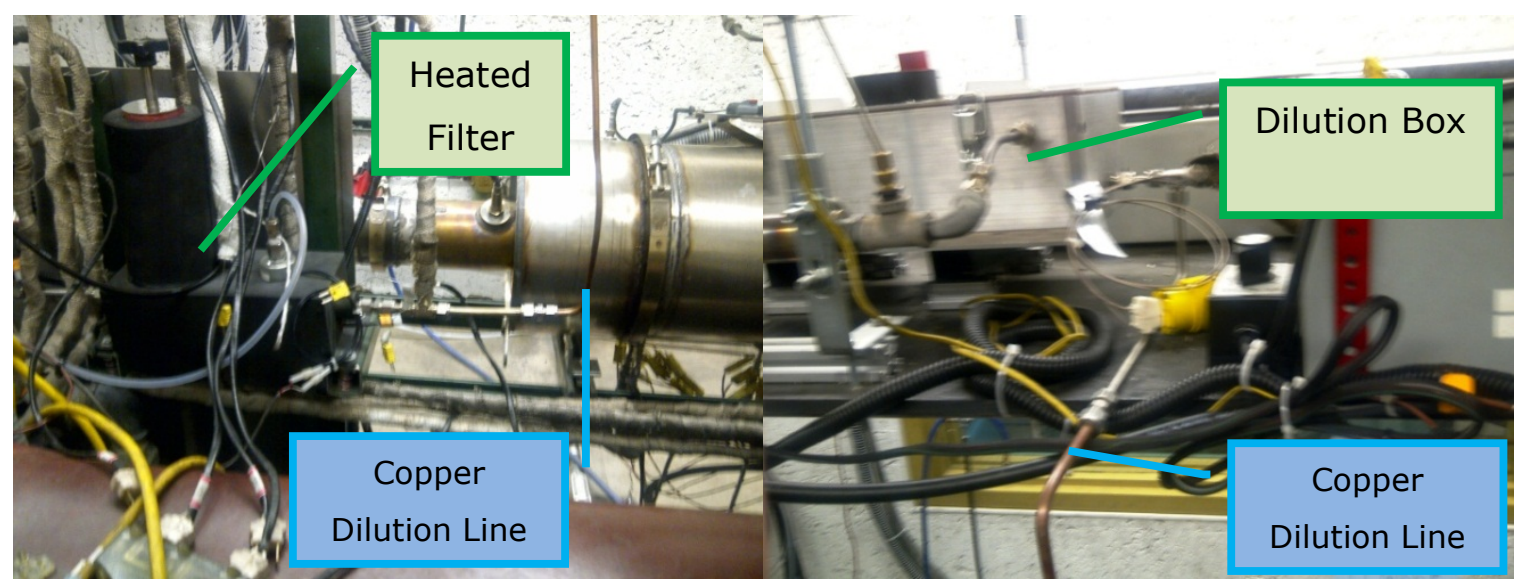

Figure B1: Copper Dilution Line Connected from the Heated Filter to the Dilution Box Outlet 


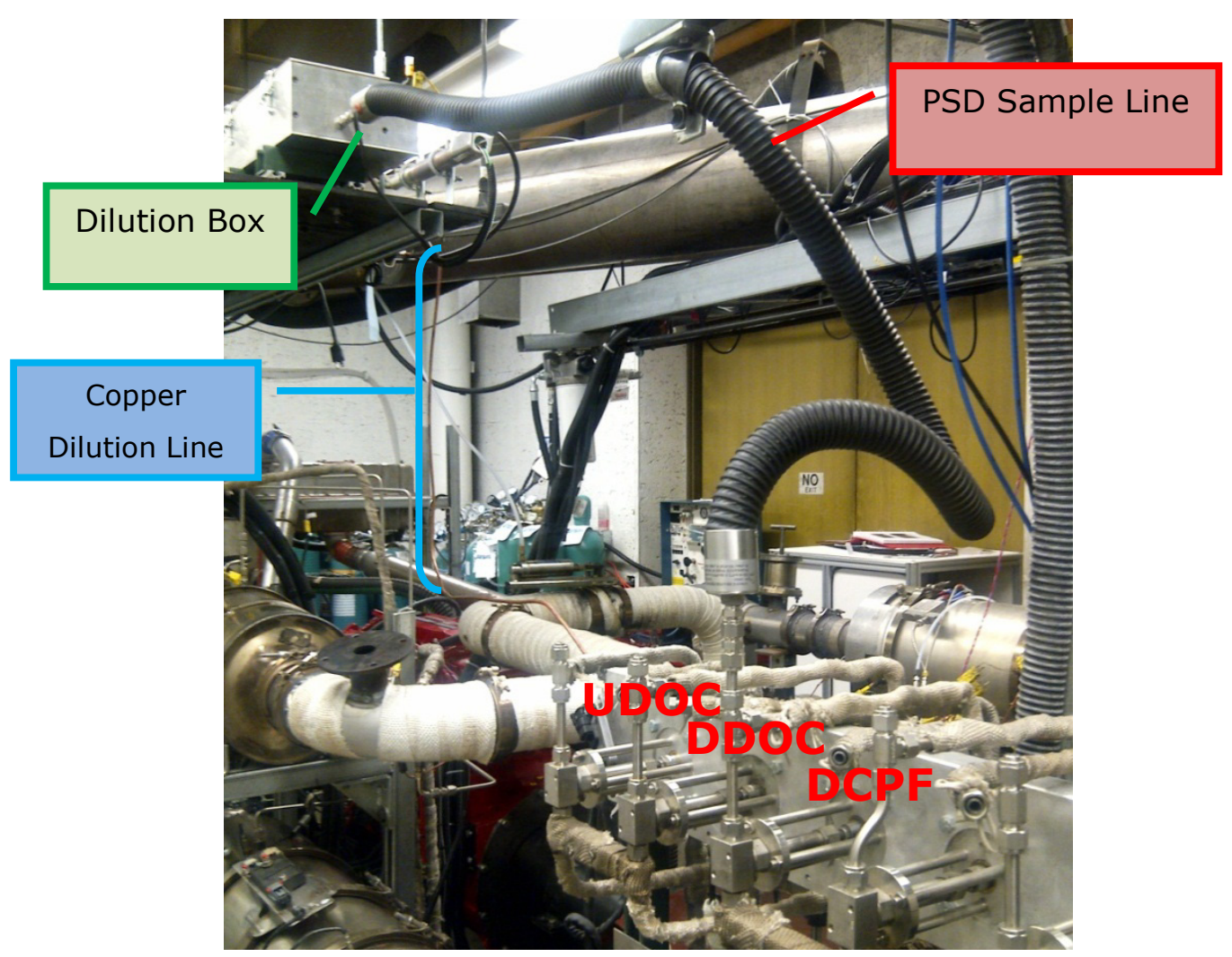

Figure B2: PSD Sample Line Connected to the DDOC Gaseous Emissions Port

With the dilution line and PSD sample line in place emissions data is collected with the Pierburg emissions analyzer. This data collection is performed with the exhaust sample valves for UDOC, DDOC, and DCPF, controlled by LabView, closed for five minutes. The value of $\mathrm{CO}_{2}$ measured by the Pierburg emissions analyzer at all sampling locations $\left(d_{\mathrm{CO} 2}\right)$ is used with Eqn. 1 to find the dilution ratio at that point for the engine operating condition being run. The value of $\mathrm{CO}_{2}$ measured by the Pierburg at all sampling locations during loading and active regeneration is used as $\mathrm{a}_{\mathrm{co} 2}$ in Eqn. B1 for each engine condition.

$$
\text { Dilution Ratio }=\frac{\mathrm{a}_{\mathrm{co} 2}}{\mathrm{~d}_{\mathrm{co} 2}}
$$

The PSD sample line is then moved to the next point to be tested and emissions data is collected for five minutes as with the prior point. All three points (UDOC, DDOC, and DCPF) are collected in this manner. Every engine operating condition and fuel type during which PSD data is to be collected must have dilution data collected in this way. 


\section{Appendix C PSD Data Correction Method}

In order to properly report the data collected by the Scanning Mobility Particle Sizing (SMPS) System, corrections to the data collected must be applied. These correction necessities are due to exhaust sample dilution and the particles that are present in the compressed air used in the dilution system.

The total procedure for collecting PSD measurements was originally written by Hutton [6].

1. Prior to measuring PSD data, determine the experimental dilution ratios that are being used at each of the three sample locations, UDOC, DDOC, and DCPF. The dilution ratios were collected at loading and active regeneration engine conditions for each of the three test fuels (ULSD, B10, and B20) in this study.

2. Determine the concentration of particles in the compressed air $\left(C_{C A}\right)$ used for the dilution system by measuring the size distribution within the air.

3. Record the PSD data during testing using the dilution system and thermodenuder at all sampling locations when measuring a 'dry' sample. This method allows for consistent conditioning of the sample before measurement

4. After the collection of raw data has been performed, the first step of post processing is accounting for the losses created by the use of the thermodenuder using Eqn C1 and Eqn C2

5. Then finish post processing by taking into account the dilution ratio and number of particles contained in the compressed air using Eqn. C3.

$$
\begin{array}{cc}
\mathrm{TP}=\mathrm{A} \cdot \mathrm{T}+\mathrm{B} \cdot \mathrm{D}+\mathrm{C} & \text { Eqn. } \mathrm{C} 1 \\
\mathrm{~T}_{\text {Loss }}=1-\mathrm{TP} & \text { Eqn. C2 }
\end{array}
$$

$\mathrm{TP}=\%$ of particles passing through thermodenuder [\%]

$$
\begin{aligned}
& A=-0.0864\left[{ }^{\circ} \mathrm{C}^{-1}\right] \\
& B=0.0108\left[\mathrm{~nm}^{-1}\right] \\
& C=91.9 \\
& D=\text { Particle diameter }[\mathrm{nm}] \\
& T_{\text {Loss }}=\text { Thermodenuder losses in fraction form }
\end{aligned}
$$




$$
\begin{aligned}
& C_{\text {exhaust }}=\frac{\left(D_{R}+1\right) \cdot D_{C P C}}{\left(1-T_{\text {Loss }}\right)}-D_{R} \cdot C_{C A} \\
& \text { Eqn. C3 } \\
& \mathrm{C}_{\text {exhaust }}=\text { Particle concentration in the exhaust }\left[\text { particle } / \mathrm{cm}^{3} \text { or } \mathrm{nm}^{3} / \mathrm{cm}^{3}\right. \text { ] } \\
& \mathrm{D}_{\mathrm{R}}=\text { Dilution ratio } \\
& \mathrm{D}_{\mathrm{CPC}}=\text { Displayed value on CPC counter } \\
& \text { TLoss }=\text { Thermodenuder losses in fraction form from Eqn. C2 } \\
& \mathrm{C}_{\mathrm{CA}}=\text { Concentration of particles in compressed air used for dilution }
\end{aligned}
$$




\section{Appendix D CPF Mass Measurement Procedure}

During different portions of the test, the CPF is removed from the aftertreatment system for weighing. The complete aftertreatment assembly is shown in Figure D1. In order to allow for clear communication, the individual parts are listed below and are correlated by number listed on the picture.

1. Inlet Cone

2. Diesel Oxidation Catalyst (DOC)

3. Catalyzed Particulate Filter (CPF)

4. Exit Cone

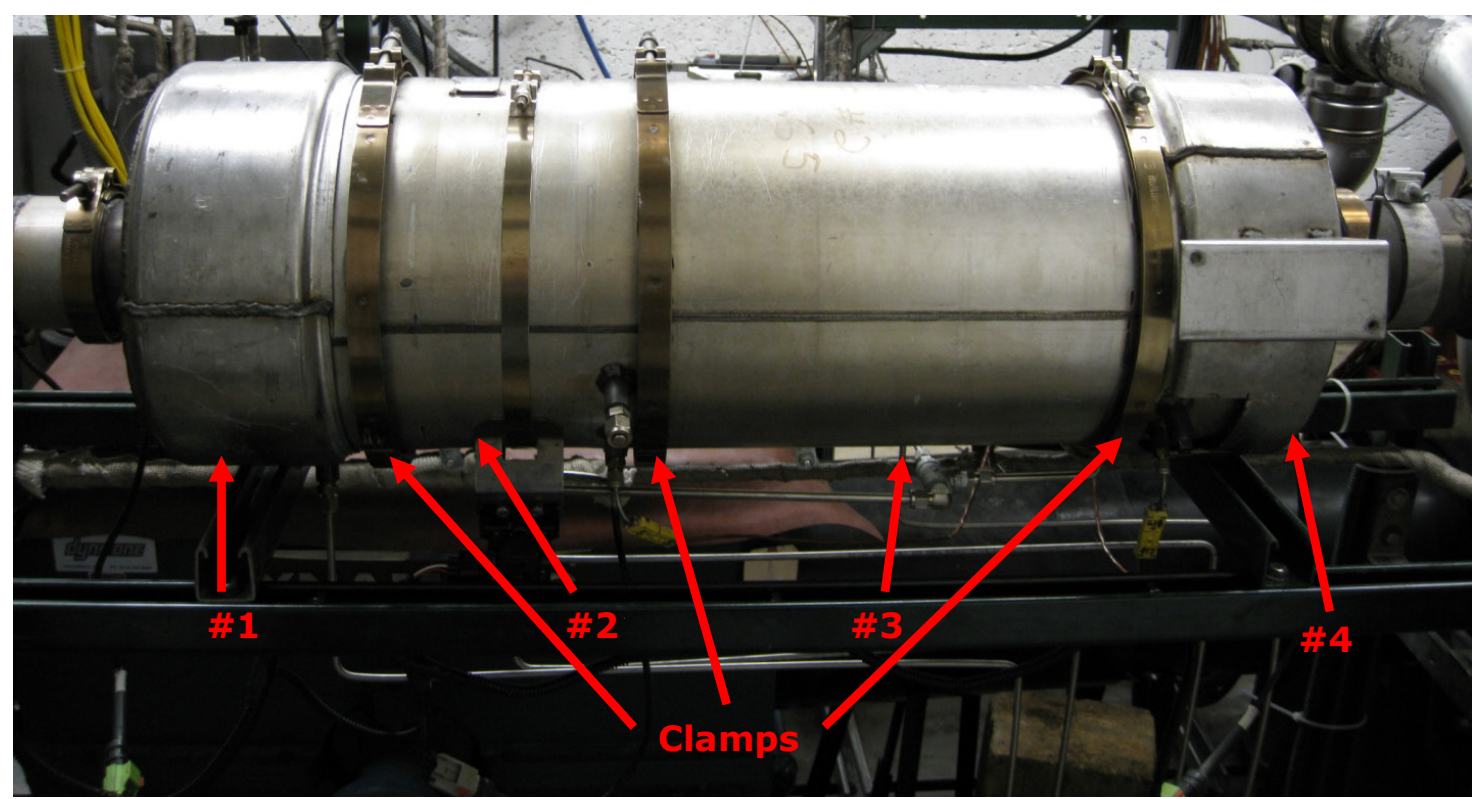

Figure D1: Cummins 2007 ISL After-treatment System

Disassembly and weighing of the CPF takes place a minimum of four times for each of the active regeneration tests. The filter and associated hardware are removed from the system hot, with surface temperatures up to and exceeding $300^{\circ} \mathrm{C}$. The weighing is done at elevated temperatures for two main reasons. First, as the CPF cools there is the possibility that the CPF will gain mass due to moisture absorption from the ambient air. Second, it has been shown that the weighing procedure is a dynamic process with the CPF appearing to gain mass as it cools due to the reduction of the buoyancy effect provided by the temperature of the filter. Therefore filter weighing takes place at similar temperatures during the different portions of the test. 
A detailed analysis investigating the variability of the mass measurement due to temperature variations is discussed in reference [1].

The weighing procedure is detailed below.

1. The entire after-treatment system, parts 1-4 in Figure D1, are removed from the exhaust system fully assembled.

2. The system is lowered to the ground and rests on Part \#4 which then puts the system in a vertical orientation.

3. The clamp between Part \#2 and \#3 is removed, the DOC and Inlet Cone are then removed as an assembly.

4. A steel cover is placed over the inlet of the CPF and fastened to the filter by the previously removed clamp.

5. The filter is then rotated to rest on the steel cover and the clamp between Part \#3 and \#4 is removed.

6. The exit cone is then removed and a separate steel cap is place over the exit of the CPF. This cap is fastened to the filter by the previously removed clamp.

7. The filter is then brought to the scale and temperatures are recorded throughout the filter and caps.

8. The scale is zeroed prior to each mass measurement.

9. A calibration weight is measured to ensure scale accuracy.

10. The CPF is weighed three times, with the temperatures recorded throughout the CPF prior to the first weighing; an average of the mass measurements is then calculated.

11. The actual temperature may vary from day to day somewhat based on ambient temperature. Maintain consistent temperatures between weighing sessions on the same test day. Do not to let the individual temperature measurements (at each thermocouple) vary by more than $+/-15^{\circ} \mathrm{C}$. The actual separate $\mathrm{T} / \mathrm{C}$ temperatures can be anywhere from $180^{\circ} \mathrm{C}$ to $290^{\circ} \mathrm{C}$

12. The reassembly process is the reverse of the disassembly process. 


\section{Appendix E Stage 1 Loading PM Mass Balance Calculations (by Kiran Premchand [19])}

From the ISL AR tests, we do not have measurements of the clean weight of the substrate. Rather, we have 4 other substrate weight measurements:

$\left(\mathrm{M}_{\mathrm{S} 1}\right),\left(\mathrm{M}_{\mathrm{S} 2}\right),\left(\mathrm{M}_{\mathrm{S} 3}\right)$ and $\left(\mathrm{M}_{\mathrm{S} 4}\right)$ taken at 4 points in time during each ISL AR test as shown in Figure E1.
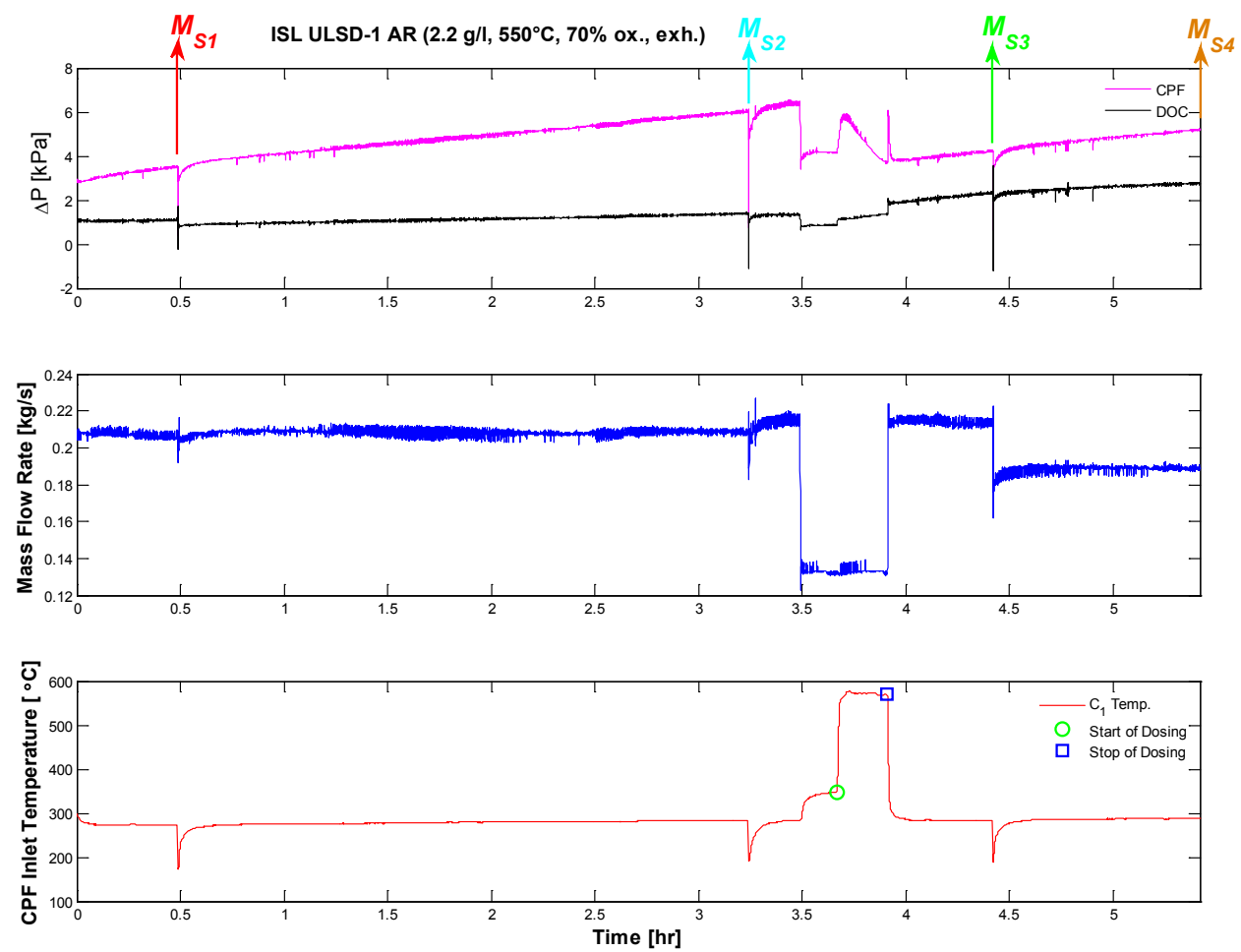

Figure E1: A typical ISL AR experiment showing a) DOC and CPF pressure drops, b) Exhaust mass flow rate and c) CPF inlet temperature

We want to get a good estimate of CPF clean weight $\left(\mathrm{M}_{\text {clean }}\right)$ assuming the following:

The fraction of PM oxidized during Stage-1 loading is equal to the fraction of PM oxidized during Stage-2 loading.

Average filtration efficiency of the CPF during Stage-1 loading and Stage-2 loading are known $\left(\left(\bar{\eta}_{\mathrm{S} 1}\right)\right.$ and $\left(\bar{\eta}_{\mathrm{S} 2}\right)$ respectively). 
We know the following relations:

$$
\begin{aligned}
& \mathrm{m}_{\text {ret }, \mathrm{S} 1}=\mathrm{M}_{\mathrm{S} 1}-\mathrm{M}_{\text {clean }} \\
& \mathrm{m}_{\text {ret,S2 }}=\mathrm{M}_{\mathrm{S} 2}-\mathrm{M}_{\text {clean }} \\
& \mathrm{m}_{\text {ret,S3 }}=\mathrm{M}_{\mathrm{S} 3}-\mathrm{M}_{\text {clean }} \\
& \mathrm{m}_{\text {ret,S4 }}=\mathrm{M}_{\mathrm{S} 4}-\mathrm{M}_{\text {clean }}
\end{aligned}
$$

Also, from cumulative PM mass balance for Stage-1 and Stage-2 can be mathematically expressed as:

$$
\begin{aligned}
& \mathrm{m}_{\mathrm{in}, \mathrm{S} 1}-\mathrm{m}_{\mathrm{ret}, \mathrm{S} 1}-\mathrm{m}_{\mathrm{ox}, \mathrm{S} 1}-\mathrm{m}_{\mathrm{out}, \mathrm{S} 1}=0-1 \text { - } 0 \\
& \mathrm{~m}_{\mathrm{ret}, \mathrm{S} 1}+\mathrm{m}_{\mathrm{in}, \mathrm{S} 2}-\mathrm{m}_{\mathrm{ret}, \mathrm{S} 2}-\mathrm{m}_{\mathrm{ox}, \mathrm{S} 2}-\mathrm{m}_{\mathrm{out}, \mathrm{S} 2}=0-\cdots-1 \text { [Stage-1] }
\end{aligned}
$$

Also, from definition of average filtration efficiencies during Stage-1 and Stage-2,

$$
\begin{aligned}
& \bar{\eta}_{\mathrm{S} 1}=\frac{m_{\mathrm{in}, \mathrm{S} 1}-\mathrm{m}_{\text {out }, \mathrm{S} 1}}{\mathrm{~m}_{\mathrm{in}, \mathrm{S} 1}} \\
& \bar{\eta}_{\mathrm{S} 2}=\frac{\mathrm{m}_{\mathrm{in}, \mathrm{S} 2}-\mathrm{m}_{\text {out } \mathrm{S} 2}}{\mathrm{~m}_{\mathrm{in}, \mathrm{S} 2}}
\end{aligned}
$$

From (5) and (1),

$\mathrm{m}_{\mathrm{ret}, \mathrm{S} 1}=\mathrm{m}_{\mathrm{in}, \mathrm{S} 1}-\mathrm{m}_{\mathrm{ox}, \mathrm{S} 1}-\mathrm{m}_{\mathrm{out}, \mathrm{S} 1}=\mathrm{M}_{\mathrm{S} 1}-\mathrm{M}_{\text {clean }}$

or

$$
\left(\mathrm{m}_{\mathrm{in}, \mathrm{S} 1}-\mathrm{m}_{\mathrm{out}, \mathrm{S} 1}\right)-\mathrm{m}_{\mathrm{ox}, \mathrm{S} 1}=\mathrm{M}_{\mathrm{S} 1}-\mathrm{M}_{\text {clean }}
$$

Substitute (7) in (9),

$$
\bar{\eta}_{\mathrm{S} 1} \mathrm{~m}_{\mathrm{in}, \mathrm{S} 1}-\mathrm{m}_{\mathrm{ox}, \mathrm{S} 1}=\mathrm{M}_{\mathrm{S} 1}-\mathrm{M}_{\text {clean }}
$$

Re-writing (10),

$$
\mathrm{M}_{\text {clean }}=\mathrm{M}_{\mathrm{S} 1}-\left(\bar{\eta}_{\mathrm{S} 1} \mathrm{~m}_{\mathrm{in}, \mathrm{S} 1}-\mathrm{m}_{\mathrm{ox}, \mathrm{S} 1}\right)
$$

or

$\mathrm{M}_{\text {clean }}=\mathrm{M}_{\mathrm{S} 1}-\bar{\eta}_{\mathrm{S} 1} \mathrm{~m}_{\mathrm{in}, \mathrm{S} 1}+\mathrm{m}_{\mathrm{ox}, \mathrm{S} 1}$

or

$$
\mathrm{m}_{\mathrm{ox}, \mathrm{S} 1}=\bar{\eta}_{\mathrm{S} 1} \mathrm{~m}_{\mathrm{in}, \mathrm{S} 1}-\left(\mathrm{M}_{\mathrm{S} 1}-\mathrm{M}_{\mathrm{clean}}\right)
$$


From (6), (2) and (1),

$$
\begin{aligned}
\mathrm{m}_{\mathrm{ox}, \mathrm{S} 2}= & \mathrm{m}_{\mathrm{ret}, \mathrm{S} 1}+\mathrm{m}_{\mathrm{in}, \mathrm{S} 2}-\mathrm{m}_{\mathrm{ret}, \mathrm{S} 2}-\mathrm{m}_{\mathrm{out}, \mathrm{S} 2} \\
& =\mathrm{m}_{\mathrm{ret}, \mathrm{S} 1}+\left(\mathrm{m}_{\mathrm{in}, \mathrm{S} 2}-\mathrm{m}_{\mathrm{out}, \mathrm{S} 2}\right)-\mathrm{m}_{\mathrm{ret}, \mathrm{S} 2} \\
& =\mathrm{m}_{\mathrm{ret}, \mathrm{S} 1}+\bar{\eta}_{\mathrm{S} 2} \mathrm{~m}_{\mathrm{in}, \mathrm{S} 2}-\mathrm{m}_{\mathrm{ret}, \mathrm{S} 2} \\
& =\bar{\eta}_{\mathrm{S} 2} \mathrm{~m}_{\mathrm{in}, \mathrm{S} 2}+\mathrm{m}_{\mathrm{ret}, \mathrm{S} 1}-\mathrm{m}_{\mathrm{ret}, \mathrm{S} 2} \\
& =\bar{\eta}_{\mathrm{S} 2} \mathrm{~m}_{\mathrm{in}, \mathrm{S} 2}+\left(\mathrm{M}_{\mathrm{S} 1}-\mathrm{M}_{\text {clean }}\right)-\left(\mathrm{M}_{\mathrm{S} 2}-\mathrm{M}_{\text {clean }}\right) \\
& =\bar{\eta}_{\mathrm{S} 2} \mathrm{~m}_{\mathrm{in}, \mathrm{S} 2}-\left(\mathrm{M}_{\mathrm{S} 2}-\mathrm{M}_{\mathrm{S} 1}\right)-\ldots-
\end{aligned}
$$

From (11c),

$$
\frac{\mathrm{m}_{\mathrm{ox}, \mathrm{S} 1}}{\mathrm{~m}_{\mathrm{in}, \mathrm{S} 1}}=\bar{\eta}_{\mathrm{S} 1}-\frac{\mathrm{M}_{\mathrm{S} 1}-\mathrm{M}_{\mathrm{clean}}}{\mathrm{m}_{\mathrm{in}, \mathrm{S} 1}}
$$

And from (12),

$\frac{\mathrm{m}_{\mathrm{Ox}, \mathrm{S} 2}}{\mathrm{~m}_{\mathrm{in}, \mathrm{S} 2}}=\bar{\eta}_{\mathrm{S} 2}-\frac{\mathrm{M}_{\mathrm{S} 2}-\mathrm{M}_{\mathrm{S} 1}}{\mathrm{~m}_{\mathrm{in}, \mathrm{S} 2}}$

So then if we equate the LHS of (13) and (14) [Assumption 1],

$\bar{\eta}_{\mathrm{S} 1}-\frac{\mathrm{M}_{\mathrm{S} 1}-\mathrm{M}_{\mathrm{clean}}}{\mathrm{m}_{\mathrm{in}, \mathrm{S} 1}}=\bar{\eta}_{\mathrm{S} 2}-\frac{\mathrm{M}_{\mathrm{S} 2}-\mathrm{M}_{\mathrm{S} 1}}{\mathrm{~m}_{\mathrm{in}, \mathrm{S} 2}}$
$\frac{\mathrm{M}_{\mathrm{S} 1}-\mathrm{M}_{\mathrm{clean}}}{\mathrm{m}_{\mathrm{in}, \mathrm{S} 1}}=\bar{\eta}_{\mathrm{S} 1}-\left(\bar{\eta}_{\mathrm{S} 2}-\frac{\mathrm{M}_{\mathrm{S} 2}-\mathrm{M}_{\mathrm{S} 1}}{\mathrm{~m}_{\mathrm{in}, \mathrm{S} 2}}\right)$

or

$$
\mathrm{m}_{\mathrm{ret}, \mathrm{S} 1}=\mathrm{M}_{\mathrm{S} 1}-\mathrm{M}_{\text {clean }}=\bar{\eta}_{\mathrm{S} 1} \mathrm{~m}_{\mathrm{in}, \mathrm{S} 1}-\left(\bar{\eta}_{\mathrm{S} 2}-\frac{\mathrm{M}_{\mathrm{S} 2}-\mathrm{M}_{\mathrm{S} 1}}{\mathrm{~m}_{\mathrm{in}, \mathrm{S} 2}}\right) \mathrm{m}_{\mathrm{in}, \mathrm{S} 1}
$$

or

$$
\mathrm{m}_{\mathrm{ret}, \mathrm{S} 1}=\left(\mathrm{m}_{\mathrm{in}, \mathrm{S} 1}\left(\bar{\eta}_{\mathrm{S} 1}-\bar{\eta}_{\mathrm{S} 2}\right)+\left(\mathrm{M}_{\mathrm{S} 2}-\mathrm{M}_{\mathrm{S} 1}\right) \frac{\mathrm{m}_{\mathrm{in}, \mathrm{S} 1}}{\mathrm{~m}_{\mathrm{in}, \mathrm{S} 2}}\right)
$$

or

$$
\mathrm{M}_{\text {clean }}=\mathrm{M}_{\mathrm{S} 1}-\left(\bar{\eta}_{\mathrm{S} 1} \mathrm{~m}_{\mathrm{in}, \mathrm{S} 1}-\left(\bar{\eta}_{\mathrm{S} 2}-\frac{\mathrm{M}_{\mathrm{S} 2}-\mathrm{M}_{\mathrm{S} 1}}{\mathrm{~m}_{\mathrm{in}, \mathrm{S} 2}}\right) \mathrm{m}_{\mathrm{in}, \mathrm{S} 1}\right)
$$

Where:

$\mathrm{m}_{\mathrm{in}, \mathrm{S} 1}=\mathrm{C}_{\mathrm{in}, \mathrm{S} 1}\left(\frac{1}{1 \times 10^{3}} \frac{\mathrm{g}}{\mathrm{mg}}\right) \dot{\mathrm{V}}_{\mathrm{S} 1} \mathrm{t}_{\mathrm{S} 1}$ and $\mathrm{m}_{\mathrm{in}, \mathrm{S} 2}=\mathrm{C}_{\mathrm{in}, \mathrm{S} 2}\left(\frac{1}{1 \times 10^{3}} \frac{\mathrm{g}}{\mathrm{mg}}\right) \dot{\mathrm{V}}_{\mathrm{S} 2} \mathrm{t}_{\mathrm{S} 2}$ 
Table E1: Symbols

\begin{tabular}{|c|c|c|}
\hline Variable & Description & Units \\
\hline $\mathrm{M}_{\mathrm{S} 1}$ & Substrate weight measurement at the end of Stage-1 & [g] \\
\hline $\mathrm{M}_{\mathrm{S} 2}$ & Substrate weight measurement at the end of Stage-2 & [g] \\
\hline $\mathrm{M}_{\mathrm{S} 3}$ & Substrate weight measurement at the end of Stage-3 & [g] \\
\hline $\mathrm{M}_{\mathrm{S} 4}$ & Substrate weight measurement at the end of Stage-4 & [g] \\
\hline $\mathrm{m}_{\mathrm{in}, \mathrm{S} 1}$ & PM mass into the CPF during Stage-1 & [g] \\
\hline $\mathrm{m}_{\mathrm{in}, \mathrm{S} 2}$ & PM mass into the CPF during Stage-2 & [g] \\
\hline $\mathrm{m}_{\mathrm{in}, \mathrm{S} 3}$ & PM mass into the CPF during Stage-3 & [g] \\
\hline $\mathrm{m}_{\mathrm{in}, \mathrm{S} 4}$ & PM mass into the CPF during Stage- 4 & [g] \\
\hline $\mathrm{m}_{\text {out }, \mathrm{S} 1}$ & PM mass out of the CPF during Stage- 1 & [g] \\
\hline $\mathrm{m}_{\text {out,S2 }}$ & PM mass out of the CPF during Stage-2 & [g] \\
\hline $\mathrm{m}_{\text {out }, \mathrm{S} 3}$ & PM mass out of the CPF during Stage- 3 & [g] \\
\hline $\mathrm{m}_{\mathrm{out}, \mathrm{S} 4}$ & PM mass out of the CPF during Stage- 4 & [g] \\
\hline $\mathrm{m}_{\mathrm{ret}, \mathrm{S} 1}$ & PM mass retained in the CPF at the end of Stage- 1 & [g] \\
\hline $\mathrm{m}_{\mathrm{ret}, \mathrm{S} 2}$ & PM mass retained in the CPF at the end of Stage- 2 & [g] \\
\hline $\mathrm{m}_{\mathrm{ret}, \mathrm{S} 3}$ & PM mass retained in the CPF at the end of Stage- 3 & [g] \\
\hline $\mathrm{m}_{\mathrm{ret}, \mathrm{S} 4}$ & PM mass retained in the CPF at the end of Stage- 4 & [g] \\
\hline $\mathrm{m}_{\mathrm{ox}, \mathrm{S} 1}$ & PM mass oxidized in the CPF during Stage-1 & [g] \\
\hline $\mathrm{m}_{\mathrm{ox}, \mathrm{S} 2}$ & PM mass oxidized in the CPF during Stage- 2 & [g] \\
\hline $\mathrm{m}_{\mathrm{ox}, \mathrm{S} 3}$ & PM mass oxidized in the CPF during Stage- 3 & {$[\mathrm{~g}]$} \\
\hline $\mathrm{m}_{\mathrm{ox}, \mathrm{S} 4}$ & PM mass oxidized in the CPF during Stage- 4 & [g] \\
\hline $\bar{\eta}_{\mathrm{S} 1}$ & Average filtration efficiency of the CPF during Stage-1 & {$[]$.} \\
\hline $\bar{\eta}_{\mathrm{S} 2}$ & Average filtration efficiency of the CPF during Stage-2 & {$[\cdot]$} \\
\hline $\mathrm{C}_{\mathrm{in}, \mathrm{S} 1}$ & CPF inlet PM concentration during Stage-1 & {$\left[\mathrm{mg} / \mathrm{std} \cdot \mathrm{m}^{3}\right]$} \\
\hline $\mathrm{C}_{\mathrm{in}, \mathrm{S} 2}$ & CPF inlet PM concentration during Stage-2 & {$\left[\mathrm{mg} / \mathrm{std} \cdot \mathrm{m}^{3}\right]$} \\
\hline$\dot{\mathrm{V}}_{\mathrm{S} 1}$ & Volumetric flow rate of exhaust during Stage-1 & {$\left[\mathrm{std} . \mathrm{m}^{3} / \mathrm{s}\right]$} \\
\hline$\dot{\mathrm{V}}_{\mathrm{S} 2}$ & Volumetric flow rate of exhaust during Stage-2 & {$\left[\mathrm{std} . \mathrm{m}^{3} / \mathrm{s}\right]$} \\
\hline $\mathrm{t}_{\mathrm{S} 1}$ & Duration of Stage-1 loading & {$[\mathrm{s}]$} \\
\hline $\mathrm{t}_{\mathrm{S} 2}$ & Duration of Stage-2 loading & {$[\mathrm{s}]$} \\
\hline
\end{tabular}




\section{Appendix F PM Sample Preparation Procedure}

1. Label twelve plastic filter holders (Millipore Catalog Number PDMA04700) with the appropriate test number and filter number (i.e., B20-1-1, B20-1-2, etc.).

2. Place one filter (Pall Corporation $P / N$ 61631) in each filter holder.

3. The oven used for baking filters is located in the MEEM building, room B006 which is also the welding shop. The temperature on the oven is set to $575^{\circ} \mathrm{F}$. The oven needs to be turned on and allowed to warm up for one hour prior to baking filters.

4. After the oven has warmed up for one hour, place each filter, without the filter holder, onto the metal baking tray and place the tray in the oven. Leave the filters to bake for 15 minutes.

5. After the filters have baked for 15 minutes, remove them from the oven and place each one in its filter holder

6. Place each filter/filter holder combination, with the lid removed, in the humidity chamber located in the MEEM building, room SB013. The filters must stay in the chamber for 24 hours before weighing. The humidity chamber is maintained at $75 \pm 5 \%$ relative humidity.

7. Weigh each filter three times and record their weights, along with two control filters. the control filters are weighed at the time of filter weighing to track the weight change due to humidity changes in the chamber

8. After each filter is weighed three times and recorded, the filters are ready to be removed from the chamber and are prepared for the upcoming test. The filters can stay in the chamber until test day. 


\section{Appendix G Auxiliary Fuel Dosing Injector Calibration Procedure}

It is important to know the flow rate out of the doser injector during each test. The gaseous concentrations are not measured upstream of the DOC during active regenerations, so the $\mathrm{HC}$ concentrations are determined from the flow rate of the injector, fuel properties, and the flow rate of the exhaust. The doser is calibrated before each test to give the most accurate data.

The calibration process is as follows:

1. Disconnect the doser injector from the mount on the exhaust pipe.

2. Connect the doser injector to the doser injector calibration mount.

3. Place the doser, connected to the calibration mount, on top of a $500 \mathrm{~mL}$ beaker

4. Starting at $10 \%$ duty cycle, inject fuel into the beaker until at least $150 \mathrm{~mL}$ of fuel are collected. For duty cycles over $50 \%$, collect at least $250 \mathrm{~mL}$ of fuel.

5. Remove the beaker and pour entire contents into $500 \mathrm{~mL}$ graduated cylinder.

6. Verify that there are no bubbles in the fuel, and then take a reading from the graduated cylinder to determine how much fuel was injected at that duty cycle.

7. Empty contents of the graduated cylinder into fuel tank and move to the next duty cycle, in increments of $10 \%$.

8. Use the LabVIEW data file to determine how long the fuel was injected at each duty cycle, and subsequently, determine the injector flow rate at each duty cycle.

Figure $\mathrm{G} 1$ is an example of the calibration curve for the auxiliary doser injector with ULSD. 


\section{Doser Calibration}

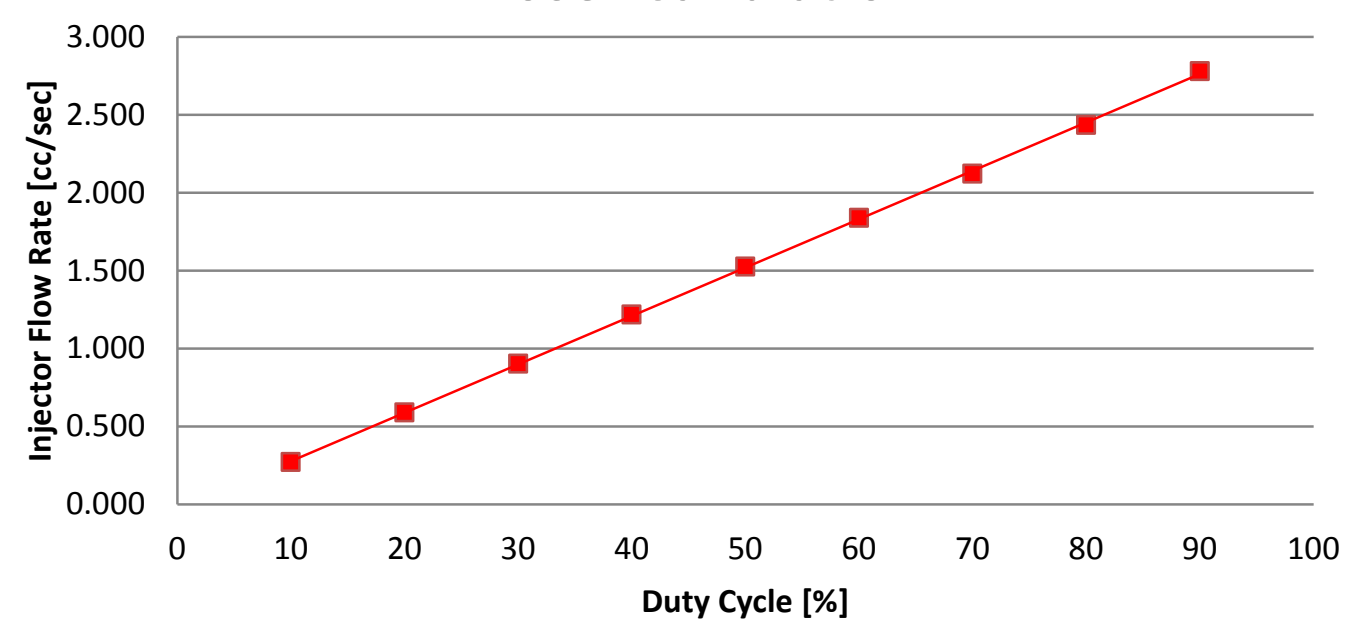

Figure G1: Example Auxiliary Doser Injector Calibration Curve with ULSD 


\section{Appendix H Data Integrity Analysis for Modeling}

From a modeling and data integrity perspective, it is important that the integrity of the experimental data collected during the active regeneration testing is good. This is important because inaccuracies with experimental data lead to difficulty in the modeling of the experimental data or inaccurate models all together. By analyzing a set of key variables throughout the course of each active regeneration test, the integrity of the experimental data to be used in the modeling studies can be determined. The key variables analyzed in this study include: exhaust flow rate, PM mass balance, CPF pressure drop profile, PM oxidation during loading, and the PM oxidation during active regeneration. Exhaust flow rate inaccuracies may lead to inaccurate PM mass balance, inaccurate PM mass balance can lead to inaccurate PM reaction rate analysis, visible variation in the CPF pressure drop profile at steady state conditions show data acquisition problems or pinpoint possible exhaust flow problems (such as a stuck exhaust diversion valve), and PM oxidation during loading and active regeneration help pinpoint PM concentration data and CPF mass flow rate measurement errors.

\section{Air Flow Rate and CPF Pressure Drop Profile}

Analyzing the air flow rate over the course of the entire test is important because errors in air flow rate data can lead to inaccurate CPF pressure drop modeling and PM mass balance results.

If the air flow rate and pressure drop profiles are not in error, the result is what is shown in Figure $\mathrm{H} 1$. Figure $\mathrm{H} 1$ shows the air flow entering the engine and $\mathrm{CPF}$ pressure drop profiles as a function of time for Run 2 (B20-2). It can be seen that the flow rate has two distinct values, corresponding to loading and active regeneration engine conditions. The pressure drop profile should be smooth and continuous through the loading phases, with the only major changes occurring during active regeneration. If the air flow rate and pressure drop profiles appear as shown in Figure $\mathrm{H} 1$, it can be said that the data, with respect to these two variables, has the correct trends. If the pressure drop recorded by the NI data acquisition system $\Delta \mathrm{P}$ sensor shows variation between phases, but the pressure drop recorded by CalTerm $\Delta \mathrm{P}$ sensor does not, it can be assumed that the data integrity is still good, 
but the variations were caused by errors in the data acquisition system itself, and these variations can be corrected prior to modeling and data analysis.
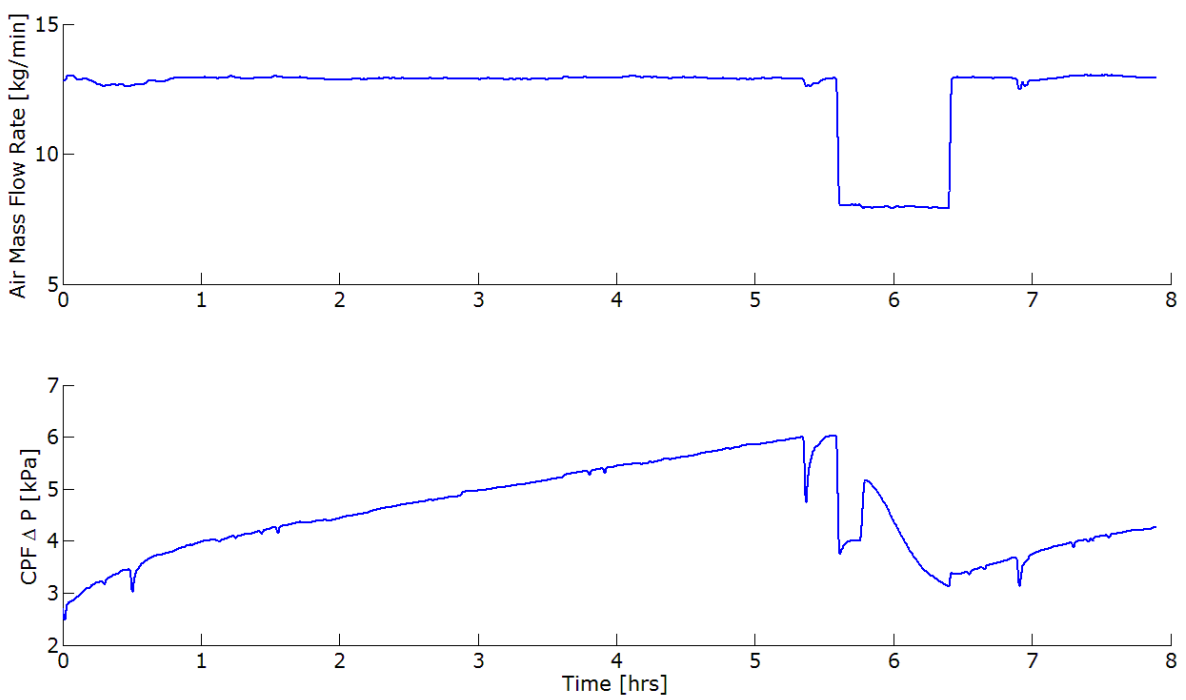

Figure H1: Air Flow Rate and CPF Pressure Drop for Run 2 (B20-2)
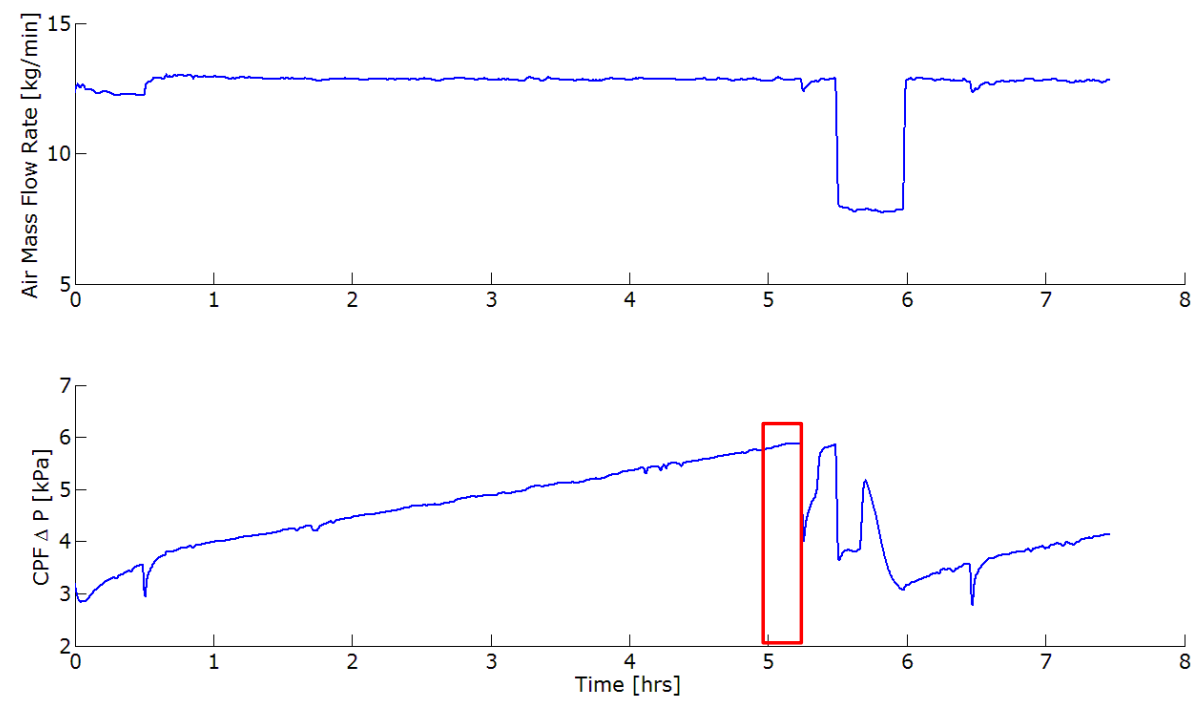

Figure H2: Air Flow Rate and CPF Pressure Drop Profile for Run 3 (B20-5)

The exhaust diversion valve is believed to be the cause for the drops in CPF pressure drop profile during loading ramp shown in Figure $\mathrm{H} 2$. Figure $\mathrm{H} 2$ is the same type of plot as Figure $\mathrm{H} 1$ except that Run $3(\mathrm{~B} 20-5)$ is shown. Within the area outlined in red 
in Figure $\mathrm{H} 2$, at $5.3 \mathrm{hrs}$, a rapid increase can be seen in the pressure drop profile during the loading ramp phase, prior to active regeneration. This was caused by the exhaust valve in the base line sticking slightly open. The rapid increase of the pressure drop was caused by this valve fully closing upon being struck with a hammer. This stuck valve results in an error in the exhaust flow rate at the CPF inlet i.e., all the engine air flow does not go through the CPF. This requires an air flow rate correction as described later in this section. If the pressure drop profile looks as expected (smooth and steady increase during loading, followed by smooth decrease during active regeneration, and another steady increase during post loading), and the flow rate data looks to be in error, the flow rate can be corrected based on prior test data. This is because the ISL 365 engine is operated at the same conditions during loading (2100 RPM and $195 \mathrm{Nm}$ ) and active regeneration (1400 RPM and 460 $\mathrm{Nm}$ ). Exhaust flow rate is computed based on the pressure drop across the laminar flow element on the engine intake system. One possible error source within the DAQ system is that the pressure transducers, responsible for measuring pressure drop profiles across the LFE, DOC, and CPF, have an offset due to the variation in ambient temperature, resulting in inaccurate Stage 1 pressure drop data.

Another way of determining if the CPF pressure drop measurements are in error is to compare the CPF pressure drop measured by the DAQ system to the CPF pressure drop measured by the engine calibration software. One such comparison can be seen in Figure H3, where the CPF pressure drop, measured by both systems, are displayed together as a function of time for Run 11 (B10-2).

It can be seen that during the Stage 1 loading portion of the experiment, the pressure drop measured by the DAQ system is slightly lower (with respect to Stage 2 loading) than the pressure drop measured by CalTerm. This could be caused by the changing of the zero-pressure point due to the temperature change in the test cell through the end of Stage 1 . The decreased pressure drop was not measured by CalTerm, which is why errors with the DAQ system are believed to have been present. With respect to the Stage 1 to Stage 2 vertical shifts in pressure drop across the CPF, the trend in the CalTerm data is assumed to be correct since the test cell temperature does not appear to affect this data as it has shown to affect the data recorded by the NI DAQ system. 


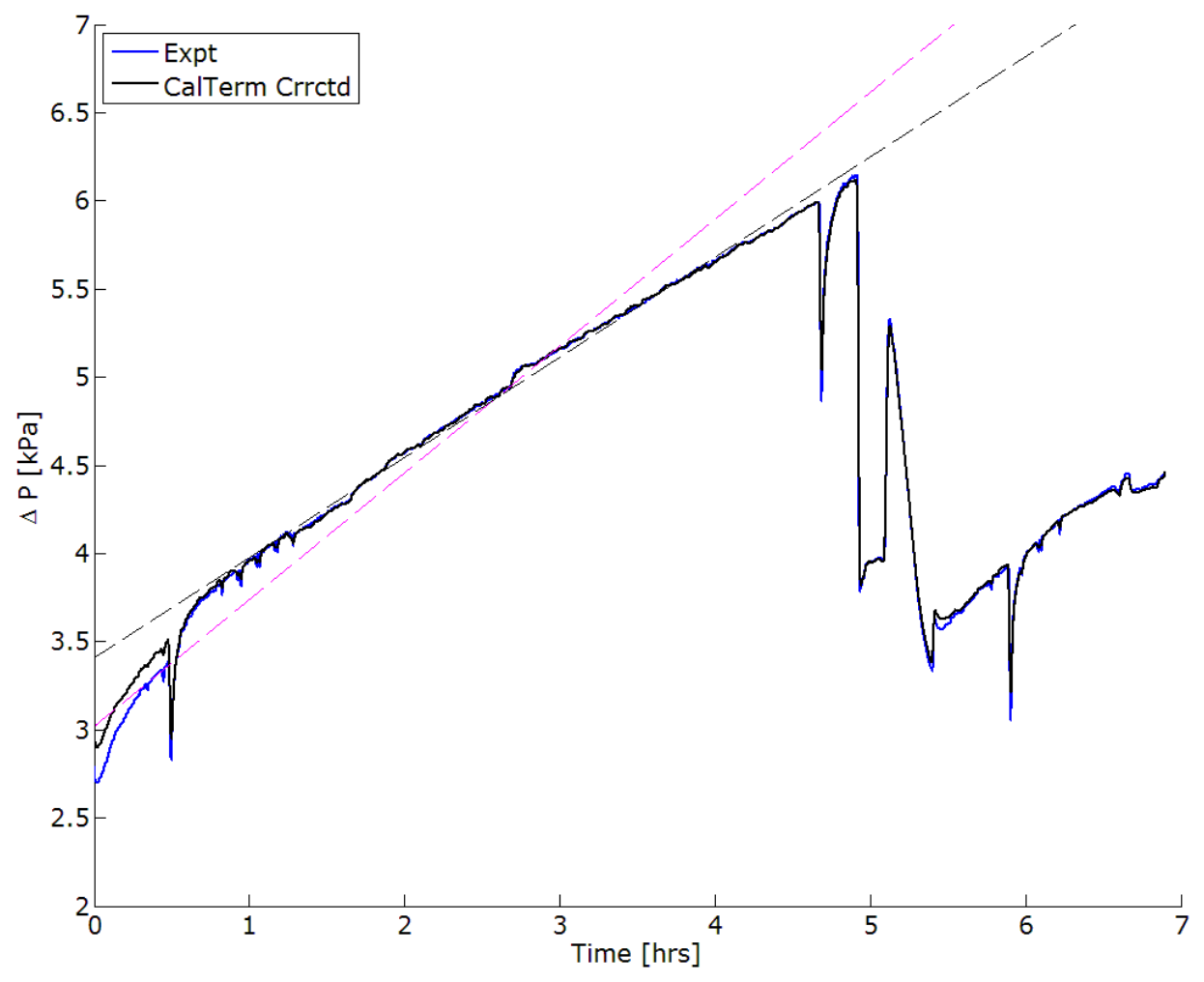

\section{Figure H3: CPF Pressure Drop Profile for Run 11 (B10-2) Measured by NI DAQ System and CaITerm Engine Management Software}

If the air flow rate and pressure drop profiles are not in error, the result is similar to which can be seen in Figure $\mathrm{H} 4$ which shows the air flow entering the engine and CPF pressure drop profiles as a function of time for Run 2 (B20-2). It can be seen that the flow rate has two distinct values, corresponding to loading and active regeneration engine conditions, as expected. The pressure drop profile is also smooth and continuous through the loading phases, with the only major fluctuations occurring during active regeneration. If the air flow rate and pressure drop profiles appear as shown in Figure $\mathrm{H} 4$, it can be said that the data, with respect to these two variables, is good. If the pressure drop profile appears as expected, but there are variations in the measured flow rate, the data remains good because the flow rate data can be corrected. 

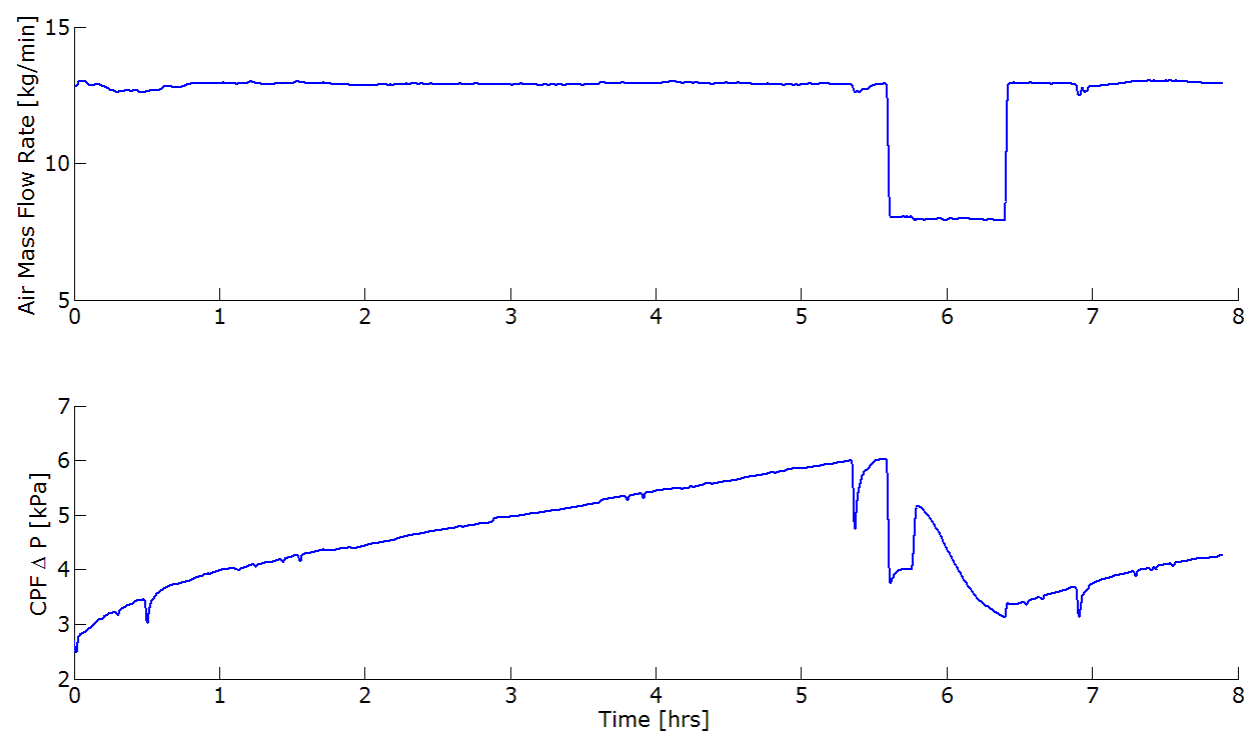

Figure H4: Air Flow Rate and CPF Pressure Drop Profile for Run 2 (B20-2)

The experimentally measured air flow rate and CPF pressure drop profile plots for all tests can be found in Appendix $\mathrm{N}$ while the CPF pressure drop comparison between the NI LabVIEW DAQ system and CalTerm for all tests (where CalTerm data was not corrupted) can be found in Appendix P. The CalTerm data in Appendix P was corrected to lie on the data from the NI LabVIEW DAQ system using the calibration equation that was obtained from separate calibration of the CalTerm CPF pressure drop sensor.

\section{Stage 2 Loading PM Mass Balance}

The PM mass balance throughout the various phases of each experiment is also important from a modeling and a data analysis point of view because accurate CPF PM mass retained prediction is a vital component to the MTU-1D CPF model. The model relies on accurate flow rate and PM concentration data to accurately predict the amount of PM entering the CPF at any given point during the test. If the flow rate or PM concentration data are in error, the resulting CPF PM mass retained is also in error, resulting in difficulty with model calibration and validation.

The amount of PM oxidized during Stage 2 loading indicates potential irregularities with PM concentration, flow rate, $\mathrm{NO}_{2}$ concentration, exhaust gas temperature, or CPF weight measurements. During the ISL 365 testing presented in this study, the 
mean PM oxidation during Stage 2 loading for all test cases was $21 \%$ with a standard deviation of $9 \%$. The test cases outside of this boundary were extreme cases, such as test ULSD-3, where 38\% PM oxidation was observed.

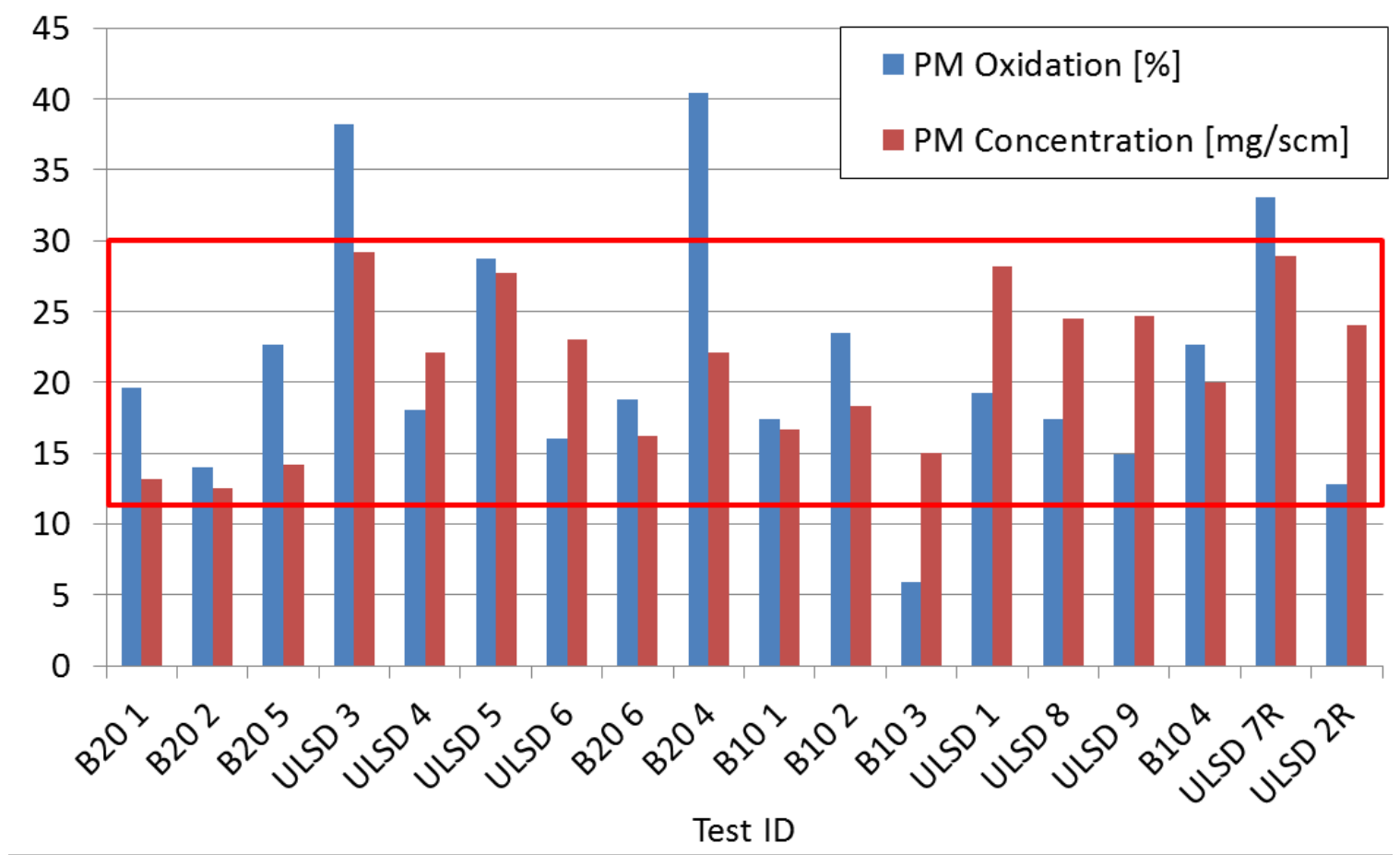

Figure H5: Stage 2 Loading PM Concentration and Percent Oxidation for All Tests

The red rectangle in Figure $\mathrm{H} 5$ outlines the $21 \pm 9 \%$ bounds for PM oxidation during Stage 2 loading. Since the CPF inlet $\mathrm{NO}_{2}$ concentrations for all test cases are within $10 \mathrm{ppm}$ of each other, and since the test cases with PM oxidation above $30 \%$ did not show elevated $\mathrm{CPF}$ inlet $\mathrm{NO}_{2}$ concentrations, gaseous emission measurement errors are not believed to be a contributing factor to the results shown in Figure $\mathrm{H} 5$. Engine-out PM concentration and CPF mass measurement errors have the potential to introduce error into the CPF PM retained calculations, thereby affecting the PM oxidation calculation results.

If the Stage 2 loading PM oxidation falls within the described bounds, the data set is assumed to be good with respect to the Stage 2 loading PM mass balance. PM oxidation for runs ULSD-3, B20-4, B10-3, and ULSD-7R are outside the $21 \pm 9 \%$ bounds. 
The experimental results from test ULSD-3 show that the PM oxidation during Stage 2 was approaching 40\%, which was inconsistent with previous ISL 365 data. In order for the Stage 2 PM oxidation to be reduced, the engine-out PM concentration or CPF mass measurement data is in error. The PM concentration data is the most likely source of error in this case because the CPF mass measurements at the end of Stage 1 and Stage 2 loading were within 3 grams of each other for tests ULSD-3, 4, 5, and 6 , which were run within the same two week window. The Stage 2 PM oxidation and engine-out PM concentration data for ULSD-3 and ULSD-5 were elevated compared to ULSD-4 and 6, which can be seen by the blue and red bars in Figure H5. Reducing the experimental engine-out PM concentration by $4 \mathrm{mg} / \mathrm{scm}$ reduces the Stage 2 PM oxidation to $30 \%$ for ULSD-3, which is within the described boundaries.

The elevated PM oxidation during Stage 2 of test B20-4 is also a function of elevated PM concentration data. The PM concentration for B20-4 was the highest of all the B20 tests, as shown by the red bars in Figure H5. As with ULSD-3, the CPF mass measurements are believed to be accurate. Reducing the engine-out PM concentration by $4 \mathrm{mg} / \mathrm{scm}$ reduces the Stage 2 PM oxidation to 30\% for B20-4, which is within the described boundaries.

Similarly, the elevated Stage 2 PM oxidation data from ULSD-7R is also a function of elevated PM concentration data as well. The CPF mass measurements at the end of Stage 1 and Stage 2 loading between ULSD-7R and 2R were within 1 gram of each other with the same reported CPF PM loading for each test $(2.6 \mathrm{~g} / \mathrm{L})$. The PM concentration for ULSD-7R is similar to ULSD-3, where the PM concentrations were among the highest of all the test cases, which can be seen by the red bars in Figure H5. Reducing the engine-out PM concentration by $2 \mathrm{mg} / \mathrm{scm}$ reduces the Stage $2 \mathrm{PM}$ oxidation to $29 \%$ for ULSD-7R, which is within the described boundaries.

The low amount of PM oxidation reported during Stage 2 of test B10-3 is also a function of inaccurate PM concentration data. The PM concentration from test B10-3 is the lowest of all of the B10 tests, which can be seen by the red bars in Figure $\mathrm{H} 5$. When compared to tests $\mathrm{B} 10-1$ and 2, the CPF mass measurements at the end of Stage 1 were within 2 grams of each other. The mass measurement at the end of Stage 2 for B10-3 was an average of 7 grams lower than B10-1 and 2, but the CPF PM loading was $0.4 \mathrm{~g} / \mathrm{L}$ lower, which coincides with a 7 gram reduction in CPF mass. 
Raising the engine-out PM concentration by $2 \mathrm{mg} / \mathrm{scm}$ raises the Stage 2 PM oxidation to $15 \%$, which is within the described boundaries.

The specific reasoning behind the error associated with the PM concentration data is unknown. It is possible that filter mass errors were introduced by the physical handling of each PM sample. Any addition or loss of mass on the PM sample due to handling directly introduces error into the PM sample mass measurements, which is used directly to determine the mass of PM from a measured volume of exhaust flow.

\section{Active Regeneration PM Mass Balance}

For all experiments in this study, the target PM oxidation through active regeneration remained at $70 \%$ for a number of reasons. First, the behavior of a clean CPF vs. a partially regenerated CPF is the reason behind the post loading which occurs after regeneration. Second, if all of the PM within the CPF is oxidized, there is a chance that error in the CPF mass measurements could be introduced due to a lack of PM retained within the CPF. For example, with $2.2 \mathrm{~g} / \mathrm{L}$ PM loading prior to active regeneration, $37.6 \mathrm{~g}$ of $\mathrm{PM}$ is present in the filter. After $80 \% \mathrm{PM}$ oxidation occurs during active regeneration, $7.5 \mathrm{~g}$ of PM remain, and after 30 minutes of Stage 3 loading, there is typically an additional $5 \mathrm{~g}$ of PM deposited, for a total of $12.5 \mathrm{~g}$ of $\mathrm{PM}$ retained within the CPF.

The CPF itself weighs upwards of $17.5 \mathrm{~kg}$, so the highest amount of PM retained within the CPF at the time of weighing is desirable. The possibility of CPF weighing inaccuracy is increased with increased levels of PM oxidation during active regeneration; therefore, if PM oxidation during active regeneration is between 40 and $80 \%$, it is assumed that the PM mass retained within the CPF can accurately be determined. 


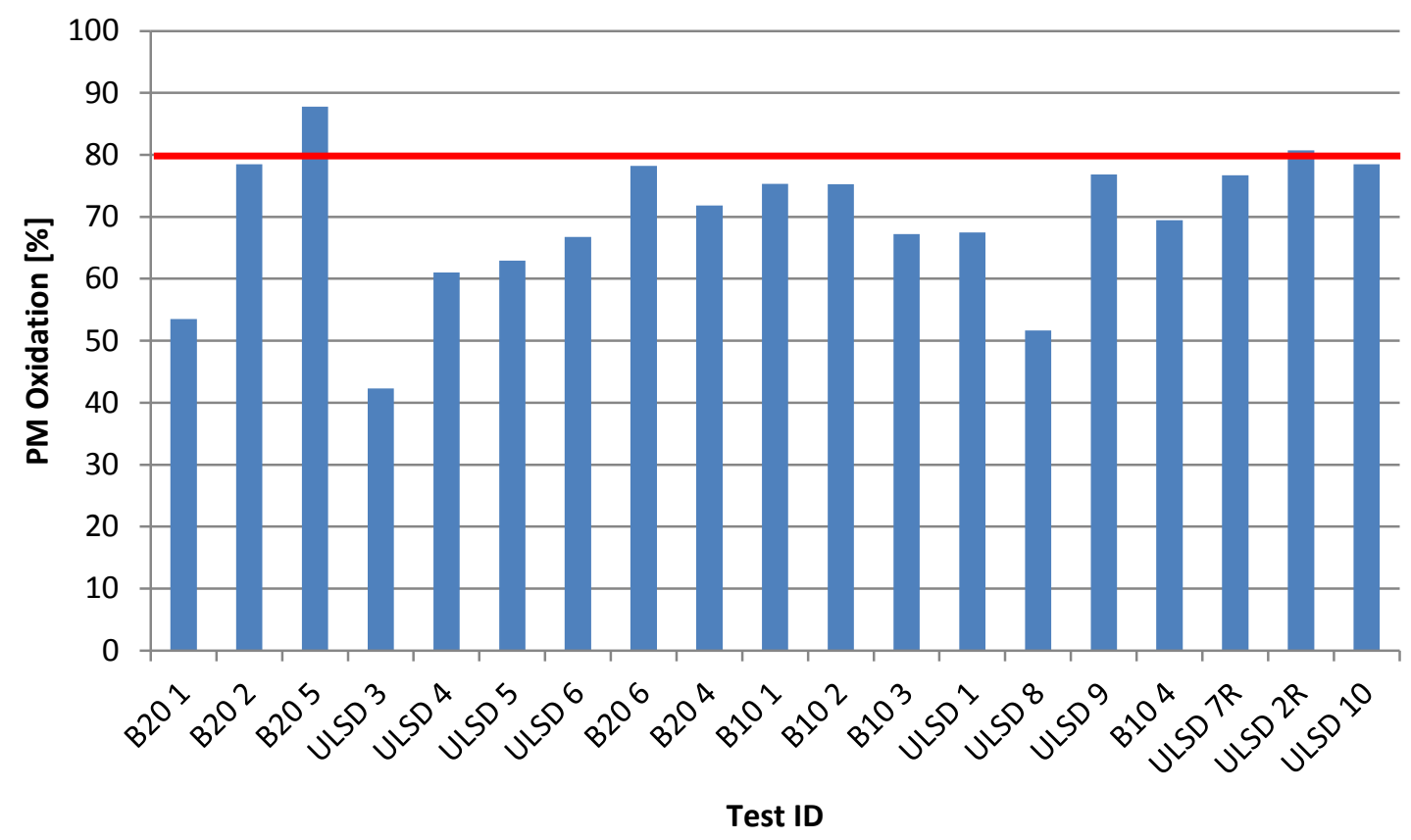

Figure H6: Active Regeneration PM Oxidation for All Tests

Figure $\mathrm{H} 6$ shows the amount of PM oxidized for each run through active regeneration, with a red line showing the cutoff point of $80 \%$. The reason low PM oxidation is not considered to invalidate the data is because the PM mass within the $\mathrm{CPF}$ at the time of weighing is increased, thereby reducing the possibility of CPF mass measurement errors.

As previously mentioned, $12.5 \mathrm{~g}$ of PM is typically retained within the CPF at the time of CPF weighing following Stage 3 loading assuming 80\% PM oxidation during active regeneration. With a scale rated for $0.1 \mathrm{~g}$ readability and $0.3 \mathrm{~g}$ repeatability, $12.5 \mathrm{~g}$ of PM can easily be calculated by using CPF mass measurements.

$27.6 \mathrm{~g}$ of PM is typically retained within the CPF at the time of CPF weighing following Stage 3 loading assuming 40\% PM oxidation during active regeneration. With $2.2 \mathrm{~g} / \mathrm{L}$ equating to $37.6 \mathrm{~g}$ of $\mathrm{PM}, 10 \mathrm{~g}$ of $\mathrm{PM}$ is oxidized. With the scale ratings described above, $10 \mathrm{~g}$ of CPF mass change due to PM oxidation can easily be calculated using CPF mass measurements. For this reason, $40 \%$ oxidation is the lower limit that is acceptable to accurately determine the change in CPF mass due to the active regeneration test phase. 


\section{CPF Resistance}

The CPF flow resistance was calculated for each test case based on the methodology from the CPF Flow Resistance section in Chapter 3 (section 3.10). The first step is to determine the CPF flow resistance based on the raw experimental data as shown in Figure H7.
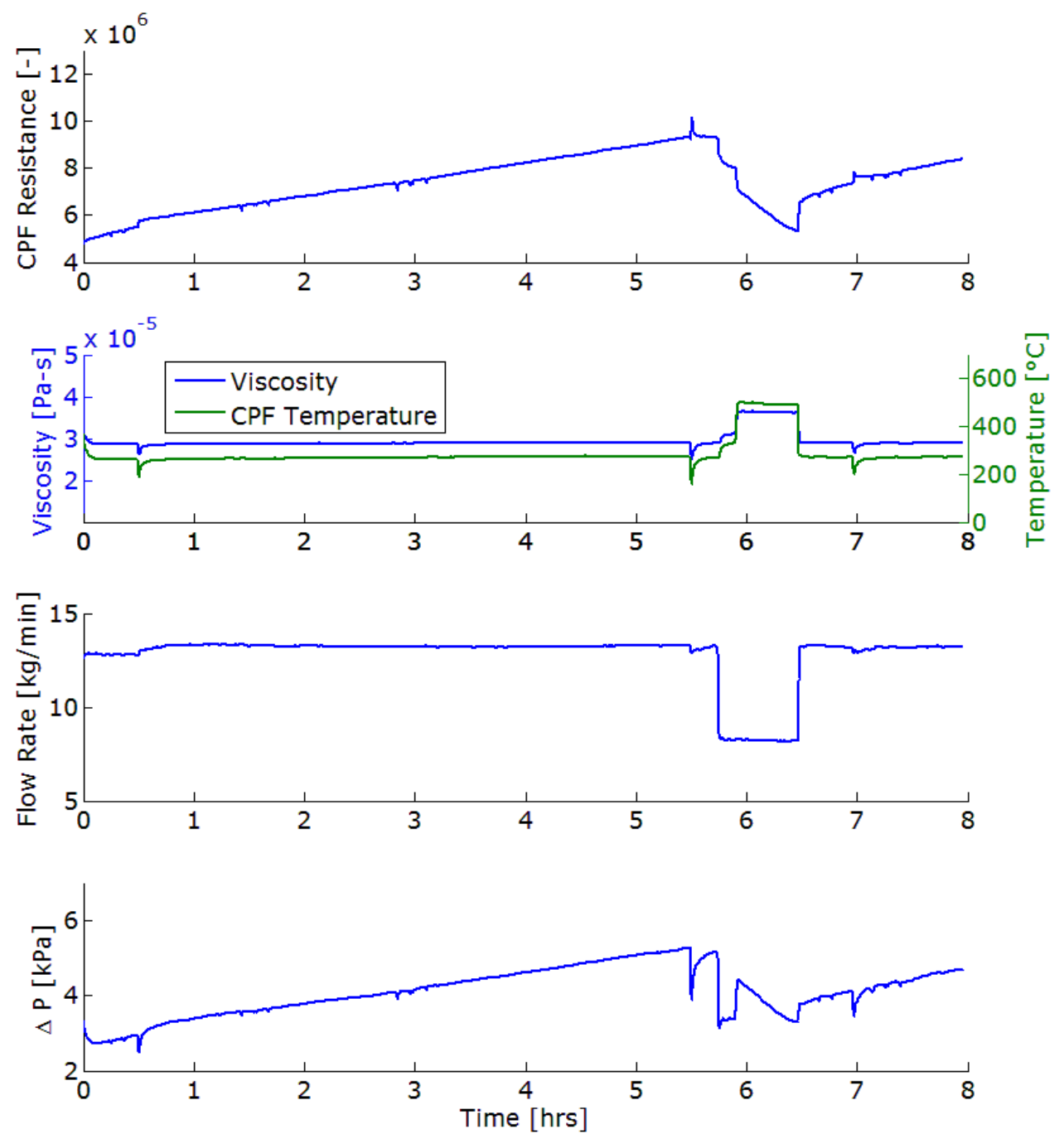

Figure H7: Run 1 (B20-1) Experimental CPF Flow Resistance (subplot 1), Exhaust Viscosity and CPF Average Temperature (subplot 2), Exhaust Mass Flow Rate (subplot 3), and CPF Pressure Drop Profile (subplot 4)

The CPF flow resistance analysis allows for the determination of the correction factor CF (Eqn. 20), during the pre-active regeneration ramp up and active regeneration 
test phases, in order to eliminate the upward and downward vertical shifts in CPF resistance that should not be present, as explained earlier in section 3.10. In order to determine $\mathrm{CF}$ for each test case, a specific procedure for experimental data corrections need to be utilized. The steps for this procedure are outlined below.

1. Correct the engine-out mass flow rate based upon DAQ system error associated with pressure transducer readings as well as exhaust bypass valve leaks which result in less mass flow rate through the CPF.

2. Correct CPF pressure drop data based on Stage 1 vs. Stage 2 loading CPF pressure drop offset

3. Determine the $\mathrm{CF}$ for active regeneration ramp and active regeneration test phases based on a resistance curve without upward and downward vertical shifts as present in Figure $\mathrm{H} 7$.

\section{Step 1}

LFE pressure drop errors are believed to have been introduced during Stage 1 loading due to the temperature change in the test cell, affecting the calculated engine-out mass flow rate as a result. The increase in test cell temperature during Stage 1 loading is believed to have introduced an error in the DAQ system and its ability to properly read a zero-pressure reading on the pressure transducers. Since the engine-in air flow rate is calculated based on the pressure drop of the LFE, the errors associated with the pressure drop readings affect the exhaust mass flow rate. The pressure transducer on the LFE has a measurement limit of $3.4 \mathrm{kPa}$. A $20^{\circ} \mathrm{F}$ change in test cell temperature can influence the LFE pressure drop by $0.2 \mathrm{kPa}$, subsequently resulting in a difference in exhaust mass flow rate of $0.3 \mathrm{~kg} / \mathrm{min}(2.4 \%$ of a typical average equivalent to $12.7 \mathrm{~kg} / \mathrm{min}$ ).

Table $\mathrm{H} 1$ shows the average exhaust mass flow rate for S1, S2, Loading Ramp, S3, and S4 loading phases, for all experiments. The average exhaust mass flow rate for all loading phases was calculated for each experiment and is shown in the 'Loading Average' column of Table H1. The green cells in Table H1 correspond to those tests which are within $5 \%$ of the average value for the loading phases of that particular test, because experimental measurements within $5 \%$ of one another are acceptable from an experimental data collection standpoint. 
Table H1: Experimental Exhaust Mass Flow Rate

\begin{tabular}{|c|c|c|c|c|c|c|c|}
\hline \multirow{2}{*}{ Run } & \multirow{2}{*}{ Test } & \multicolumn{5}{|c|}{ Test Phase Exhaust m $[\mathrm{kg} / \mathrm{min}]$} & Loading \\
\cline { 3 - 7 } & & S1 & S2 & LD_RMP & S3 & S4 & Average \\
\hline 1 & B20 1 & 12.8 & 13.3 & 13.1 & 13.2 & 13.2 & 13.1 \\
\hline 2 & B20 2 & 13.0 & 13.2 & 13.1 & 13.2 & 13.2 & 13.1 \\
\hline 3 & B20 5 & 12.7 & 13.2 & 13.0 & 13.1 & 13.0 & 13.0 \\
\hline 4 & ULSD 3 & 12.7 & 12.9 & 12.8 & 12.8 & 13.0 & 12.8 \\
\hline 5 & ULSD 4 & 10.9 & 12.7 & 12.5 & 12.7 & 12.5 & 12.6 \\
\hline 6 & ULSD 5 & 12.8 & 12.7 & 12.8 & 12.9 & 12.9 & 12.8 \\
\hline 7 & ULSD 6 & 12.8 & 12.8 & 13.0 & 13.0 & 12.9 & 12.9 \\
\hline 8 & B20 6 & 12.7 & 13.0 & 13.0 & 13.1 & 13.0 & 13.0 \\
\hline 9 & B20 4 & 12.8 & 13.0 & 13.0 & 13.0 & 13.0 & 13.0 \\
\hline 10 & B10 1 & 12.7 & 12.9 & 12.8 & 12.9 & 12.9 & 12.8 \\
\hline 11 & B10 2 & 12.4 & 12.8 & 12.9 & 13.0 & 12.9 & 12.8 \\
\hline 12 & B10 3 & 13.0 & 13.0 & 12.8 & 13.0 & 12.9 & 12.9 \\
\hline 13 & ULSD 1 & 12.4 & 12.5 & 12.8 & 12.8 & 11.3 & 12.6 \\
\hline 14 & ULSD 8 & 10.7 & 12.4 & 12.3 & 12.5 & 12.5 & 12.4 \\
\hline 15 & ULSD 9 & 12.4 & 11.0 & 12.8 & 12.6 & 12.6 & 12.6 \\
\hline 16 & B10 4 & 12.2 & 12.5 & 12.3 & 12.7 & 12.7 & 12.5 \\
\hline 17 & ULSD 7R & 12.1 & 12.5 & 12.2 & 12.4 & 12.3 & 12.3 \\
\hline 18 & ULSD 2R & 12.1 & 12.4 & 12.4 & 12.4 & 12.4 & 12.3 \\
\hline
\end{tabular}

In order to correct for the error in the Stage 1 loading LFE pressure drop, the pressure transducer readings at the beginning and end of Stage 1, when the engine was not running, was analyzed. The difference in the zero-pressure readings between the start and stop of Stage 1 were tabulated, with the results shown in Table H2. The positive Stage 1 LFE pressure drop offset, measured exhaust mass flow rate, the change in the flow rate due to the LFE pressure drop offset, the corrected flow rate, and the percent change in flow rate are shown in Table H2. Only Runs 5 and 14 required a flow rate correction that is large enough to be considered an error not due to experimental variability. They were the only test cases which experienced more than $5 \%$ change in the measured exhaust mass flow rate, as compared to the results shown in the S1 column of Table H1. 
Table H2: LFE Pressure Drop Corrections

\begin{tabular}{|c|c|c|c|c|c|c|}
\hline Run & Variable & $\begin{array}{c}\text { S1 LFE } \\
\text { DP Offset }\end{array}$ & $\begin{array}{c}\text { S1 Measured } \\
\text { Exhaust Mass } \\
\text { Flow Rate }\end{array}$ & $\begin{array}{c}\text { Flow Rate } \\
\text { Change }\end{array}$ & $\begin{array}{c}\text { S1 Corrected } \\
\text { Exhaust Mass } \\
\text { Flow Rate }\end{array}$ & $\begin{array}{c}\text { Percent } \\
\text { Change in } \\
\text { Flow Rate }\end{array}$ \\
\cline { 2 - 7 } & Test/Units & $\mathrm{kPa}$ & $\mathrm{kg} / \mathrm{min}$ & $\mathrm{kg} / \mathrm{min}$ & $\mathrm{kg} / \mathrm{min}$ & $\%$ \\
\hline 1 & B20 1 & 0.02 & 12.8 & 0.2 & 13.0 & 1.7 \\
\hline 2 & B20 2 & 0.01 & 13.0 & 0.2 & 13.2 & 1.4 \\
\hline 3 & B20 5 & 0.01 & 12.7 & 0.2 & 12.9 & 1.5 \\
\hline 4 & ULSD 3 & 0.01 & 12.7 & 0.1 & 12.8 & 0.6 \\
\hline 5 & ULSD 4 & 0.11 & 10.9 & 1.6 & 12.5 & 14.5 \\
\hline 6 & ULSD 5 & 0.02 & 12.8 & 0.2 & 13.0 & 1.7 \\
\hline 7 & ULSD 6 & 0.02 & 12.8 & 0.3 & 13.1 & 2.1 \\
\hline 8 & B20 6 & 0.00 & 12.7 & 0.1 & 12.8 & 0.5 \\
\hline 9 & B20 4 & 0.01 & 12.8 & 0.1 & 12.9 & 0.7 \\
\hline 10 & B10 1 & 0.02 & 12.7 & 0.3 & 13.0 & 2.2 \\
\hline 11 & B10 2 & 0.02 & 12.4 & 0.2 & 12.6 & 1.8 \\
\hline 12 & B10 3 & 0.02 & 13.0 & 0.2 & 13.2 & 1.7 \\
\hline 13 & ULSD 1 & 0.01 & 12.4 & 0.2 & 12.6 & 1.7 \\
\hline 14 & ULSD 8 & 0.11 & 10.7 & 1.6 & 12.3 & 14.9 \\
\hline 15 & ULSD 9 & 0.01 & 12.4 & 0.2 & 12.6 & 1.4 \\
\hline 16 & B10 4 & 0.02 & 12.2 & 0.2 & 12.4 & 1.8 \\
\hline 17 & ULSD 7R & 0.02 & 12.1 & 0.2 & 12.3 & 1.9 \\
\hline 18 & ULSD 2R & 0.02 & 12.1 & 0.2 & 12.3 & 1.9 \\
\hline
\end{tabular}

The information from Table $\mathrm{H} 2$ was used to determine the exhaust mass flow rate scaling factors (SF) for all phases of each test. The scaling factors (SF) for each test case can be seen in Table H3. The cells which are green in Table H3 correspond to the test phases which did not require any scaling because the experimental flow rates were measured within acceptable experimental variability. The scaling factors shown in Table H3 for S4 and S2 of Runs 14 and 15, respectively, were due to an unknown error source during LFE pressure drop measurements. The scaling factors shown in the ' $\mathrm{S} 1$ ' column of Table $\mathrm{H} 3$ for each test was due to the LFE pressure drop corrections from Table $\mathrm{H} 2$.

The exhaust flow rate also required scaling factors to be applied where exhaust bypass valve leaks were occurring. A leaking exhaust bypass valve results in decreased pressure drop across the CPF due to a reduction in exhaust flow. The reduction in CPF pressure drop is proportional to the reduction in flow rate. Scaling factors were applied to the exhaust flow rate in the same method which was used to 
correct LFE pressure drop measurement errors. For Runs 3, 4, 5, and 6, the bypass exhaust valve was leaking as evidenced by their respective CPF pressure drop profiles, which were shown to be inconsistent with the characteristics associated with CPF PM loading (steady increase in CPF pressure drop at steady state engine conditions) between and/or during test phases.

The exhaust flow rate scaling factors for each test case can be seen in Table H3. The scaling factors (SF) shown in Table H3 account for LFE pressure drop errors as well as exhaust flow rate reduction due to a leaking exhaust bypass valve. As previously mentioned, up to $5 \%$ variation was seen within the test phases corresponding to green cells in Table H3, but this range was considered to be due to experimental variability. The MTU-1D CPF model does not have any problems operating with these small variations in experimental data.

Table H3: Exhaust Mass Flow Rate Scaling Factors (SF)

\begin{tabular}{|c|c|c|c|c|c|c|c|c|}
\hline \multirow{2}{*}{ Run } & \multirow{2}{*}{ Test } & \multicolumn{7}{|c|}{ Average Mass Flow Rate Correction by Phase* [-] } \\
\hline & & S1 & S2 & LD RMP & AR RMP & AR & S3 & S4 \\
\hline 1 & B20 1 & 1.02 & & & & & & \\
\hline 2 & B20 2 & 1.01 & & & & & & \\
\hline 3 & B20 5 & 1.02 & & $0.92^{* *}$ & & & & \\
\hline 4 & ULSD 3 & 1.01 & & $0.86^{* *}$ & $0.86^{* *}$ & $0.86^{* *}$ & $0.90^{* *}$ & $0.90^{* *}$ \\
\hline 5 & ULSD 4 & 1.15 & $0.95^{* *}$ & $0.82^{* *}$ & $0.95^{* *}$ & $0.95^{* *}$ & $0.95^{* *}$ & $0.84^{* *}$ \\
\hline 6 & ULSD 5 & 1.02 & & $0.94^{* *}$ & & & & \\
\hline 7 & ULSD 6 & 1.02 & & & & & & \\
\hline 8 & B20 6 & 1.01 & & & & & & \\
\hline 9 & B20 4 & 1.01 & & & & & & \\
\hline 10 & B10 1 & 1.02 & & & & & & \\
\hline 11 & B10 2 & 1.02 & & & & & & \\
\hline 12 & B10 3 & 1.02 & & & & & & \\
\hline 13 & ULSD 1 & 1.02 & & & & & & 1.15 \\
\hline 14 & ULSD 8 & 1.15 & & & & & & \\
\hline 15 & ULSD 9 & 1.01 & 1.13 & & & & & \\
\hline 16 & B10 4 & 1.02 & & & & & & \\
\hline 17 & ULSD 7R & 1.02 & & & & & & \\
\hline 18 & ULSD 2R & 1.02 & & & & & & \\
\hline
\end{tabular}

* Corrects for LFE flow rate measurement and bypass valve errors

$* *$ Corrects for bypass valve leaks

The cells within Table $\mathrm{H} 3$ which are highlighted green are the test phases which required slight scaling factors greater than 0.95 and less than 1.05 because experimental measurement within $5 \%$ of the actual exhaust flow rate is acceptable. 
The cells within Table H3 which include a numerical value are the test phases which required SF to compensate for flow rate errors (Runs 5, 13, 14, and 15) and exhaust bypass valve leaks (Runs 3, 4, 5, 6).

In terms of the active regeneration analysis in this study, no experimental data requires alteration due to the exhaust mass flow rate scaling factors (SF). This is because the active regeneration analysis in this study (i.e., PM reaction rate, regeneration efficiency of fuel dosing, etc.) is based off of the CPF mass measurements.

The exhaust flow rate is important from a modeling perspective because the PM flowing into the CPF at any test point is a function of exhaust mass flow rate and engine-out PM concentration. For test cases, such as ULSD-4, the scaling factors should be applied to the MTU-1D CPF Model exhaust mass flow rate input data. For purposes of the analysis of PM oxidation during Stage 2 loading phases, the flow rate data shown in the CPF mass balances for Stage 2 loading (Appendix $\mathrm{K}$ ) has been updated using the SF · experimental mass flow rate data.

\section{Step 2}

As previously stated, it is believed that the test cell temperature rise through the end of Stage 1 loading is negatively affecting the experimental data by introducing error into the CPF and LFE pressure drop measurements. In order to correct the CPF pressure drop data during Stage 1 loading, comparison of the CPF pressure drop recorded by the National Instruments DAQ system and Cummins CalTerm software are compared.

The Cummins CPF pressure drop sensor was calibrated by the Heavy Duty Diesel Group over a pressure range from 0 to $30 \mathrm{kPa}$. The first step is applying the calibration correction to the CalTerm pressure drop where the experimental readings are $\mathrm{DP}_{\mathrm{CPF}-\mathrm{Cal}}$ and the corrected readings are $\mathrm{DP}_{\text {actual }}$. The calibration curve equation was determined to be $\mathrm{DP}_{\text {actual }}[\mathrm{kPa}]=1.0597 \cdot \mathrm{DP}_{\mathrm{CPF}-\mathrm{Cal}}[\mathrm{kPa}]+0.8946$ with an $\mathrm{R}^{2}$ value of 0.9996 over five data points.

After the CalTerm pressure drop data calibration correction has been applied, the difference between CalTerm and DAQ system pressure drop readings is calculated from the start of Stage 2 through the end of Stage 4 loading. The average of this 
difference is applied to the CalTerm data so that the curves lie on each other after Stage 1 loading, with the results for B20-1 visible in Figure $\mathrm{H} 8$.

In Figure $\mathrm{H} 8$, the blue curve is the experimental CPF pressure drop measured by the DAQ system and the black curve is the corrected CalTerm pressure drop. The correlation between the two signals is good after Stage 2 loading, confirming the hypothesis that the Stage 1 loading pressure drop measurements are subject to error. The red line at the end of Stage 1 loading represents the offset to be applied to the DAQ system pressure drop and is equal to $0.19 \mathrm{kPa}$ for test $\mathrm{B} 20-1$.

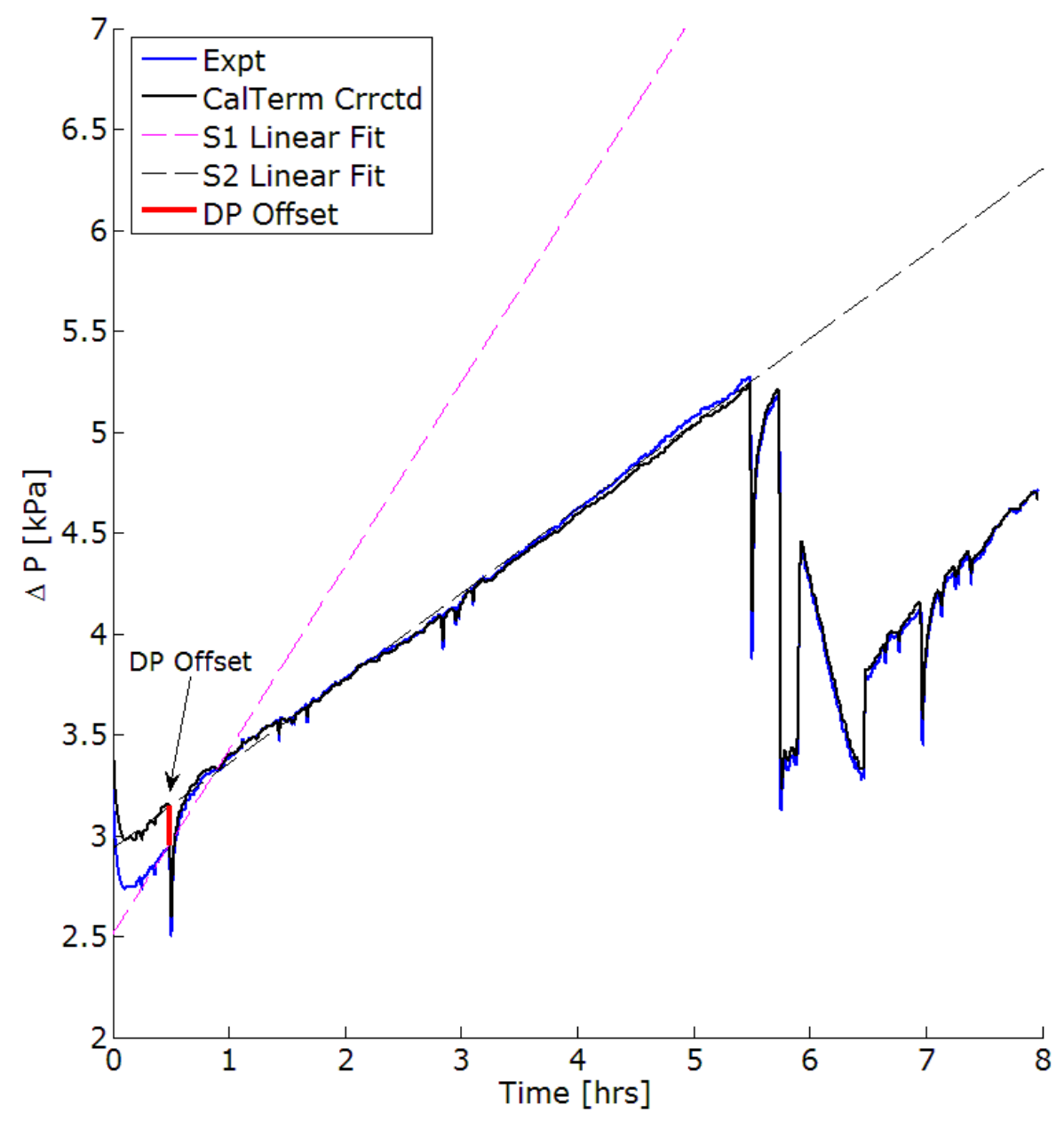

Figure H8: Run 1 (B20-1) NI and Corrected CalTerm Pressure Drop Profiles Including Linear Fit of NI Stage 1 and Stage 2 Loading and Pressure Drop Offset 
For tests in which CalTerm data was unavailable, the liner fit curves were employed. The difference in linear fit curves of Stage 1 and Stage 2 loading at $t=0.5$ hours is assumed to be the offset to be used for that specific test case. The specific values for the Stage 1 loading pressure drop offsets applied to the DAQ system pressure drop profile can be seen in Table H4.

The CPF and LFE pressure drop measurements during Stage 1 were subject to error, as previously explained. The offset corrections for the LFE and CPF pressure transducers can be seen in Table H4. The LFE data presented in the 'S1 LFE DP Offset' column of Table H4 is the same which is presented in the 'S1 LFE DP Offset' column of Table $\mathrm{H} 2$. Runs 5 and 14 required the highest LFE pressure drop corrections, which are within 2\% of corrections required during S4 and S2 of Runs 13 and 15 , respectively.

Table H4: Stage 1 Loading CPF Pressure Drop Offset Corrections

\begin{tabular}{|c|c|c|c|}
\hline \multirow{2}{*}{ Run } & Variable & $\begin{array}{c}\text { S1 CPF DP } \\
\text { Offset }\end{array}$ & $\begin{array}{c}\text { S1 LFE DP } \\
\text { Offset }\end{array}$ \\
\cline { 2 - 4 } & Test/Units & $\mathrm{kPa}$ & $\mathrm{kPa}$ \\
\hline 1 & B20 1 & 0.19 & 0.02 \\
\hline 2 & B20 2 & 0.11 & 0.01 \\
\hline 3 & B20 5 & 0.11 & 0.01 \\
\hline 4 & ULSD 3 & 0.05 & 0.01 \\
\hline 5 & ULSD 4 & 0.34 & 0.11 \\
\hline 6 & ULSD 5 & 0.18 & 0.02 \\
\hline 7 & ULSD 6 & 0.21 & 0.02 \\
\hline 8 & B20 6 & 0.03 & 0.00 \\
\hline 9 & B20 4 & 0.07 & 0.01 \\
\hline 10 & B10 1 & 0.27 & 0.02 \\
\hline 11 & B10 2 & 0.17 & 0.02 \\
\hline 12 & B10 3 & 0.00 & 0.02 \\
\hline 13 & ULSD 1 & 0.17 & 0.01 \\
\hline 14 & ULSD 8 & 0.18 & 0.11 \\
\hline 15 & ULSD 9 & 0.18 & 0.01 \\
\hline 16 & B10 4 & 0.19 & 0.02 \\
\hline 17 & ULSD 7R & 0.21 & 0.02 \\
\hline 18 & ULSD 2R & 0.22 & 0.02 \\
\hline & & & \\
\hline
\end{tabular}




\section{Step 3}

Once the CPF pressure drop offset and exhaust flow rate scaling factors were applied, the correction factor (CF) discussed in section 3.10 is determined. First, the $\mathrm{CPF}$ resistance is calculated using the CPF pressure drop corrected for offsets and exhaust mass flow rate corrected with the scaling factors. The CPF resistance for test B20-1 is shown in Figure H9. Again, the corrections applied to the data in Figure H9 are only to account for LFE pressure drop measurement error and/or exhaust bypass valve leaks affecting the mass flow rate and pressure drop offset affecting the CPF pressure drop curve. 

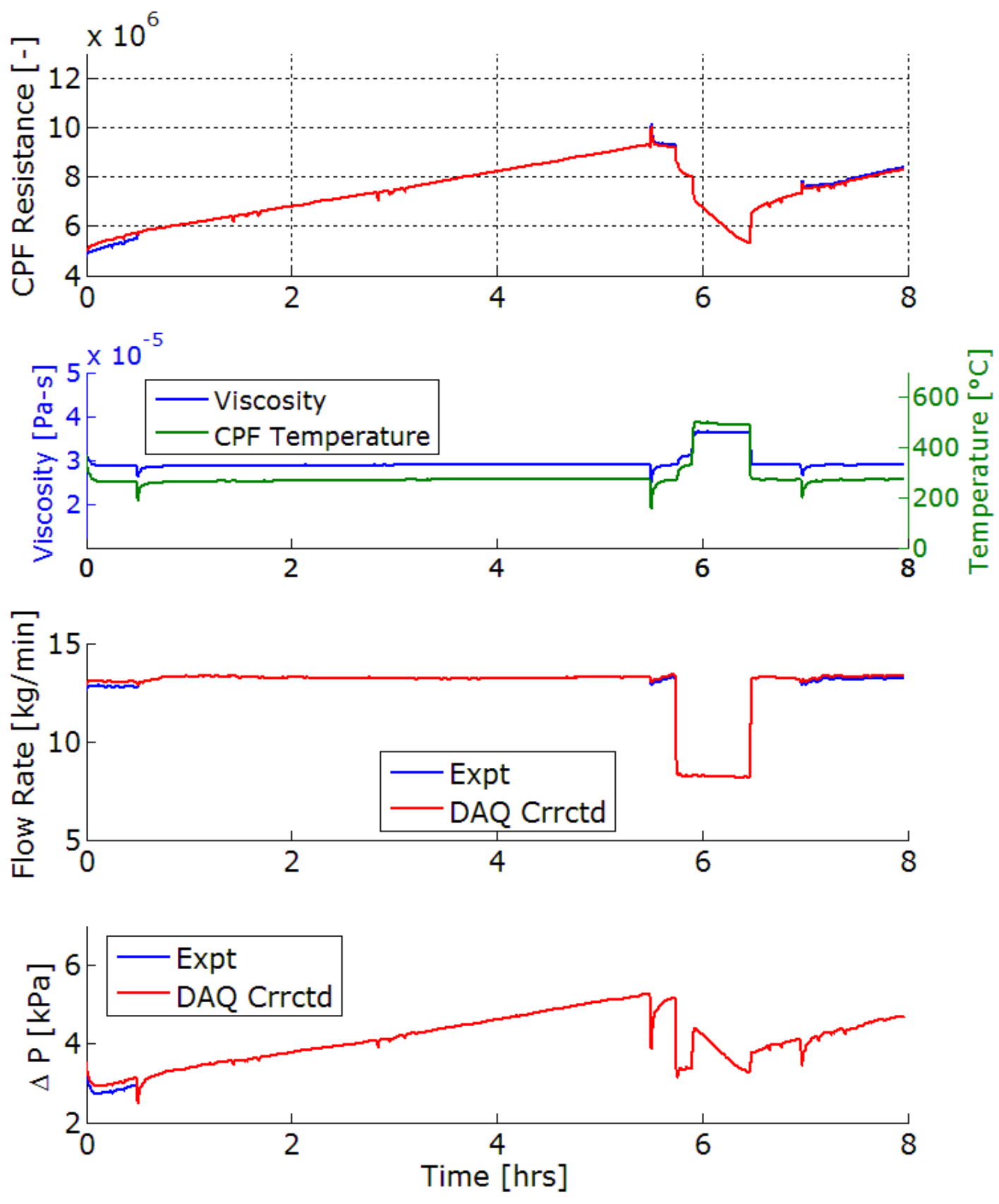

Figure H9: Run 1 (B20-1) Corrected and Experimental CPF Flow Resistance (subplot 1), Exhaust Viscosity and CPF Average Temperature (subplot 2), Corrected and Corrected Experimental Exhaust Mass Flow Rate (subplot 3), Corrected and Experimental CPF Pressure Drop Profile (subplot 4)

In Figure $\mathrm{H9}$, the pressure drop offset during Stage 1 loading of $0.19 \mathrm{kPa}$ was applied. 
Next, the graphical input tool within MATLAB is used to re-construct the plausible resistance curve based on the DAQ measurement error corrected CPF pressure drop and exhaust mass flow rates (shown in red on the first subplot in Figure H9). Using this resistance curve from the graphical input, the required CF is determined using the CPF resistance equation, Eqn. 20.

Average values for the corrections (SF) applied to all test phases based on DAQ system measurement errors and/or bypass valve leaks as tabulated in Table $\mathrm{H} 3$ are used in the analysis. The active regeneration ramp and active regeneration phase correction factor (CF) is determined using the experimental exhaust mass flow rate (after SF from Table H3 was applied, where required).

The plausible resistance curve is used to calculate a correction factor (CF) for the pre-active regeneration ramp and active regeneration test phases. Eqn. 20 can be re-written to solve for the correction factor, CF, which is shown by Eqn. $\mathrm{H} 1$.

$$
\mathrm{CF}=\frac{\Delta \mathrm{P} \cdot \mathrm{V}_{\mathrm{t}} \cdot \rho_{\mathrm{exh}}}{\dot{\mathrm{m}} \cdot \mu \cdot \mathrm{Resistance}}
$$

The 'Resistance' variable in Eqn. $\mathrm{H} 1$ comes from the re-constructed plausible resistance curve where all other variables used to solve for CF come from the experimental data.

The resulting CF is a scalar multiplier to be applied to the experimental mass flow rate in order to simplify input data preparation for the MTU-1D CPF model. The average $\mathrm{CF}$ for pre-active regeneration ramp and active regeneration phases for each experiment can be seen in Table $\mathrm{H} 5$. 
Table H5: Active Regeneration Ramp and Active Regeneration CF

\begin{tabular}{|c|c|c|c|}
\hline \multirow{2}{*}{ Run } & \multirow{2}{*}{ Test } & \multicolumn{2}{c|}{ Correction Factor } \\
\cline { 3 - 4 } & & AR RMP & AR \\
\hline 1 & B20 1 & 0.87 & 0.77 \\
\hline 2 & B20 2 & 0.88 & 0.74 \\
\hline 3 & B20 5 & 0.86 & 0.72 \\
\hline 4 & ULSD 3 & 0.85 & 0.75 \\
\hline 5 & ULSD 4 & 0.93 & 0.73 \\
\hline 6 & ULSD 5 & 0.87 & 0.76 \\
\hline 7 & ULSD 6 & 0.87 & 0.74 \\
\hline 8 & B20 6 & 0.87 & 0.73 \\
\hline 9 & B20 4 & 0.88 & 0.76 \\
\hline 10 & B10 1 & 0.88 & 0.75 \\
\hline 11 & B10 2 & 0.87 & 0.74 \\
\hline 12 & B10 3 & 0.87 & 0.76 \\
\hline 13 & ULSD 1 & 0.89 & 0.76 \\
\hline 14 & ULSD 8 & 0.87 & 0.75 \\
\hline 15 & ULSD 9 & 0.88 & 0.73 \\
\hline 16 & B10 4 & 0.87 & 0.76 \\
\hline 17 & ULSD 7R & 0.88 & 0.75 \\
\hline 18 & ULSD 2R & 0.87 & 0.73 \\
\hline Average & 0.87 & 0.74 \\
\hline Std. Deviation & 0.02 & 0.01 \\
\hline
\end{tabular}

The resulting CF is equal to 1 in all test phases except active regeneration ramp and active regeneration, because CF corrects for possible temperature and PM maldistribution in the CPF, exhaust flow maldistribution at the CPF inlet, and changing cake layer permeability which cannot be quantified from experimental data at this time. It is believed that there are two triggers which drive the need for the correction factor (CF). The first is the switch to the active regeneration engine condition during the AR-ramp test phase. The second is the initiation of active regeneration by fuel dosing because the CF rapidly changes during the first few minutes of temperature increase after dosing has been initiated and PM oxidation has started.

The average CF during the active regeneration ramp and active regeneration phases are 0.87 and 0.74 , respectively, with a standard deviation of 0.2 and 0.1 , respectively. This shows that the CF likely does not carry an effect of biodiesel blends 
or CPF inlet temperature, but is affected by unknown variables that cannot be determined with the experimental data that has been measured.

The CF for test B20-1 is shown below in Figure H10. CF figures for each test can be found at the end of Appendix $\mathrm{H}$ in Figures $\mathrm{H} 29-\mathrm{H} 34$.

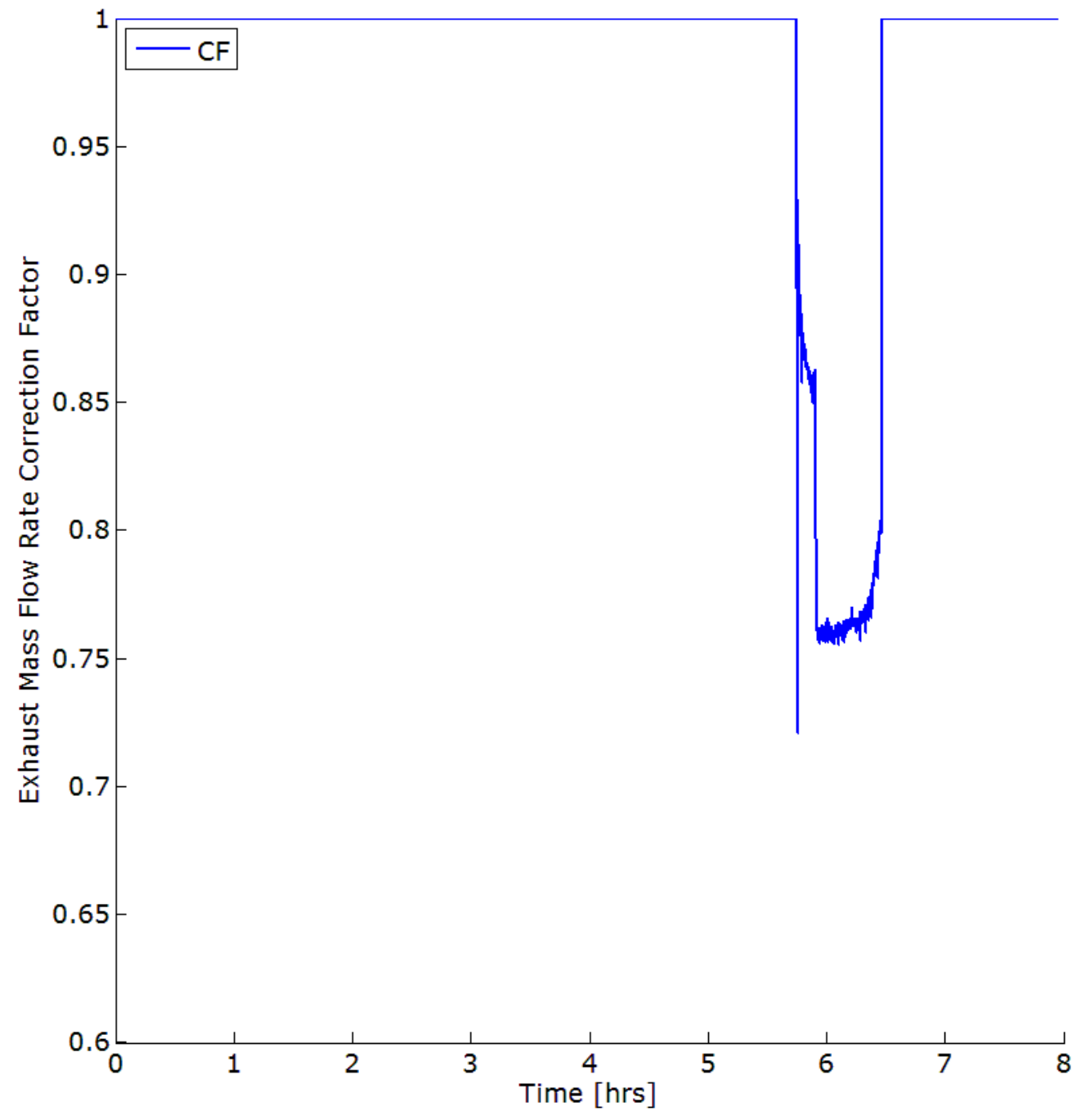

\section{Figure H10: Run 1 (B20-1) CF}

In Figure $\mathrm{H} 10$, the correction factor (CF) for the active regeneration ramp and active regeneration phases is shown. The $\mathrm{CF}$, as previously described, is 1 for all test phases except the two phases at the active regeneration engine condition. 
With the exhaust mass flow rate scaling factors determined and implemented based on DAQ system and measurement error (pressure transducer error and/or exhaust bypass valve leaks), the pressure drop offset corrections applied, and the CF determined for the active regeneration ramp and active regeneration phases, the result is what can be seen in Figure $\mathrm{H} 11$. Figure $\mathrm{H} 11$ shows the experimental and corrected, continuous CPF flow resistance curve (subplot 1), exhaust temperature and viscosity (subplot 2), the experimental and corrected (corrections from Steps 2 and 3 combined - assuming the CF is applied to the mass flow rate which is the way it is used in the MTU-1D CPF Model) exhaust mass flow rate (subplot 3), and the experimental and corrected CPF pressure drop (subplot 4).

With the pressure drop offset corrections, mass flow rate DAQ and measurement error scaling factors (SF), and the active regeneration ramp and active regeneration correction factors (CF) known, they can be appropriately applied to the experimental exhaust mass flow rate input data for the MTU 1-D CPF model. The corrected resistance plots for all tests, similar to Figure $\mathrm{H} 11$, can be found in Figures $\mathrm{H} 12-\mathrm{H} 28$. The plots showing CF for all test cases can be seen in Figures H29-H34. 

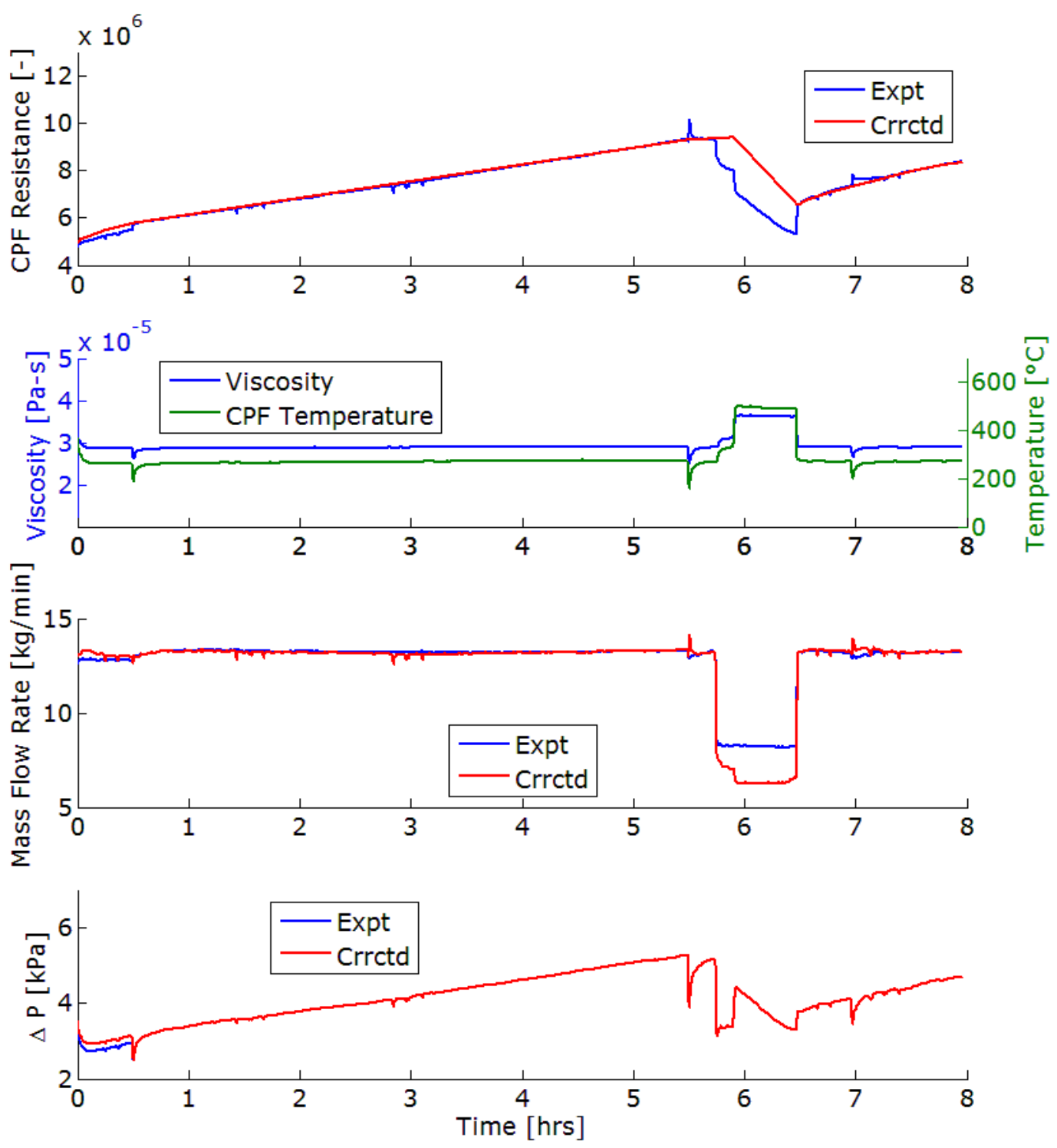

Figure H11: Run 1 (B20-1) Corrected and Experimental CPF Flow Resistance (subplot 1), Exhaust Viscosity and CPF Average Temperature (subplot 2), Experimental and Corrected Experimental Exhaust Mass Flow Rate (subplot 3), Corrected and Experimental CPF Pressure Drop Profile (subplot 4)

In Figure $\mathrm{H} 11$, the most significant corrections are the Stage 1 loading CPF pressure drop and mass flow rate, the CF applied to the mass flow rate during the regeneration phases of the experiment, and the temperature stabilization periods of Stage 4 loading and the loading ramp phase. 

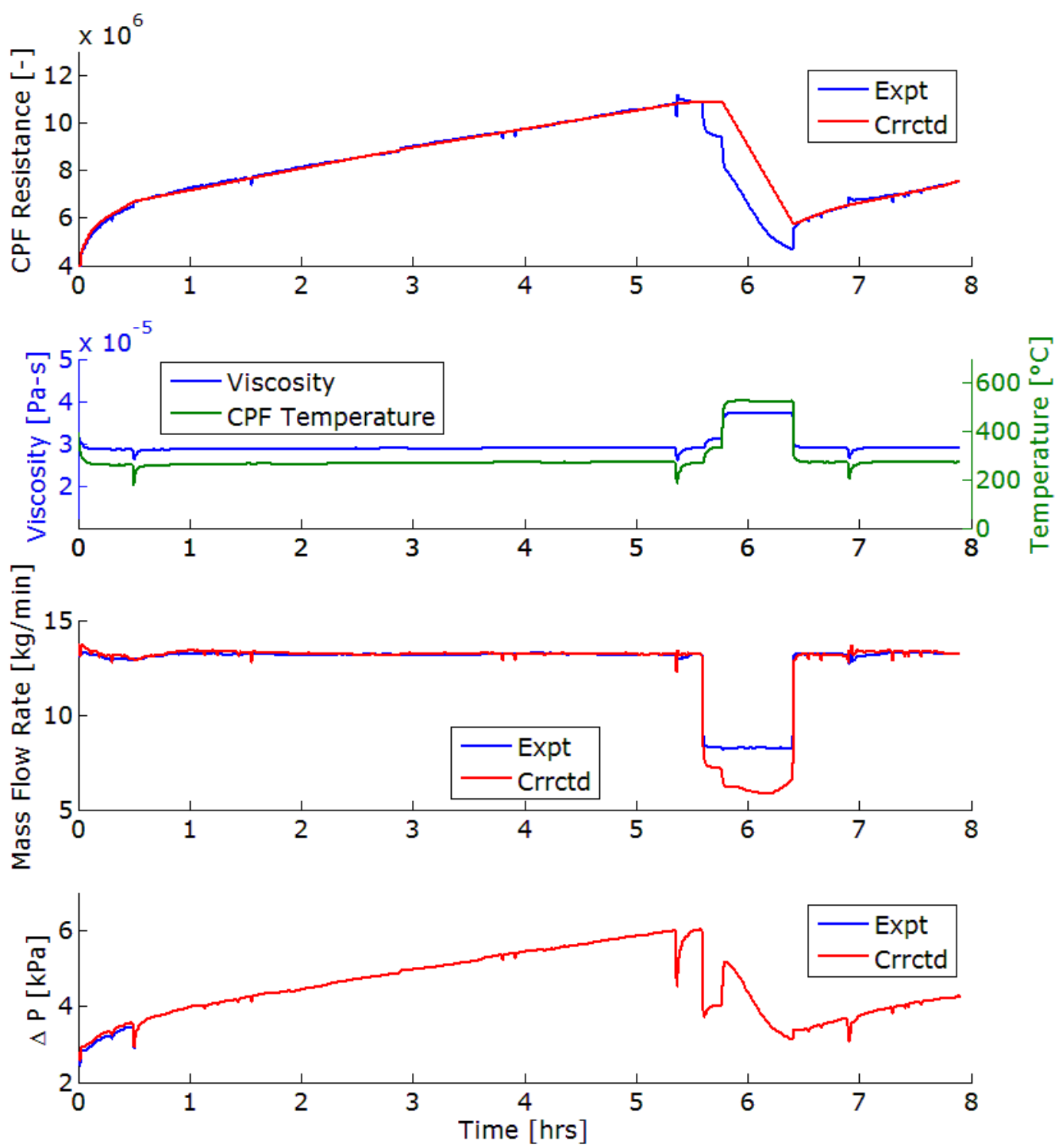

Figure H12: Run 2 (B20-2) Corrected and Experimental CPF Flow Resistance (subplot 1), Exhaust Viscosity and CPF Average Temperature (subplot 2), Experimental and Corrected Experimental Exhaust Mass Flow Rate (subplot 3), Corrected and Experimental CPF Pressure Drop Profile (subplot 4)

In Figure $\mathrm{H} 11$, the most significant corrections are the Stage 1 loading CPF pressure drop, the CF applied to the mass flow rate during the regeneration phases of the experiment, and the temperature stabilization period of Stage 4 loading and the loading ramp phase. 

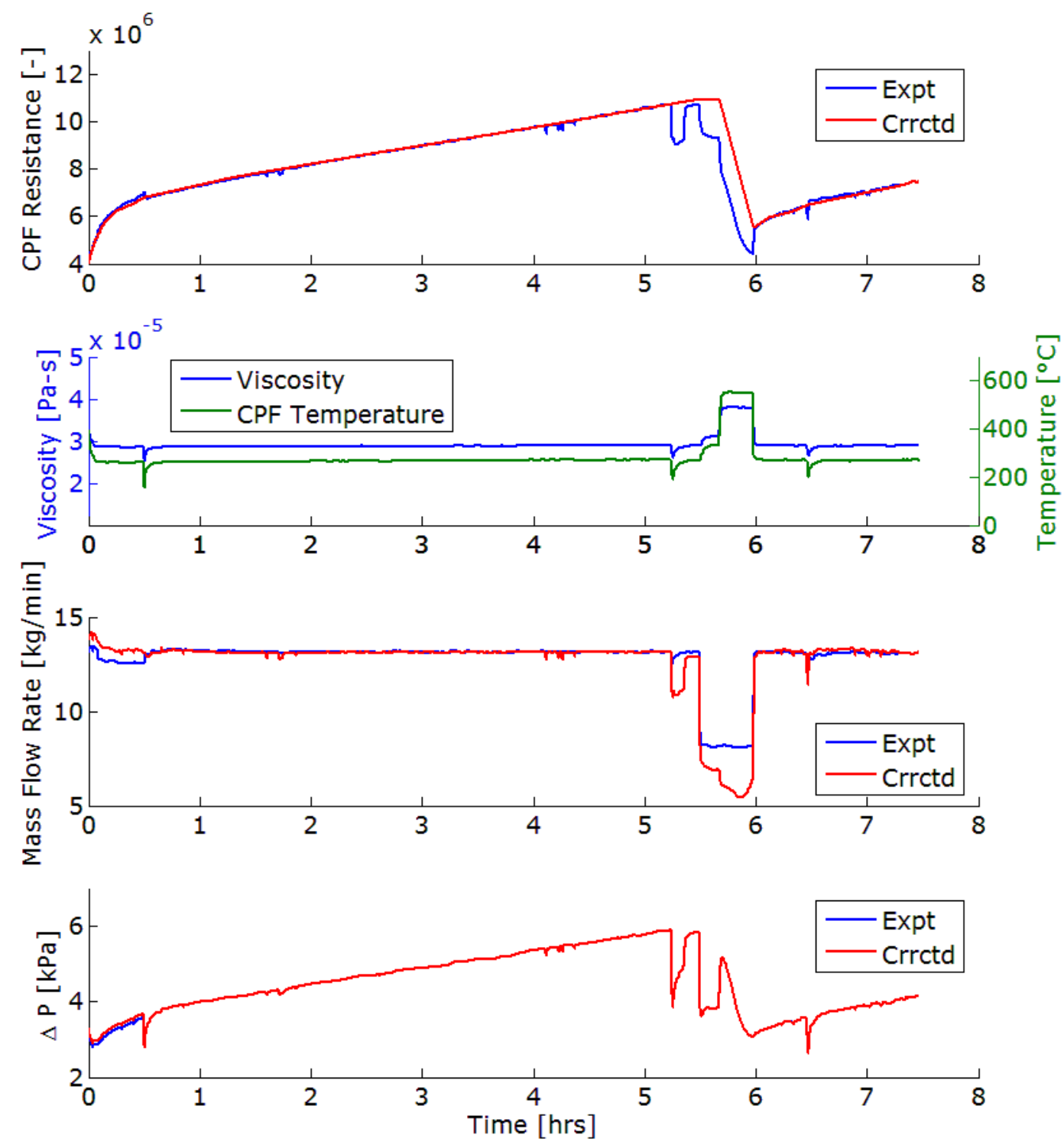

Figure H13: Run 3 (B20-5) Corrected and Experimental CPF Flow Resistance (subplot 1), Exhaust Viscosity and CPF Average Temperature (subplot 2), Experimental and Corrected Experimental Exhaust Mass Flow Rate (subplot 3), Corrected and Experimental CPF Pressure Drop Profile (subplot 4)

In Figure $\mathrm{H} 13$, the most significant corrections are the Stage 1 loading CPF pressure drop and mass flow rate, the CF applied to the mass flow rate during the regeneration phases of the experiment, and the temperature stabilization periods of Stage 4 loading. 

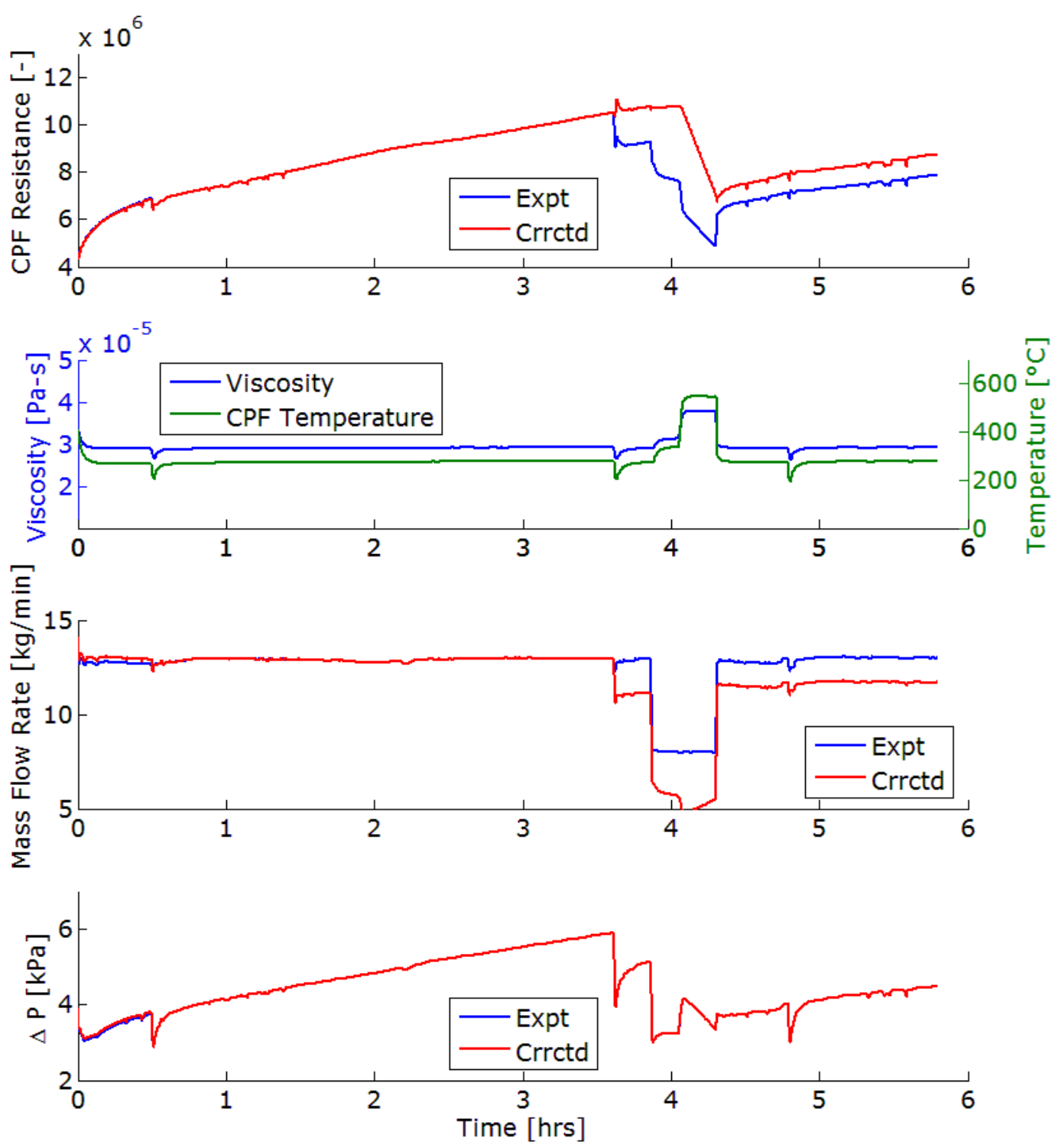

Figure H14: Run 4 (ULSD-3) Corrected and Experimental CPF Flow Resistance (subplot 1), Exhaust Viscosity and CPF Average Temperature (subplot 2), Experimental and Corrected Experimental Exhaust Mass Flow Rate (subplot 3), Corrected and Experimental CPF Pressure Drop Profile (subplot 4)

In Figure $\mathrm{H} 14$, the most significant corrections are the Stage 1 loading CPF pressure drop and mass flow rate and the CF applied to the mass flow rate during the regeneration phases of the experiment. The mass flow rate for test phases after Stage 2 loading was adjusted to compensate for a leaking exhaust bypass valve. 

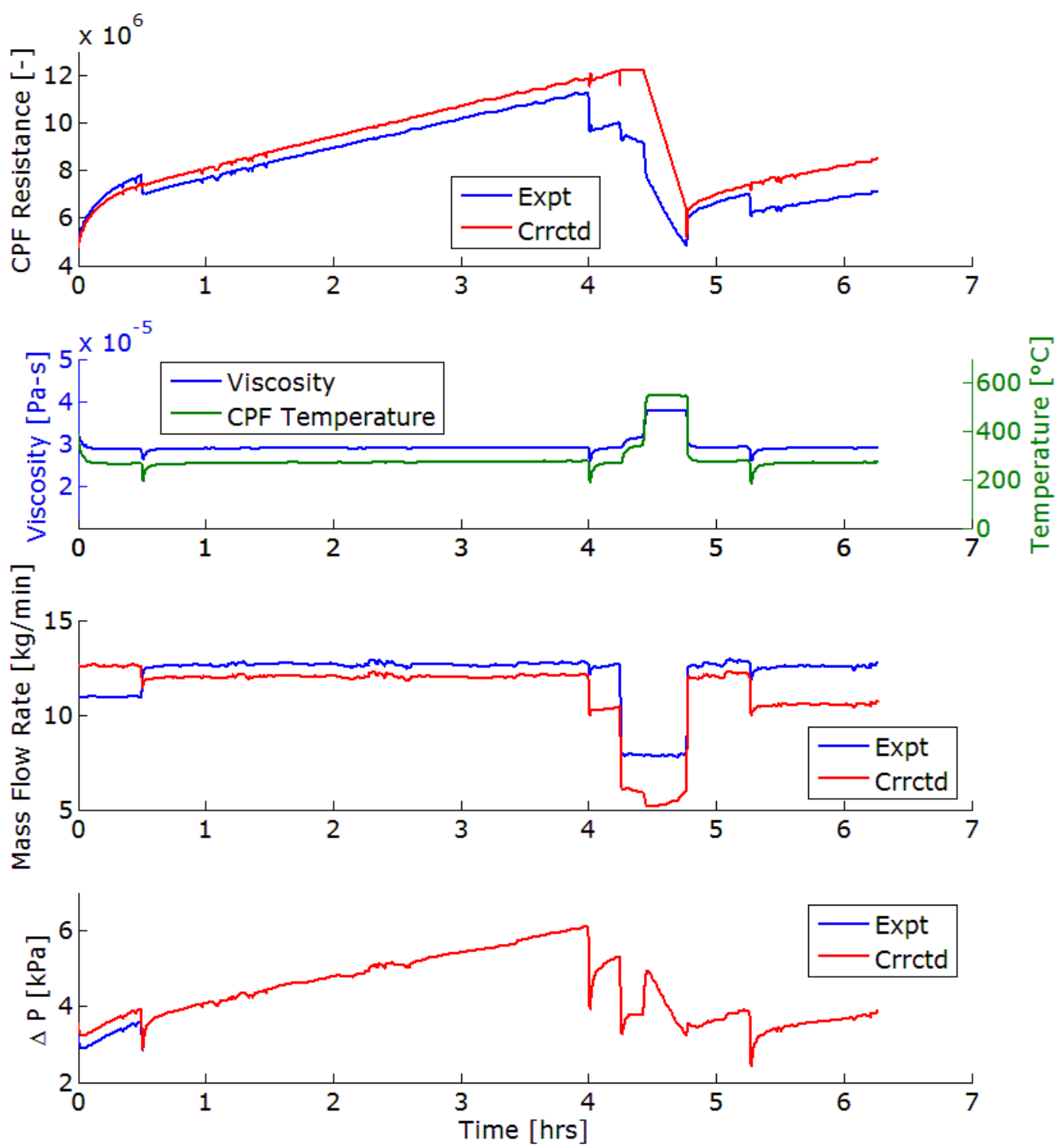

Figure H15: Run 5 (ULSD-4) Corrected and Experimental CPF Flow Resistance (subplot 1), Exhaust Viscosity and CPF Average Temperature (subplot 2), Experimental and Corrected Experimental Exhaust Mass Flow Rate (subplot 3), Corrected and Experimental CPF Pressure Drop Profile (subplot 4)

In Figure $\mathrm{H} 15$, the most significant corrections are the Stage 1 loading CPF pressure drop and mass flow rate and the CF applied to the mass flow rate during the regeneration phases of the experiment. The mass flow rate for test phases after Stage 1 loading was adjusted to compensate for a leaking exhaust bypass valve. 

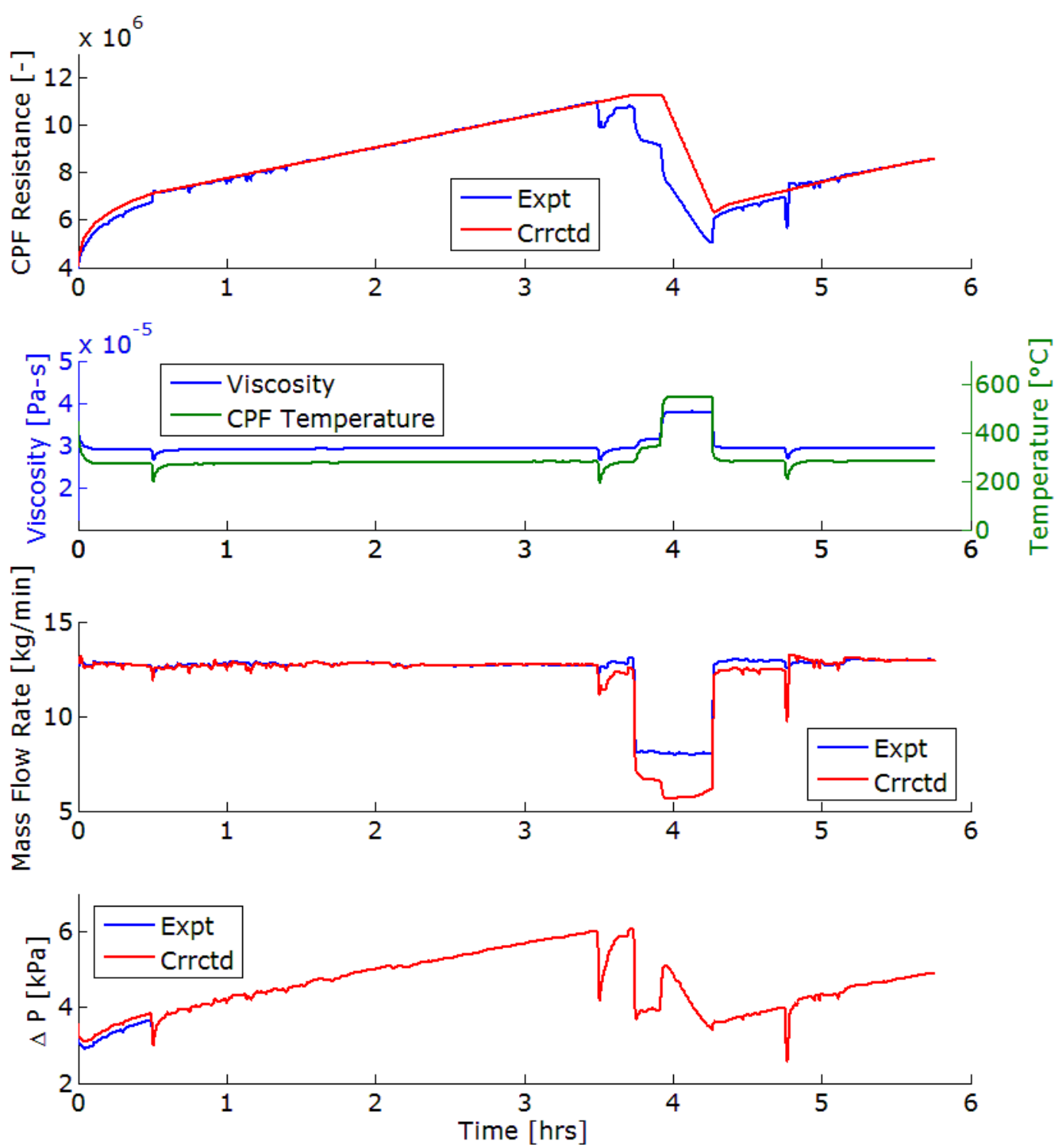

Figure H16: Run 6 (ULSD-5) Corrected and Experimental CPF Flow Resistance (subplot 1), Exhaust Viscosity and CPF Average Temperature (subplot 2), Exp. and Crrctd. Exp. Exhaust Mass Flow Rate (subplot 3), Corrected and Experimental CPF Pressure Drop Profile (subplot 4)

In Figure $\mathrm{H} 16$, the most significant corrections are the Stage 1 loading CPF pressure drop, the CF applied to the mass flow rate during the regeneration phases of the experiment, and the temperature stabilization periods of Stage 4 loading. The mass flow rate for the loading ramp and Stage 3 loading phases was adjusted to compensate for a leaking exhaust bypass valve. 

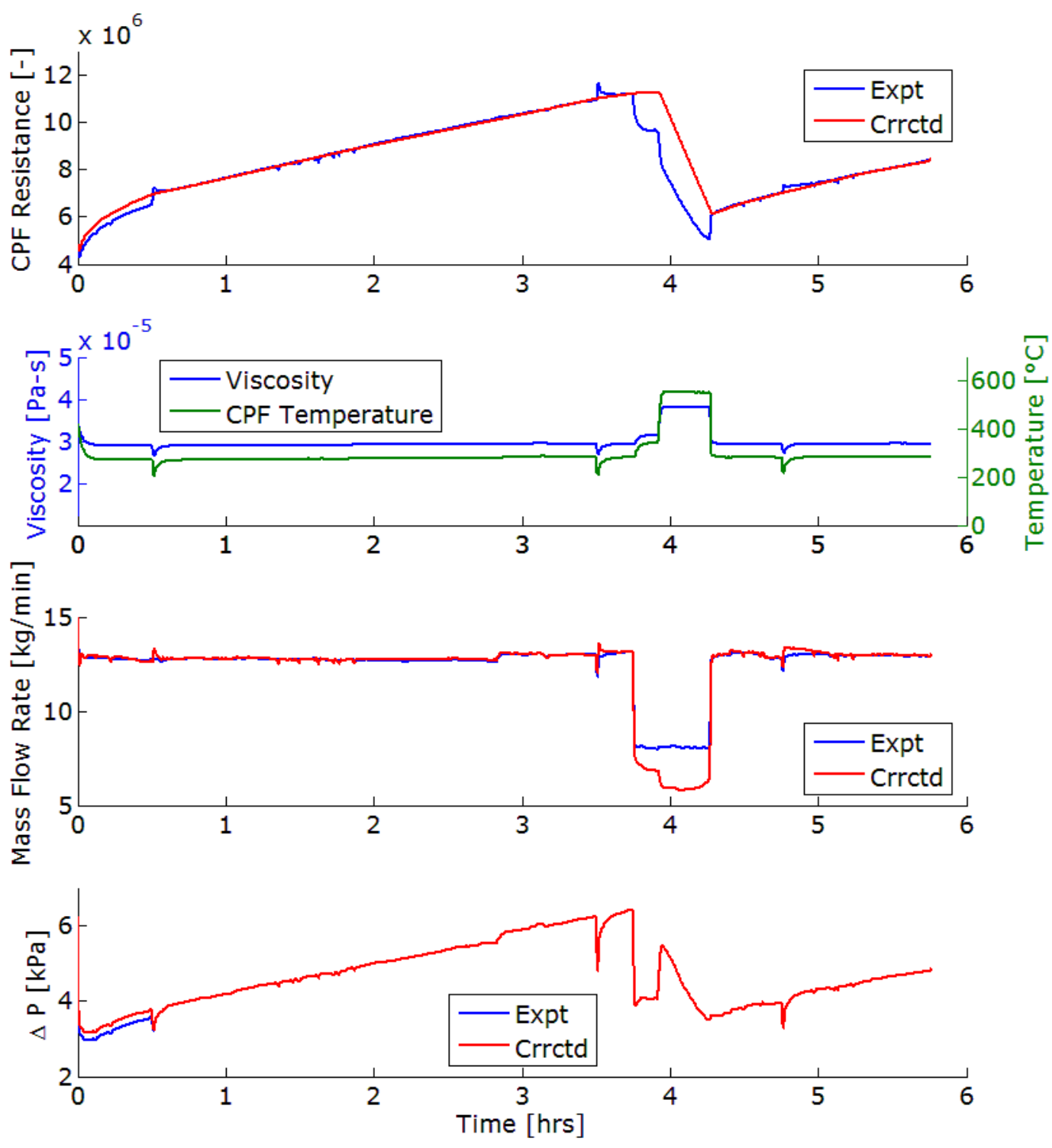

Figure H17: Run 7 (ULSD-6) Corrected and Experimental CPF Flow Resistance (subplot 1), Exhaust Viscosity and CPF Average Temperature (subplot 2), Experimental and Corrected Experimental Exhaust Mass Flow Rate (subplot 3), Corrected and Experimental CPF Pressure Drop Profile (subplot 4)

In Figure $\mathrm{H} 17$, the most significant corrections are the Stage 1 loading CPF pressure drop, the CF applied to the mass flow rate during the regeneration phases of the experiment, and the temperature stabilization periods of Stage 2 and Stage 4 loading and the loading ramp phase. 

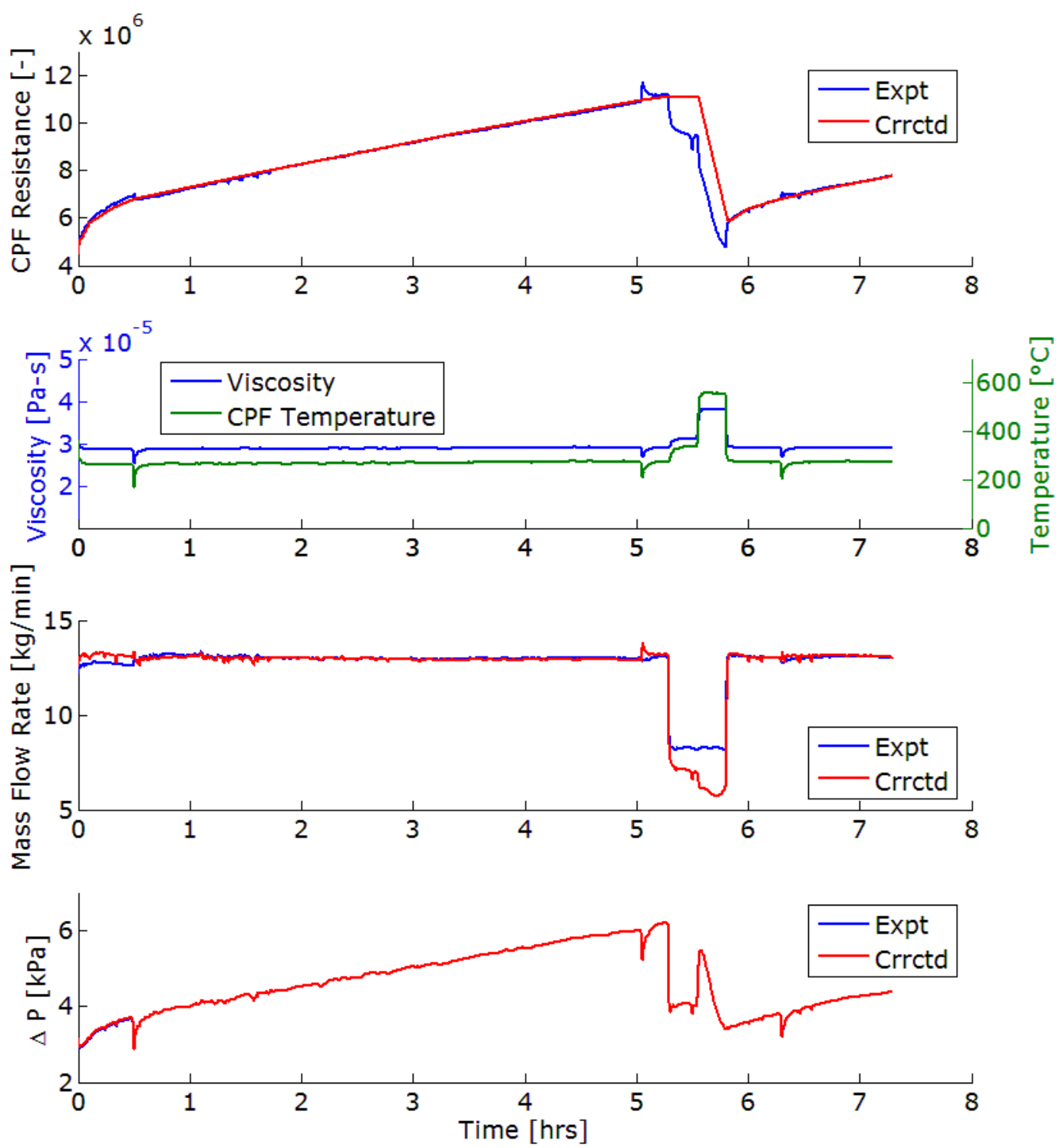

Figure H18: Run 8 (B20-6) Corrected and Experimental CPF Flow Resistance (subplot 1), Exhaust Viscosity and CPF Average Temperature (subplot 2), Experimental and Corrected Experimental Exhaust Mass Flow Rate (subplot 3), Corrected and Experimental CPF Pressure Drop Profile (subplot 4)

In Figure $\mathrm{H} 18$, the most significant corrections are the Stage 1 loading CPF pressure drop and mass flow rate, the CF applied to the mass flow rate during the regeneration phases of the experiment, and the temperature stabilization periods of Stage 2 and Stage 4 loading and the loading ramp phase. 

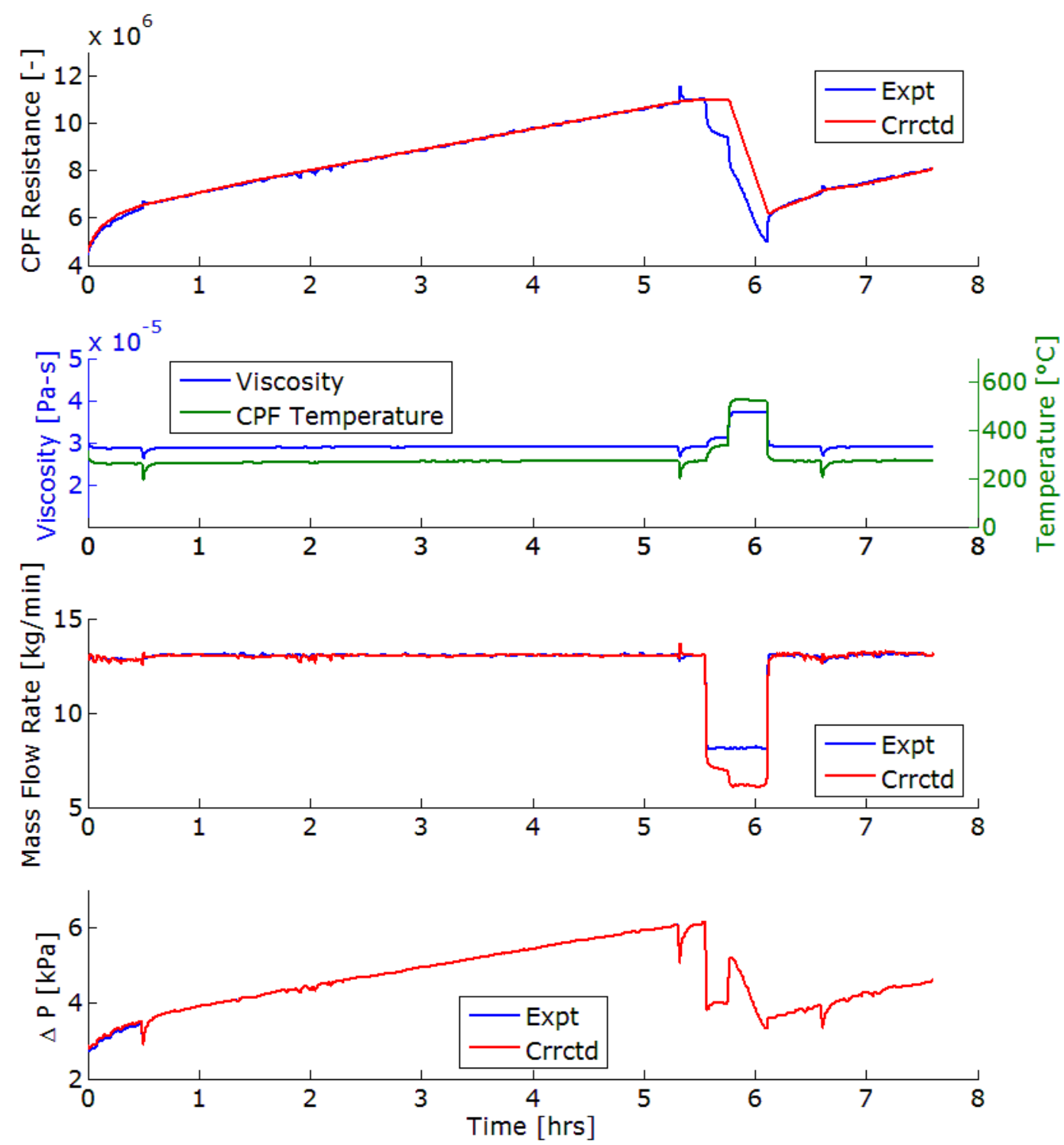

Figure H19: Run 9 (B20-4) Corrected and Experimental CPF Flow Resistance (subplot 1), Exhaust Viscosity and CPF Average Temperature (subplot 2), Experimental and Corrected Experimental Exhaust Mass Flow Rate (subplot 3), Corrected and Experimental CPF Pressure Drop Profile (subplot 4)

In Figure $\mathrm{H} 19$, the most significant corrections are the Stage 1 loading CPF pressure drop, the CF applied to the mass flow rate during the regeneration phases of the experiment, and the temperature stabilization periods of Stage 2 and Stage 4 loading and the loading ramp phase. 

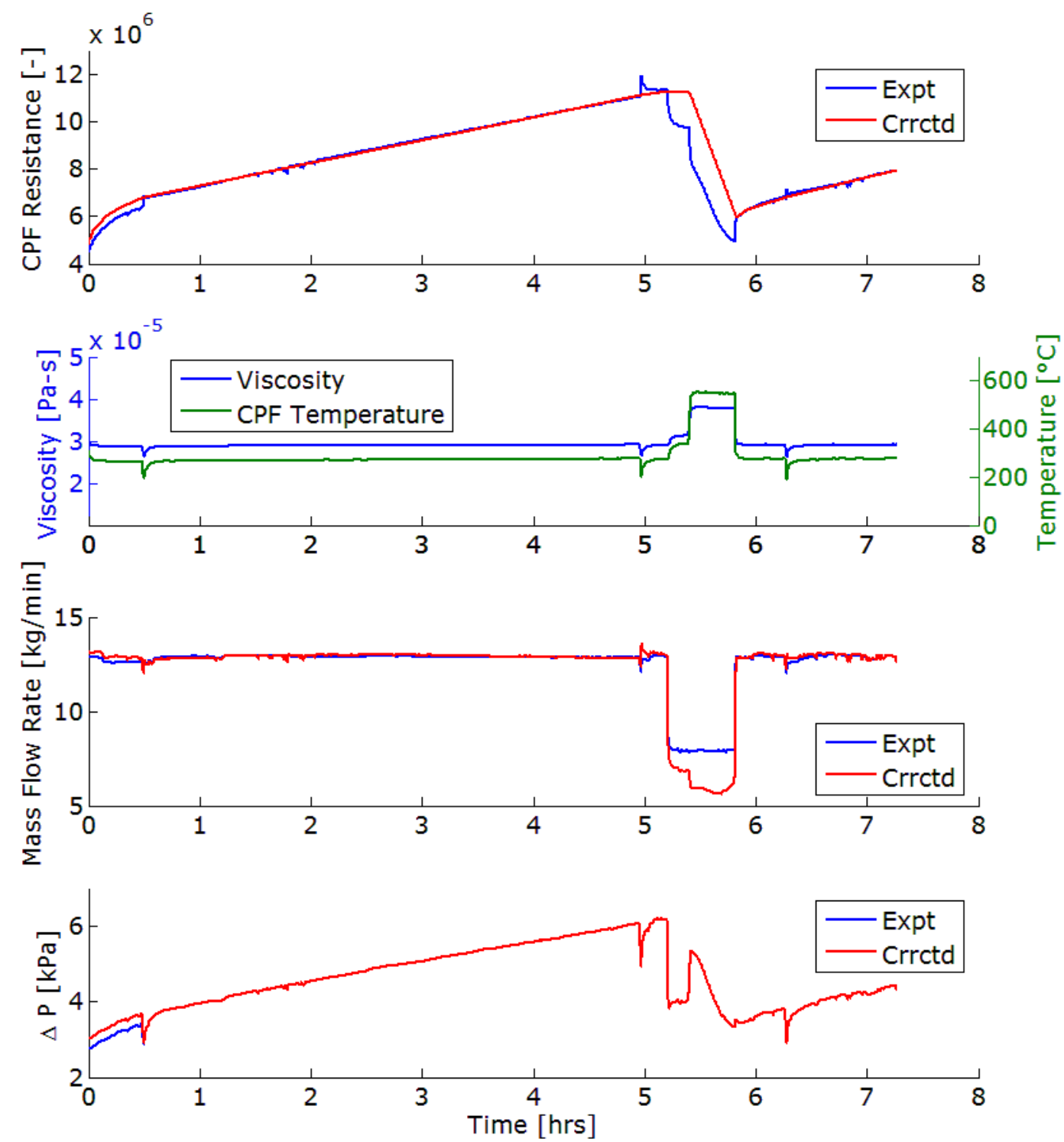

Figure H20: Run 10 (B10-1) Corrected and Experimental CPF Flow Resistance (subplot 1), Exhaust Viscosity and CPF Average Temperature (subplot 2), Experimental and Corrected Experimental Exhaust Mass Flow Rate (subplot 3), Corrected and Experimental CPF Pressure Drop Profile (subplot 4)

In Figure $\mathrm{H} 20$, the most significant corrections are the Stage 1 loading CPF pressure drop and mass flow rate, the CF applied to the mass flow rate during the regeneration phases of the experiment, and the temperature stabilization periods of Stage 2 and Stage 4 loading and the loading ramp phase. 

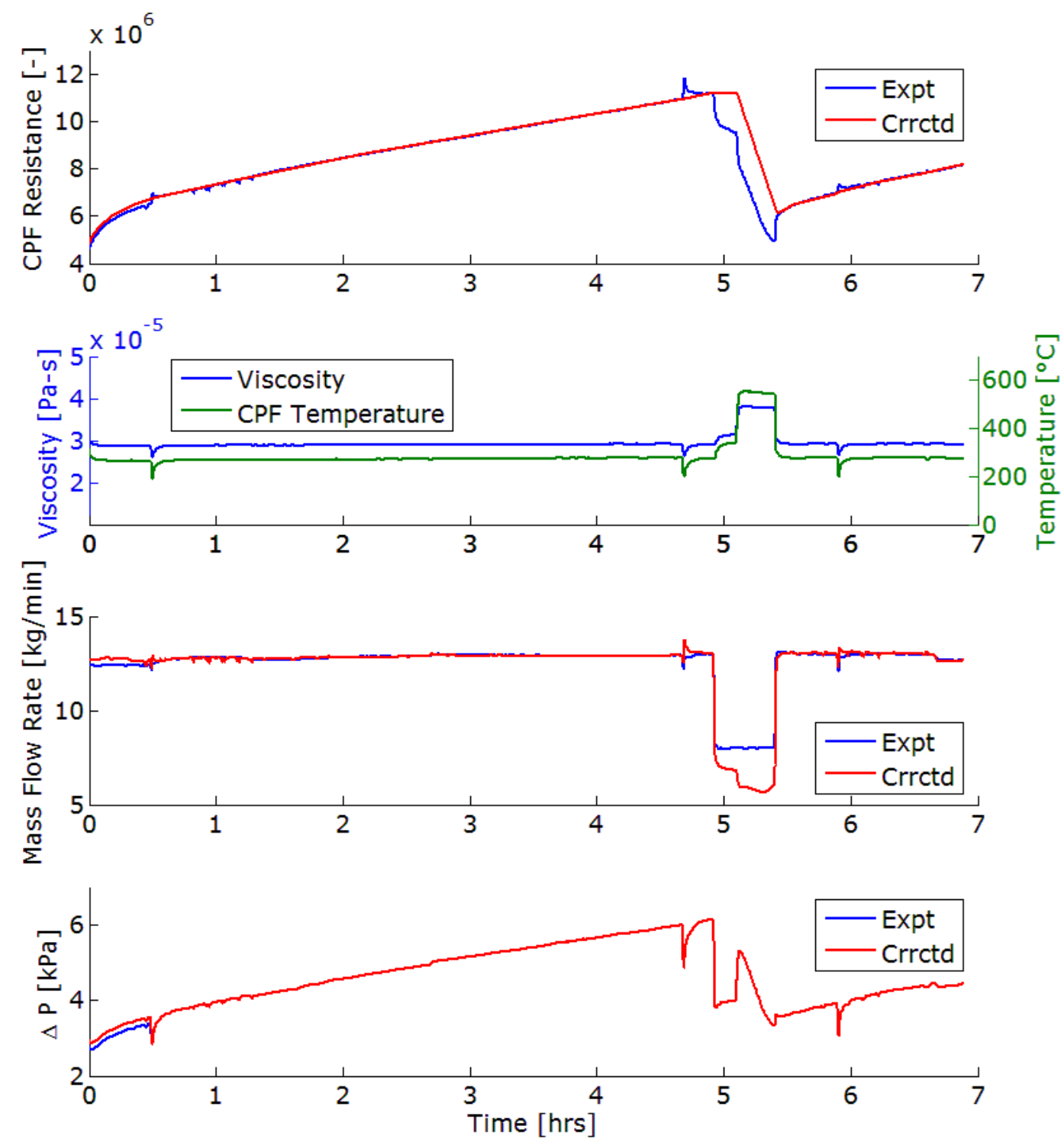

Figure H21: Run 11 (B10-2) Corrected and Experimental CPF Flow Resistance (subplot 1), Exhaust Viscosity and CPF Average Temperature (subplot 2), Experimental and Corrected Experimental Exhaust Mass Flow Rate (subplot 3), Corrected and Experimental CPF Pressure Drop Profile (subplot 4)

In Figure $\mathrm{H} 21$, the most significant corrections are the Stage 1 loading CPF pressure drop and mass flow rate, the CF applied to the mass flow rate during the regeneration phases of the experiment, and the temperature stabilization periods of Stage 2 and Stage 4 loading and the loading ramp phase. 

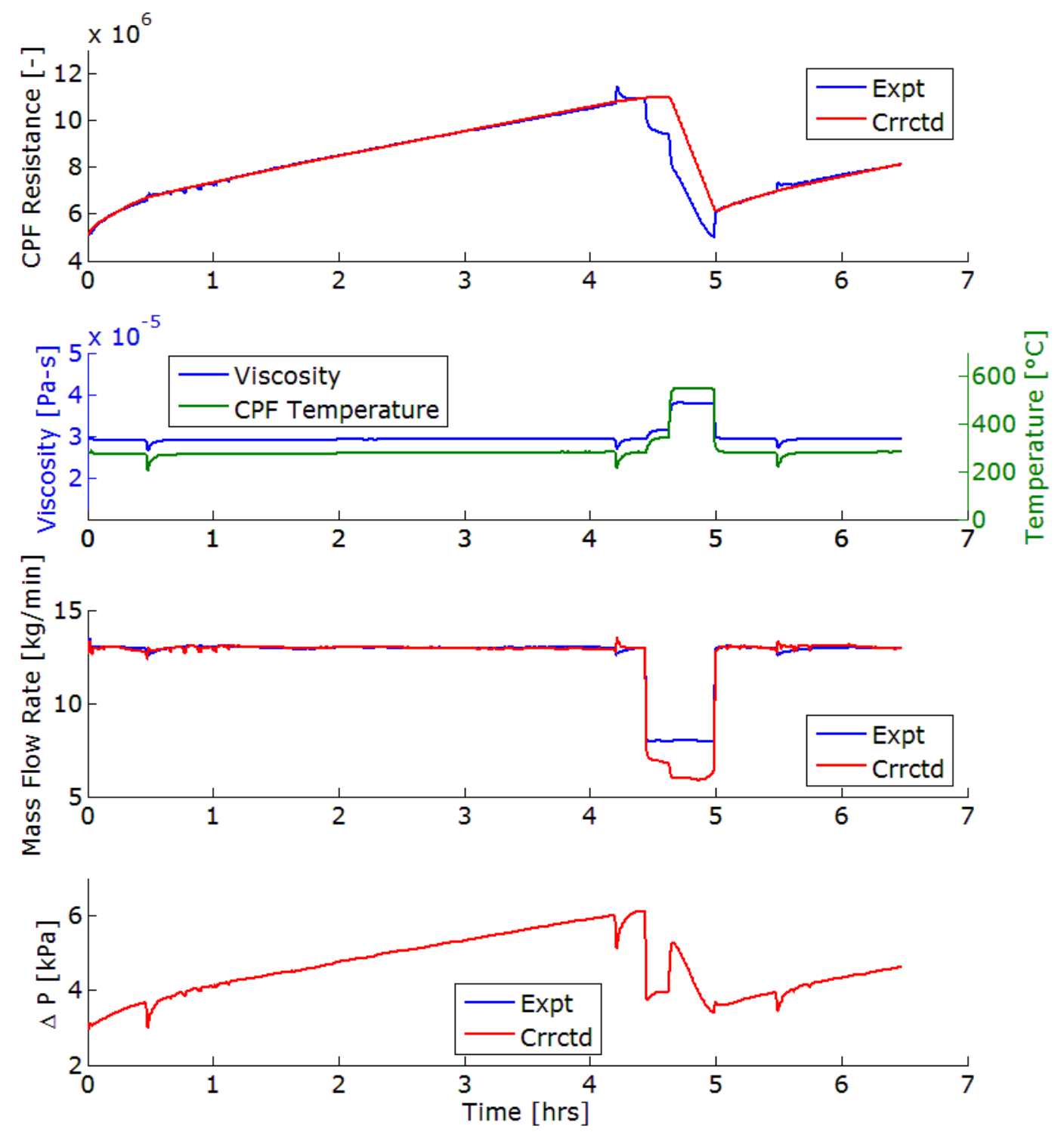

Figure H22: Run 12 (B10-3) Corrected and Experimental CPF Flow Resistance (subplot 1), Exhaust Viscosity and CPF Average Temperature (subplot 2), Experimental and Corrected Experimental Exhaust Mass Flow Rate (subplot 3), Corrected and Experimental CPF Pressure Drop Profile (subplot 4)

In Figure $\mathrm{H} 22$, the most significant corrections are the CF applied to the mass flow rate during the regeneration phases of the experiment, and the temperature stabilization periods of Stage 2 and Stage 4 loading and the loading ramp phase. 

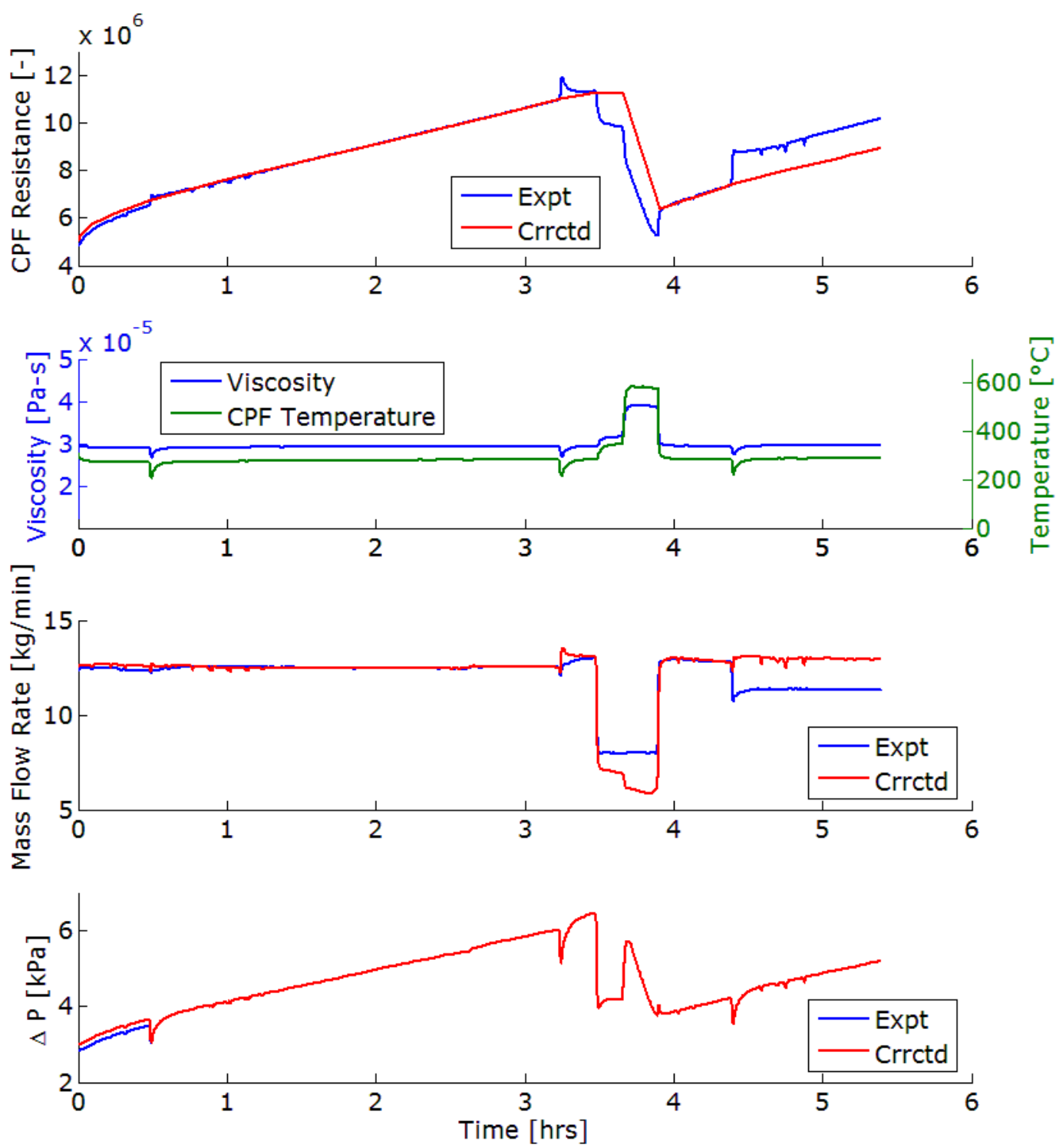

Figure H23: Run 13 (ULSD-1) Corrected and Experimental CPF Flow Resistance (subplot 1), Exhaust Viscosity and CPF Average Temperature (subplot 2), Experimental and Corrected Experimental Exhaust Mass Flow Rate (subplot 3), Corrected and Experimental CPF Pressure Drop Profile (subplot 4)

In Figure $\mathrm{H} 23$, the most significant corrections are the Stage 1 loading CPF pressure drop and mass flow rate, the CF applied to the mass flow rate during the regeneration phases of the experiment, and the temperature stabilization periods of Stage 2 and Stage 4 loading and the loading ramp phase. 

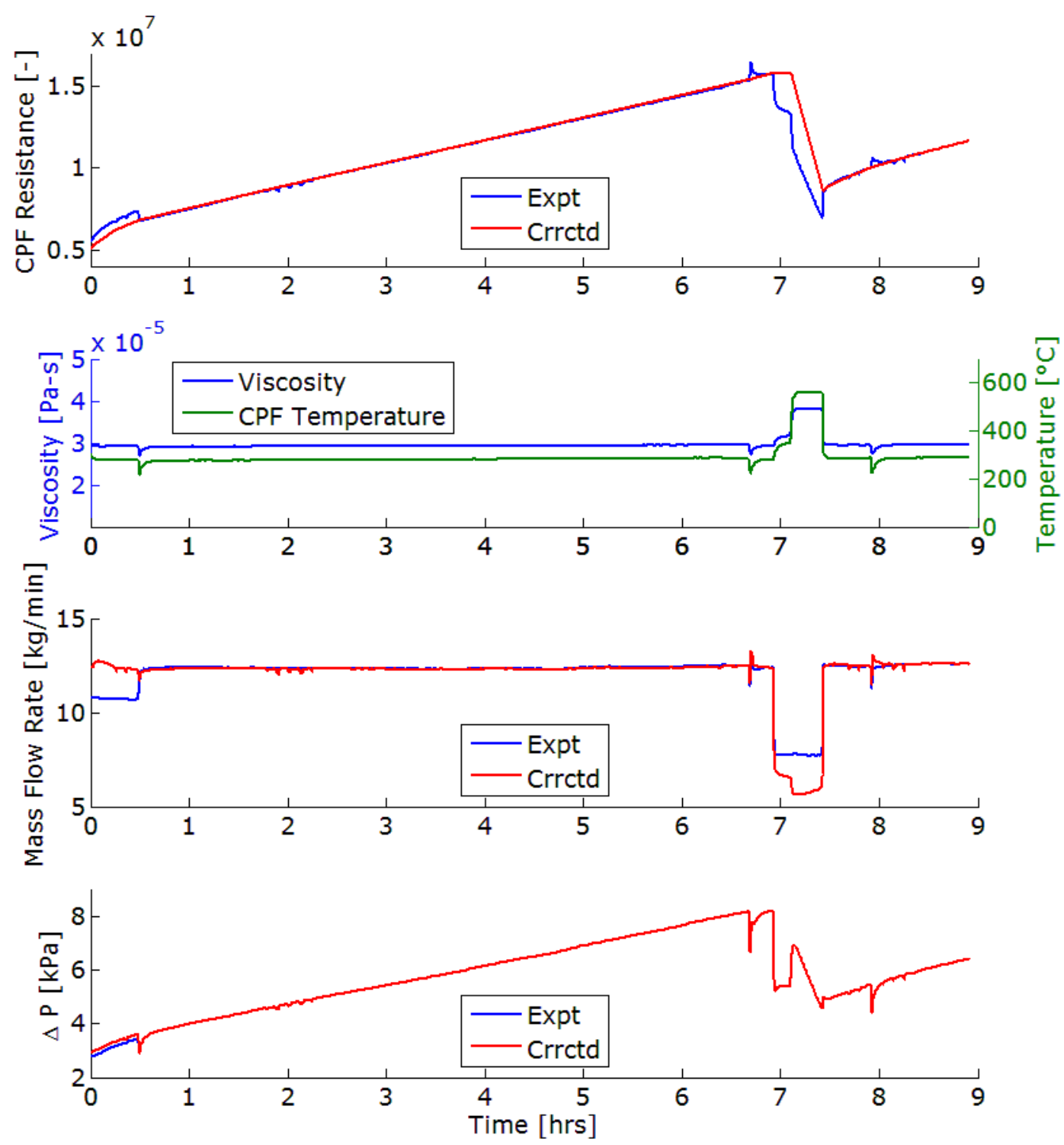

Figure H24: Run 14 (ULSD-8) Corrected and Experimental CPF Flow Resistance (subplot 1), Exhaust Viscosity and CPF Average Temperature (subplot 2), Experimental and Corrected Experimental Exhaust Mass Flow Rate (subplot 3), Corrected and Experimental CPF Pressure Drop Profile (subplot 4)

In Figure $\mathrm{H} 24$, the most significant corrections are the Stage 1 loading CPF pressure drop and mass flow rate, the CF applied to the mass flow rate during the regeneration phases of the experiment, and the temperature stabilization periods of Stage 2 and Stage 4 loading and the loading ramp phase. 

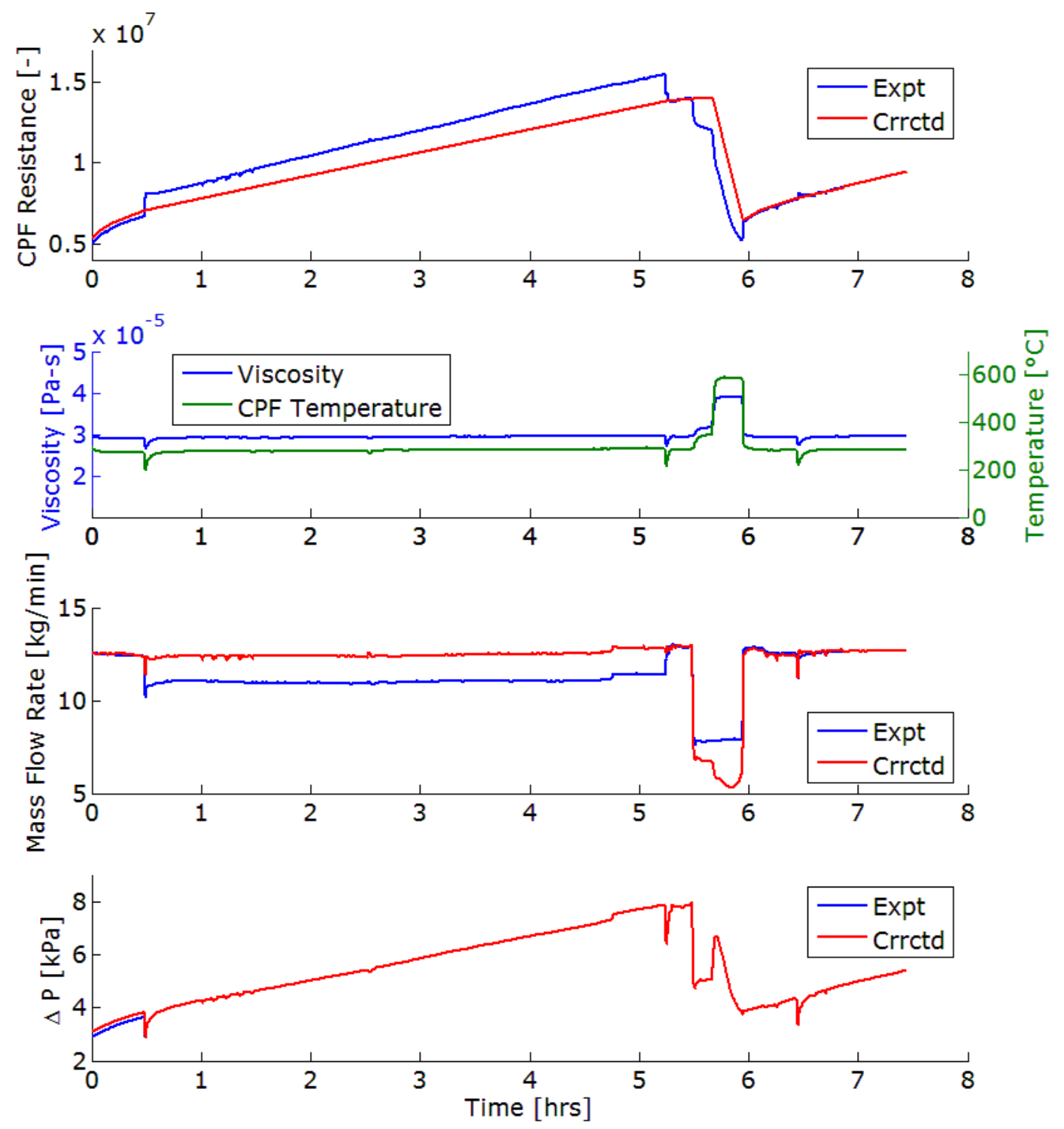

Figure H25: Run 15 (ULSD-9) Corrected and Experimental CPF Flow Resistance (subplot 1), Exhaust Viscosity and CPF Average Temperature (subplot 2), Experimental and Corrected Experimental Exhaust Mass Flow Rate (subplot 3), Corrected and Experimental CPF Pressure Drop Profile (subplot 4)

In Figure $\mathrm{H} 25$, the most significant corrections are the Stage 1 loading CPF pressure drop, the Stage 2 mass flow rate due to LFE error, the CF applied to the mass flow rate during the regeneration phases of the experiment, and the temperature stabilization periods of Stage 2 and Stage 4. 

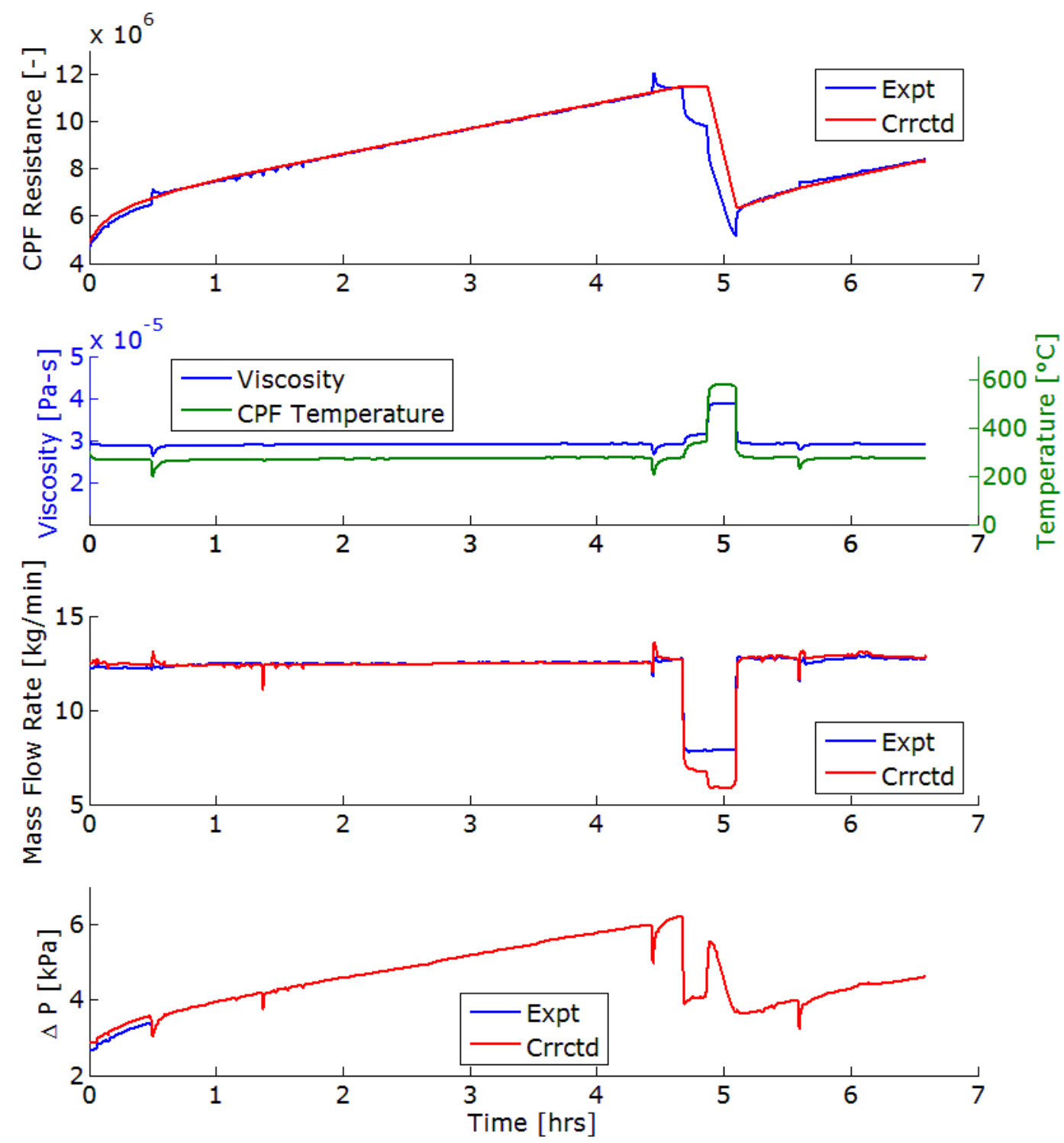

Figure H26: Run 16 (B10-4) Corrected and Experimental CPF Flow Resistance (subplot 1), Exhaust Viscosity and CPF Average Temperature (subplot 2), Experimental and Corrected Experimental Exhaust Mass Flow Rate (subplot 3), Corrected and Experimental CPF Pressure Drop Profile (subplot 4)

In Figure $\mathrm{H} 26$, the most significant corrections are the Stage 1 loading CPF pressure drop and mass flow rate, the CF applied to the mass flow rate during the regeneration phases of the experiment, and the temperature stabilization periods of Stage 2 and Stage 4 loading and the loading ramp phase. 

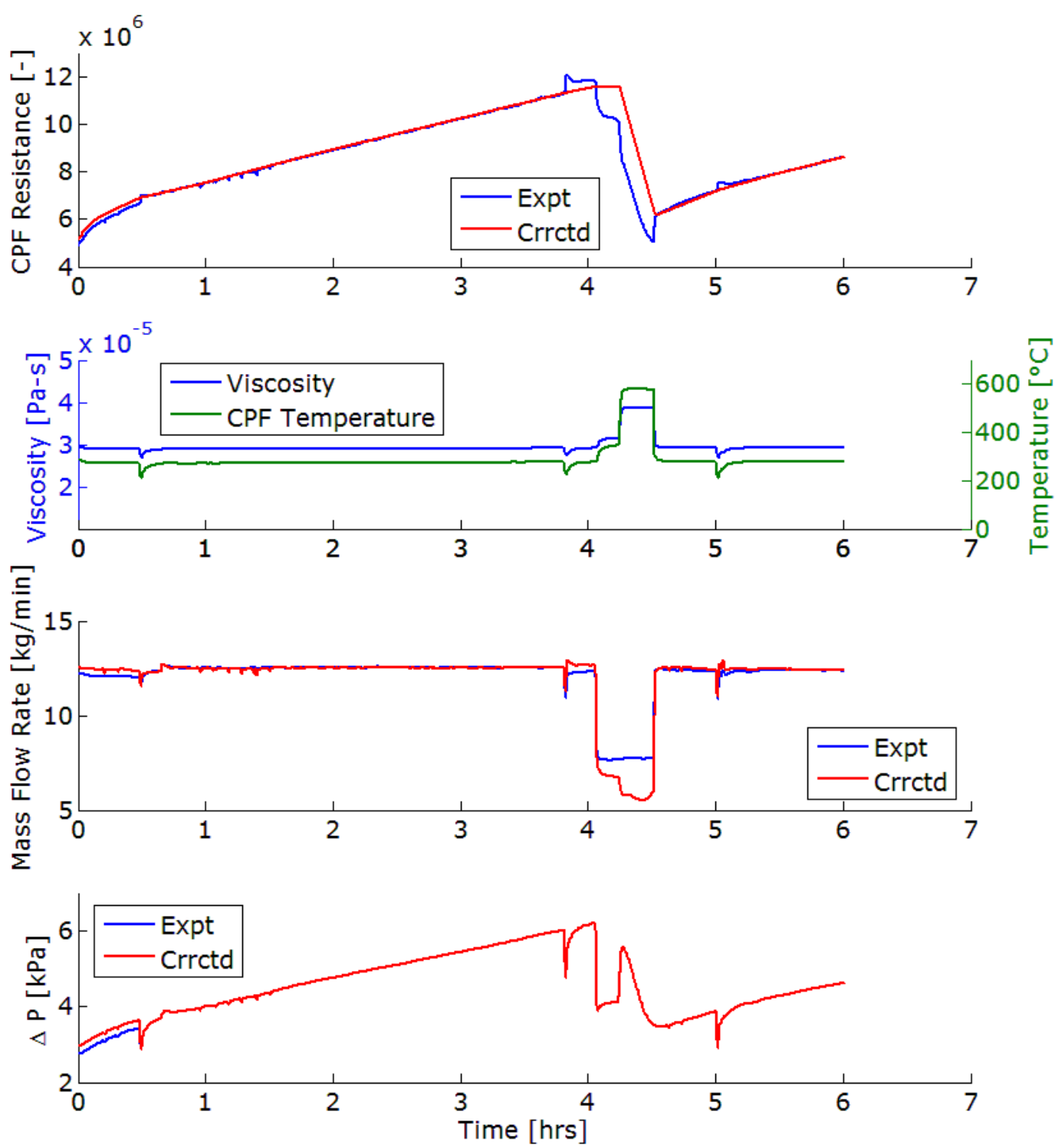

Figure H27: Run 17 (ULSD-7R) Corrected and Experimental CPF Flow Resistance (subplot 1), Exhaust Viscosity and CPF Average Temperature (subplot 2), Exp. and Crrctd. Exp. Exhaust Mass Flow Rate (subplot 3), Corrected and Experimental CPF Pressure Drop Profile (subplot 4)

In Figure $\mathrm{H} 27$, the most significant corrections are the Stage 1 loading CPF pressure drop and mass flow rate, the loading ramp mass flow rate due to LFE error, the CF applied to the mass flow rate during the regeneration phases of the experiment, and the temperature stabilization periods of Stage 2 and Stage 4 loading and the loading ramp phase. 

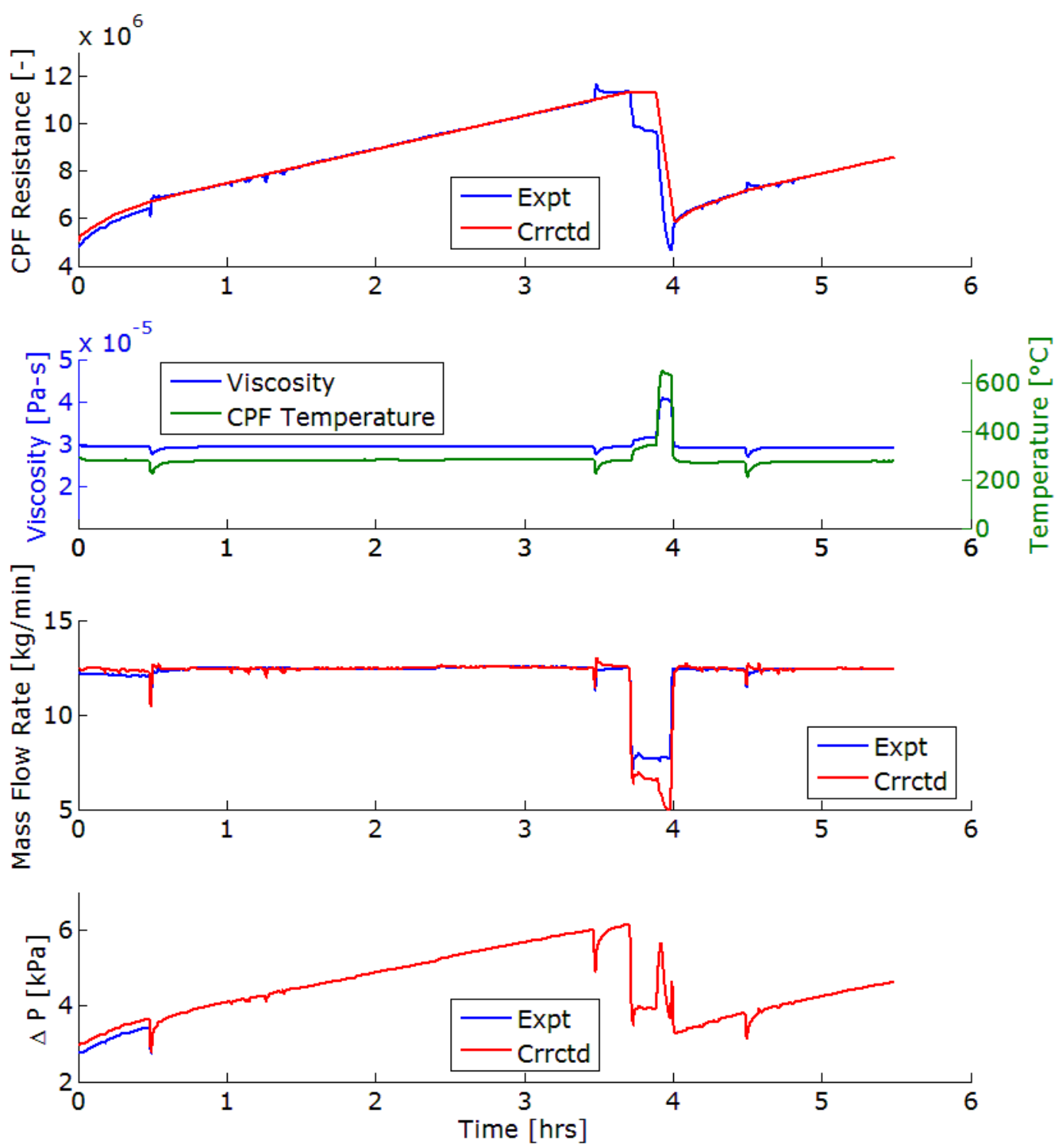

Figure H28: Run 18 (ULSD-2R) Corrected and Experimental CPF Flow Resistance (subplot 1), Exhaust Viscosity and CPF Average Temperature (subplot 2), Experimental and Corrected Experimental Exhaust Mass Flow Rate (subplot 3), Corrected and Experimental CPF Pressure Drop Profile (subplot 4)

In Figure $\mathrm{H} 28$, the most significant corrections are the Stage 1 loading CPF pressure drop and mass flow rate, the CF applied to the mass flow rate during the regeneration phases of the experiment, and the temperature stabilization periods of Stage 2 and Stage 4 loading and the loading ramp phase. 

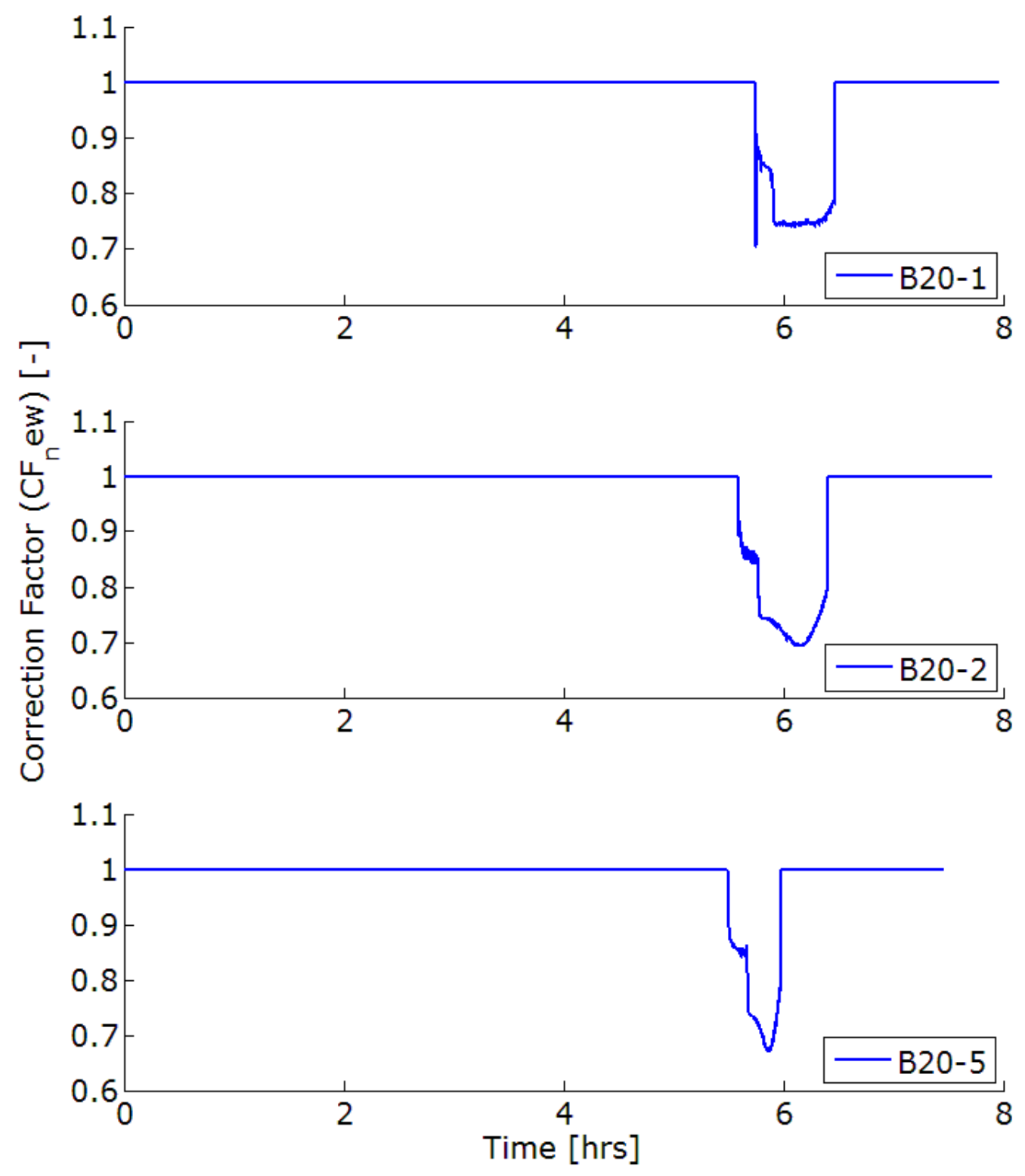

Figure H29: CF for B20-1, B20-2, B20-5 


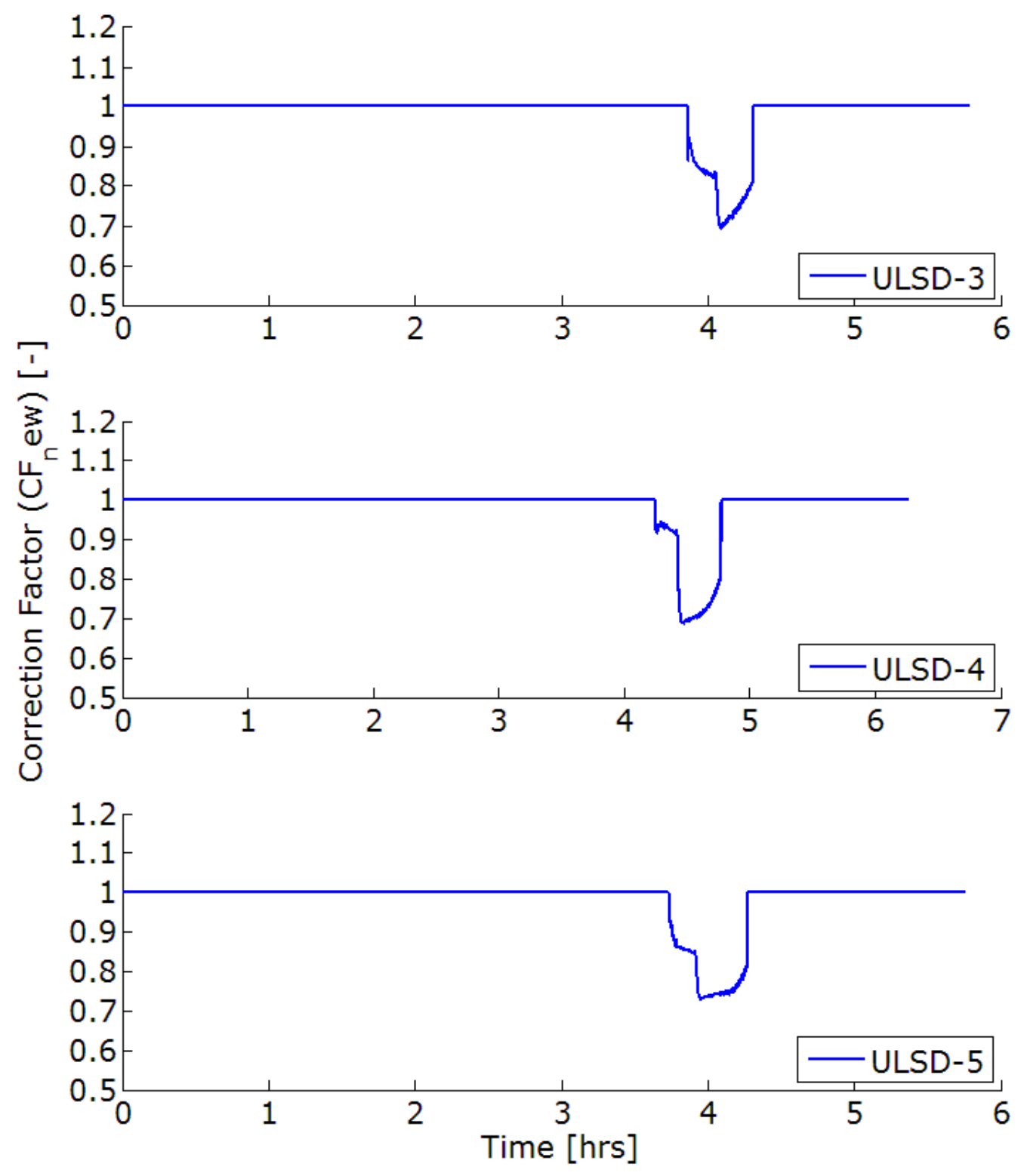

Figure H30: CF for ULSD-3, ULSD-4, ULSD-5 

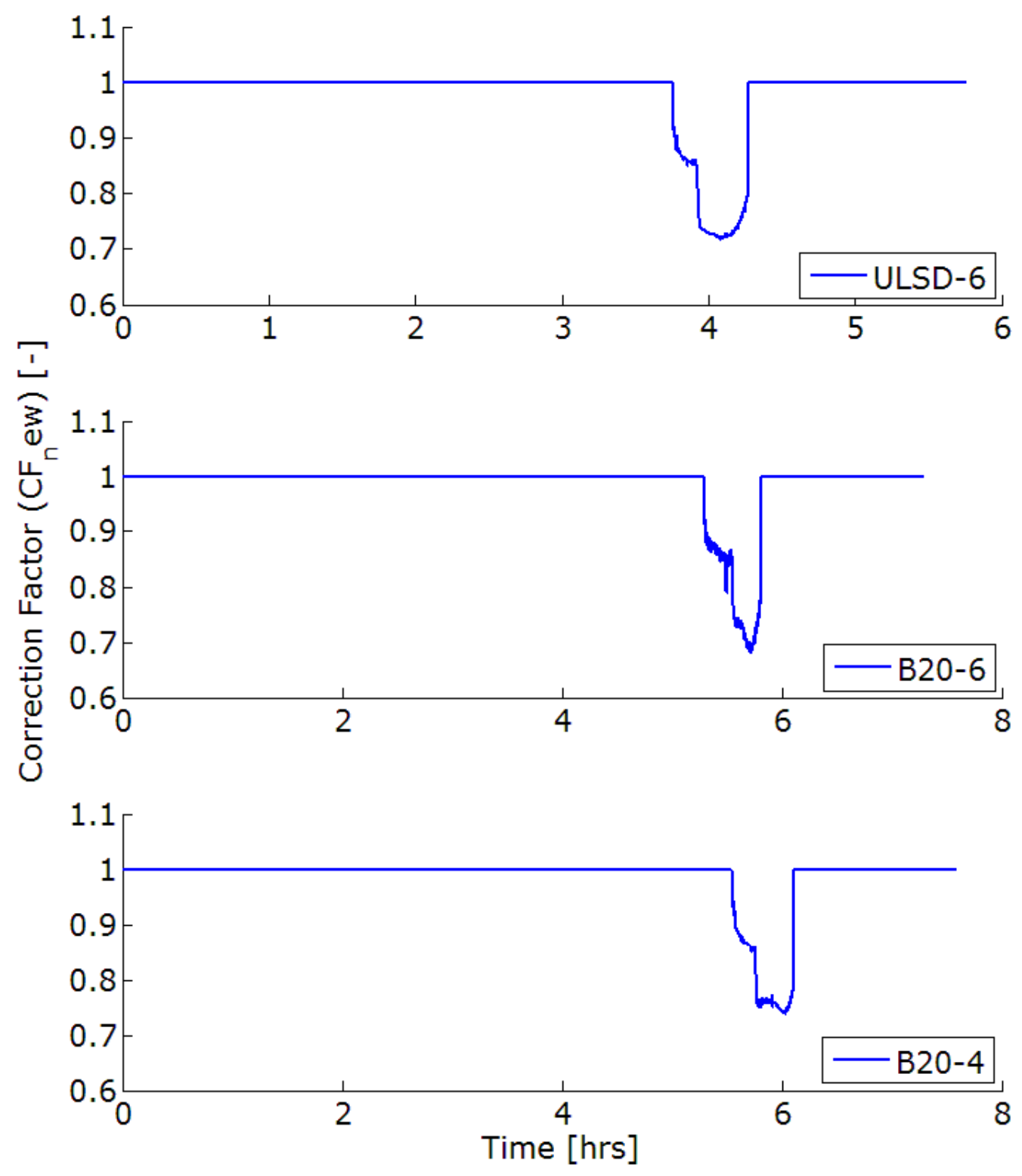

Figure H31: CF for ULSD-6, B20-6, B20-4 

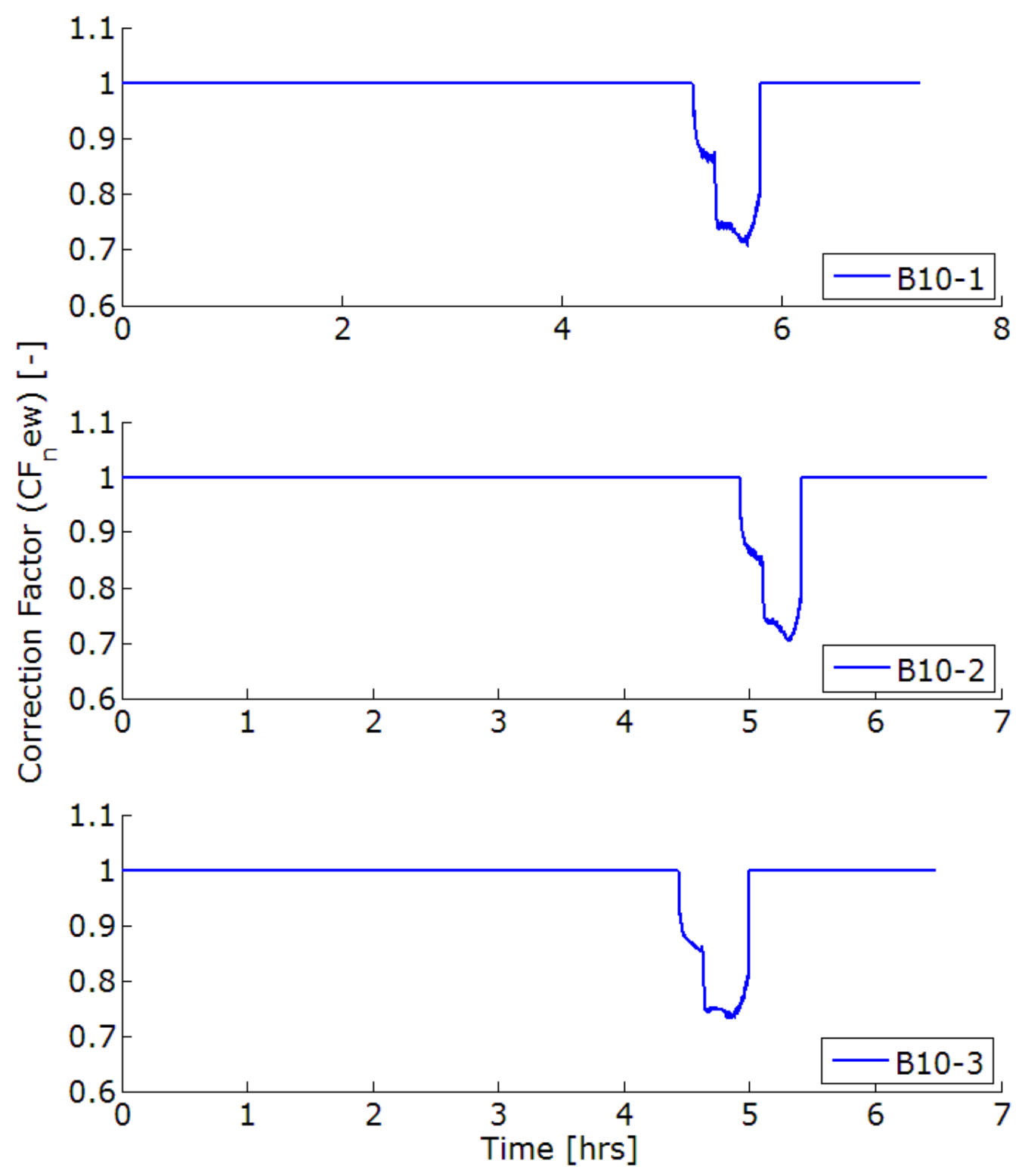

Figure H32: CF for B10-1, B10-2, B10-3 


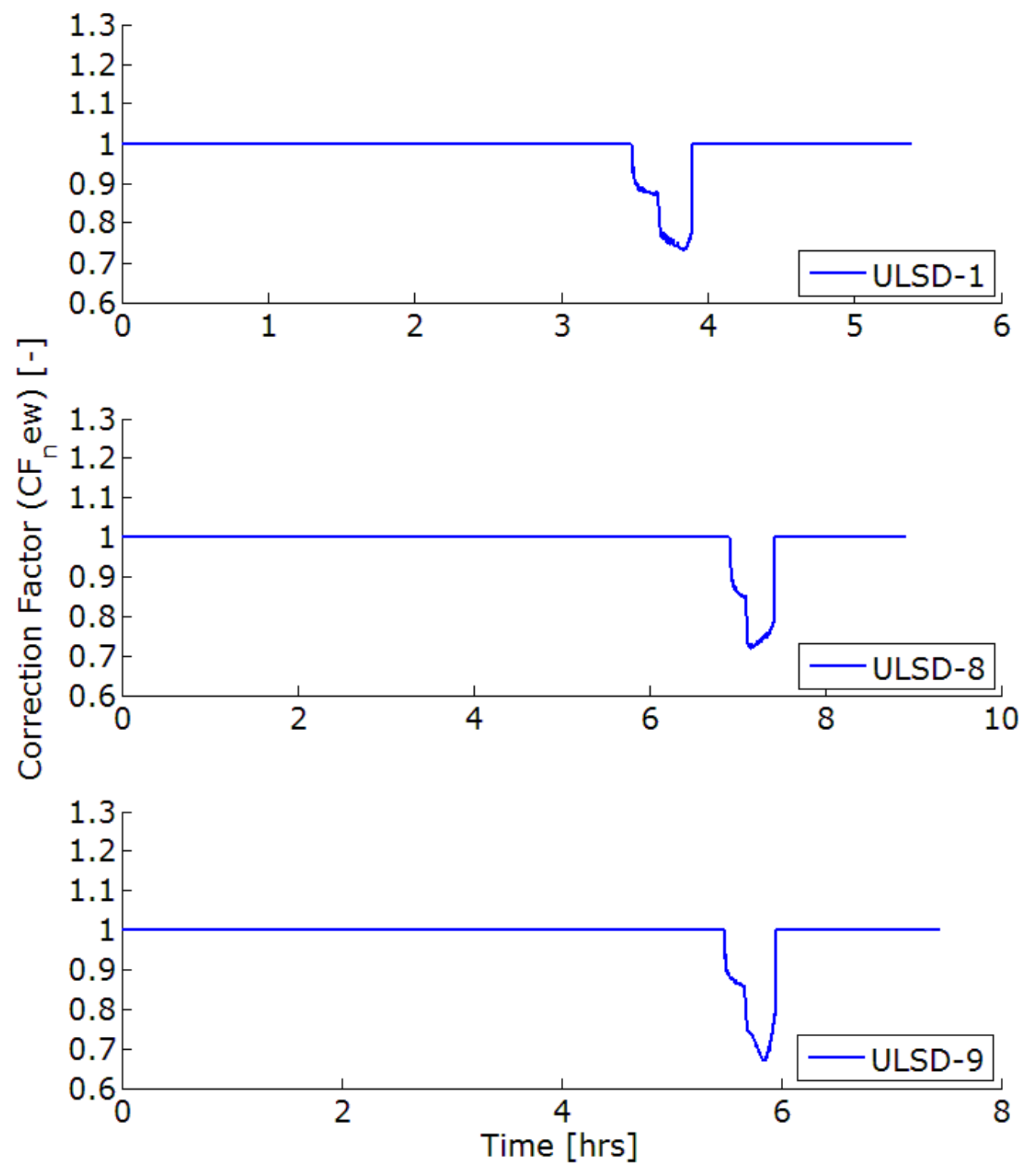

Figure H33: CF for ULSD-1, ULSD-8, ULSD-9 


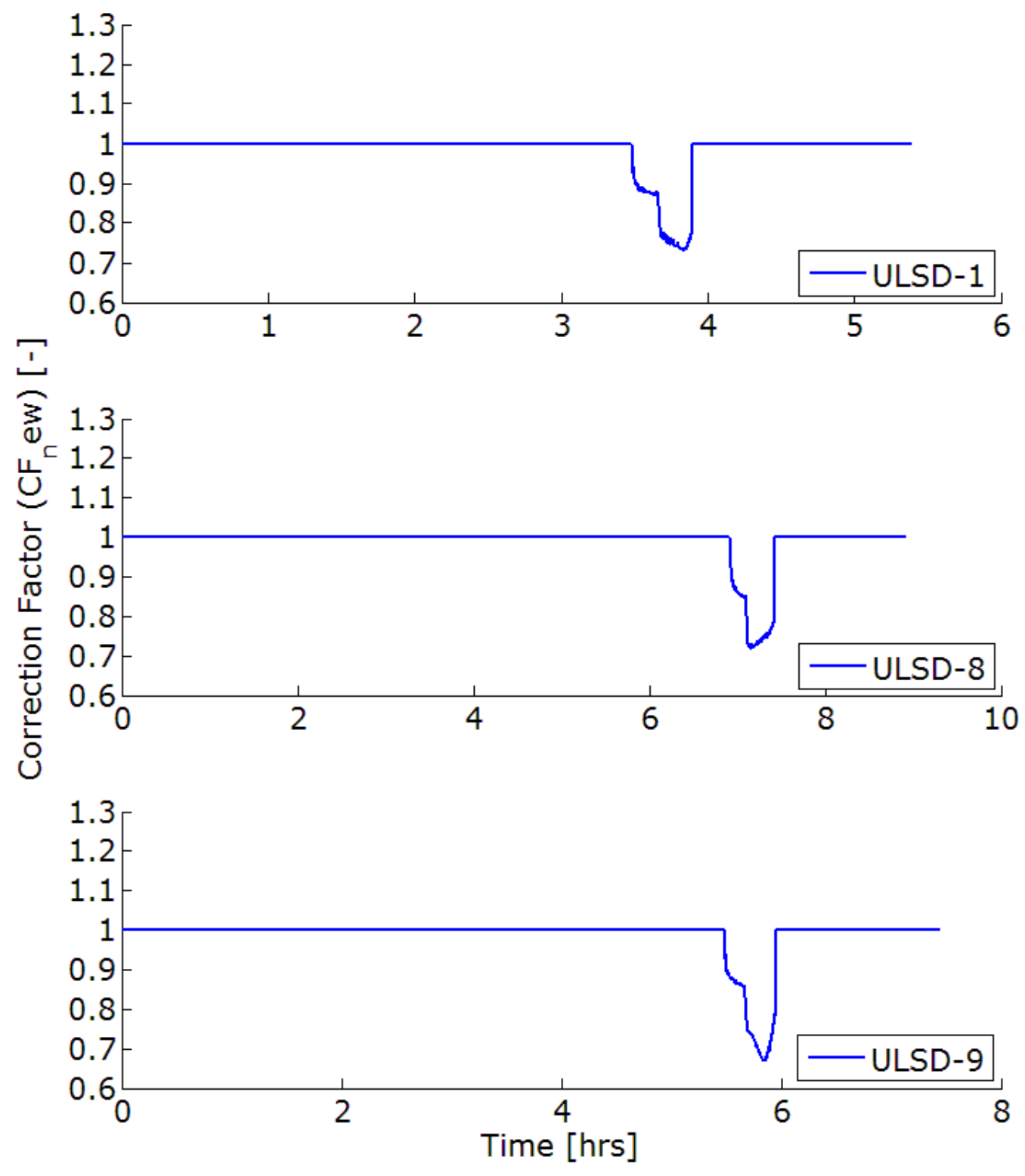

Figure H34: CF for B10-4, ULSD-7R, ULSD-2R 


\section{Appendix I Stage 2 Loading}

Following the CPF cleanout and subsequent CPF weighing following the Stage 1 loading phase, Stage 2 loading is carried out until the desired amount of PM has been deposited within the CPF. As described in Chapter 3, loading was performed on the ISL 365 at 2100 RPM and $195 \mathrm{Nm}$ and 2090 RPM and $255 \mathrm{Nm}$ on the ISL 425. Throughout Stage 2 loading, gaseous emissions, engine and CPF out PM concentrations, and PSD are measured along with the logging of temperature and pressure drop across the aftertreatment system components.

\section{Gaseous Emissions}

Average engine out gaseous emissions during Stage 2 loading are shown in Figure I1. The concentrations were averaged over all ISL 365 runs with the same test fuel type and the error bars shown correspond with \pm 1 standard deviation of the average values. As stated in Chapter 3, all gaseous concentrations reported in this study are wet concentrations as measured by the emissions bench.

The engine-out HC concentrations were lower with increasing biodiesel concentrations, but overlapping error bars indicate that the differences between them may be insignificant. Average HC concentrations for ULSD, B10, and B20 were 98,84 , and 70 ppmC, respectively. As previously described, $\mathrm{NO}_{\mathrm{x}}$ values have been shown to increase or decrease depending on the fuel type and test conditions. In the case of this study, average engine-out $\mathrm{NO}_{x}$ concentrations were shown to decrease with increasing test fuel biodiesel content, however, overlapping error bars indicate that the differences between them may be negligible, as with the HC concentrations. Austin [1] discusses this in further detail where it was shown that the variation in $\mathrm{NO}_{\mathrm{x}}$ concentrations between tests with one test fuel was greater than the variation in concentrations between test utilizing various ULSD and biodiesel blended fuels.

The NO concentrations also followed the trend with respect to variations in the $\mathrm{NO}_{\mathrm{x}}$ concentrations, while the $\mathrm{NO}_{2}$ concentrations were increasing with increased test fuel biodiesel content. The engine-out $\mathrm{CO}, \mathrm{CO}_{2}$, and $\mathrm{O}_{2}$ concentration differences with respect to the test fuel were negligible. Detailed emissions summaries for Stage 2 and Stage 4 loading as well as active regeneration test phases are available in Appendix M. 


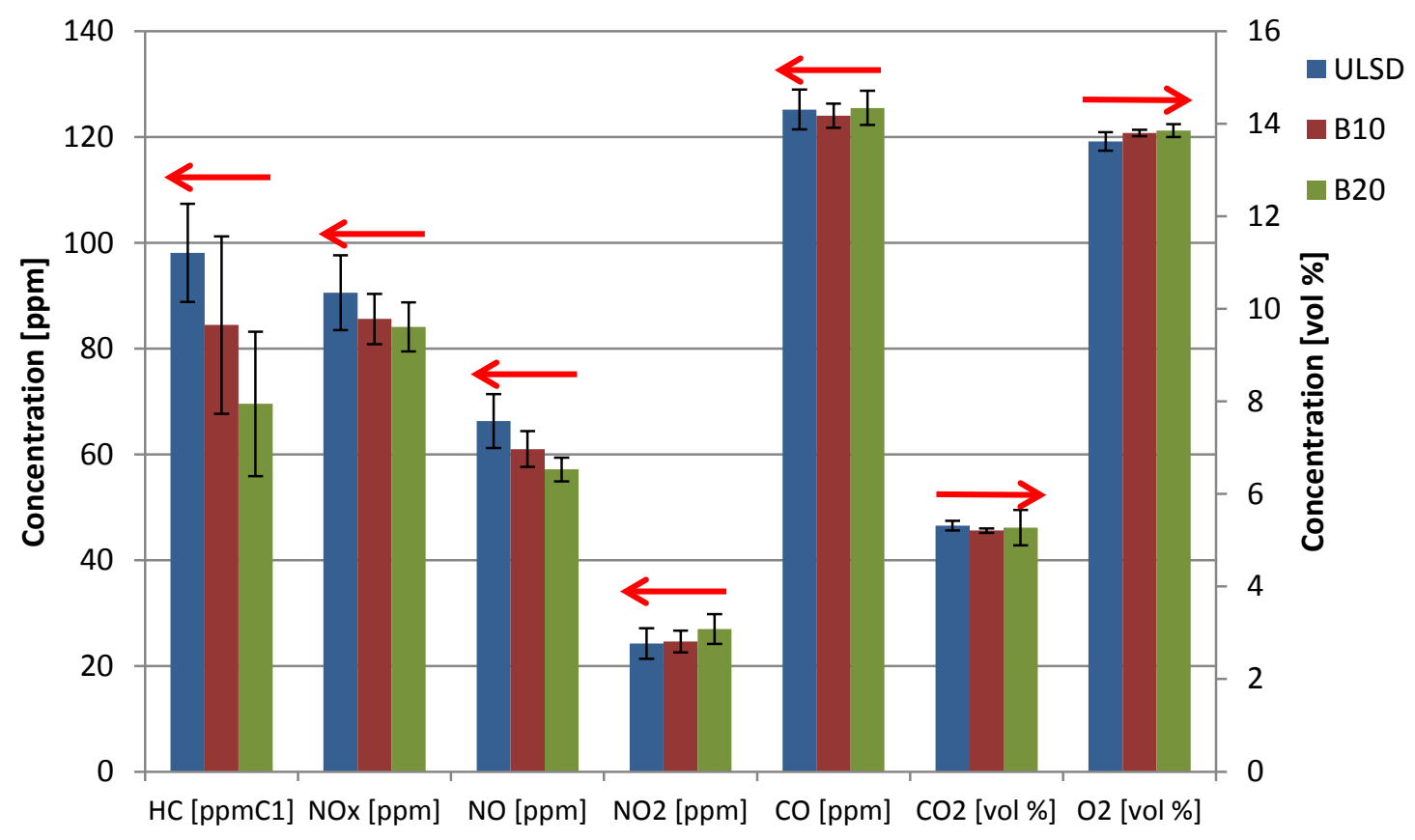

Figure I1: Average Engine-out Gaseous Emissions during Stage 2 Loading for Each Test Fuel

\section{PSD Data}

Particle size distribution (PSD) data were collected during active regeneration tests performed, when the SMPS system was operational. The PSD samples were taken from each sampling location (UDOC, DDOC, and DCPF) throughout each phase of testing, with the exception of active regeneration phases. During active regeneration, PSD samples cannot be taken UDOC due to the excess hydrocarbons in the exhaust stream. Therefore, only DDOC and DCPF PSD samples were collected during active regeneration phases. It is believed that a cracked fitting on the SMPS system occurred near the time that test B10-2 was performed, corresponding to run 11 of 19 , and as such, only the data collected to this point will be presented.

The data sets obtained with the same test fuel were averaged and the resulting trend for all three test fuels is shown in Figure I2, where the engine-out (UDOC) and CPFout (DCPF) data are both shown. The data sets at a higher vertical location represent the UDOC samples while the data sets at the lower vertical location represent the DCPF samples. The vertical axis corresponds to the particle number concentration 
normalized by bin size within the SMPS system. The peak particle count, for both UDOC and DCPF cases, was shown to be with ULSD, followed by B10 and B20, which were the same trends shown by Austin [1]. Austin [1] reported that as the percent biodiesel in the test fuel increases, the particle count decreases, which is also shown in Figure I2.

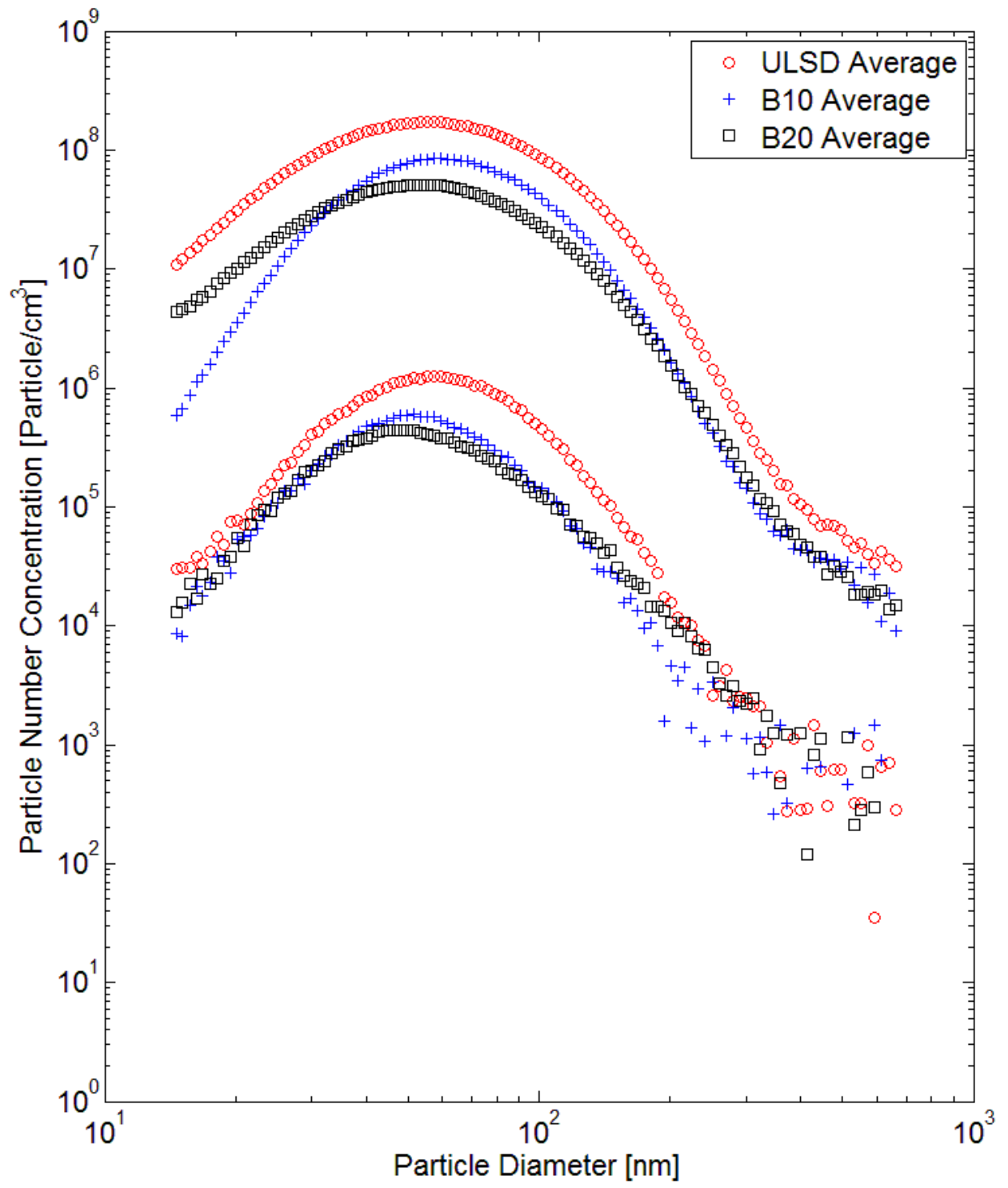

Figure I2: Stage 2 Loading Engine-Out and CPF-out Particle Size Distribution Weighed by Number for ULSD, B10, and B20. 


\section{PM Concentration Data}

Particulate matter (PM) hot samples were collected at various times throughout each test to determine the exhaust PM concentration. The measured PM concentrations for ULSD, B10, and B20 were between 21.2 and $29.4 \mathrm{mg} / \mathrm{scm}, 15.7$ and $19.0 \mathrm{mg} / \mathrm{scm}$, and 12.7 to $21.6 \mathrm{mg} / \mathrm{scm}$, respectively. Variation between test fuels and between tests with the same fuel was observed and can be seen in Figure I3, where the results are plotted vs. test number to show the trends throughout the testing period. In Figure I3, the PM concentrations measured throughout Stage 2 loading were averaged and the error bars correspond with standard deviations of the samples used to calculate that average. The error bars appear to be hidden for some of the data shown in Figure I3, meaning that the standard deviation between the samples was small and therefore, the samples taken during that test were very consistent. For a small number of tests, not all PM samples were used to calculate the average PM concentration during each test, because damage to the filter can occur during handling resulting with inaccurate filter mass measurements, and subsequently, inaccurate PM concentration data. The tests with large error bars, i.e., Tests 2 and 13 indicate that a PM sample could have been damaged and the associated PM sample was removed from calculation of the average engine-out PM concentration.

In general, it can be seen that the measured engine-out PM concentration was lower with increasing percent biodiesel in the test fuel, which was expected following the work reported in references [1,6, and 11] because the same trends were shown. Test 9 is one anomaly in the data where the PM concentration measured was significantly higher than Test 8 . The specific reason for this is unknown, but it is suspected that the changes in the test cell ambient air temperature and humidity were a factor. 


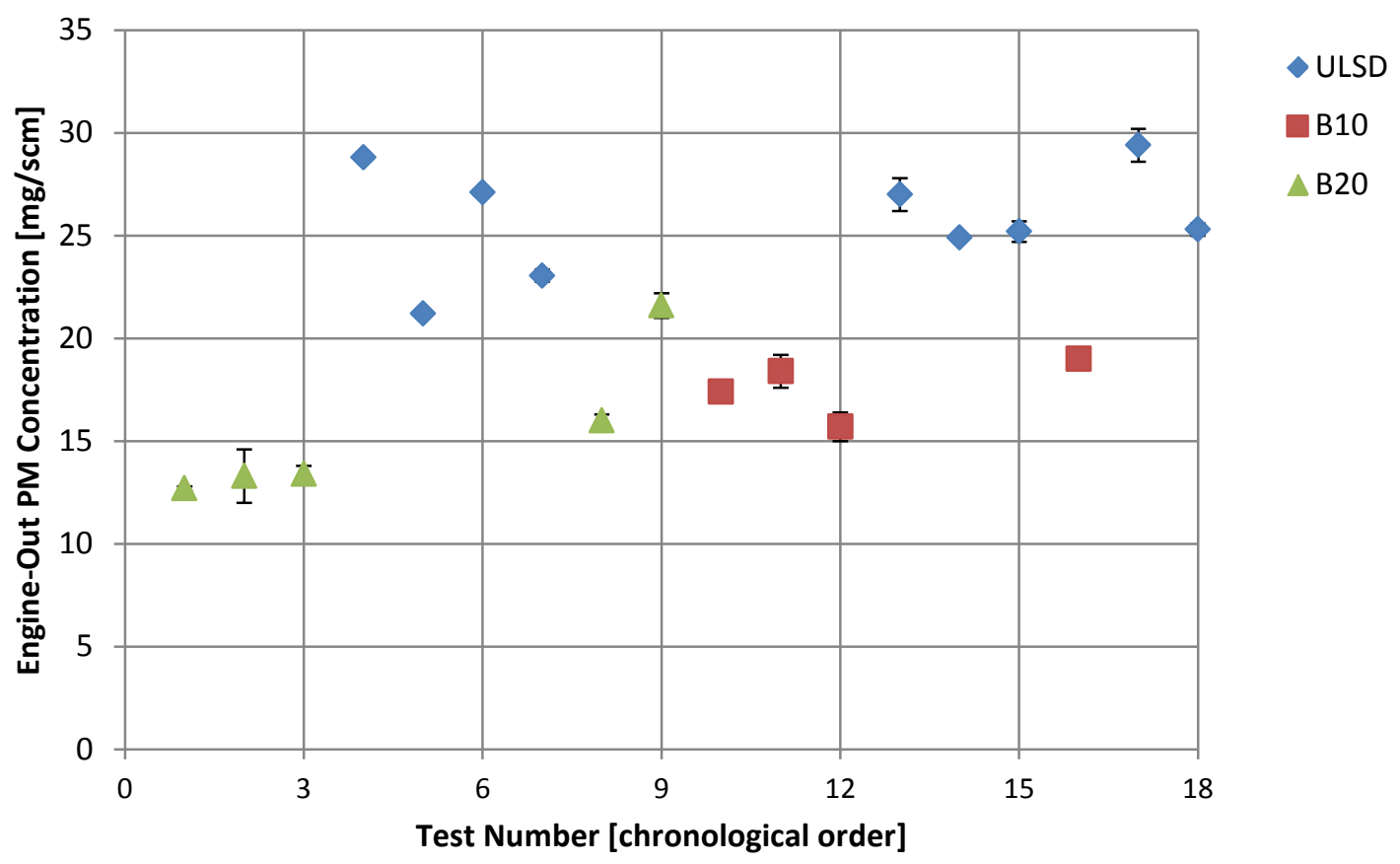

\section{Figure I3: Stage 2 Loading Average Engine-Out PM Concentrations in Chronological Order}

The increase in PM concentrations over time, with the same test fuel, suggests that the PM concentration increases with increasing temperature and humidity in the test cell, because testing initiated during the winter with test B20-1. Additional analysis on this phenomenon was carried out and explained in detail by Austin [1].

\section{CPF Pressure Drop Profile}

Figure I4 presents the CPF pressure drop vs. the CPF PM loading at the conclusion of Stage 2 loading. It can be seen that a CPF pressure drop of $6 \mathrm{kPa}$ corresponds to 2.2 to $2.5 \mathrm{~g} / \mathrm{L} \mathrm{CPF} \mathrm{PM} \mathrm{loading.} \mathrm{The} \mathrm{two} \mathrm{tests} \mathrm{between} 4$ and $5 \mathrm{~g} / \mathrm{L}$ CPF PM loading were the two test cases in which a target CPF PM loading of $4.1 \mathrm{~g} / \mathrm{L}$ was utilized. One B20 test (circled in blue) shows a CPF pressure drop below the $5.5 \mathrm{kPa}$ threshold that also corresponds to a CPF loading between 2.2 and $2.3 \mathrm{~g} / \mathrm{L}$. This is believed to have been caused by a leaking bypass line valve. The valve is intended to seal the bypass line off from any flow while running in the trap line. If this valve sticks, exhaust is able to flow into the bypass line, reducing the total amount of exhaust reaching the aftertreatment system, where a decreased pressure drop is measured. 
The ULSD test in the same pressure drop regime (circled in red) is the single test ran on the ISL 425, where a lower CPF pressure drop correlates to the same PM loading as with the ISL 365 , which is also reported in Shiel [11].

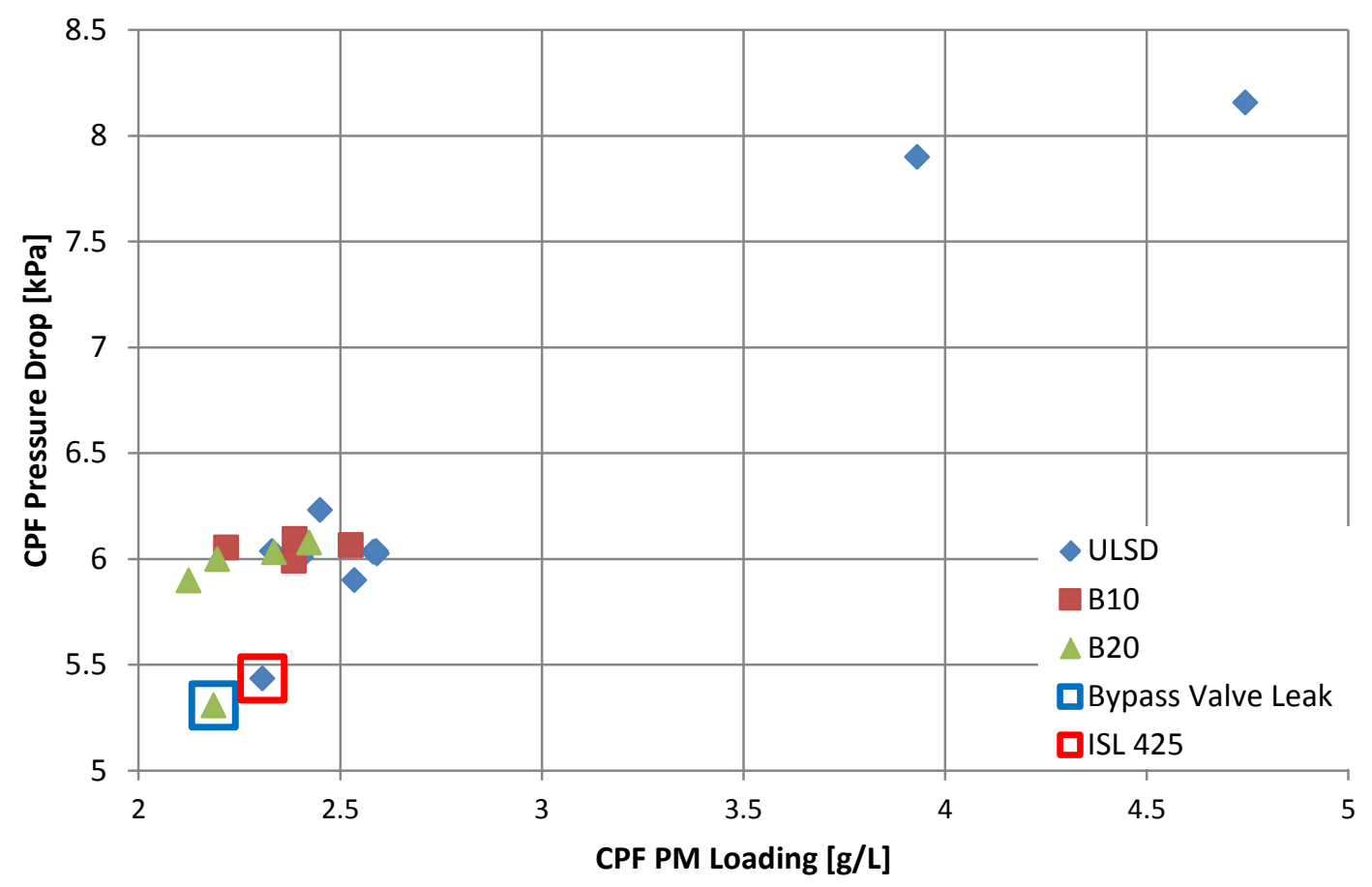

Figure I4: CPF Pressure Drop vs. CPF PM Loading at the Conclusion Stage 2 Loading 


\section{Appendix J Stage 4 Loading}

Following the CPF weighing at the conclusion of active regeneration, Stage 4 loading is carried out for sixty minutes. As described in Chapter 3, loading was performed on the ISL 365 at 2100 RPM and $195 \mathrm{Nm}$ and 2090 RPM and $255 \mathrm{Nm}$ on the ISL 425. The purpose of Stage 4 loading is to observe changes in the CPF performance related to gaseous emissions and CPF pressure drop after a partial regeneration as opposed to a full regeneration, such as at the beginning of each experiment. Throughout Stage 4 loading, gaseous emissions, engine and CPF out PM concentrations and PSD are measured along with the constant monitoring of temperature and pressure drop across the aftertreatment system components.

\section{Gaseous Emissions}

The engine-out gaseous emissions are graphically represented in Figure J1. The average engine-out gaseous emissions are presented with error bars representing the standard deviation resulting from calculating those average values.

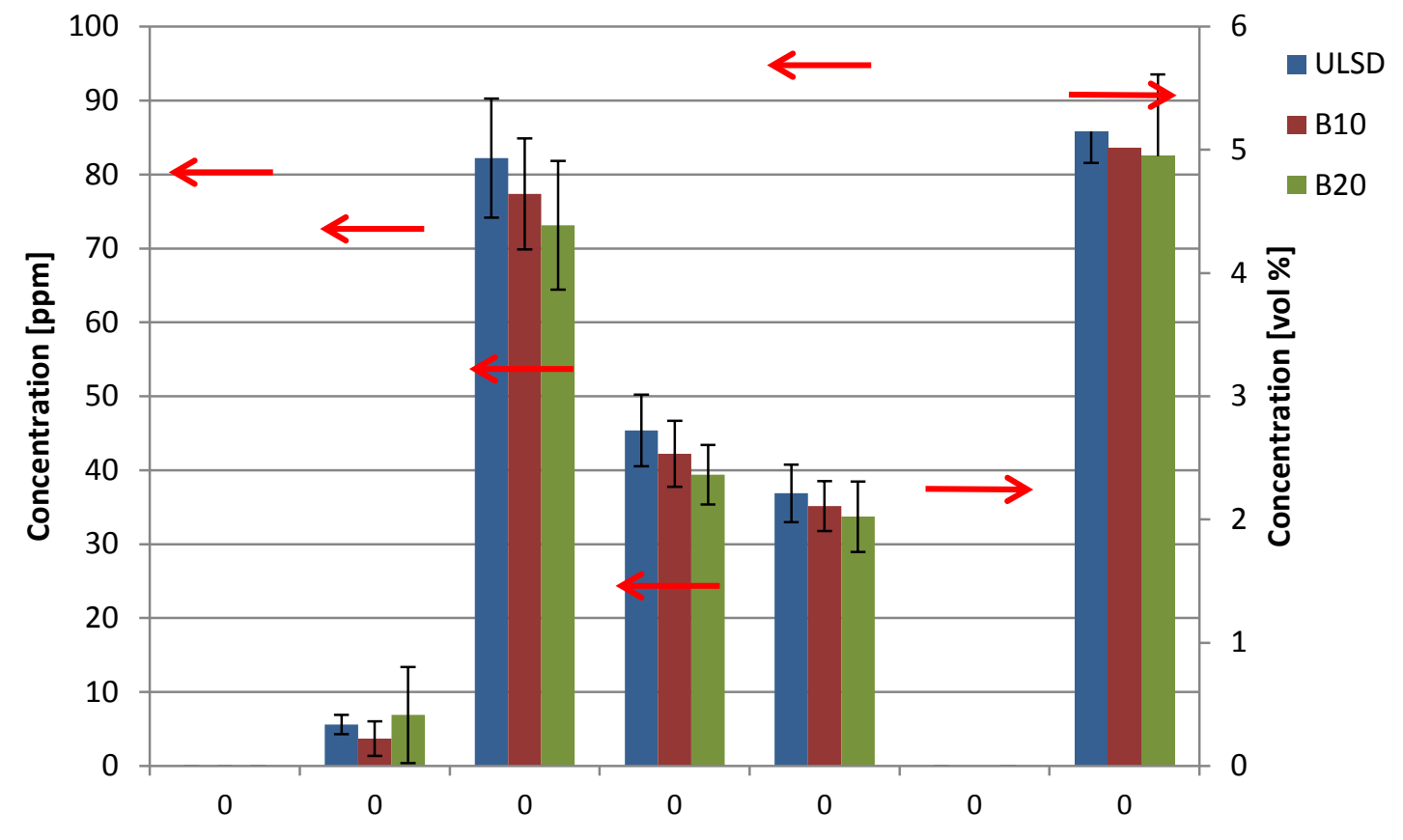

Figure J1: Average Engine-out Gaseous Emissions during Stage 4 Loading for Each Test Fuel 
Since Stage 4 loading takes place at the same operating conditions as Stage 2 loading, there are no significant changes in fuel use, gaseous emissions, or PM concentrations between the two. The only significant differences between the gaseous emissions during loading prior to and after active regeneration were seen in the hydrocarbon concentrations measured by the emissions bench. For all tests, the hydrocarbon measurement range had to be increased prior to active regeneration in order to capture the elevated hydrocarbon concentrations DDOC during active regeneration. For some tests, the range was adjusted back to its low level after active regeneration, but for other tests, it was not because this part of the test had not been incorporated into the standard testing procedure, and had been forgotten. Since the high range can read up to $4200 \mathrm{ppmC}$ of hydrocarbons compared to the low range which can only read up to $150 \mathrm{ppmC}$, the hydrocarbon measurements for the tests where the low range was not used during Stage 4 loading could have been elevated due to such a small fraction of the bench's range being used for actual hydrocarbon measurements. Another factor which could have led to these elevated readings could be attributed to the length of measurement time between Stage 2 and Stage 4 loading. During Stage 2 loading, hydrocarbons are measured in each location (UDOC, DDOC, or DCPF) for an entire hour, where each location is sampled for 20 minutes during Stage 4 loading, which gave the emissions bench more time for the hydrocarbon measurements to stabilize at the low concentrations.

\section{PSD Data}

The PSD data collected during Stage 4 loading follows the same trend as Stage 2 loading, as expected, and is shown in Figure $\mathrm{J} 1$. The particle count is highest with ULSD, followed by B10 and B20 in both sample locations (UDOC and DCPF) which was expected based on the results reported by Austin [1]. 


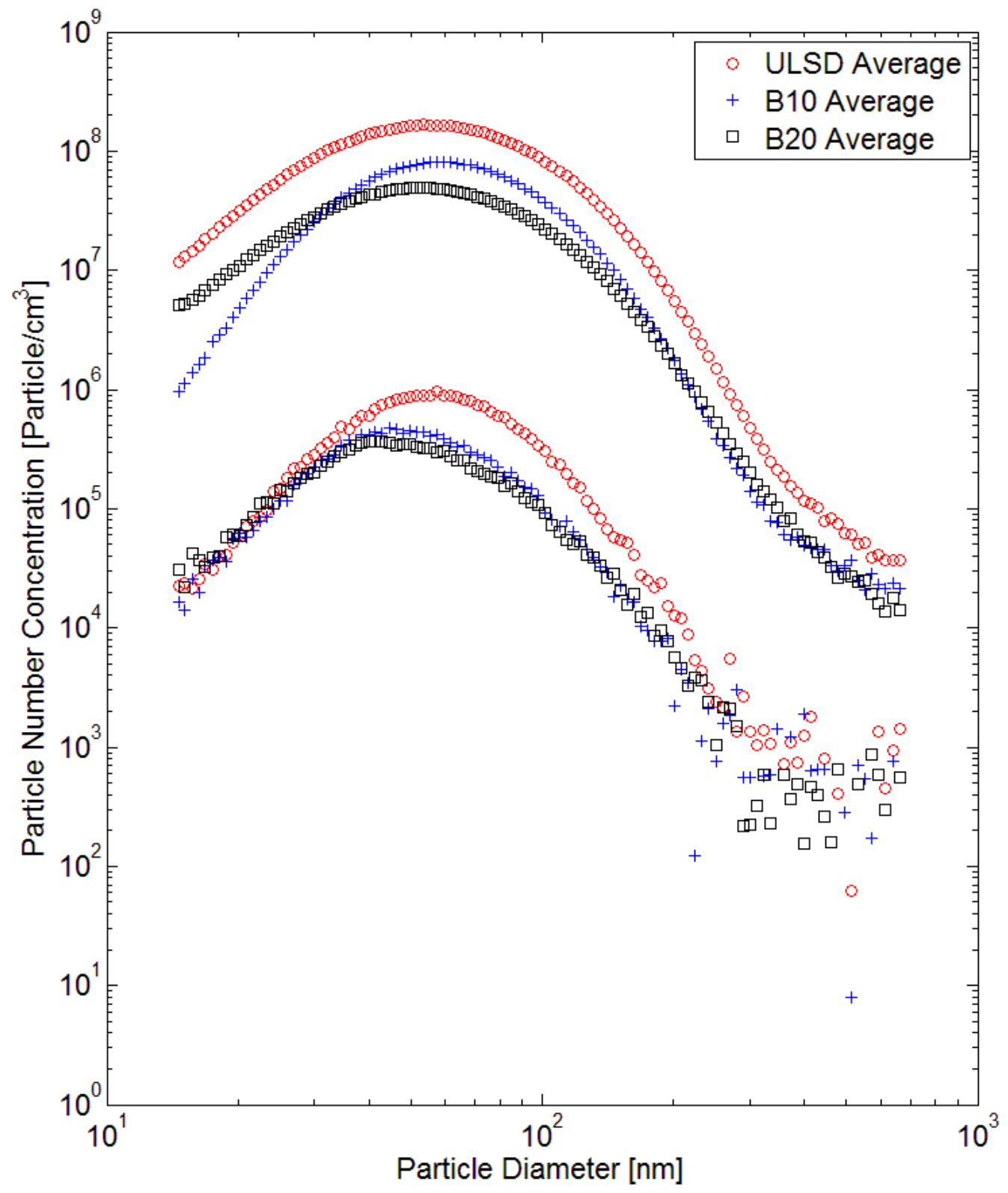

Figure J2: Particle Size Distribution by Particle Numbers Averaged by Fuel Type during Stage 4 Loading sampled DDOC and DCPF

\section{CPF Pressure Drop Profile}

One area where visible differences between Stage 2 and Stage 4 loading can be observed is in the pressure drop across the CPF. Figure $\mathrm{J3}$ below displays the 
pressure drop and associated CPF PM load for all $2.2 \mathrm{~g} / \mathrm{L}$ targeted ISL 365 tests, from the beginning and end of Stage 2 and Stage 4 loading phases. The data are categorized by fuel and estimated trend-lines are added to the Stage 2 and Stage 4 data sets.

It can be seen in Figure 33 that the pressure drop between Stage 2 and Stage 4 loading do not match for a given CPF PM loading. For example, following the B20 trend lines, for a given CPF PM load of 20 grams, the pressure drop during Stage 4 loading was about $0.5 \mathrm{kPa}$ lower than during Stage 2 loading.

As the CPF is regenerated, the PM that is in the channel walls is oxidized during active regeneration. A cake layer could still remain present after a partial regeneration, resulting in the PM entering the CPF following regeneration to not reach the wall itself. This occurs because the filtration efficiency of the cake layer is $94 \%$ or greater, preventing the PM from reaching the wall of the CPF channels. This results in the wall's porosity being increased from when the wall is loaded with PM, reducing the pressure drop across the CPF [1]. This leads to an increased level of difficulty when relating the total pressure drop of the CPF to the PM mass inside it.

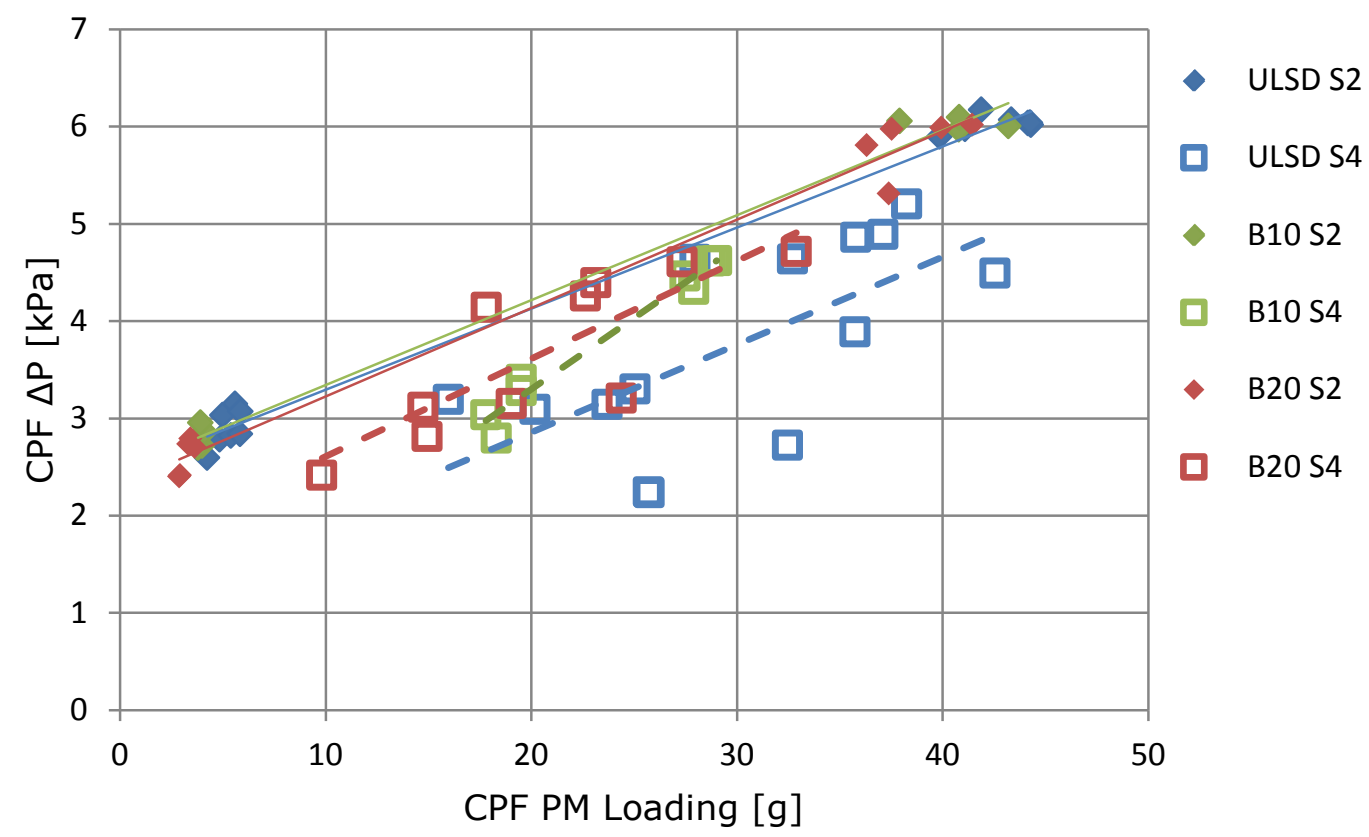

Figure J3: CPF Pressure Drop at the Start and Stop of Stage 2 and Stage 4 Loading for all tests. 
One trend in Figure 33 that was noted in Austin [1] is that there is less separation between Stage 2 and Stage 4 loading data sets at lower levels of CPF PM loading. This is possibly due to decreased cake PM layer thickness after active regeneration which possibly could let more PM into the wall. This conclusion is reinforced by the fact that the Stage 2 loading pressure drop vs. CPF PM loading trend lines are nearly identical for all tests.

\section{Loading Reaction Rate}

In order to compare the loading characteristics of the CPF between Stage 2 and Stage 4 loading, the reaction rate for each phase was calculated based on the CPF PM mass retained at the beginning and end of each phase. Eqn. J1 is used to calculate the reaction rate.

$$
\mathrm{m}_{\text {stop }}=\frac{\mathrm{Q}_{\text {exh }} \cdot \mathrm{C}_{\text {in }} \cdot \eta_{\mathrm{f}}}{\mathrm{RR}_{\mathrm{f}} \cdot 1000}\left[1-\mathrm{e}^{\left(-\mathrm{RR}_{\mathrm{o}} \cdot \mathrm{t}_{\mathrm{eff}}\right)}\right]+\mathrm{m}_{\text {start }} \cdot \mathrm{e}^{\left(-\mathrm{RR}_{\mathrm{o}} \cdot \mathrm{t}_{\mathrm{eff}}\right)} \quad \text { Eqn. } \mathrm{J} 1
$$

$\mathrm{RR}_{0}=\mathrm{PM}$ reaction rate $[1 / \mathrm{sec}]$

$\eta_{\mathrm{f}}=\mathrm{CPF}$ filtration efficiency [fractional]

$\mathrm{C}_{\text {in }}=$ Engine-out $\mathrm{PM}$ concentration $[\mathrm{mg} / \mathrm{scm}]$

$\mathrm{Q}_{\text {exh }}=$ Exhaust standard volumetric flow rate $[\mathrm{scm} / \mathrm{sec}]$

$t_{\text {eff }}=$ Time of the phase for which $R_{0}$ is being calculated [sec]

$\mathrm{m}_{\text {stop }}=\mathrm{PM}$ mass retained in the CPF at phase end $[\mathrm{g}]$

$\mathrm{m}_{\text {start }}=\mathrm{PM}$ mass retained in the CPF at phase start $[\mathrm{g}]$ 


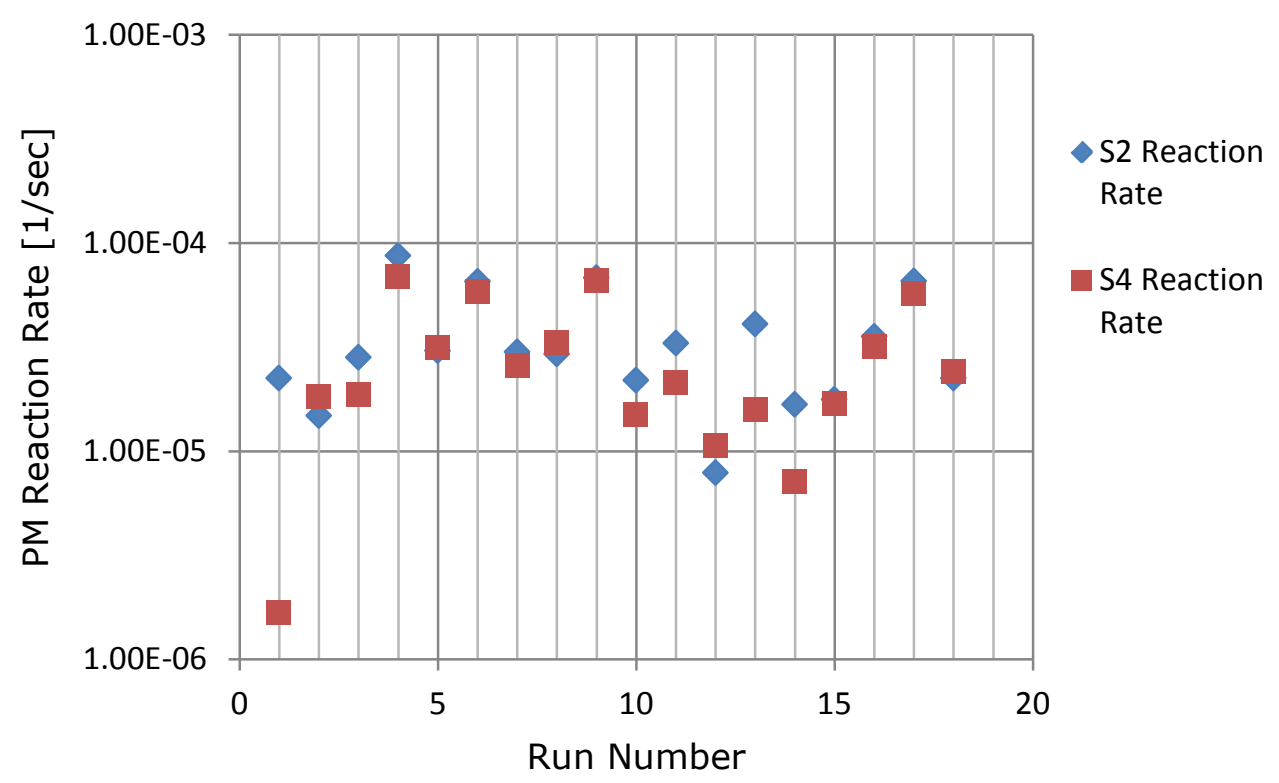

Figure J4: Stage 2 and Stage 4 Loading Reaction Rate Organized by Run Number

All of the variables presented in Eqn. $\mathrm{J} 1$ are gathered from the experimental test data with the exception of the reaction rate. The reaction rate is solved iteratively until the calculated PM mass retained within the CPF at the end of the phase is matched. The resulting reaction rate calculations from Stage 2 and Stage 4 loading phases are shown in Figure $\mathrm{J4}$.

It can be seen in Figure 34 that some runs experience similar reaction rates between Stage 2 and Stage 4 loading while some runs are significantly different. The reaction rates which do not match between the two loading phases could be attributed to CPF mass measurement errors volumetric flow rate measurement errors, or PM concentration measurement errors, all of which would be responsible for inaccurate reaction rate data. The PM entering the CPF for any given phase is calculated based on the volumetric flow rate and engine-out PM concentration, which is why errors in these measurements could contribute to the differences in PM reaction rates during Stage 2 and Stage 4 loading. Determining whether the experimental data is valid from a modeling point of view is aided by analyzing the reaction rates between Stage 2 and Stage 4 loading. 


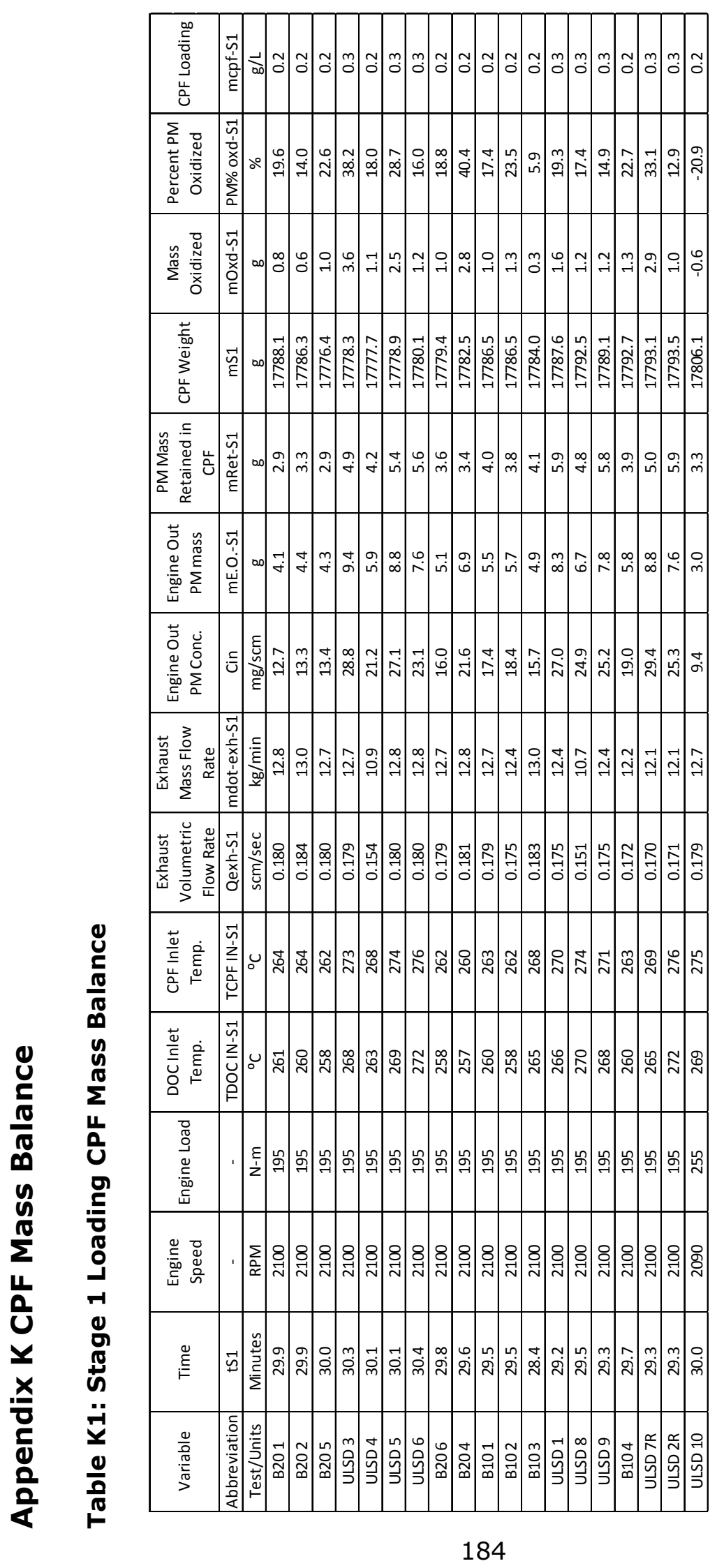




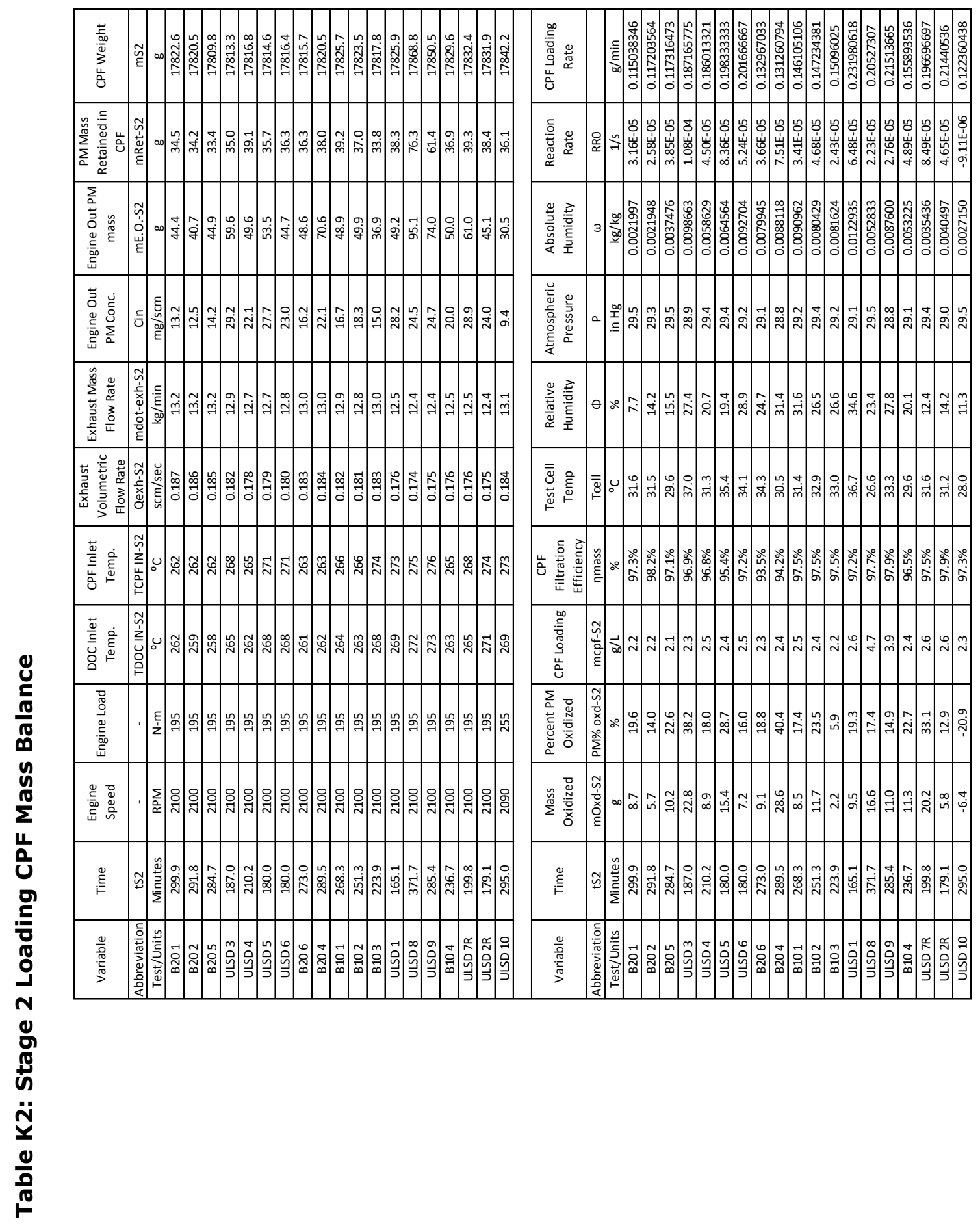




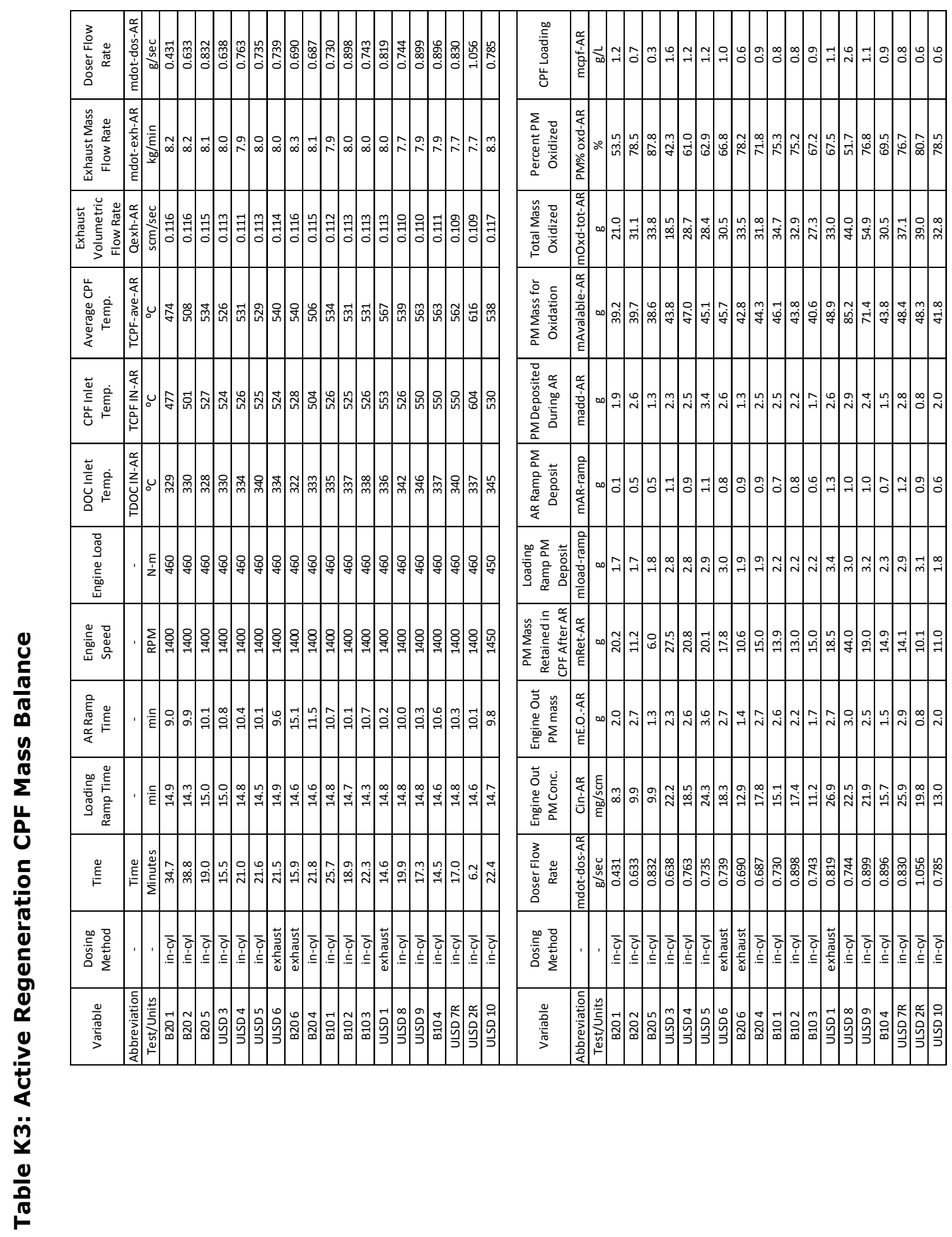




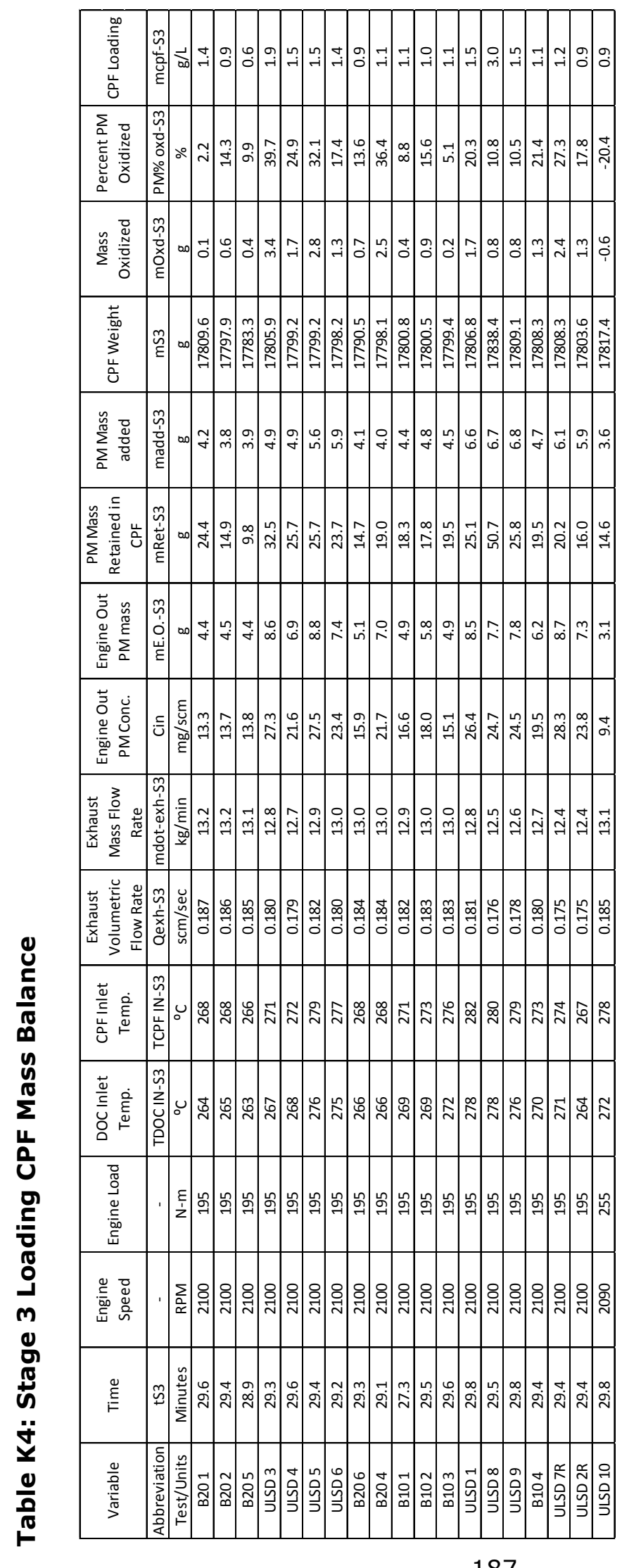

187 


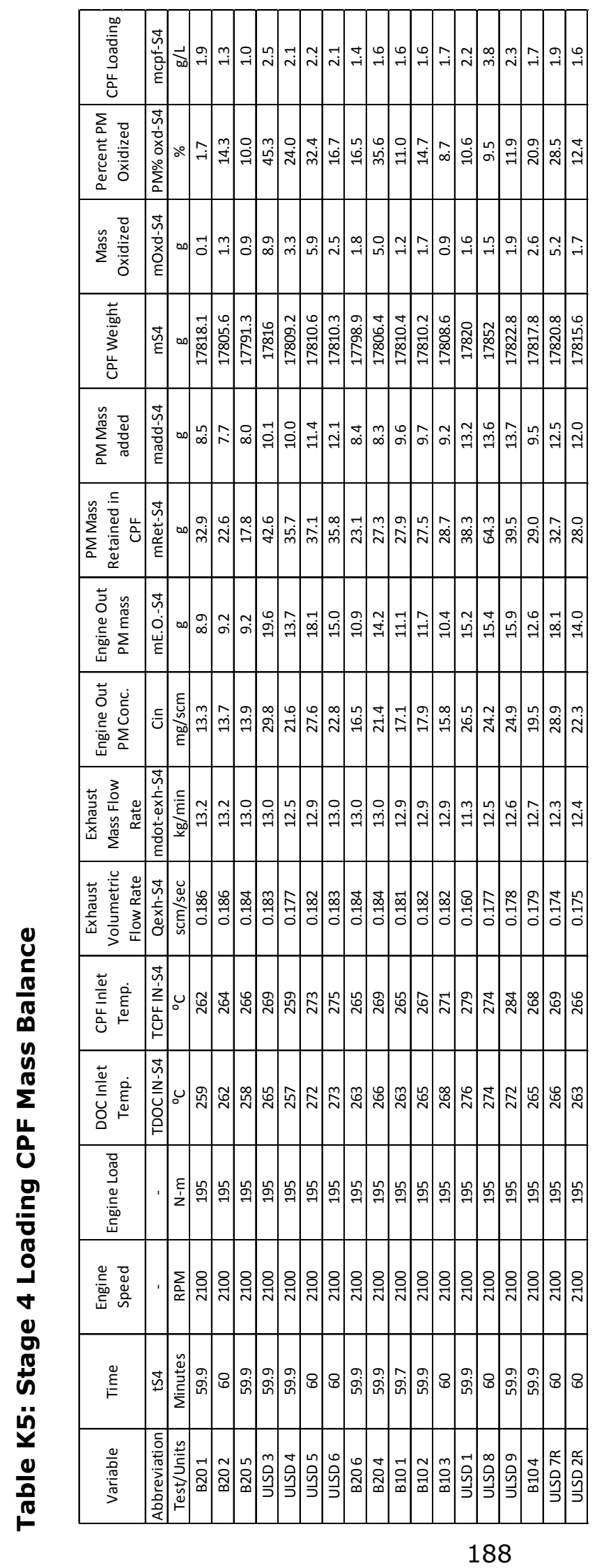




\section{Appendix L Doser Flow Rate Comparison}

Differences in the doser flow rates were noticed throughout some of the tests conducted in this study. For example, the doser flow rates between tests B10-1 and B10-2, which were run under the same experimental conditions (same target CPF inlet temperature, dosing method, and CPF PM loading), but test B10-2 required $0.168 \mathrm{~g} / \mathrm{sec}$ more fuel than what was required during B10-1 to maintain the same desired CPF inlet temperature. Other tests showed differences in the doser flow rate as well, therefore, a DOC energy balance was carried out using the methods described in reference [17] in order to estimate the upstream DOC HC concentrations and doser flow rate. The energy balance used the experimentally measured downstream DOC HC concentrations and the measured temperature rise across the $\mathrm{DOC}$ to estimate the concentration of $\mathrm{HC}$ required at the $\mathrm{DOC}$ inlet to produce the observed temperature change. The estimated DOC inlet $\mathrm{HC}$ concentrations can then be converted back to dosing flow rate in the same manner that is used to calculate upstream DOC hydrocarbon concentrations from the experimental dosing rate. Table L1 shows the results from the energy balance carried out for all tests. The 'Difference' column is the percent difference between the experimentally determined and estimated doser flow rates using the estimated values as the reference.

It can be seen that the tests which were conducted at similar experimental conditions have similar estimated doser flow rate values as well. This suggests that there is some variability in the experimental doser flow rate. The variability could be the result of the method used to determine the fuel flow rate during an experiment. During the pre-test and pre-active regeneration ramp phases of the experiment, the engine may be consuming different amounts of fuel based on differences in CPF PM loading. If the no-dosing AVL time was recorded during the pre-test portion of the experiment, the experimental dosing flow rate could potentially be in error. The dosing flow rate is calculated by taking the difference in measured fuel flow rate between the pre-test or pre-active regeneration ramp phases and the active regeneration phase. The difference in the fuel flow rate between these two phases is the doser flow rate. Error may also be compounded by the fact that the AVL time can only be recorded to the nearest second. The estimated doser flow rates are thought to be more accurate and are presented in Table 4.1 of the report. 
Table L1: DOC Energy Balance Results

\begin{tabular}{|c|c|c|c|c|}
\hline Run & $\begin{array}{c}\text { Estimated } \\
\text { Doser } \\
\text { Flow Rate }\end{array}$ & $\begin{array}{c}\text { Experimental } \\
\text { Doser Flow } \\
\text { Rate }\end{array}$ & Difference & $\begin{array}{c}\text { CPF Inlet } \\
\text { Temperature }\end{array}$ \\
\cline { 2 - 5 }$[\mathrm{g} / \mathrm{sec}]$ & {$[\mathrm{g} / \mathrm{sec}]$} & {$[\%]$} & {$\left[{ }^{\circ} \mathrm{C}\right]$} \\
\hline B20 1 & 0.517 & 0.431 & 16.6 & 477 \\
\hline B20 2 & 0.608 & 0.633 & -4.1 & 501 \\
\hline B20 5 & 0.695 & 0.832 & -19.8 & 527 \\
\hline ULSD 3 & - & 0.638 & - & 524 \\
\hline ULSD 4 & 0.648 & 0.763 & -17.8 & 526 \\
\hline ULSD 5 & 0.636 & 0.735 & -15.5 & 525 \\
\hline ULSD 6 & 0.667 & 0.739 & -10.7 & 524 \\
\hline B20 6 & 0.749 & 0.690 & 7.9 & 528 \\
\hline B20 4 & 0.594 & 0.687 & -15.7 & 504 \\
\hline B10 1 & 0.654 & 0.730 & -11.7 & 526 \\
\hline B10 2 & 0.646 & 0.898 & -39.0 & 525 \\
\hline B10 3 & 0.648 & 0.743 & -14.6 & 526 \\
\hline ULSD 1 & 0.759 & 0.819 & -7.8 & 553 \\
\hline ULSD 8 & 0.635 & 0.744 & -17.1 & 526 \\
\hline ULSD 9 & 0.727 & 0.899 & -23.5 & 550 \\
\hline B10 4 & 0.738 & 0.896 & -21.4 & 550 \\
\hline ULSD 7R & 0.709 & 0.830 & -17.0 & 550 \\
\hline ULSD 2R & 0.893 & 1.056 & -18.3 & 604 \\
\hline ULSD 10 & 0.663 & 0.785 & -18.4 & 530 \\
\hline & & & & \\
\hline
\end{tabular}



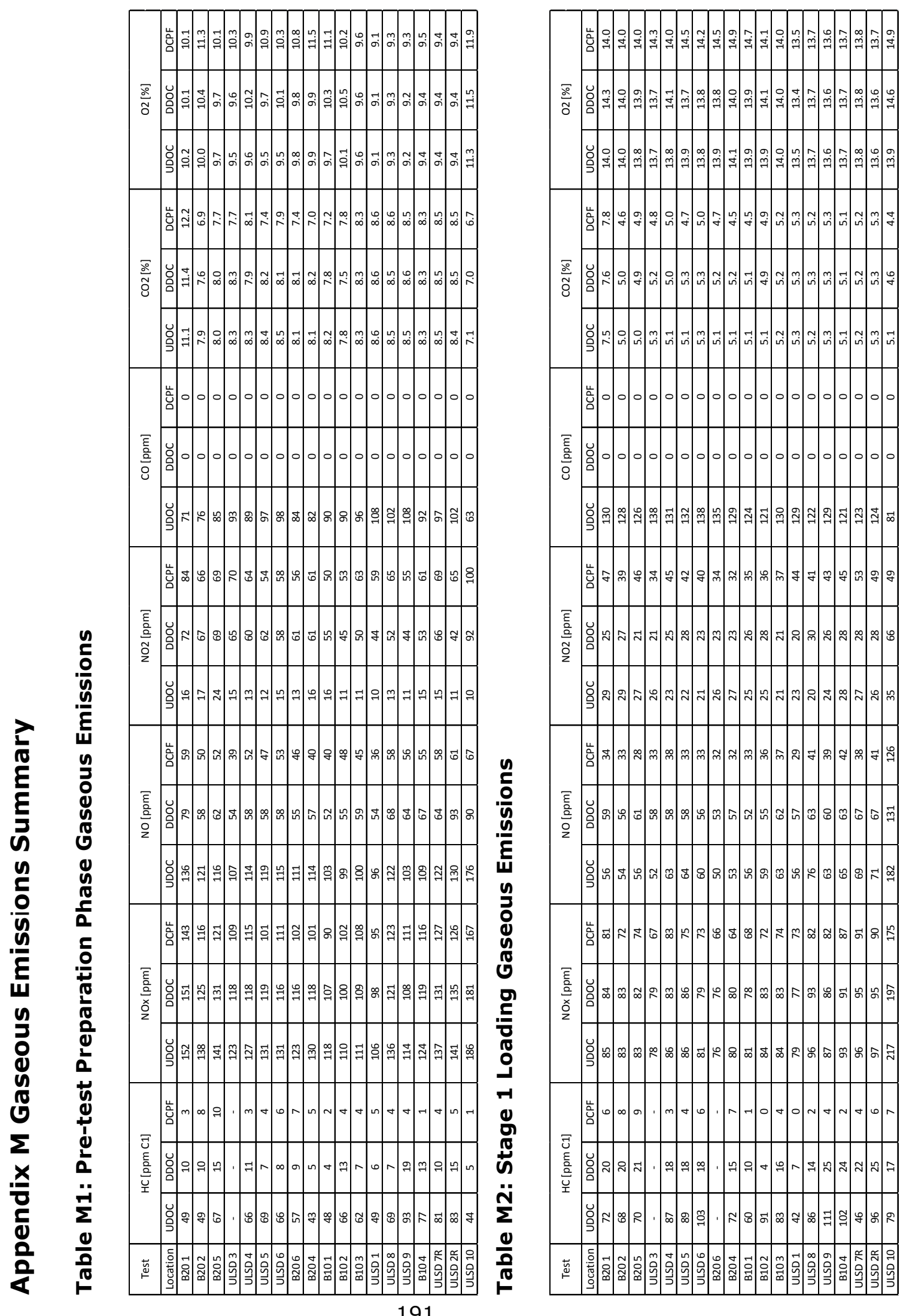

191 


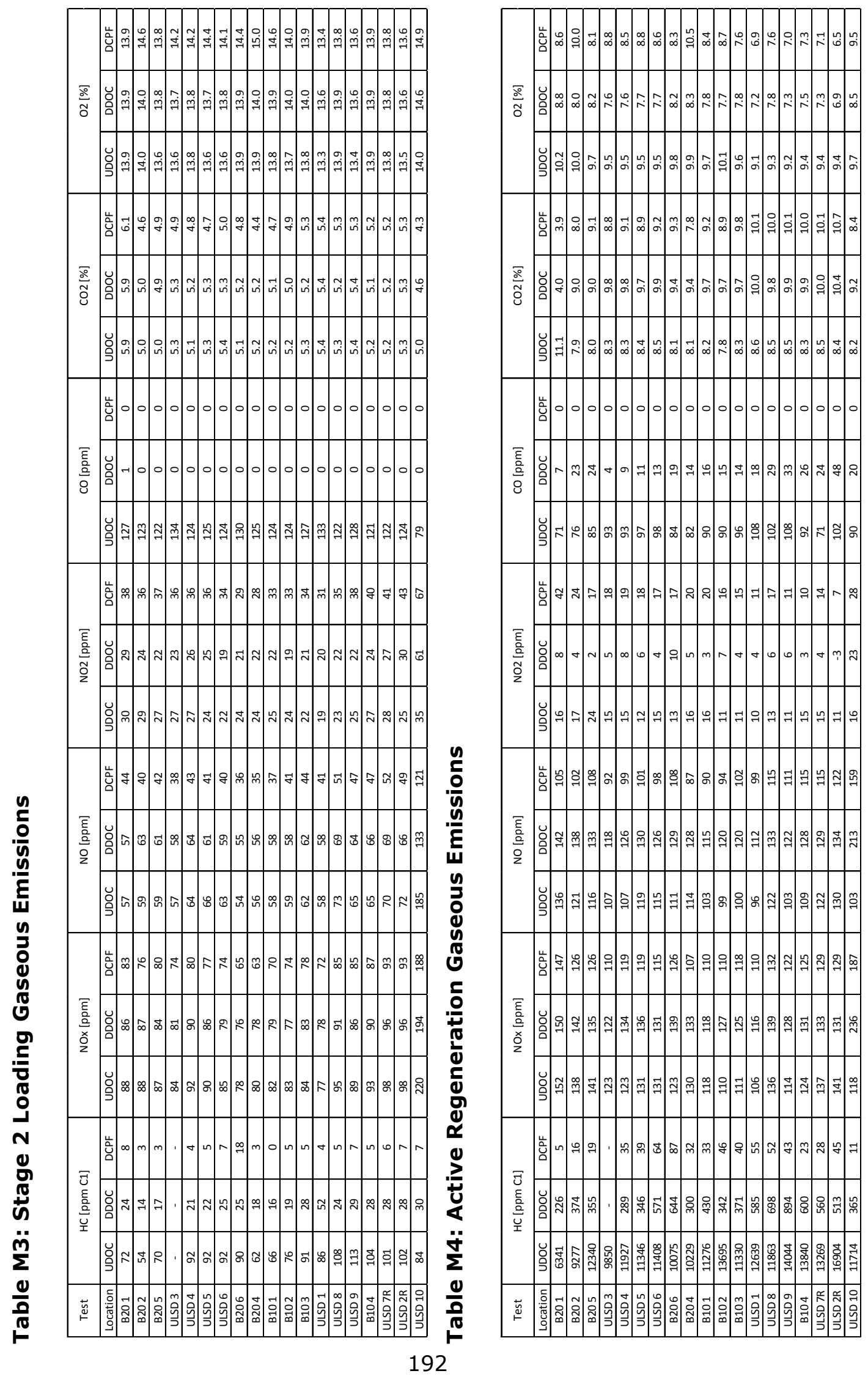



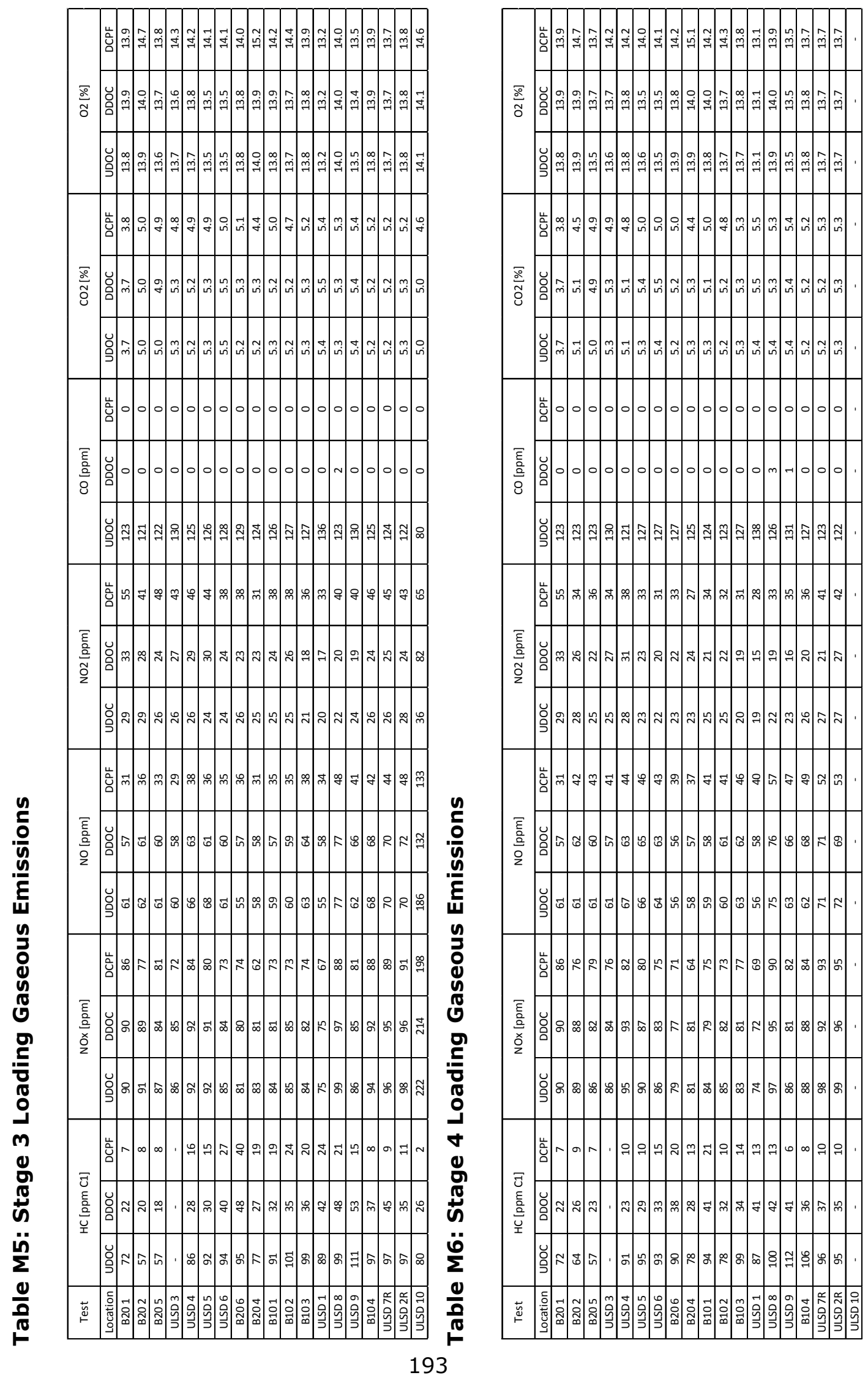
Appendix N Engine Air Flow Rate and CPF Pressure Drop Profile
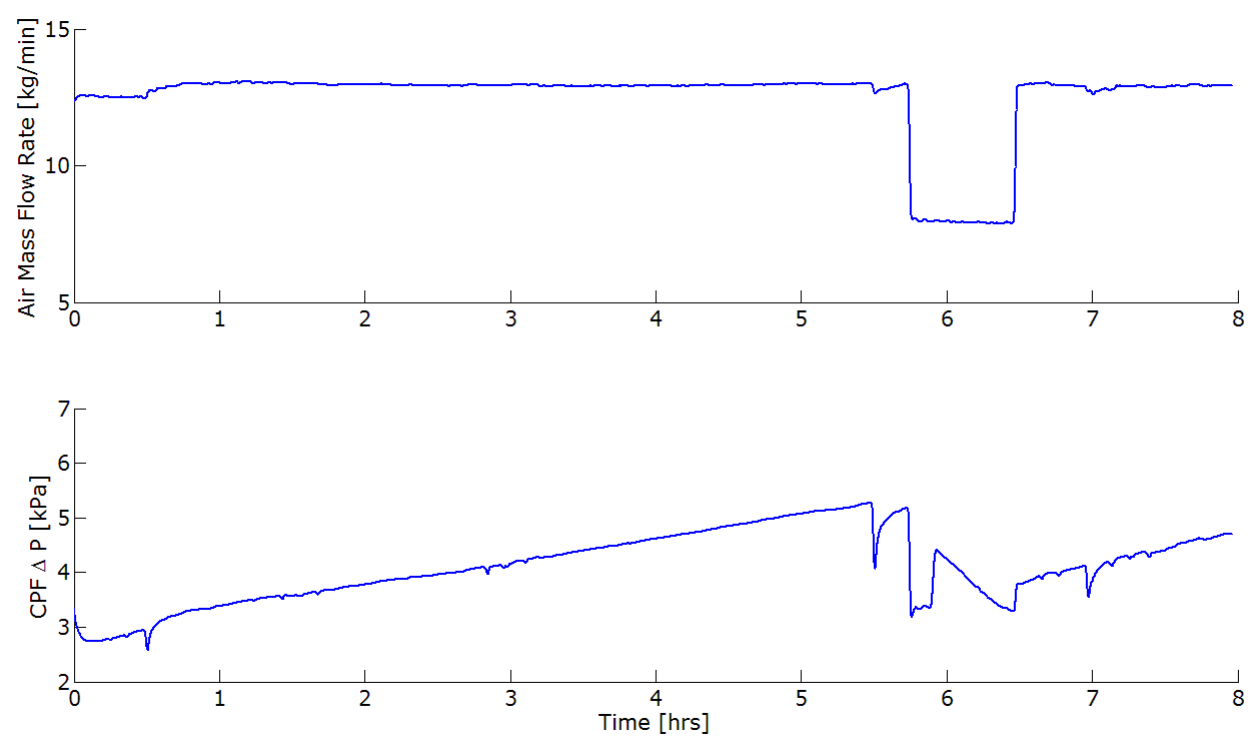

Figure N1: B20-1 Air Flow Rate (top) and CPF Pressure Drop Profile (bottom)
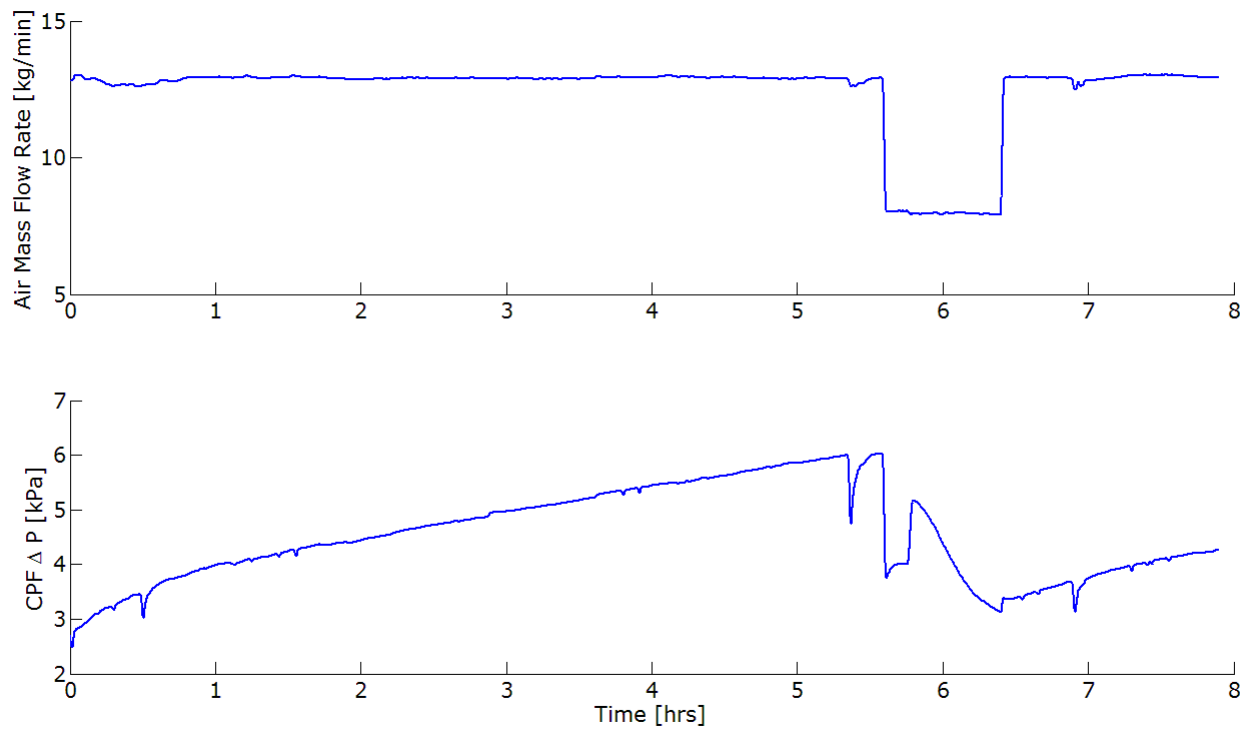

Figure N2: B20-2 Air Flow Rate (top) and CPF Pressure Drop Profile (bottom) 

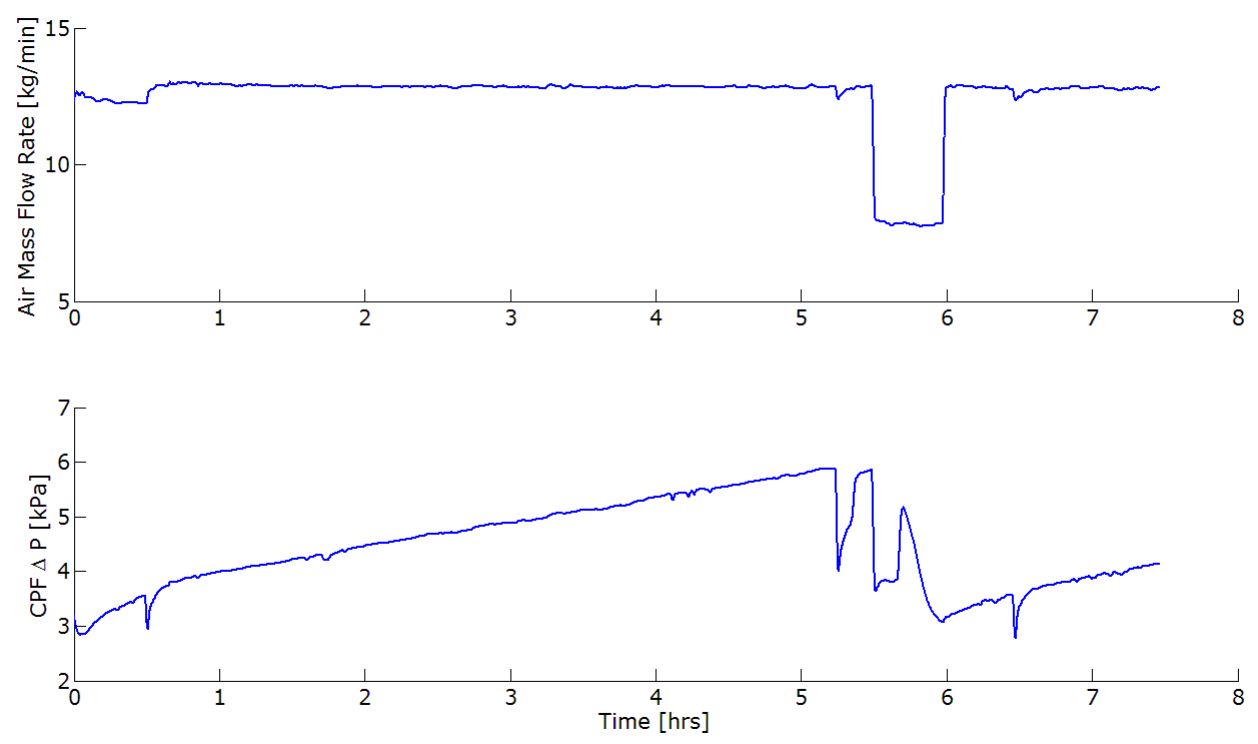

Figure N3: B20-5 Air Flow Rate (top) and CPF Pressure Drop Profile (bottom)
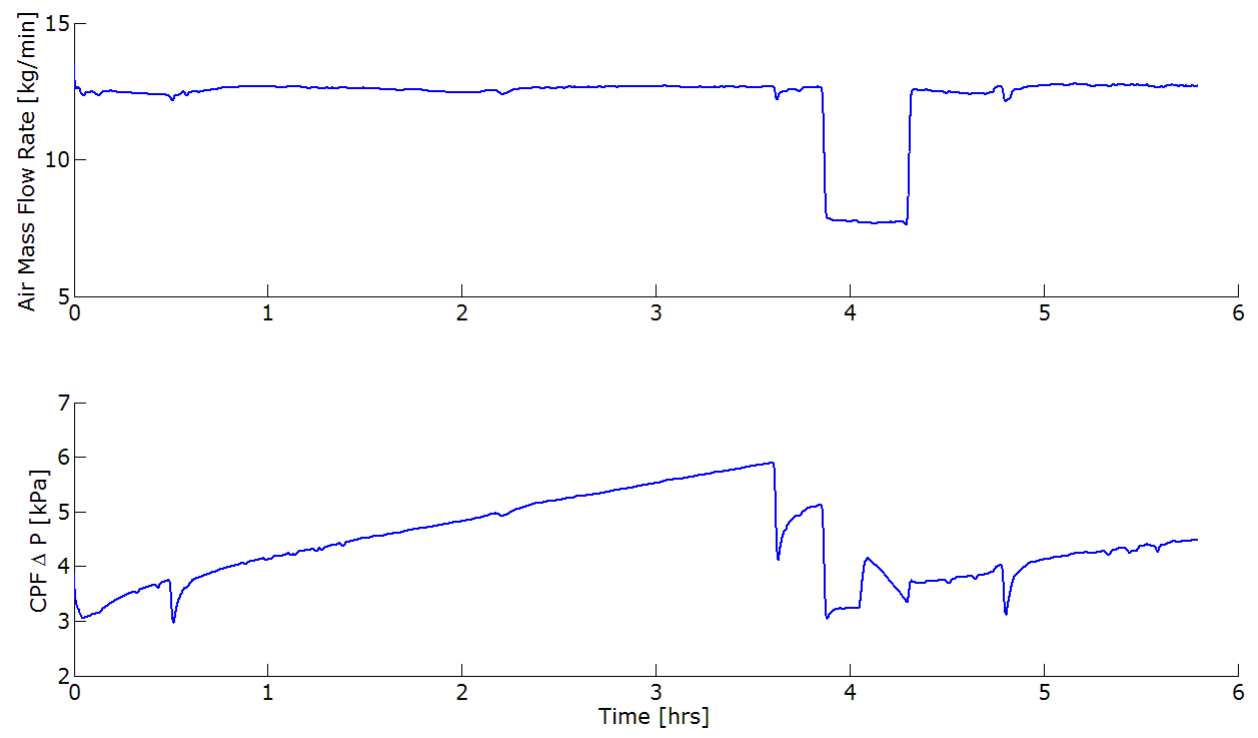

Figure N4: ULSD-3 Air Flow Rate (top) and CPF Pressure Drop Profile (bottom) 

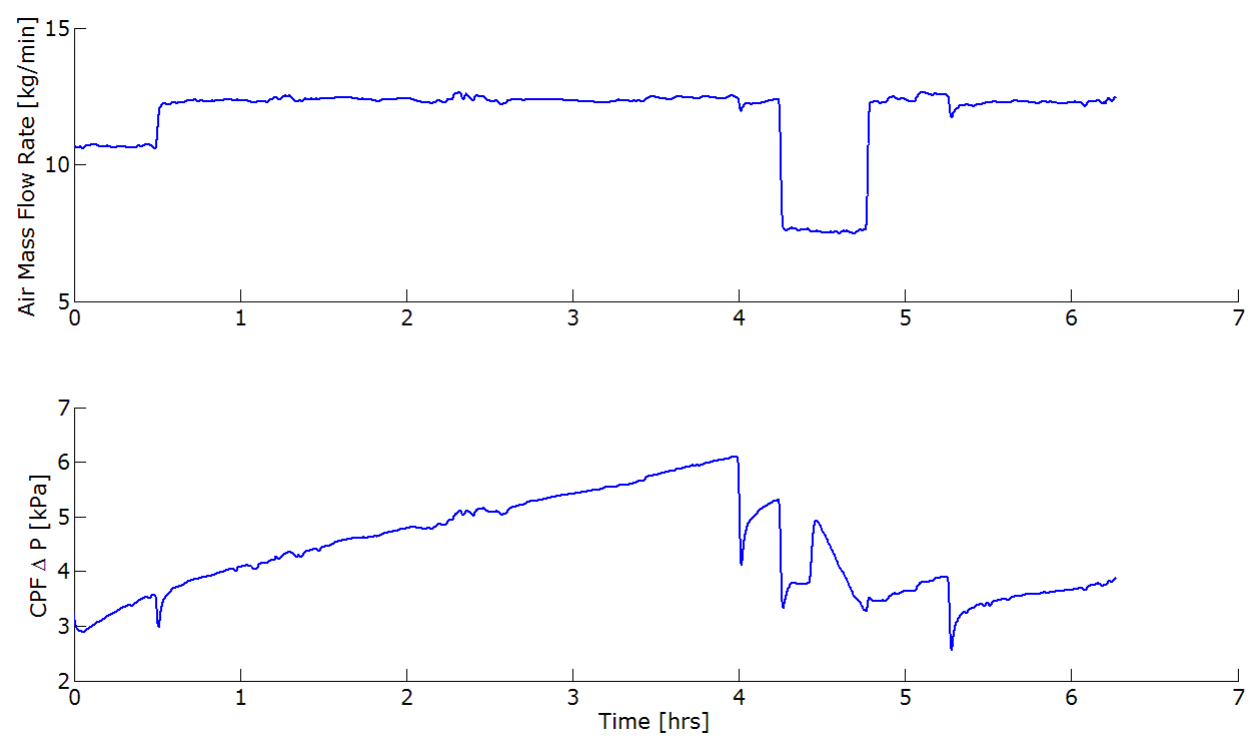

Figure N5: ULSD-4 Air Flow Rate (top) and CPF Pressure Drop Profile (bottom)
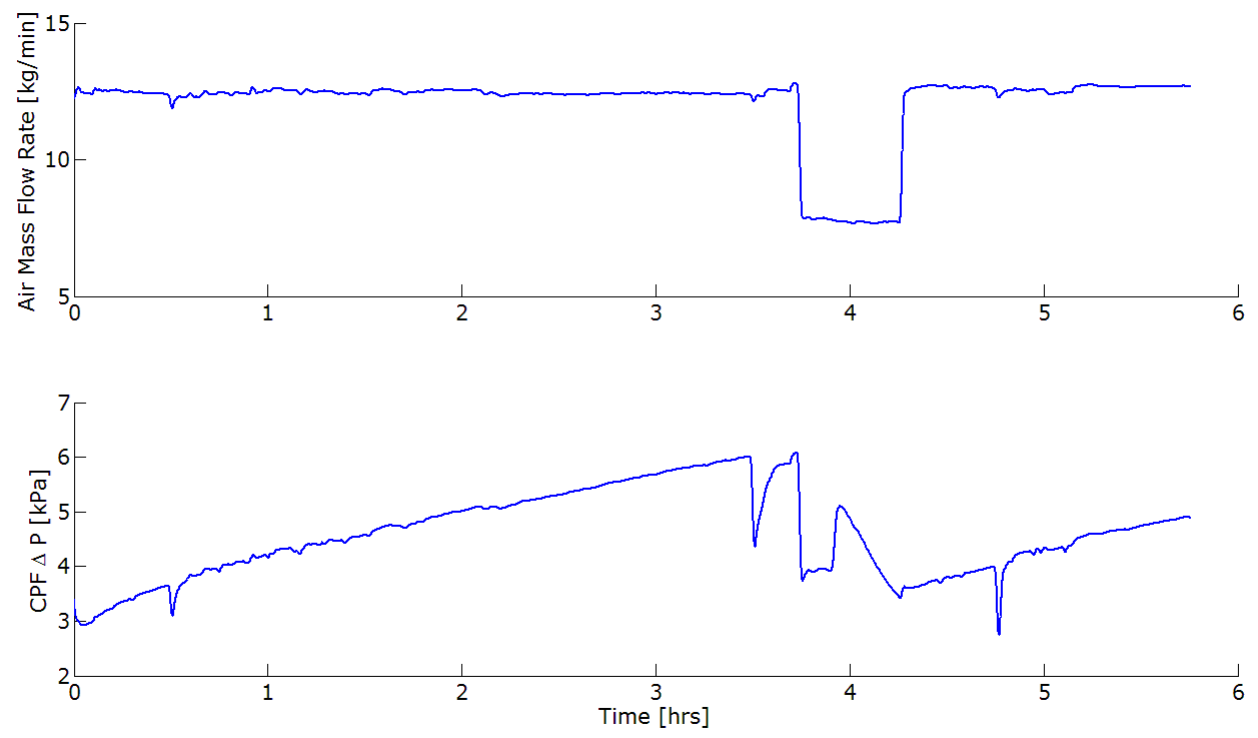

Figure N6: ULSD-5 Air Flow Rate (top) and CPF Pressure Drop Profile (bottom) 

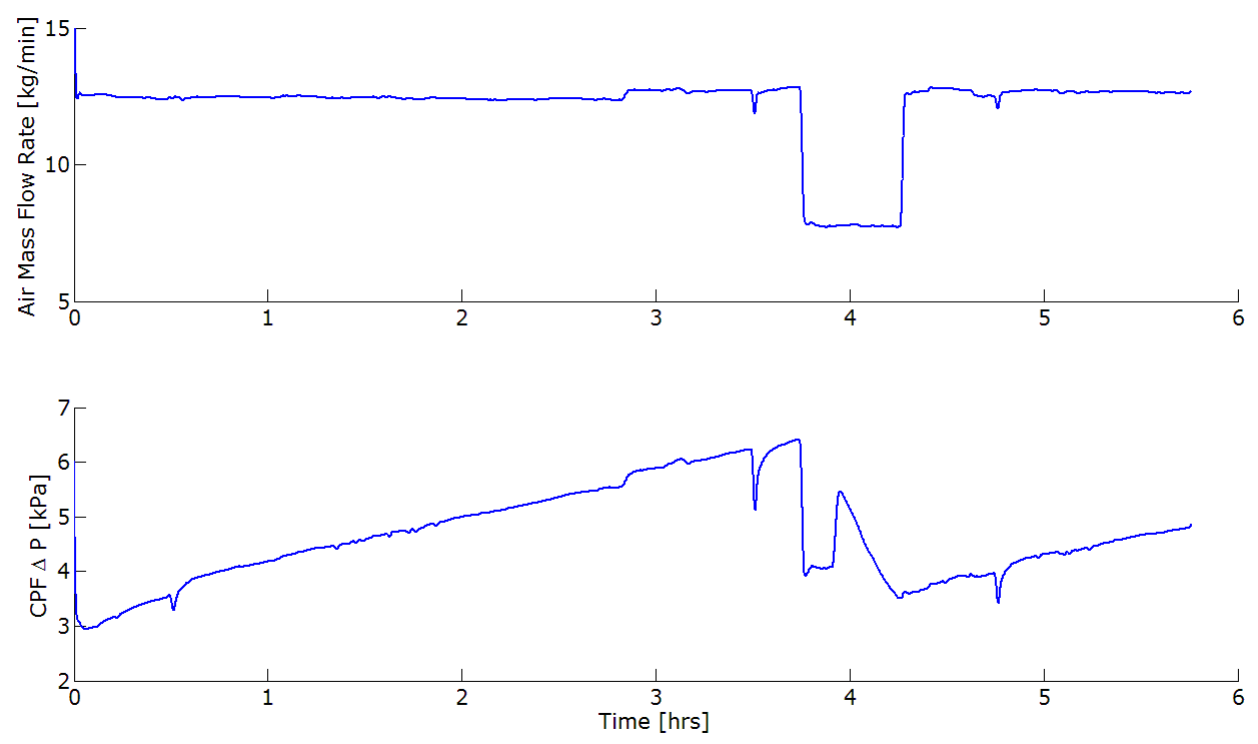

Figure N7: ULSD-6 Air Flow Rate (top) and CPF Pressure Drop Profile (bottom)
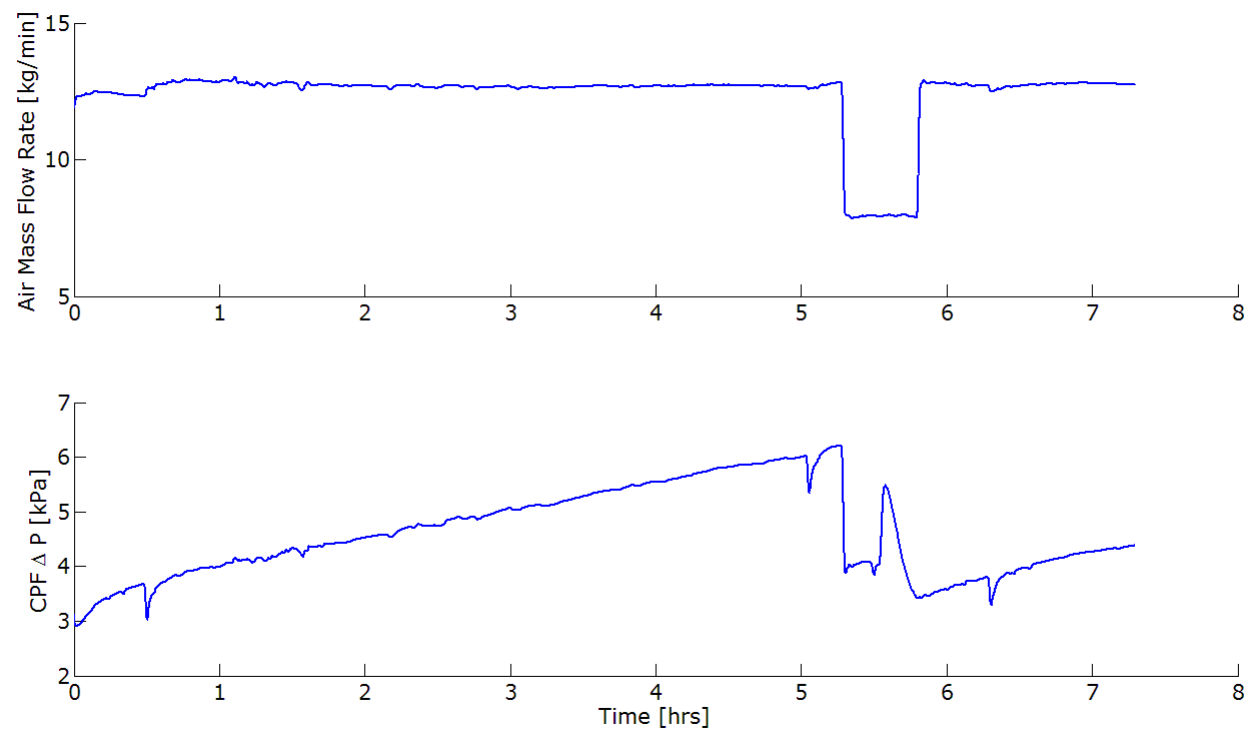

Figure N8: B20-6 Air Flow Rate (top) and CPF Pressure Drop Profile (bottom) 

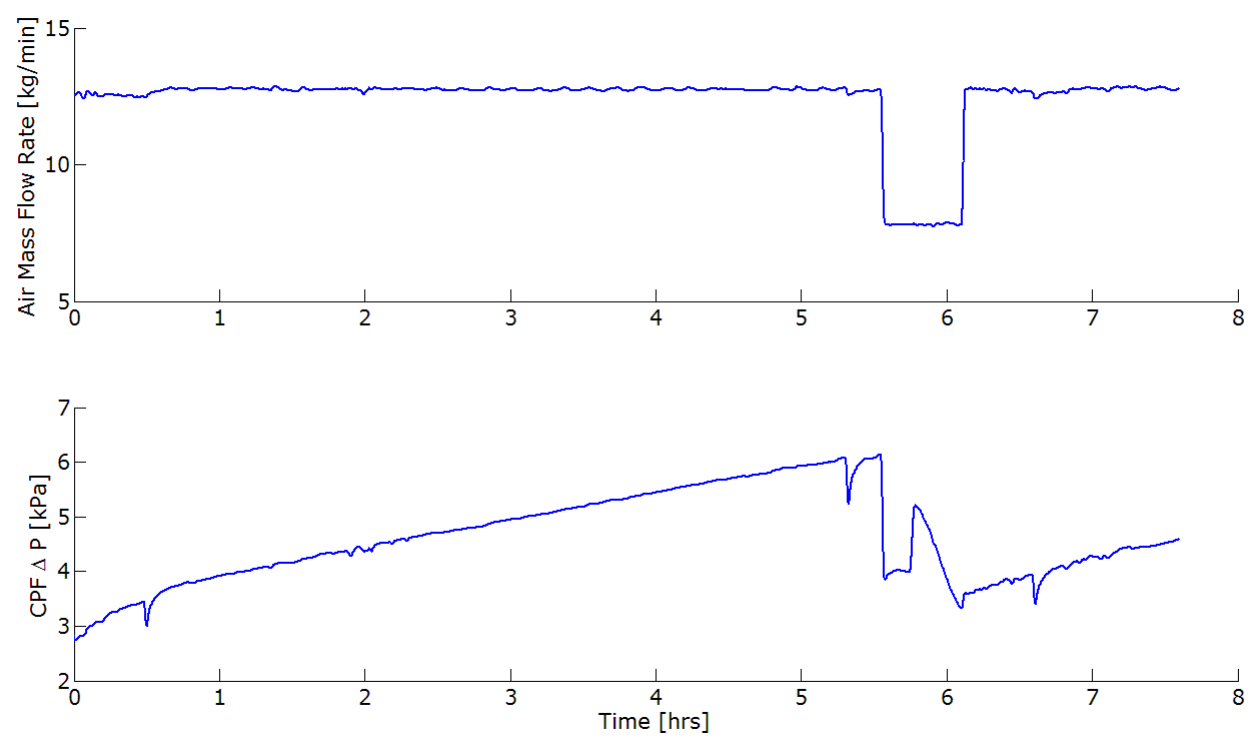

Figure N9: B20-4 Air Flow Rate (top) and CPF Pressure Drop Profile (bottom)
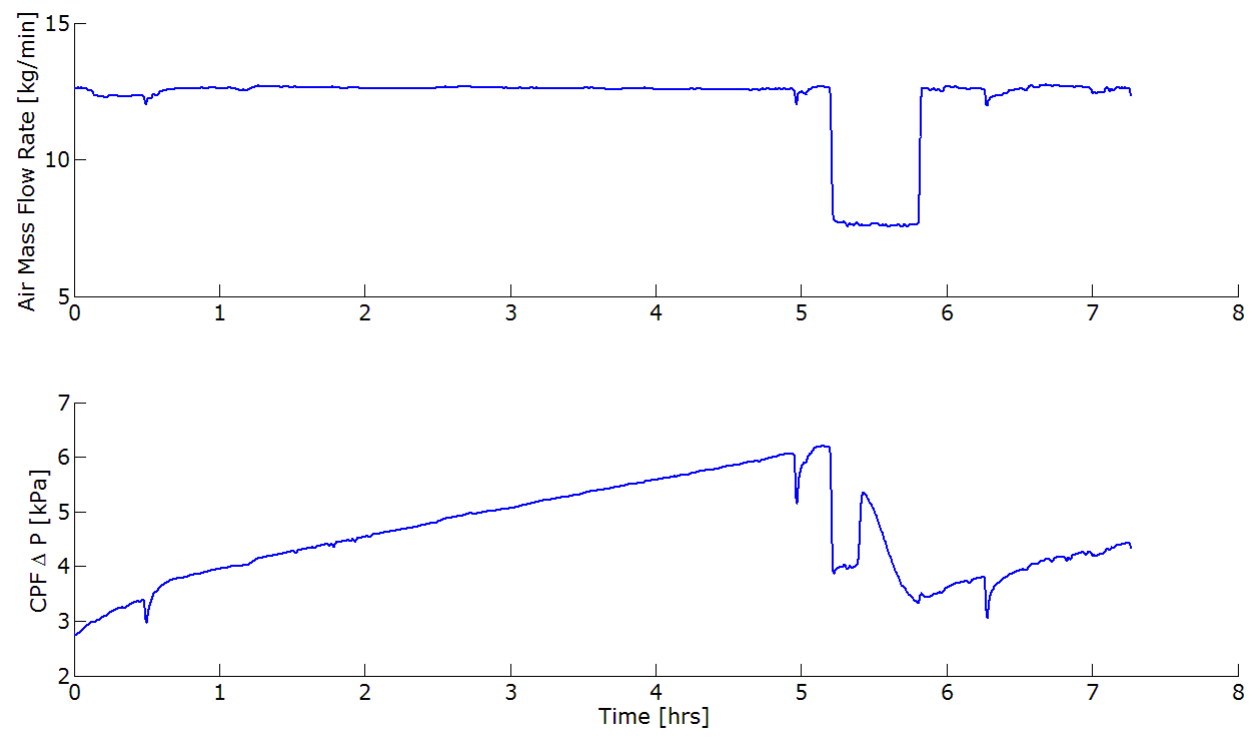

Figure N10: B10-1 Air Flow Rate (top) and CPF Pressure Drop Profile (bottom) 

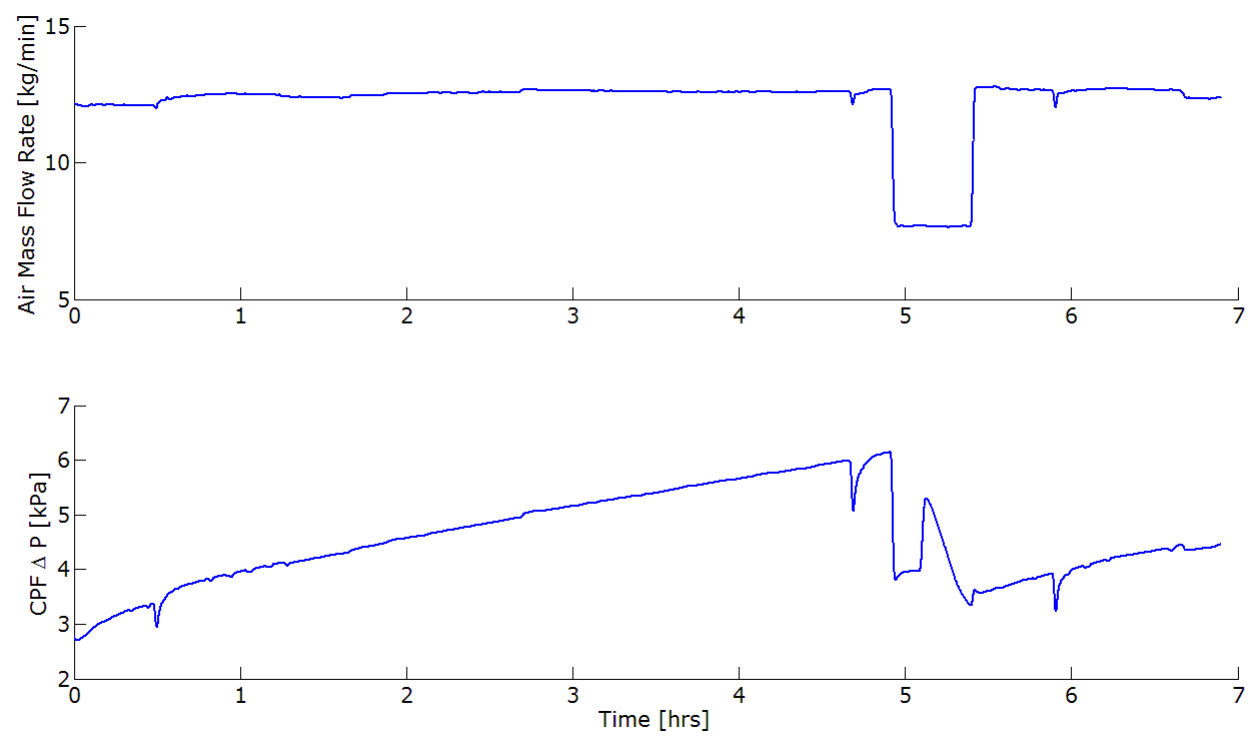

Figure N11: B10-2 Air Flow Rate (top) and CPF Pressure Drop Profile (bottom)
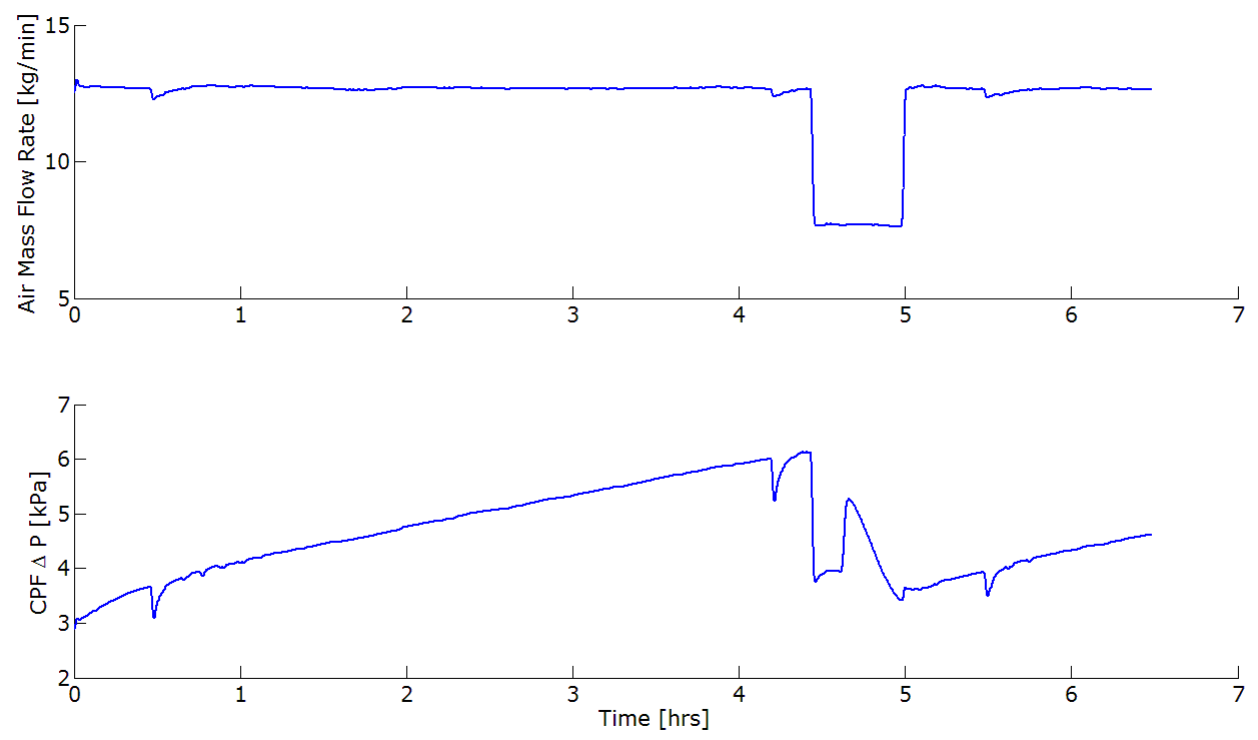

Figure N12: B10-3 Air Flow Rate (top) and CPF Pressure Drop Profile (bottom) 

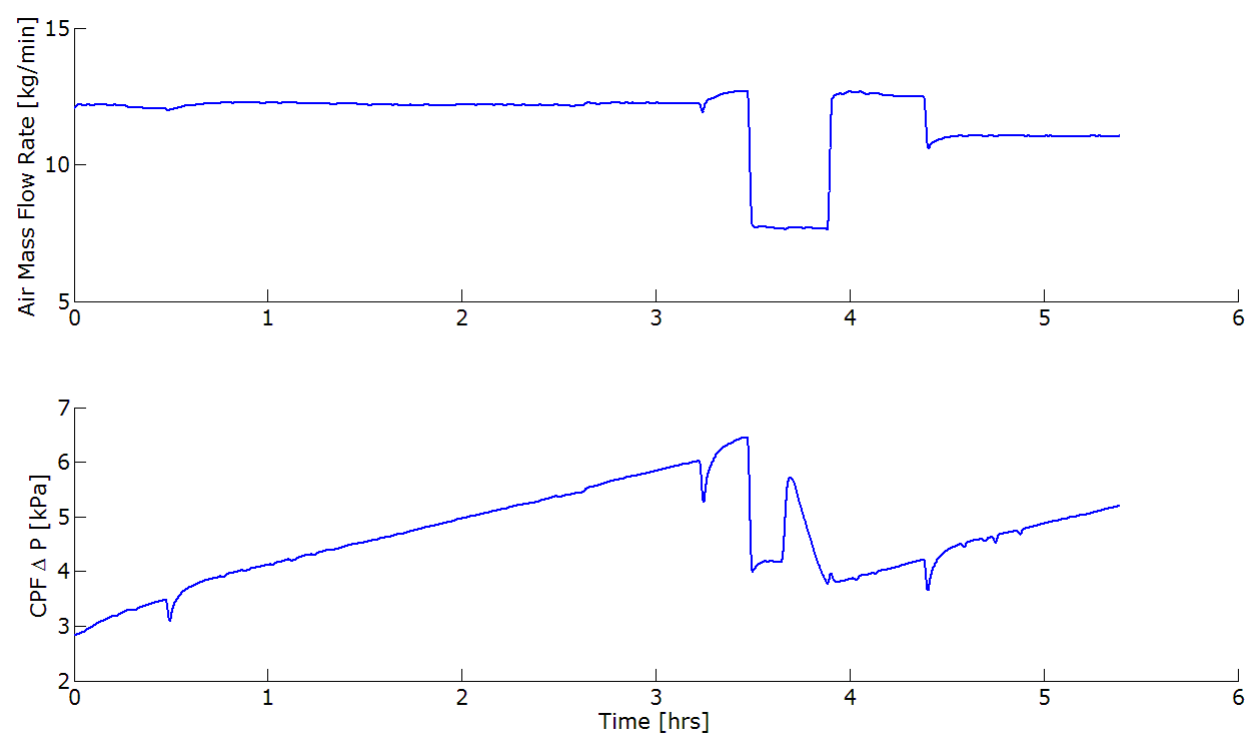

Figure N13: ULSD-1 Air Flow Rate (top) and CPF Pressure Drop Profile (bottom)
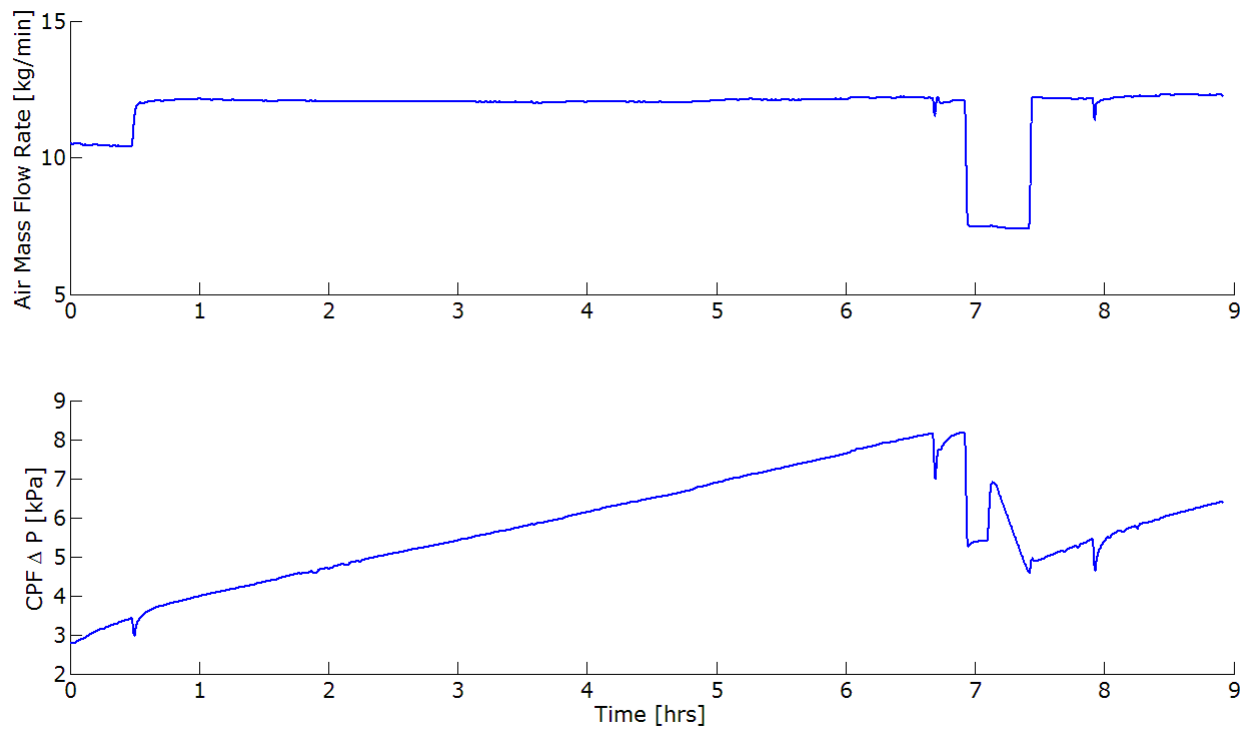

Figure N14: ULSD-8 Air Flow Rate (top) and CPF Pressure Drop Profile (bottom) 

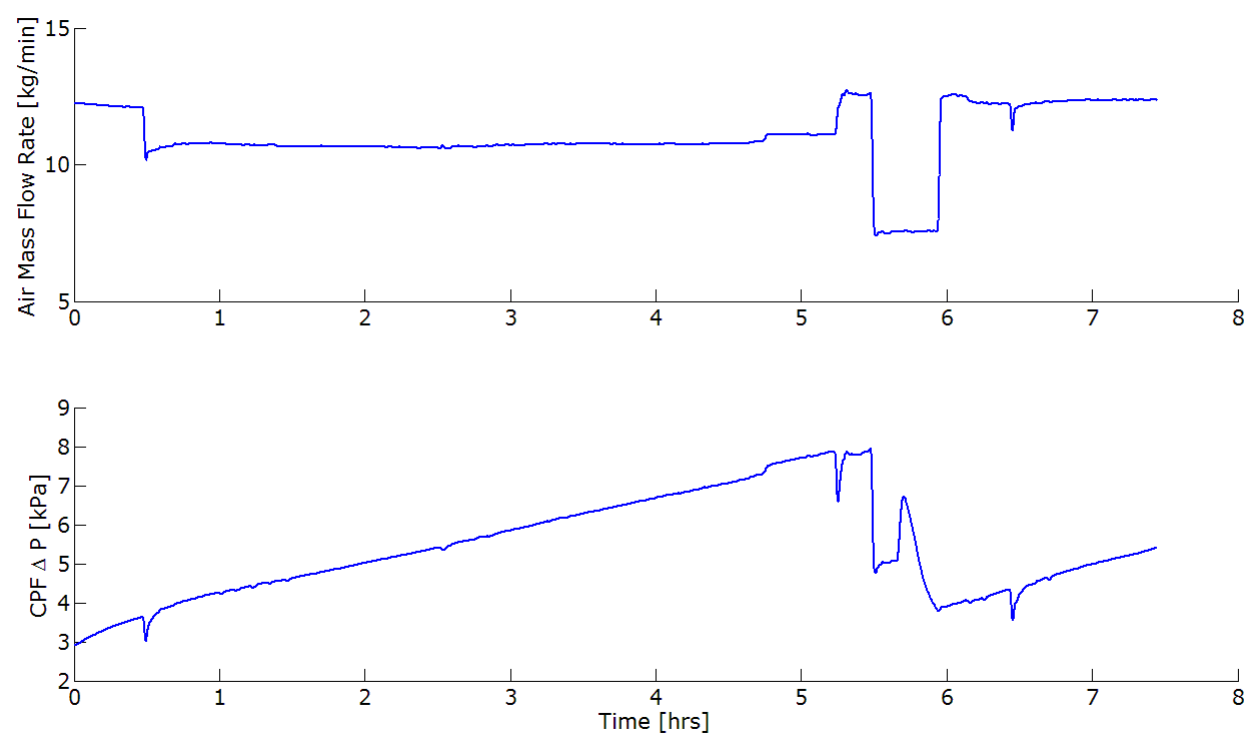

Figure N15: ULSD-9 Air Flow Rate (top) and CPF Pressure Drop Profile (bottom)
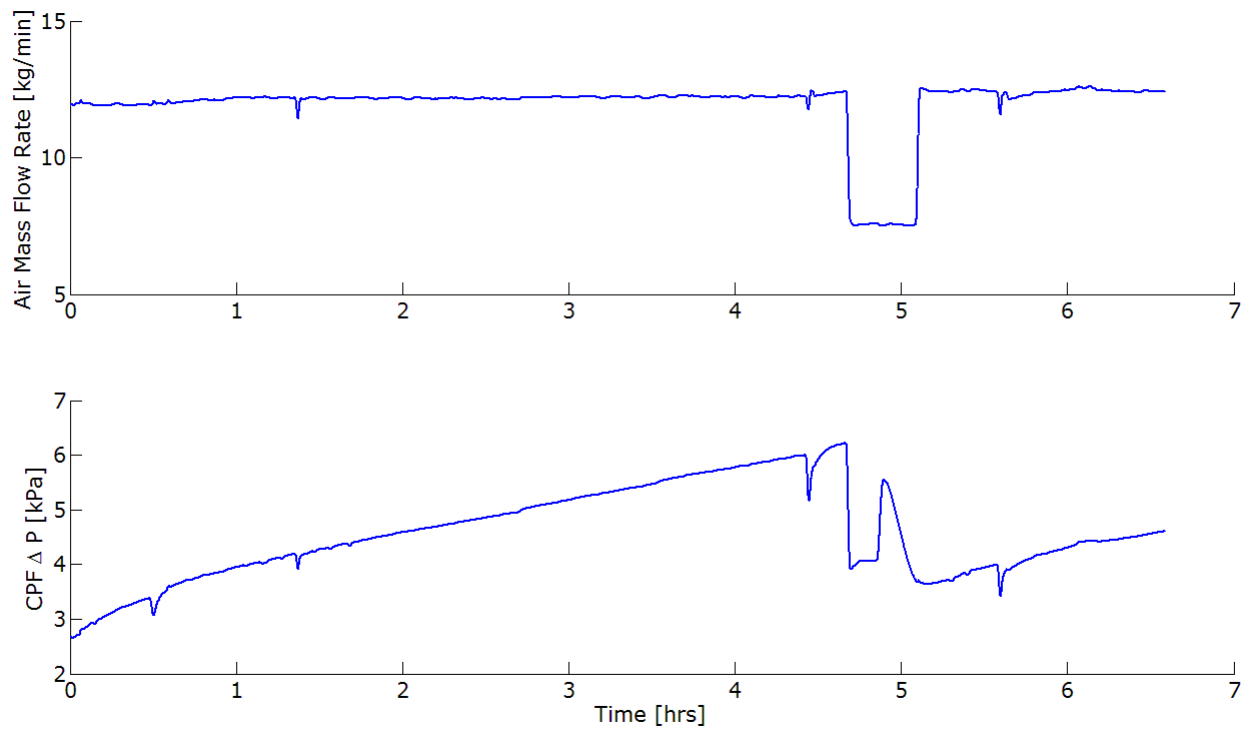

Figure N16: B10-4 Air Flow Rate (top) and CPF Pressure Drop Profile (bottom) 

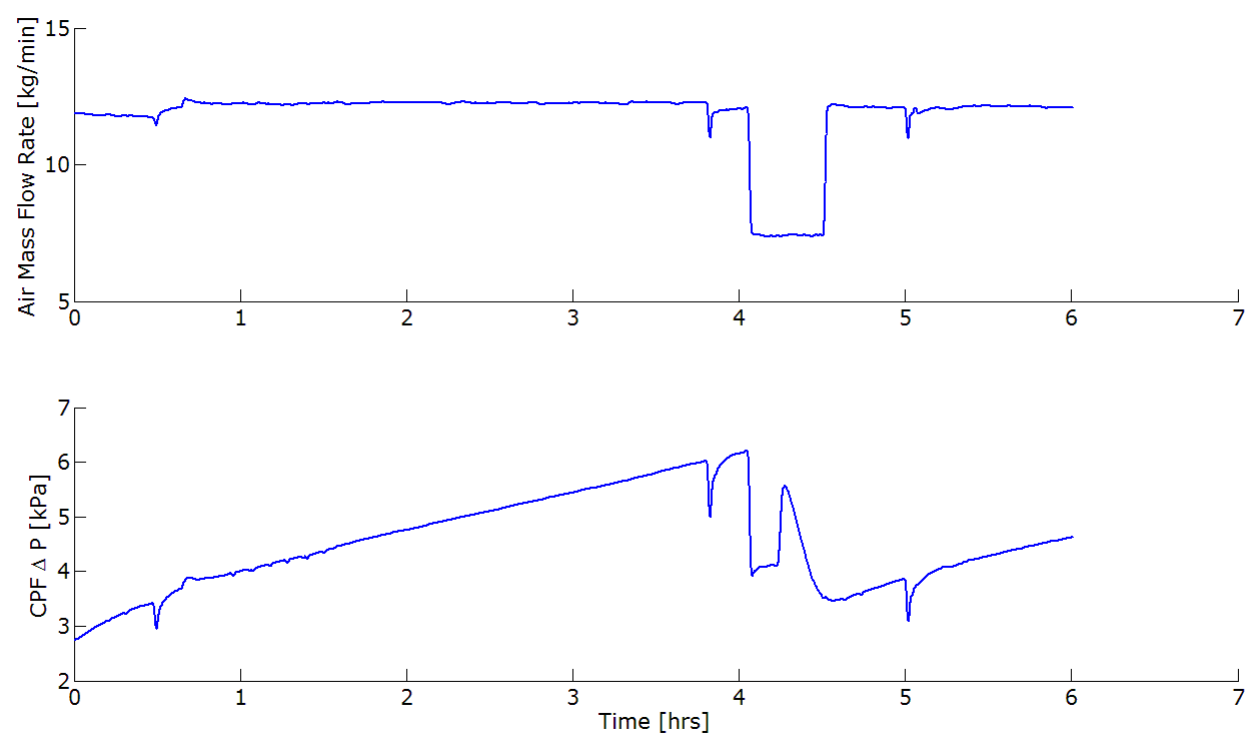

Figure N17: ULSD-7R Air Flow Rate (top) and CPF Pressure Drop Profile (bottom)
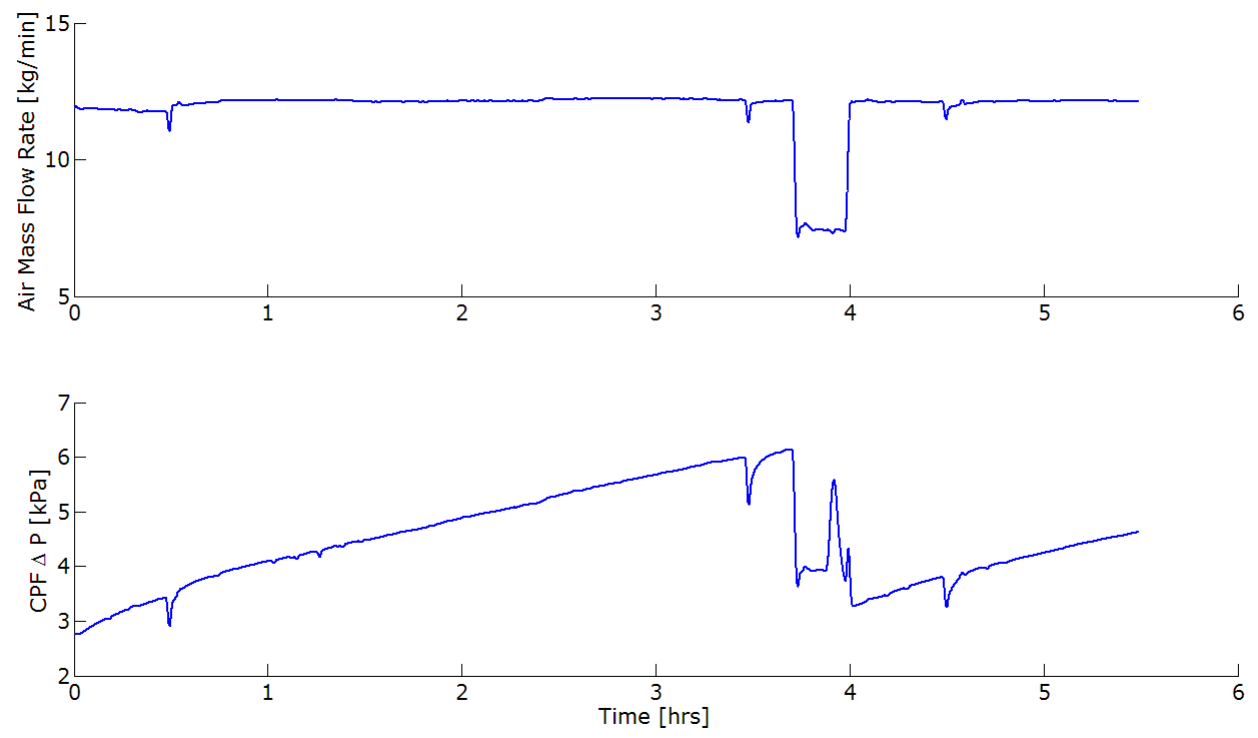

Figure N18: ULSD-2R Air Flow Rate (top) and CPF Pressure Drop Profile (bottom) 

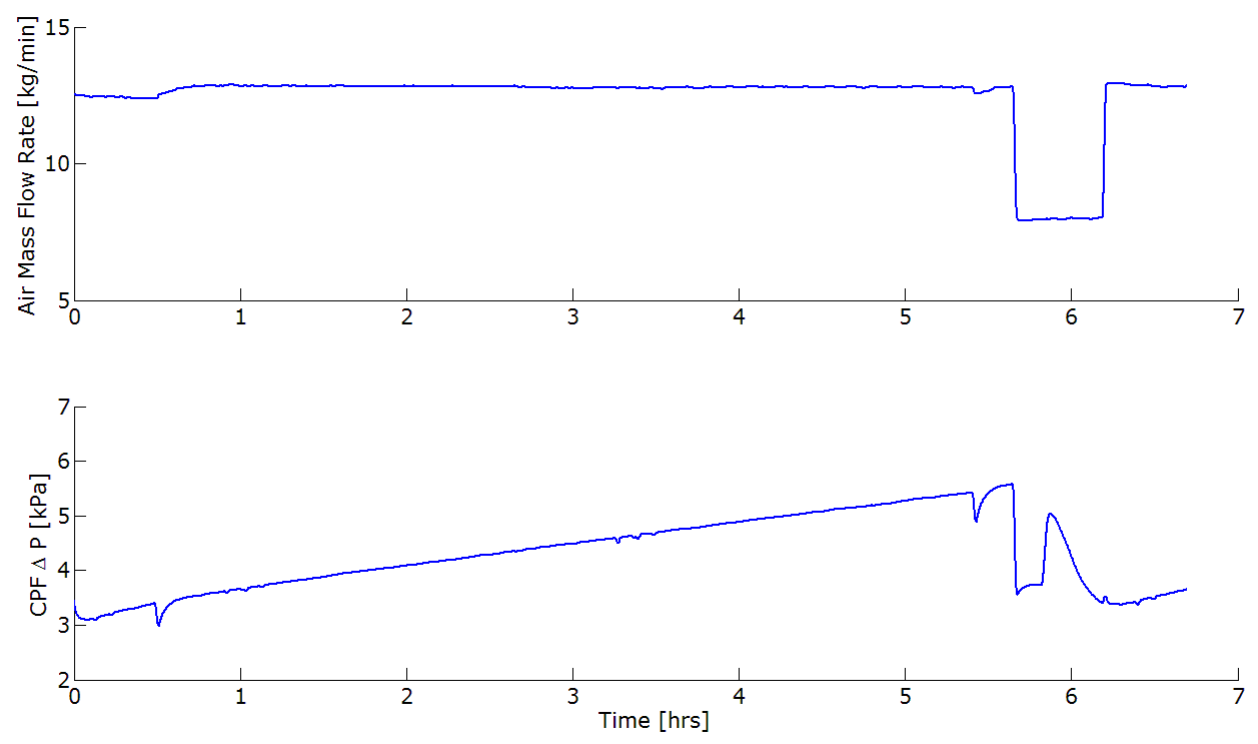

Figure N19: ULSD-10 Air Flow Rate (top) and CPF Pressure Drop Profile (bottom) 


\section{Appendix O Regeneration Efficiency of Fuel Dosing Calculation \\ Method}

In order to properly correlate grams of PM oxidized per gallon of dosing fuel injected, the experimental data must be normalized to the same initial and final PM mass inside the CPF. The initial PM mass needs to be constant because the initial PM loading of the CPF affects the PM oxidation rate. The final PM mass needs to be constant because as the PM concentration in the CPF decreases, more fuel is required to oxidize the remaining $\mathrm{PM}$.

The average of the CPF PM loading at the start of active regeneration over all tests was used as the initial PM loading value. Experimentally determined pre-exponential factors were also averaged, although they were averaged by fuel. Using the average values for the pre-exponential factor, the reaction rate for each experiment can be calculated using Eqn. $\mathrm{O} 1$ and the average CPF temperature for each individual active regeneration. $A M A T L A B \cap$ model was produced which calculates the PM mass retained in the CPF over a 2 hour active regeneration simulation using Eqn. 02

$$
\left.\mathrm{RRo}=\mathrm{A} \cdot \mathrm{e}^{\left[\mathrm{E}_{\mathrm{a}} /(\mathrm{R} \cdot \mathrm{T})\right.}\right] \quad \text { Eqn. } \mathrm{O} 1
$$

RRo $=$ Reaction rate $[1 / \mathrm{s}]$

$\mathrm{Ea}=$ Activation energy $[145 \mathrm{~kJ} / \mathrm{gmol}]$

$\mathrm{R}=$ Universal gas constant, $8.315[\mathrm{~J} /(\mathrm{mol} * \mathrm{~K})]$

$\mathrm{T}=\mathrm{CPF}$ average temperature for entire active regeneration $[\mathrm{K}]$

$$
\mathrm{m}_{\mathrm{R}}(\mathrm{i})=\left[\eta_{\text {filt }} \cdot \mathrm{C}_{\text {in }} \cdot \mathrm{Q}-\mathrm{m}_{\mathrm{R}}(\mathrm{i}-1) \cdot \mathrm{A} \cdot \mathrm{RRo}\right] \cdot \mathrm{dt}+\mathrm{m}_{\mathrm{R}}(\mathrm{i}-1) \quad \text { Eqn. } \mathrm{O} 2
$$

$\mathrm{i}=$ Incremental point in time during active regeneration [-]

$\mathrm{m}_{\mathrm{R}}(\mathrm{i})=\mathrm{PM}$ mass in CPF at time $\mathrm{i}$ during active regeneration [g]

$m_{R}(i-1)=P M$ mass in CPF calculated at time $\mathrm{i}-1$ [g]

$\eta_{\text {filt }}=$ CPF filtration efficiency $[-]$

$\mathrm{C}_{\text {in }}=$ Engine out $\mathrm{PM}$ concentration $[\mathrm{g} / \mathrm{scm}]$

$\mathrm{Q}=$ Exhaust volumetric flow rate $[\mathrm{scm} / \mathrm{sec}]$

RRo $=$ Reaction rate $[1 / \mathrm{s}]$

$\mathrm{dt}=$ Time step through active regeneration, $1[\mathrm{sec}]$

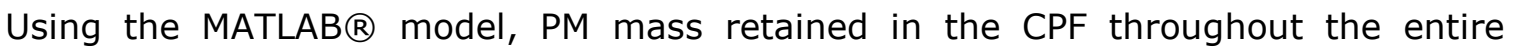
simulated regeneration is plotted as seen in Figure $\mathrm{O} 1$. Also displayed on Figure $\mathrm{O} 1$ 
is the time it takes to reach $70 \%$ PM oxidation for ULSD-5 conditions, which is the final PM loading that the experimental data was normalized to since $70 \%$ PM oxidation was the target for all tests.

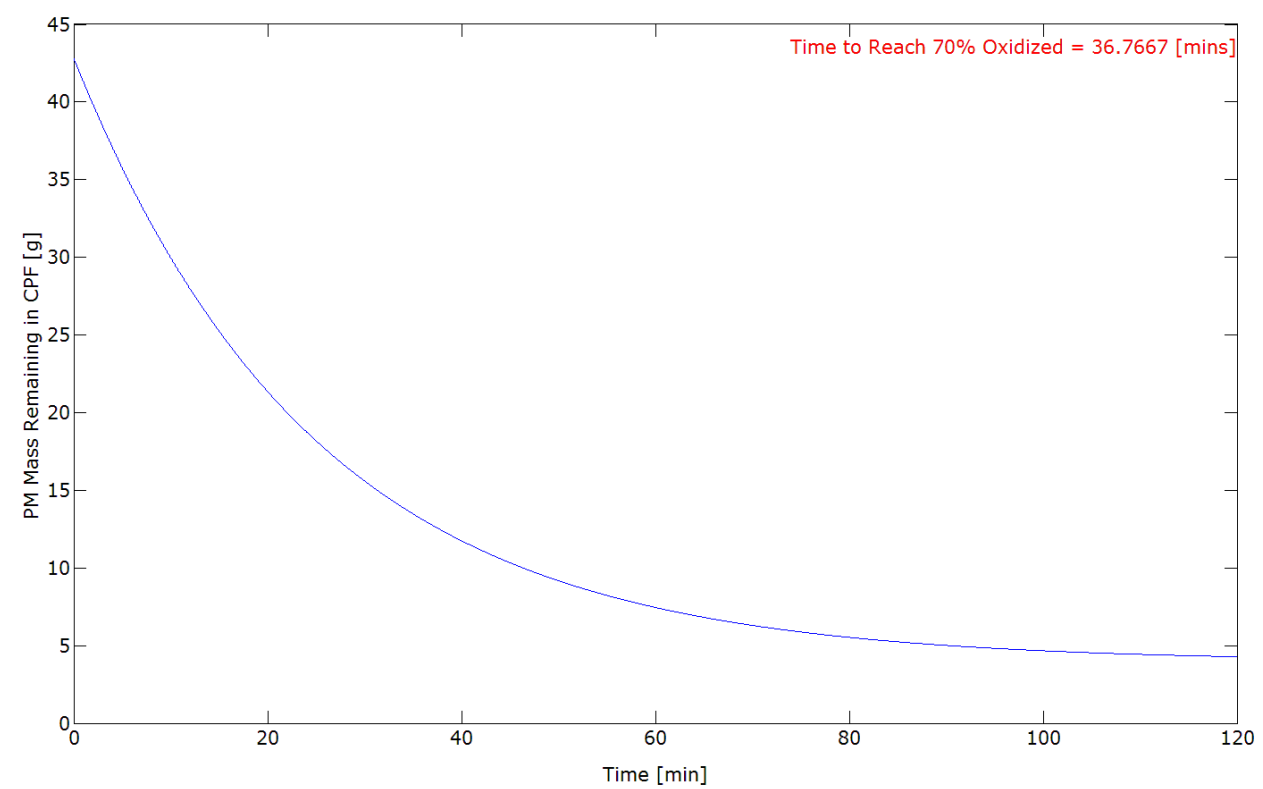

\section{Figure 01: Modeled CPF PM Mass Retained in the CPF during Active Regeneration for Test ULSD-5}

Using the model provided time to reach $70 \%$ PM oxidation within the CPF, the amount of fuel injected during dosing is calculated using Eqn. 03.

$$
\text { gal }_{\text {dosed }}=\dot{m}_{\text {doser }} \cdot t_{\mathrm{AR}} \cdot 1 / \rho_{\text {fuel }} \cdot 15.85
$$

Eqn. O3

$\mathrm{gal}_{\text {dosed }}=$ Fuel dosed during active regeneration $[\mathrm{gal}]$

$\dot{\mathrm{m}}_{\text {doser }}=$ Dosing flow rate $[\mathrm{g} / \mathrm{sec}]$

$\mathrm{t}_{\mathrm{AR}}=$ Active regeneration time $[\mathrm{min}]$

$\rho_{\text {fuel }}=$ Fuel density $\left[\mathrm{kg} / \mathrm{m}^{3}\right]$

15.85 = Constant associated with converting $\min$ to $\mathrm{sec}, \mathrm{kg}$ to $\mathrm{g}$, and $\mathrm{m}^{3}$ to gal

Using the amount of fuel injected during dosing, dividing the PM oxidized by the amount of fuel injected during dosing yields the grams of PM oxidized per gallon of dosed fuel. Table $\mathrm{O} 1$ below displays the normalized data from the calculations 
discussed above. The modeled PM oxidized is the same for all tests because $70 \%$ of the $42.8 \mathrm{~g}$ PM mass in the CPF at the start of active regeneration is $30.0 \mathrm{~g}$.

Table 01: Normalized Experimental Data

\begin{tabular}{|c|c|c|c|c|c|c|}
\hline Variable & $\begin{array}{c}\text { Average CPF } \\
\text { Temp }\end{array}$ & $\begin{array}{c}\text { Modeled 70\% } \\
\text { Oxidized Time } \\
\text { Requirement }\end{array}$ & $\begin{array}{c}\text { AVL Dosing } \\
\text { Rate }\end{array}$ & $\begin{array}{c}\text { PM } \\
\text { Concentration }\end{array}$ & Fuel Dosed & $\begin{array}{c}\text { PM } \\
\text { Oxidized/Gallon } \\
\text { Fuel Dosed }\end{array}$ \\
\hline Test/Units & ${ }^{\circ} \mathrm{C}$ & $\mathrm{min}$ & $\mathrm{g} / \mathrm{sec}$ & $\mathrm{mg} / \mathrm{scm}$ & gal & $\mathrm{g} / \mathrm{gal}$ \\
\hline B20 1 & 474 & 67.9 & 0.431 & 8.3 & 0.548 & 54.7 \\
\hline B20 2 & 508 & 26.3 & 0.633 & 9.9 & 0.311 & 96.3 \\
\hline B20 5 & 534 & 12.5 & 0.832 & 9.9 & 0.194 & 154.6 \\
\hline ULSD 3 & 526 & 40.3 & 0.638 & 22.2 & 0.475 & 63.1 \\
\hline ULSD 4 & 531 & 33.3 & 0.763 & 18.5 & 0.469 & 63.8 \\
\hline ULSD 5 & 529 & 36.8 & 0.735 & 24.3 & 0.500 & 60.0 \\
\hline ULSD 6 & 540 & 25.2 & 0.739 & 18.3 & 0.344 & 87.1 \\
\hline B20 6 & 540 & 10.7 & 0.690 & 12.9 & 0.138 & 216.7 \\
\hline B20 4 & 506 & 28.3 & 0.687 & 17.8 & 0.364 & 82.3 \\
\hline B10 1 & 534 & 22.7 & 0.730 & 15.1 & 0.312 & 96.0 \\
\hline B10 2 & 531 & 25.5 & 0.898 & 17.4 & 0.430 & 69.7 \\
\hline B10 3 & 531 & 24.1 & 0.743 & 11.2 & 0.337 & 88.8 \\
\hline ULSD 1 & 567 & 13.6 & 0.819 & 26.9 & 0.206 & 145.7 \\
\hline ULSD 8 & 539 & 26.3 & 0.744 & 22.5 & 0.361 & 83.0 \\
\hline ULSD 9 & 563 & 14.6 & 0.899 & 21.9 & 0.242 & 123.6 \\
\hline B10 4 & 563 & 11.1 & 0.896 & 15.7 & 0.187 & 160.6 \\
\hline ULSD 7R & 562 & 15.0 & 0.830 & 25.9 & 0.230 & 130.4 \\
\hline ULSD 2R & 616 & 4.4 & 1.056 & 19.8 & 0.086 & 346.8 \\
\hline
\end{tabular}


Appendix P CPF Pressure Drop Comparison between National Instruments (NI) LabVIEW and CalTerm

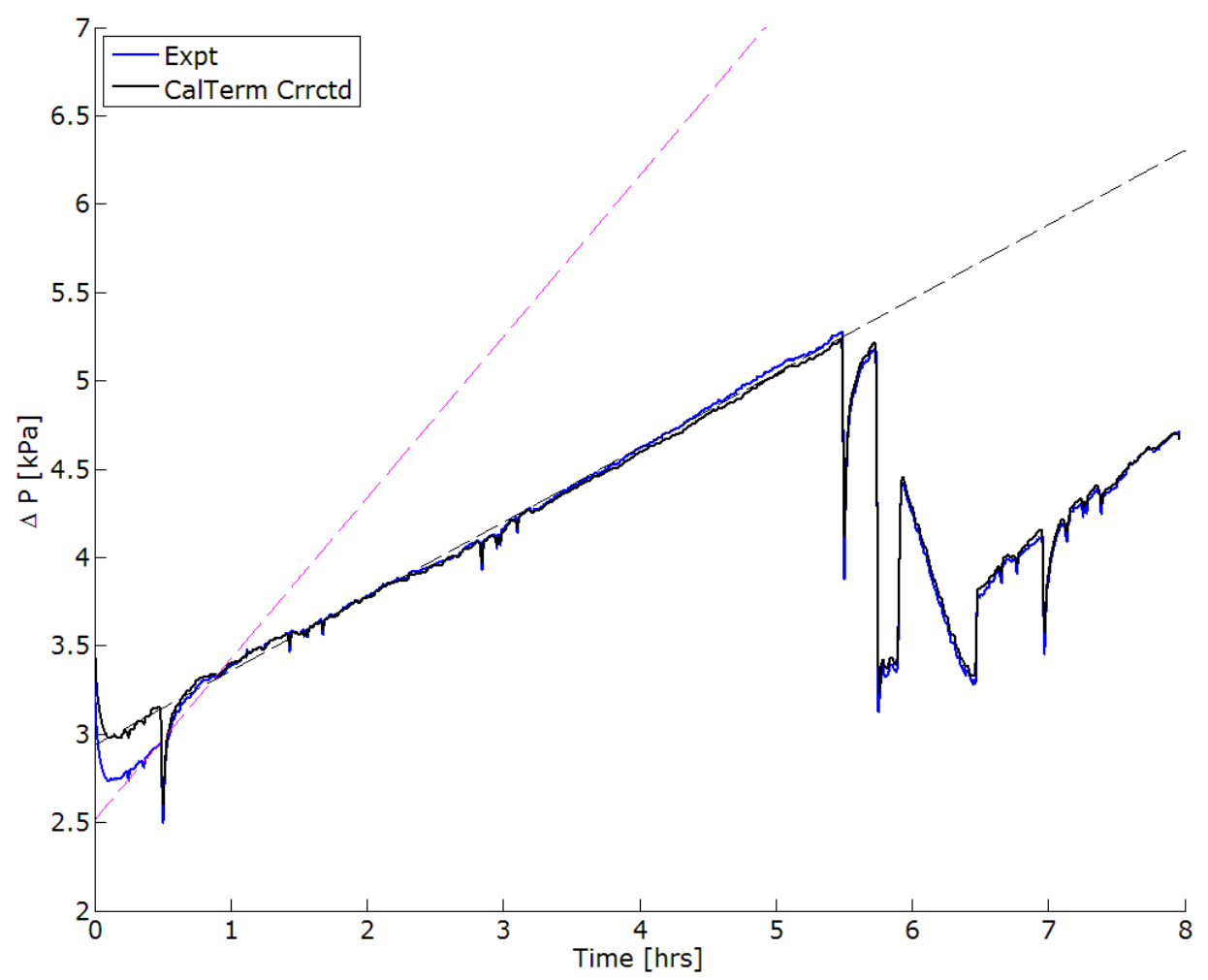

Figure P1: B20-1 CPF Pressure Drop 


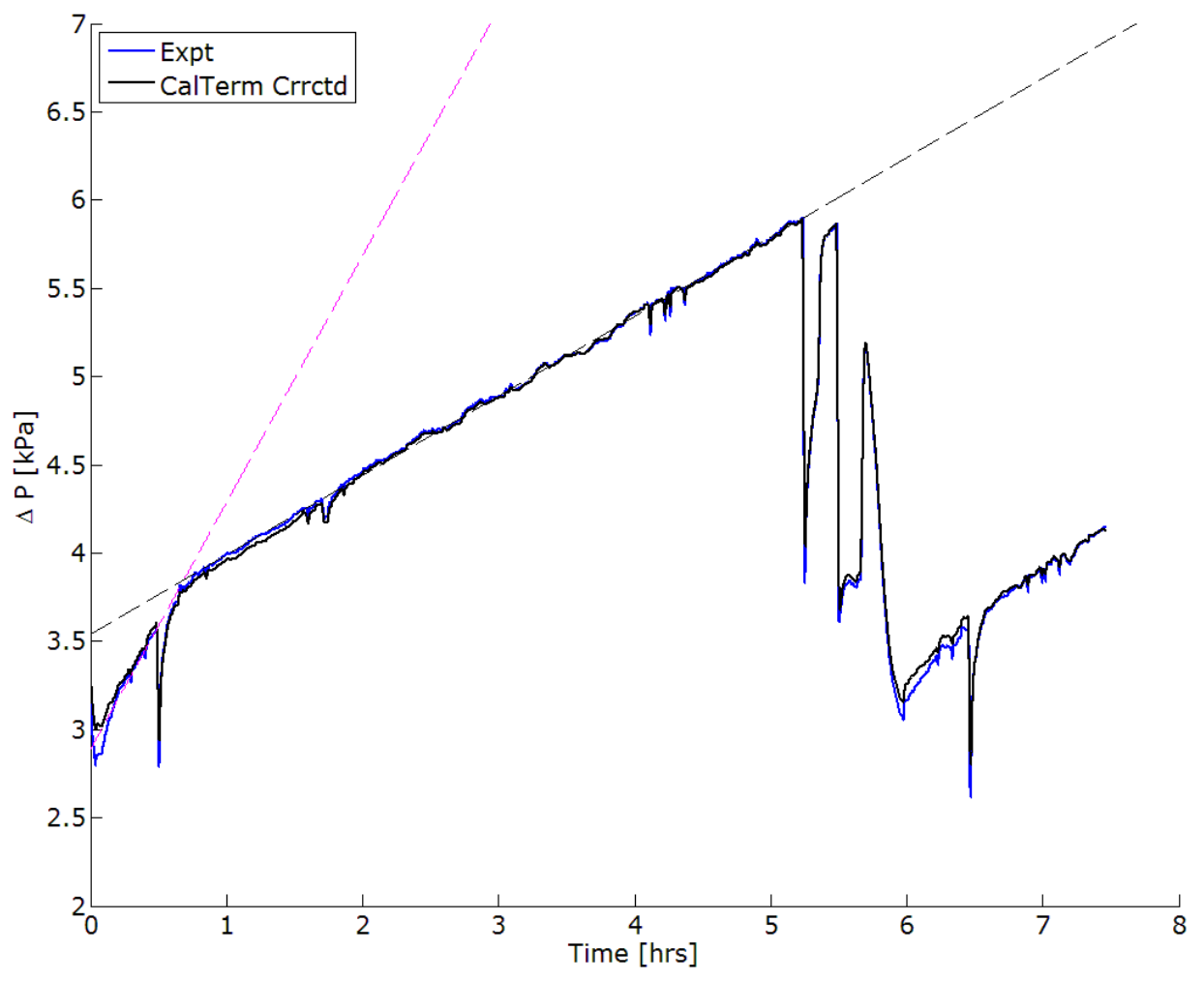

Figure P2: B20-5 CPF Pressure Drop 


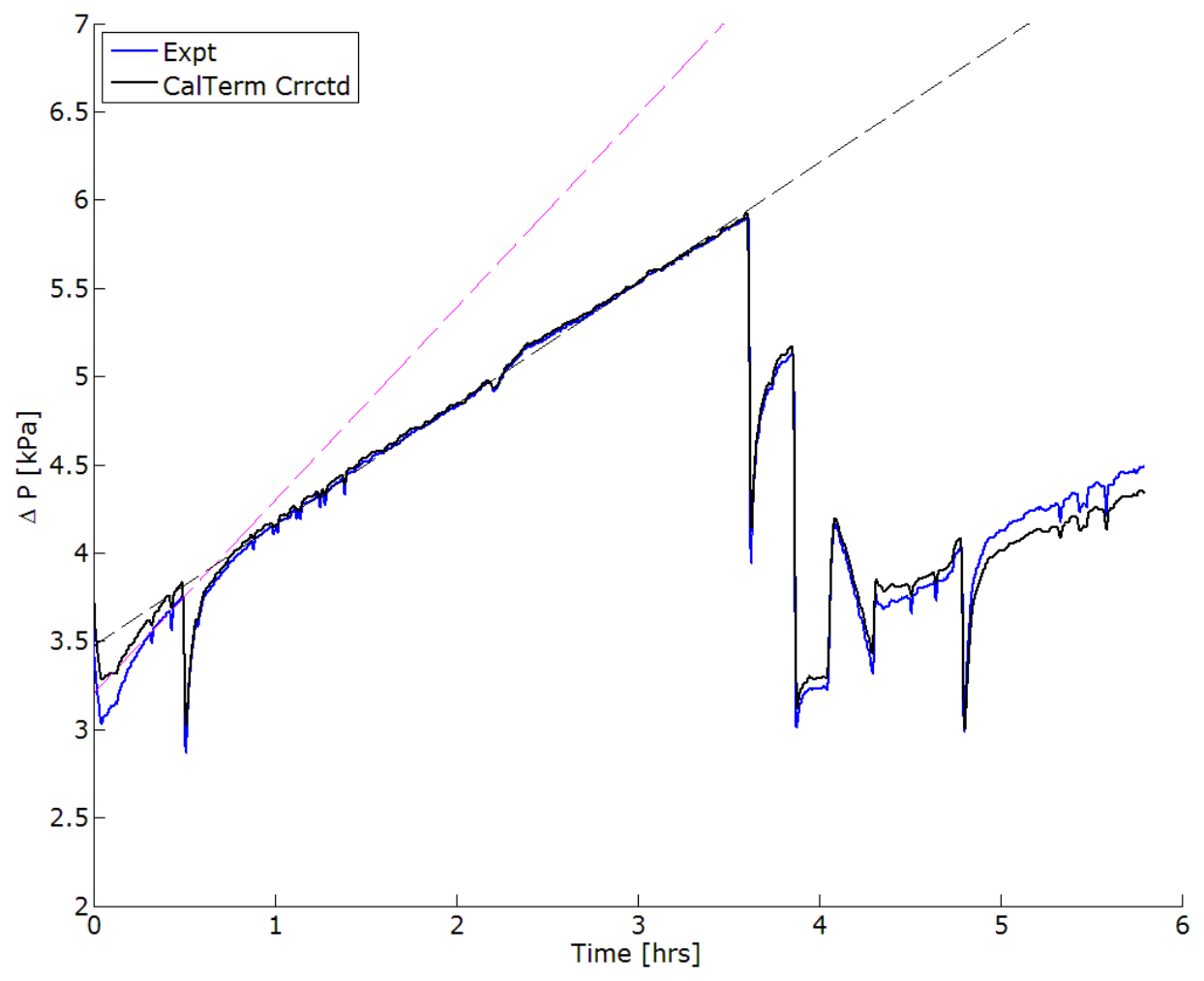

Figure P3: ULSD-3 CPF Pressure Drop 


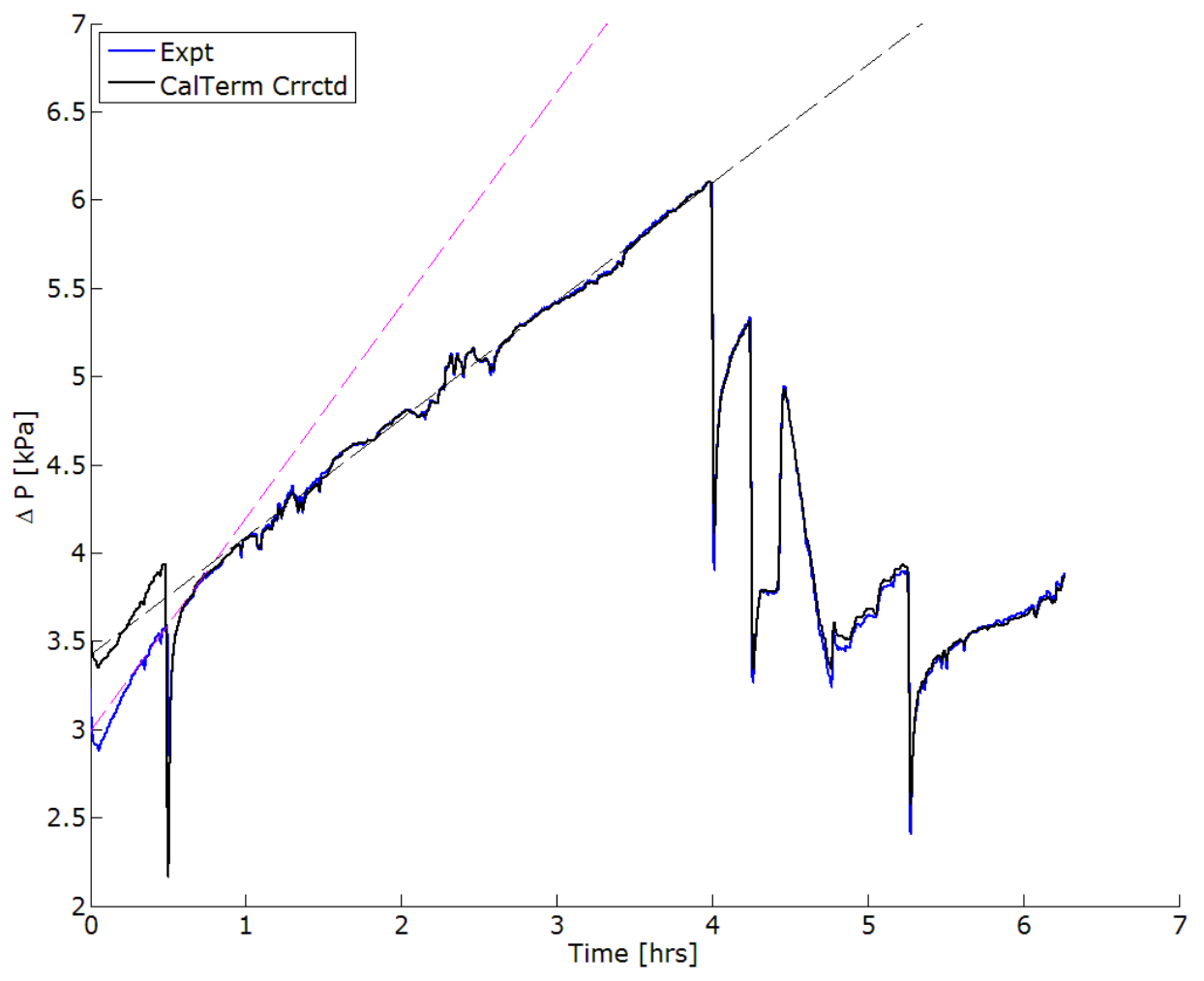

Figure P4: ULSD-4 CPF Pressure Drop 


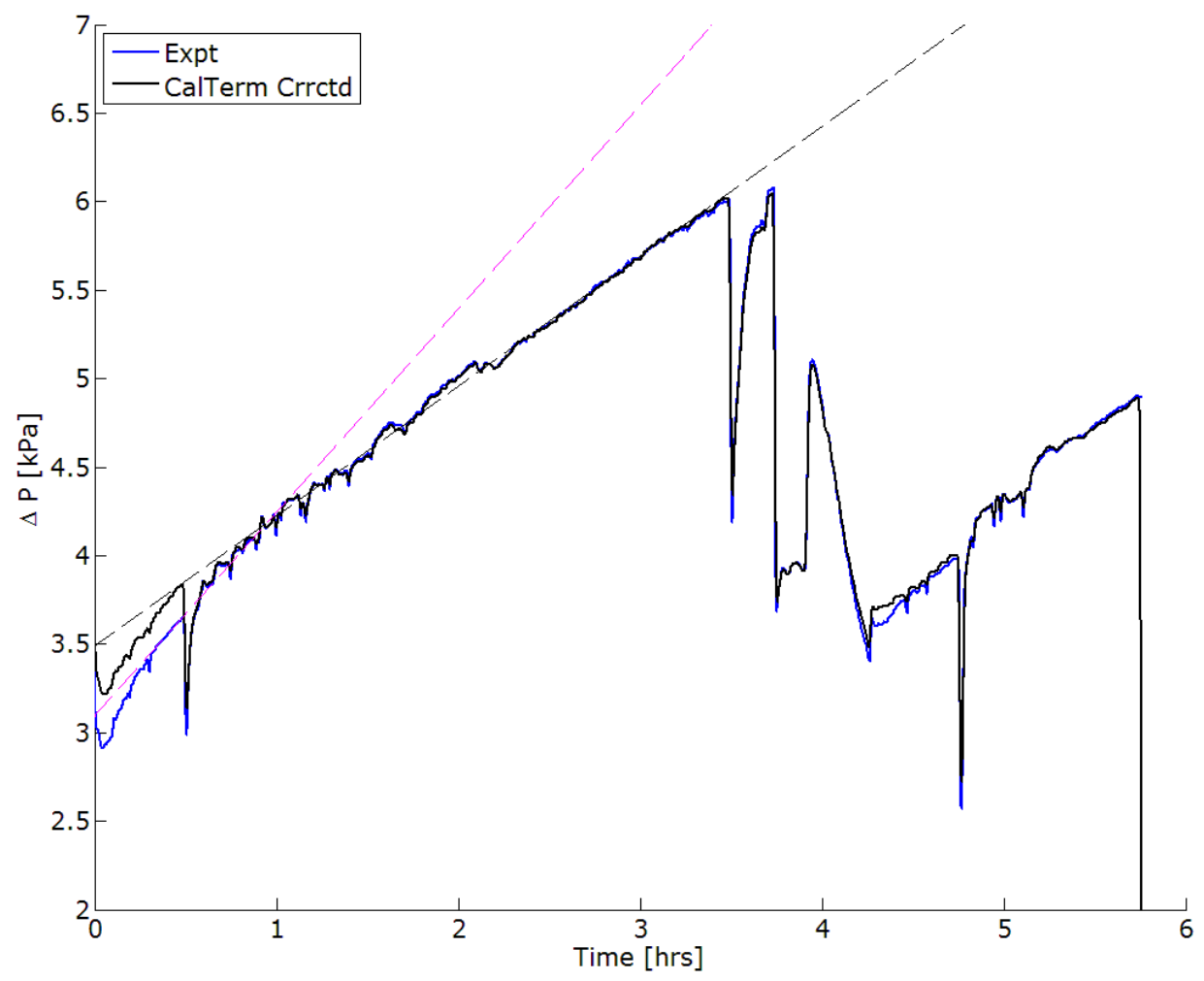

Figure P5: ULSD-5 CPF Pressure Drop 


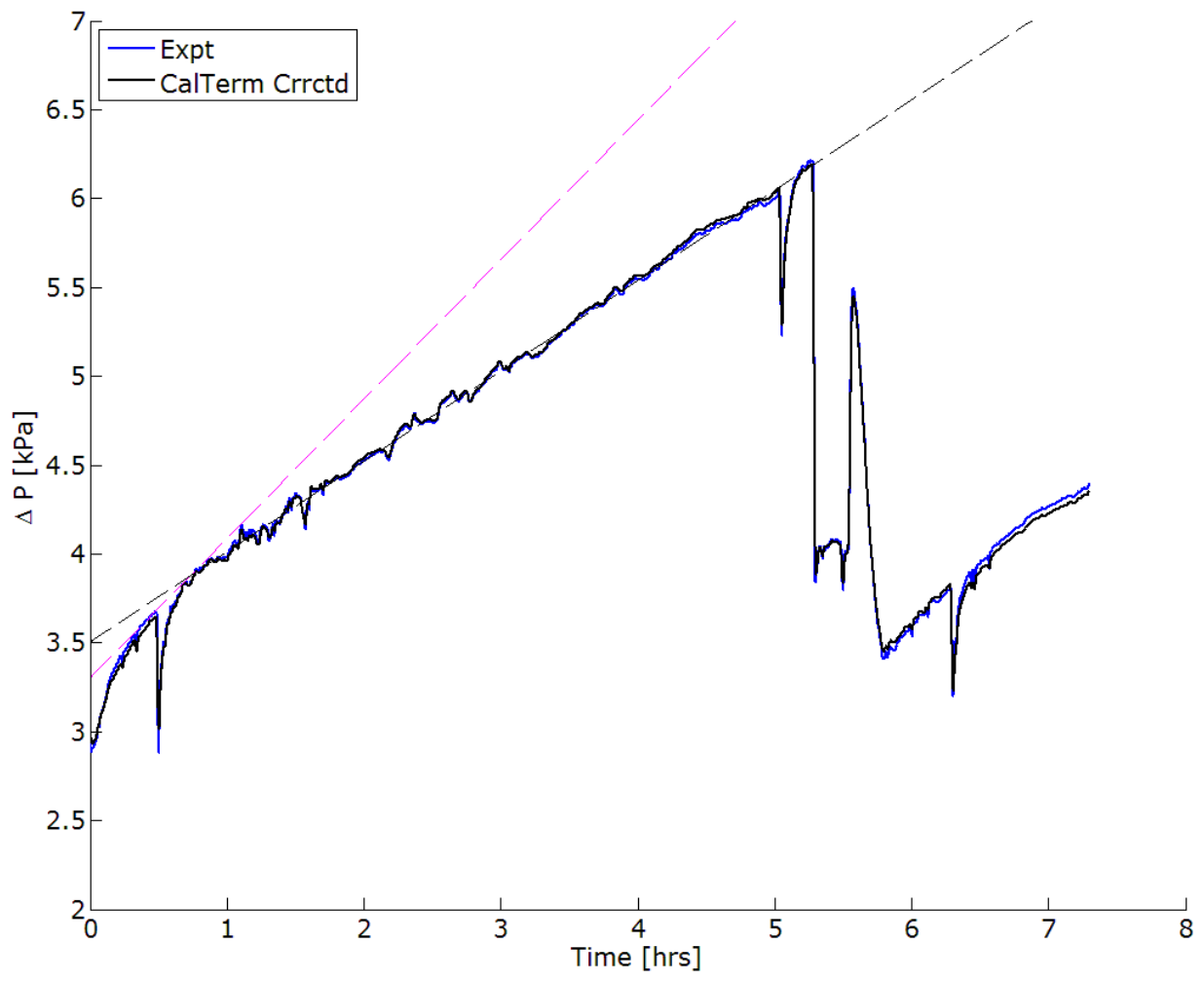

Figure P6: B20-6 CPF Pressure Drop 


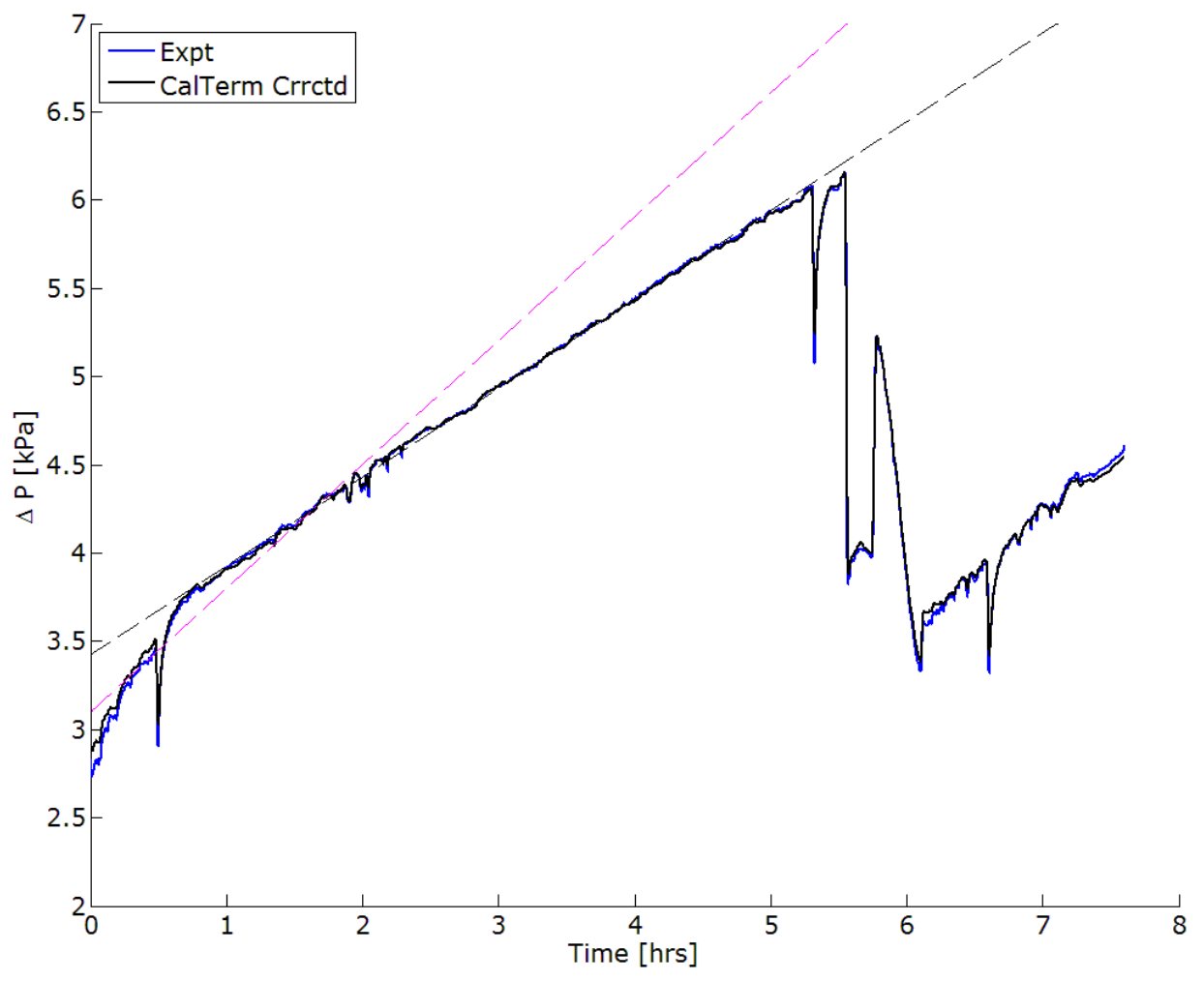

Figure P7: B20-4 CPF Pressure Drop 


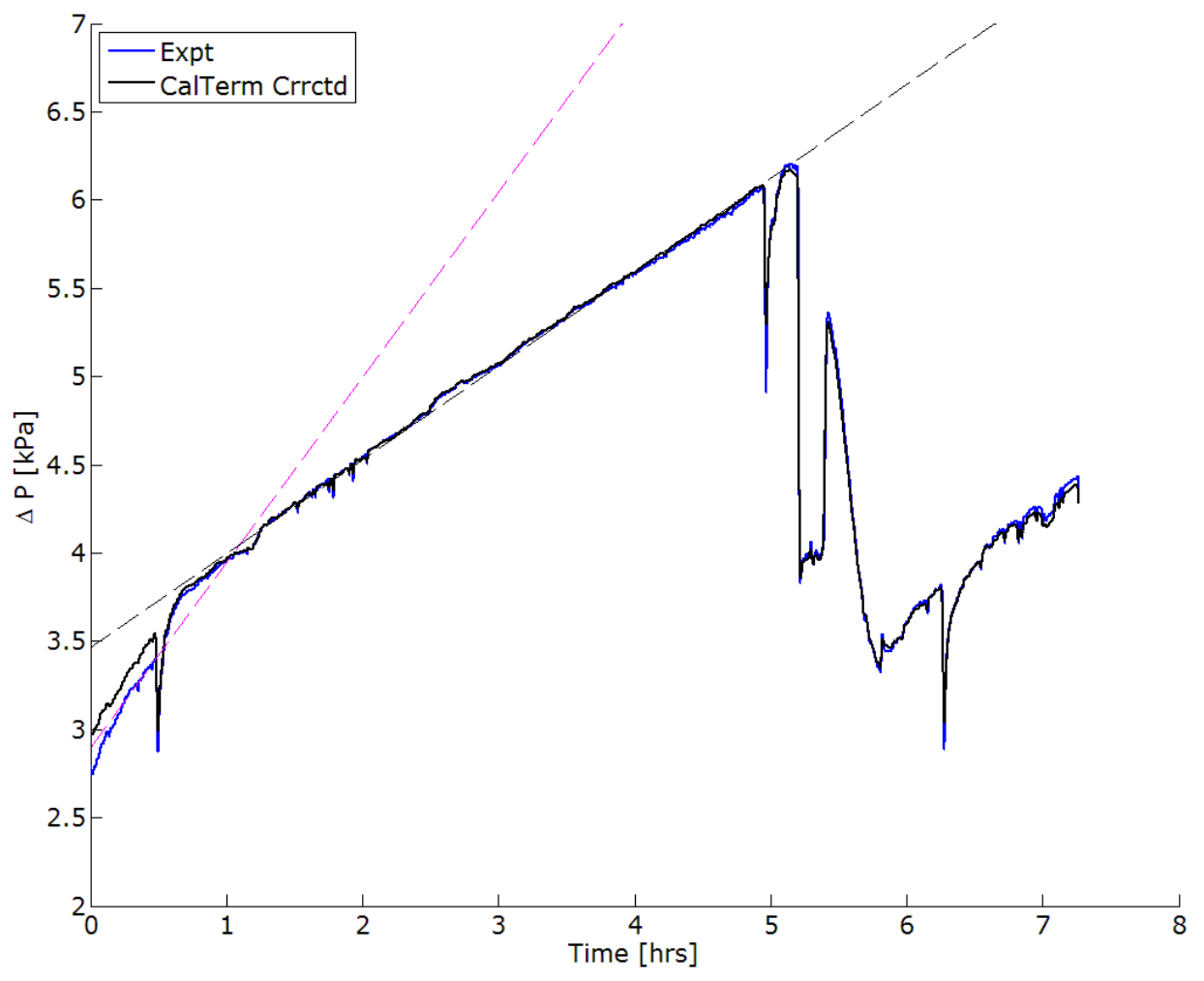

Figure P8: B10-1 CPF Pressure Drop 


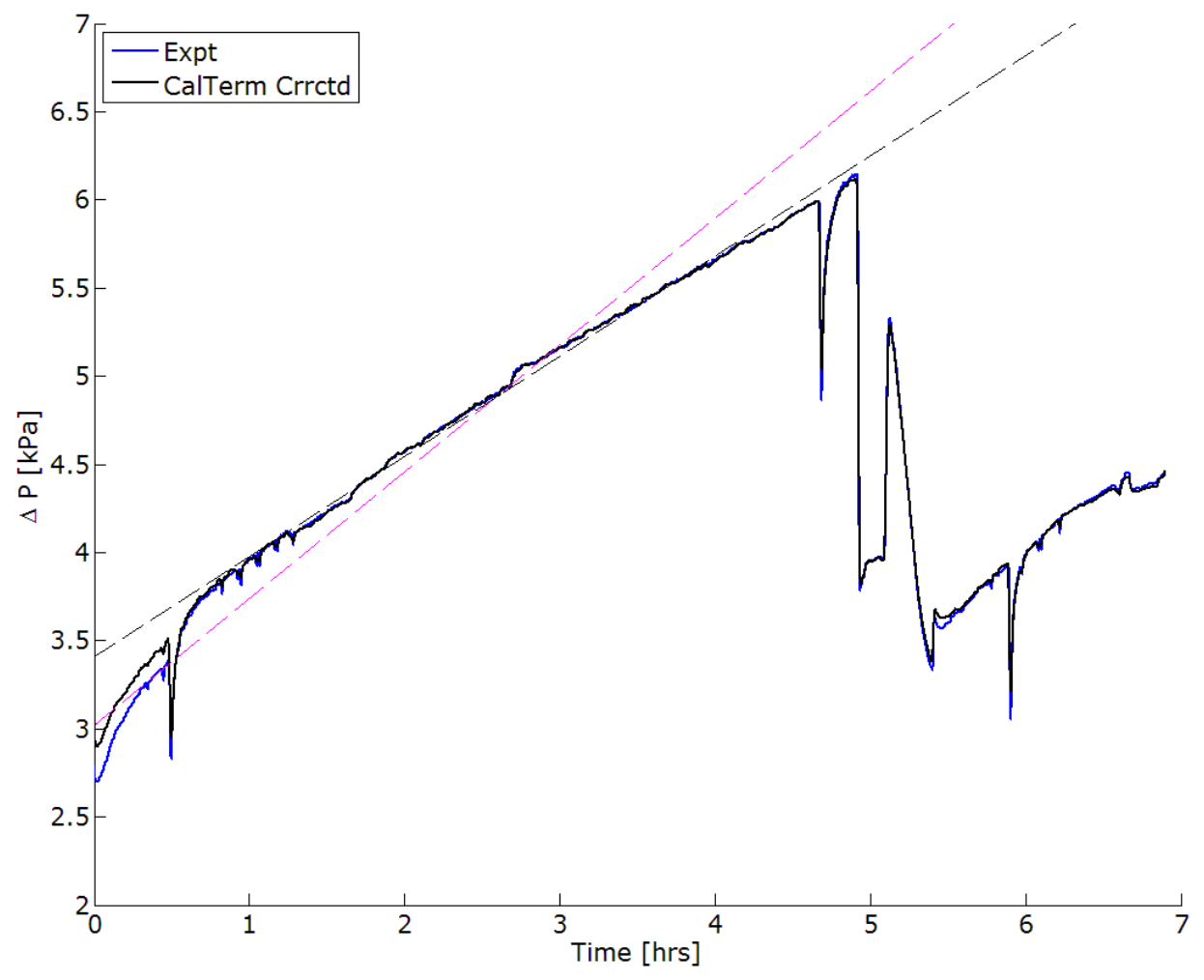

Figure P9: B10-2 CPF Pressure Drop 


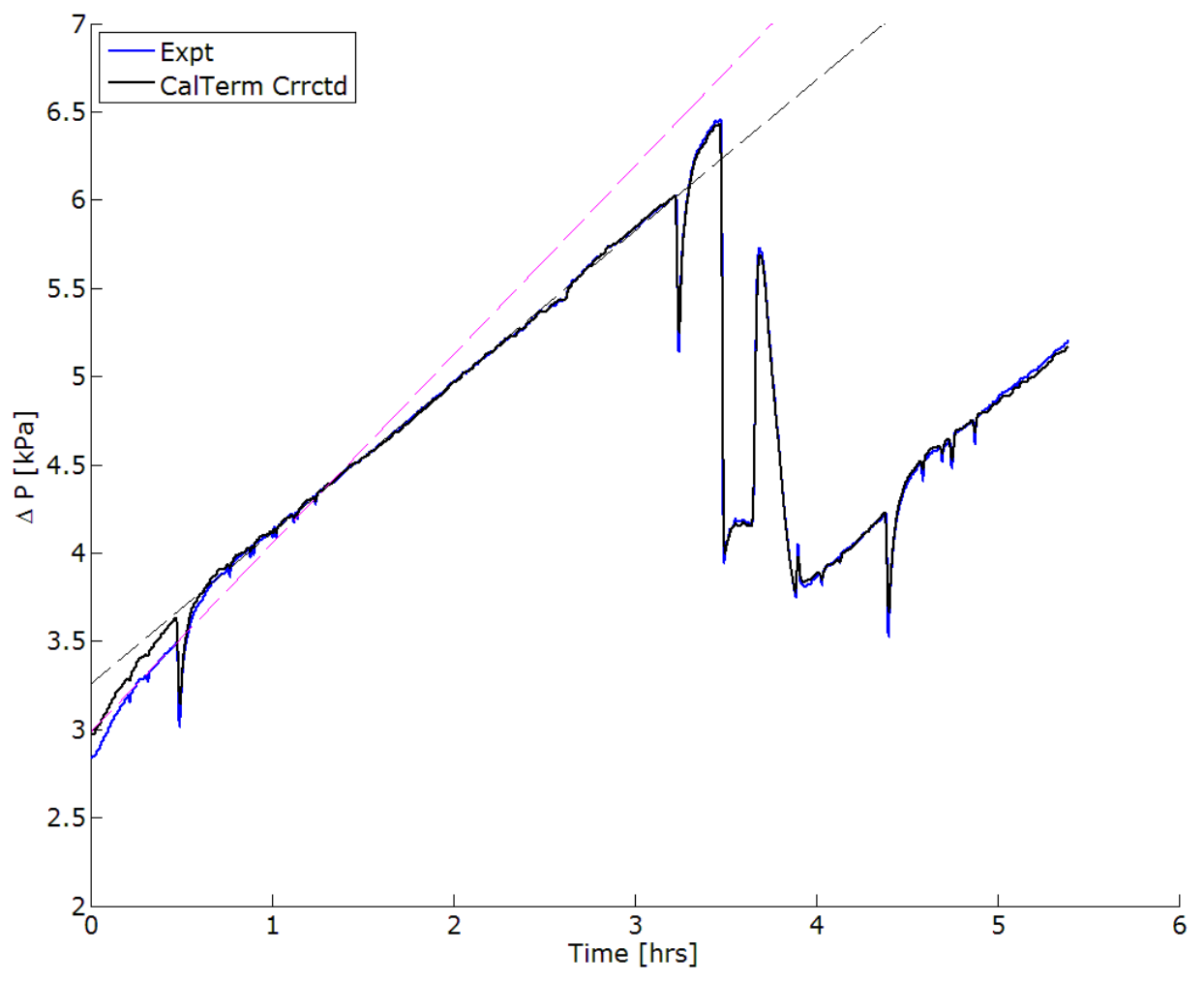

Figure P10: ULSD-1 CPF Pressure Drop 


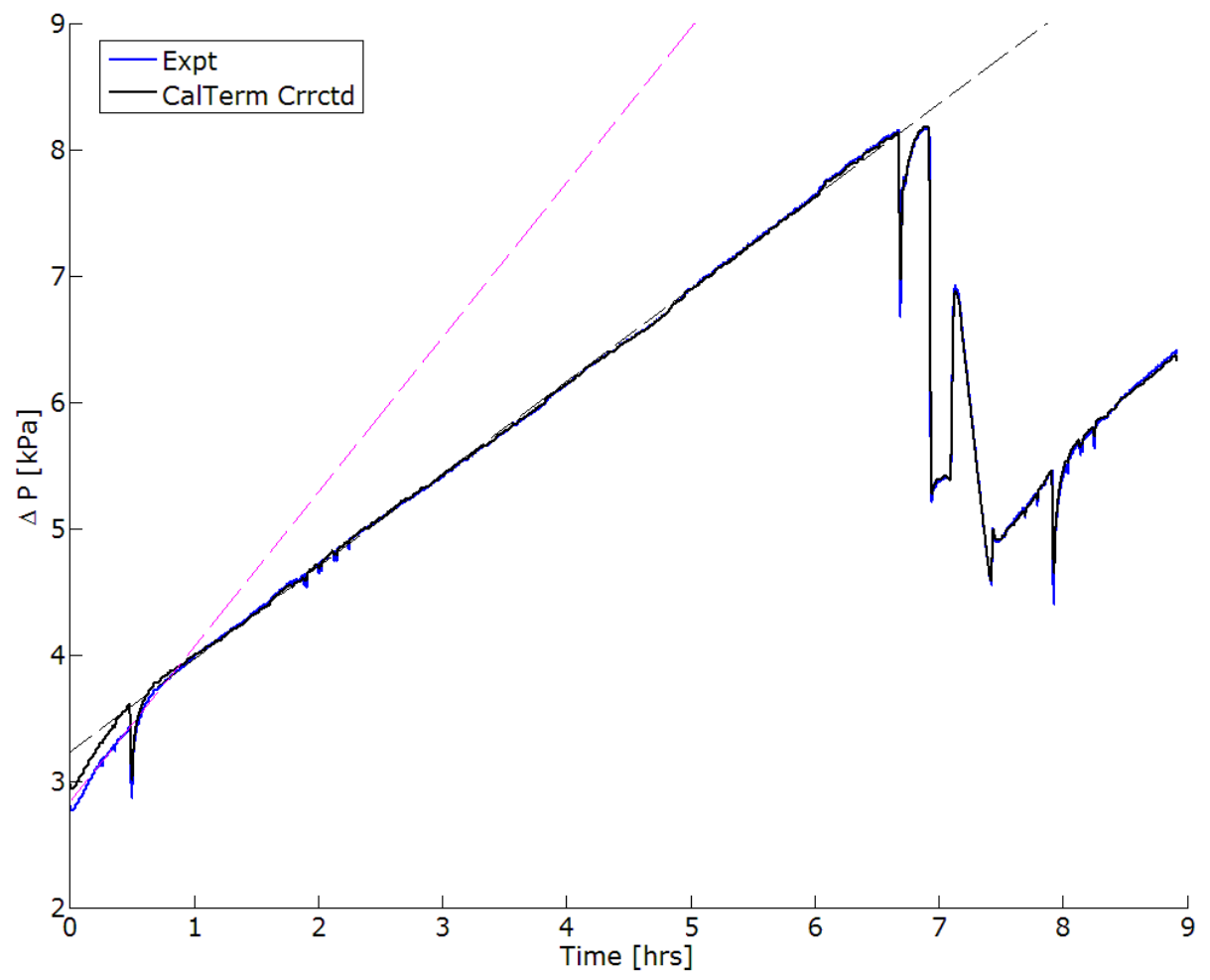

Figure P11: ULSD-8 CPF Pressure Drop 


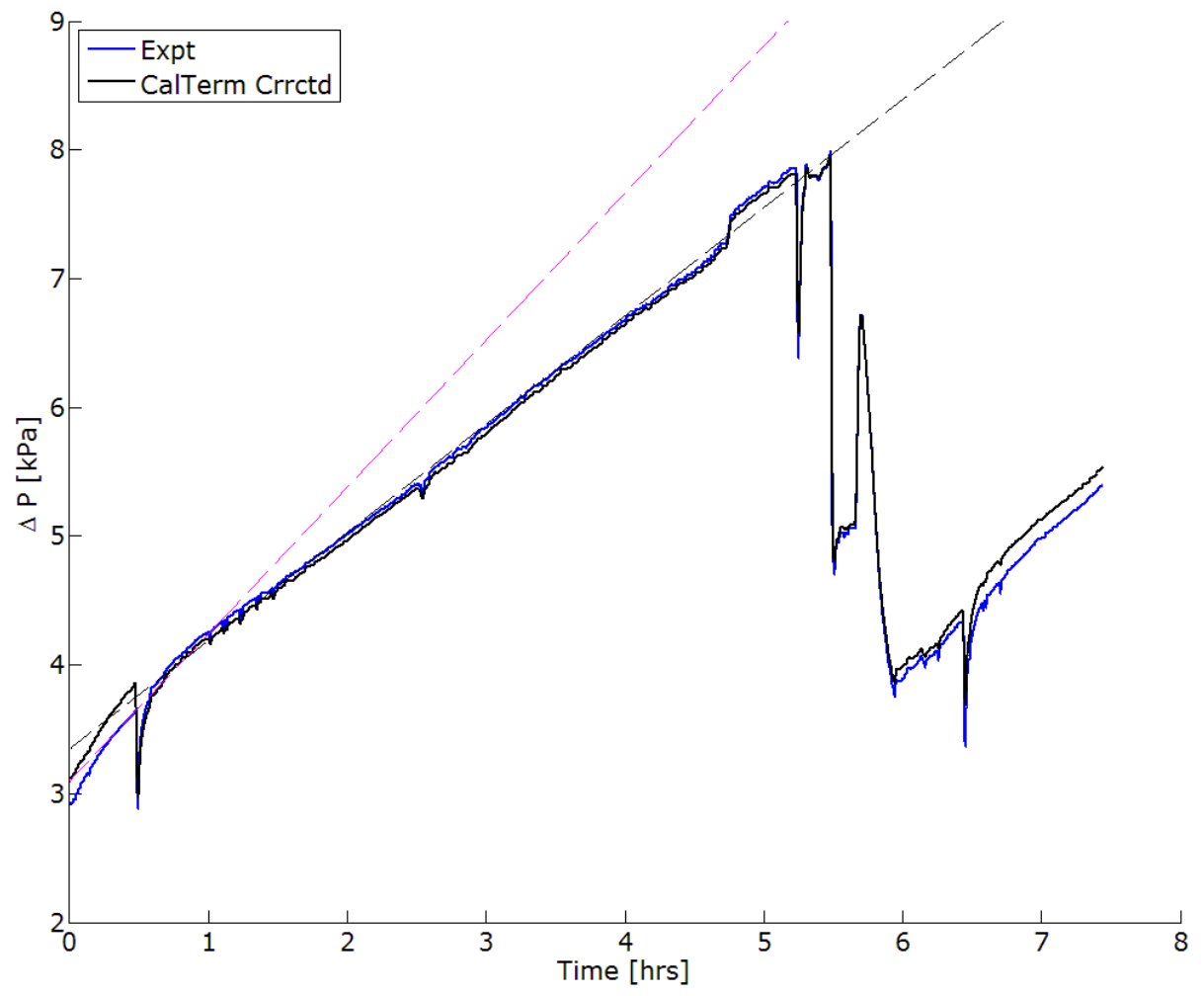

Figure P12: ULSD-9 CPF Pressure Drop 


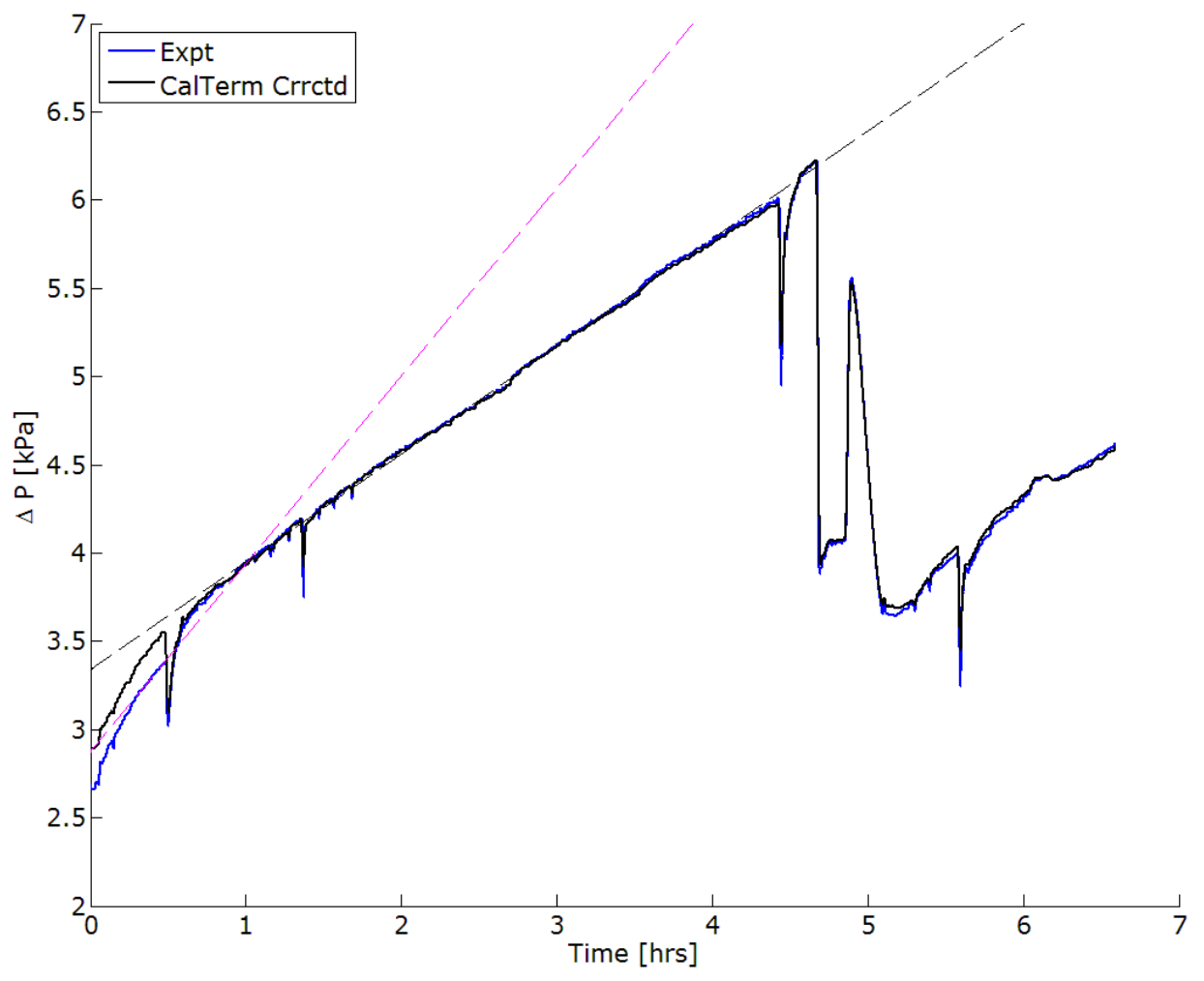

Figure P13: B10-4 CPF Pressure Drop 


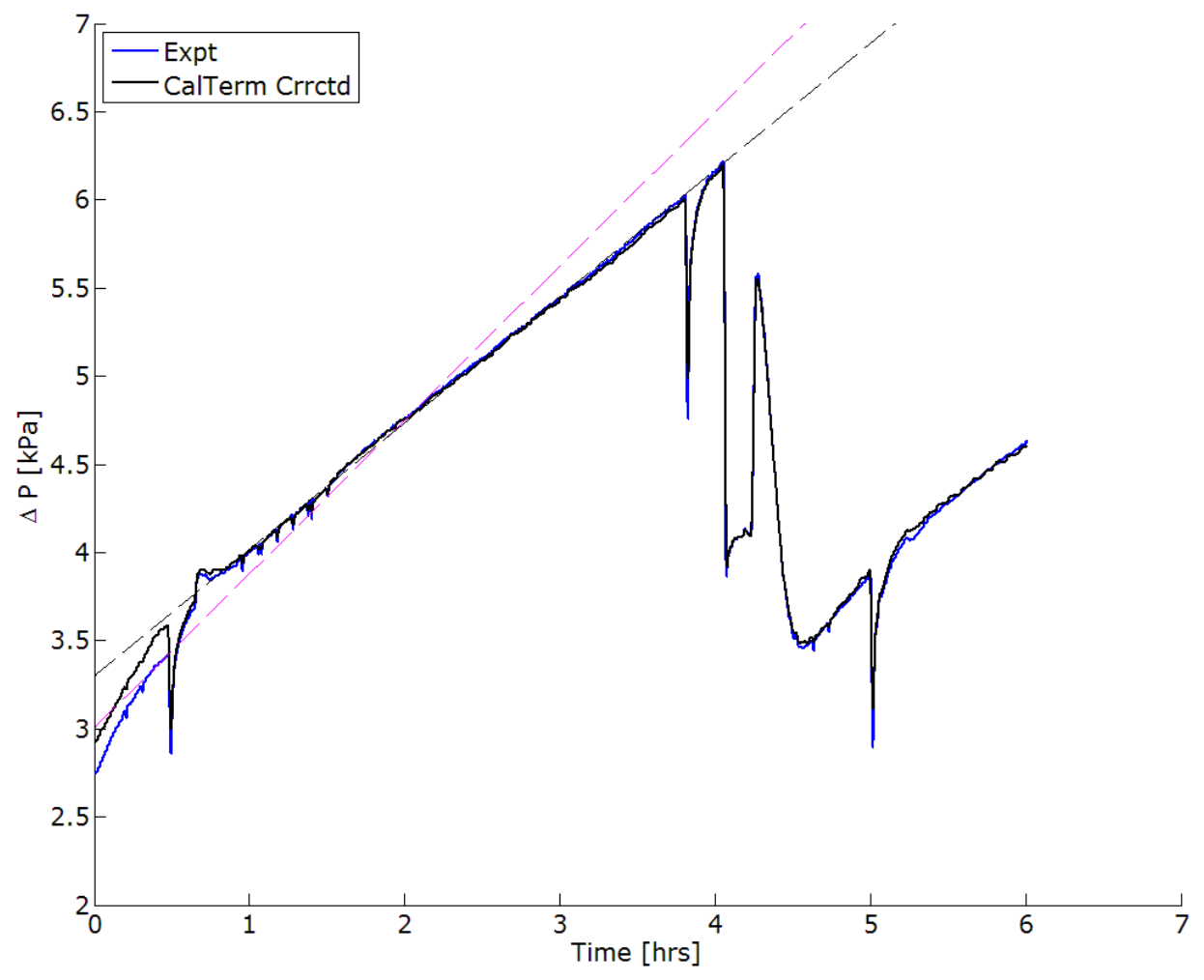

Figure P14: ULSD-7R CPF Pressure Drop 


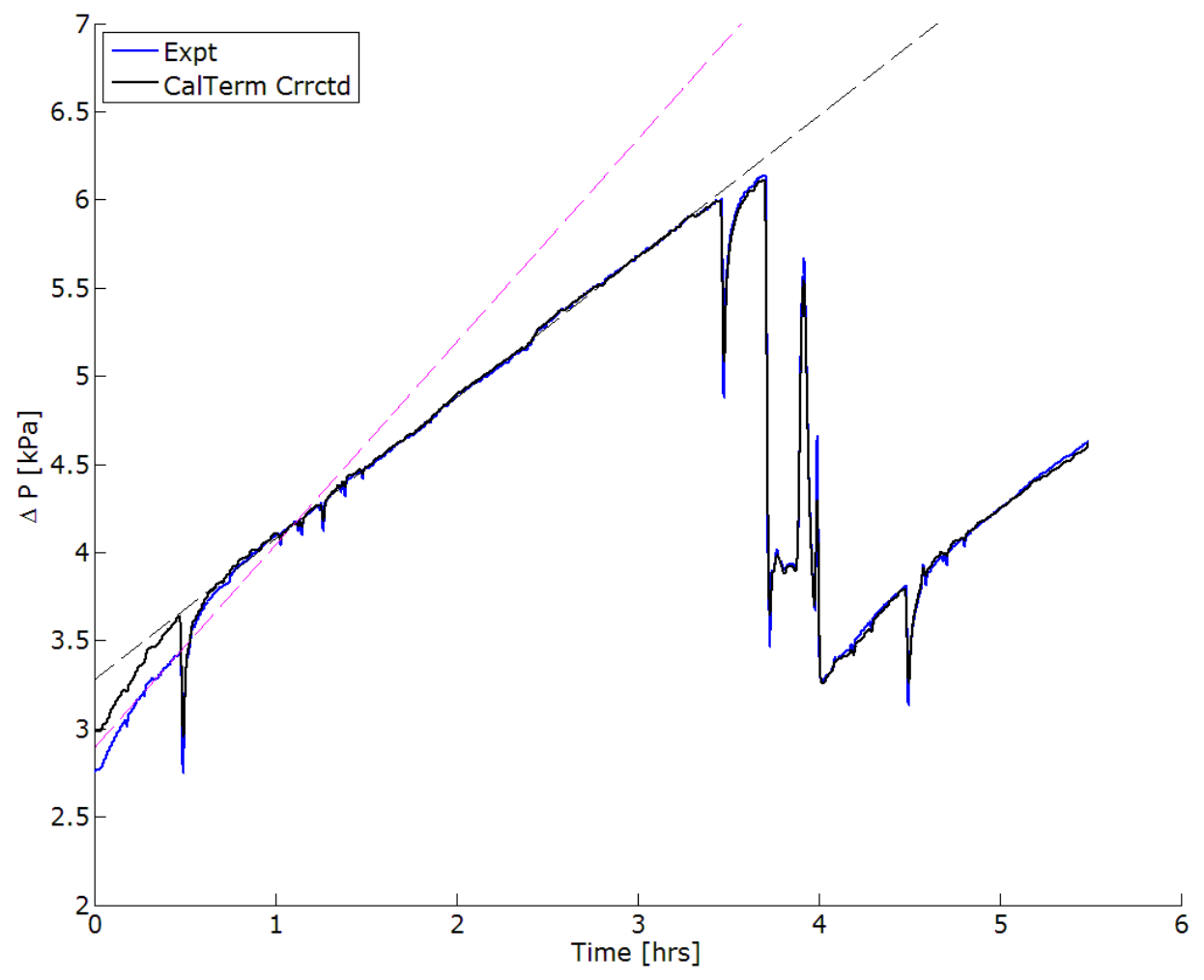

Figure P15: ULSD-2R CPF Pressure Drop 


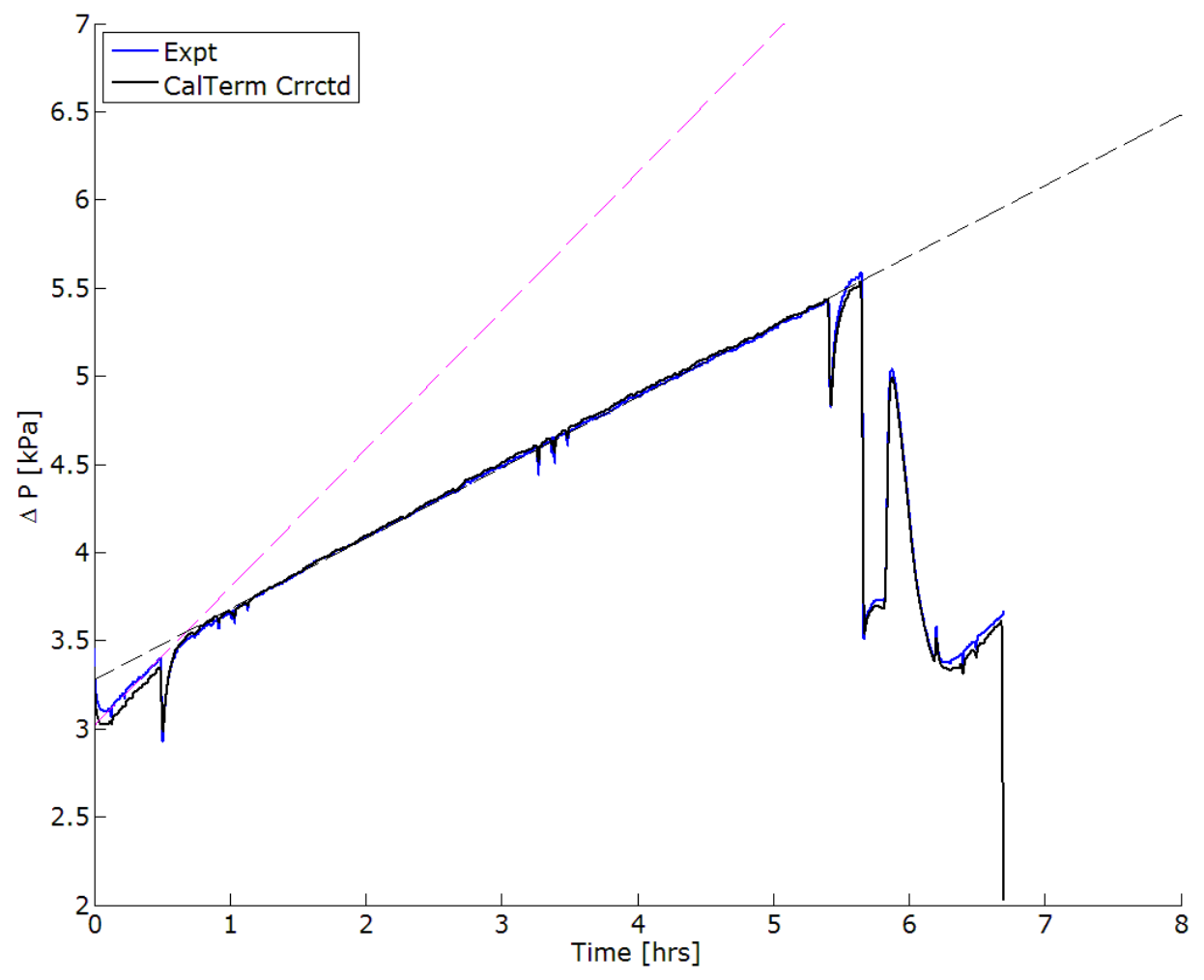

Figure P16: ULSD-10 CPF Pressure Drop 


\section{Appendix Q Permission to Use Copyrighted Material}

atherifgenteris

James Pidgeon <jmpidgeo@mtu.edu>

\section{Request for permission to use copyrighted figures}

copyright $<$ copyright@sae.org $>$

Thu, Sep 13, 2012 at 12:24 PM

To: James Pidgeon<jmpidgeo@mtu.edu>

Dear James,

Thank you for your correspondence requesting permission to include figures from SAE papers (noted below) in your thesis for a MS Mechanical Engineering degree at MTU.

Permission to reprint the figures from papers 2003-01-0833 and 2010-01-0307 is hereby granted, and is subject to the following conditions:

- Permission is granted for non-exclusive world English language rights, for this one-time single use.

- Permission is required for new requests, subsequent editions, for reprints or excerpts, or further use of the material.

- The following copyright statement must appear directly below the figures: "Copyright (C SAE International. Reprinted with permission." We also request that you credit the original source (author, paper number and SAE) in the reference section.

- $\quad$ This permission does not cover any third party copyrighted work which may appear in the material requested. If this material originated from another source, you must contact the original copyright holder for this permission.

Permission to reprint the figures from paper 2012-01-1313 cannot be granted by SAE. This is a Government paper (Canadian) and SAE does not hold the copyright. You need to contact the authors, or Environment Canada, for this permission. 
Please feel free to contact me if you need further assistance.

Best regards,

Terri Kelly

Intellectual Property Rights Administrator

SAE International | 400 Commonwealth Drive | Warrendale, PA 15096-0001 | USA

Office: $+01 \underline{724-772-4095}$ | Fax: $+01 \underline{724-776-9765}$

terri@sae.org | www.sae.org

From: James Pidgeon [mailto:impidgeo@mtu.edu]

Sent: Wednesday, August 01, 2012 10:59 AM

To: copyright

Subject: Request for permission to use copyrighted figures

To whom it may concern,

My name is James Pidgeon and I am currently writing my MS thesis for graduation from Michigan Technological University this upcoming December. I am emailing to request for permission to use a number of figures from a number of SAE papers that I would like to include in my thesis. The SAE paper number and corresponding figure numbers are listed below.

2012-01-1313: Figures 2 and 11

2003-01-0833: Figure 6

2010-01-0307: Figure 3

The title of my thesis is: An Experimental Investigation into the Effects of Biodiesel Blends on Particulate Matter Oxidation in a Catalyzed Particulate Filter during Active Regeneration 
This thesis is being written for completion of the partial requirements for the MS Mechanical Engineering degree

The thesis will be distributed electronically throughout various individuals/departments at MTU and will be printed upon completion with an expected publication date of early (January to April) 2013.

If any other information is necessary, let me know. Thank you.

$-$

James Pidgeon

Mechanical Engineering

Cell: (715) 781-5421

Nothing in this message is intended to constitute an electronic signature unless a specific statement to the contrary is included in this message. Confidentiality Note: This message is intended only for the person or entity to which it is addressed. It may contain confidential and/or proprietary material. Any review, transmission, dissemination or other use, or taking of any action in reliance upon this message by persons or entities other than the intended recipient is prohibited. If you received this message in error, please contact the sender and delete it from your computer.

This letter is for Figure 2.8 